\title{
Beyond love
}

Citation for published version (APA):

Krugu, J. (2016). Beyond love: promoting sexual and reproductive health and rights of adolescents in Ghana. [Doctoral Thesis, Maastricht University]. Maastricht University. https://doi.org/10.26481/dis.20160913jk

Document status and date:

Published: 01/01/2016

DOI:

10.26481/dis.20160913jk

Document Version:

Publisher's PDF, also known as Version of record

\section{Please check the document version of this publication:}

- A submitted manuscript is the version of the article upon submission and before peer-review. There can be important differences between the submitted version and the official published version of record.

People interested in the research are advised to contact the author for the final version of the publication, or visit the DOI to the publisher's website.

- The final author version and the galley proof are versions of the publication after peer review.

- The final published version features the final layout of the paper including the volume, issue and page numbers.

Link to publication

\footnotetext{
General rights rights.

- You may freely distribute the URL identifying the publication in the public portal. please follow below link for the End User Agreement:

www.umlib.nl/taverne-license

Take down policy

If you believe that this document breaches copyright please contact us at:

repository@maastrichtuniversity.nl

providing details and we will investigate your claim.
}

Copyright and moral rights for the publications made accessible in the public portal are retained by the authors and/or other copyright owners and it is a condition of accessing publications that users recognise and abide by the legal requirements associated with these

- Users may download and print one copy of any publication from the public portal for the purpose of private study or research.

- You may not further distribute the material or use it for any profit-making activity or commercial gain

If the publication is distributed under the terms of Article $25 \mathrm{fa}$ of the Dutch Copyright Act, indicated by the "Taverne" license above, 


\title{
BEYOND LOVE
}

\section{PROMOTING SEXUAL AND REPRODUCTIVE HEALTH AND RIGHTS OF ADOLESCENTS IN GHANA}

\author{
DISSERTATION \\ to obtain the degree of Doctor at Maastricht University, \\ on the authority of the Rector Magnificus Prof. dr. Rianne M. Letschert, \\ in accordance with the decision of the Board of Deans, \\ to be defended in public on Tuesday $13^{\text {th }}$ of September 2016, at 11.30 hours
}

by

John Kingsley Krugu 


\section{Supervisor}

Prof. dr. R.A.C. Ruiter

\section{Co-supervisor}

Dr. F.E.F. Mevissen

\section{Assessment Committee}

Prof. dr. Gerjo Kok (chair)

Prof. dr. Bart van den Borne

Dr. Anja Krumeich

Prof. dr. Ama de-Graft Aikins (University of Ghana)

Dr. Prisca Zwanikken (Koninklijk Instituut voor de Tropen - KIT, Amsterdam)

The following organisations made financial contributions to the completion of this dissertation:
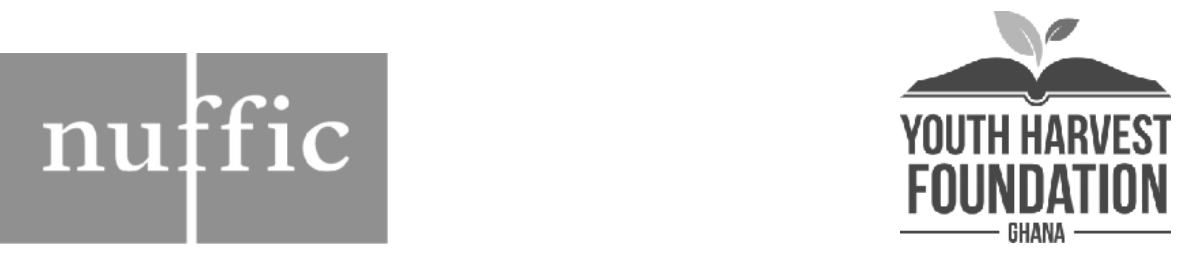

Wu Maastricht University in Leaming! 


\section{Content}

Chapter 2: Psychosocial correlates of condom use intentions among Junior High School students in the Bolgatanga Municipality of Ghana

Chapter 3: Beyond Love: A qualitative analysis of factors associated with teenage pregnancy among girls with pregnancy experience in Bolgatanga, Ghana

Chapter 4: Who's that girl? A qualitative analysis of adolescent girls' views on factors associated with teenage pregnancies in Bolgatanga, Ghana

Chapter 5: Girls cannot be trusted: Perspectives of adolescent boys on contraceptive decision making in sexual relationships in Bolgatanga, Ghana

Chapter 6: SPEEK: Effect evaluation of a Ghanaian School-based and Peer-led Sexual Education Program

Chapter 7: General Discussion 
Chapter 1

General Introduction 


\section{General Introduction}

Ghanaian adolescents, like their peers across sub-Saharan Africa, are facing sexual, and reproductive health and rights (SRHR) challenges. Worldwide, SRHR remains a controversial subject, despite many universal declarations and international treaties lending support to it. Sexual and reproductive rights are derived from internationally recognised fundamental human rights (UNFPA, 2014). SRHR refer to the rights of all persons to the highest achievable standard of health regarding sexuality. These rights include the right to access information in relation to sexuality, the right to bodily integrity, the right to sex education, the right to decide whether or not to be sexually active, the right to marry or not and with whom, the right to determine whether or not and when to have children, and the right to pursue a safe, satisfying, and pleasurable sexual life devoid of coercion, discrimination and violence (WHO, 2015). These rights guarantee that all human beings, irrespective of age, gender or race, can fulfil and express their sexuality and enjoy sexual health (WHO, 2015).

Adolescents (age 10-19 years) may not be able to enjoy their SRHR because of certain factors peculiar to them. Some of these factors are embedded within the environment, including the socio-economic status of their families, socio-cultural norms, and beliefs towards adolescent sexuality and gender issues, and the legal framework underpinning sexuality education (Chandra-Mouli, Svanemyr, Amin, et al., 2015). Growing up in such an environment can result in young people having insufficient knowledge about their SRHR and holding negative attitudes, retrogressive normative beliefs, low perception of risks, and low self- efficacy/skills towards safe sexual behaviours. Consequently, Ghanaian adolescents, like their peers across sub-Saharan Africa, are exposed to high risks of early sexual debut, contracting sexually transmitted infections (STIs), sexual coercion, forced sex, unintended pregnancies, and child marriages (Doku, 2012; Kumi-Kyereme, Awusabo-Asare, \& Biddlecom, 2007).

Comprehensive sexuality education (CSE) can play a critical role in promoting adolescents' SRHR, by providing the necessary information and skills that they need in order to take informed decisions on sexuality and sexual behaviours (Albarracin, Durantini, \& Earl, 2006; Kirby, 2007; Kirby, Obasi, \& Laris, 2006; Paul-Ebhohimhen, Poobalan, \& van Teijlingen, 2008). CSE places emphasis on the enjoyment of rights within a particular sociocultural context, with a focus on equality, social inclusion, and empowerment (WHO, 2015). Therefore, CSE emphasizes providing young people with the knowledge, skills, attitudes and values they need to make informed choices and enjoy their sexuality - physically, emotionally, individually and in relationships (IPPF, 2010). 
CSE is more likely to be effective when it is evidenced-based and has a sound theoretical grounding (Bartholomew Eldredge, Markham, Ruiter, Fernández, Kok, \& Parcel, 2016; Chandra-Mouli, Lane, \& Wong, 2015). Developing effective CSE requires an understanding of the psychosocial and cognitive determinants of adolescents' (un)safe sex behaviours. This includes understanding the specific determinants and behaviours that need to change to achieve the desired health outcomes (e.g., consistently using condoms when sexually active or delaying sexual debut until one is ready). It also includes selecting the appropriate behaviour change methods and applying them under the desired conditions tailored to the specific needs and context of the target population while taking into account the parameters for use (Bartholomew et al., 2016). There are a number of contextual factors to consider when exploring young people's sexual health behaviours: (1) the legal, policy and general political context; (2) the socio-economic and demographic context, including educational and employment opportunities; (3) the socio-cultural context including, religious and traditional beliefs regarding adolescent sexuality; (4) the interpersonal context in which young people thrives and negotiate their relationships; and (5) the context in which interventions aiming at addressing young people's sexual health needs are implemented (Chalmers, Aggleton, Ingham, \& Stone, 2006). The author of this dissertation supports the view that both the interpersonal and programmatic contexts are influenced by the other three contextual factors: the political, socio-economic and socio-cultural (community) contexts (Kotchick, Shaffer, Forehand, \& Miller, 2001; Metzler, Noell, Biglan, Ary, \& Smolkowski, 1994). Although there is an international consensus on the universal nature of SRHR, CSE remains a matter of international debates until it is adaptable, accepted and implemented within the specific local context where young people live (UNESCO, 2015). Therefore to determine the right approach and the right environmental conditions to promote adolescents SRHR requires a proper understanding of the socio-cultural, economic and political context in which adolescent sexual behaviour decision-making occurs (Bartholomew Eldredge et al., 2016; Ingham, 2006).

In this dissertation, the author also supports the view that young people's sexual behaviours do not occur in a vacuum (Couch, Dowsett, Dutertre, Keys, \& Pitts, 2006; Ingham, 2006). The SRHR behaviours of adolescents are influenced by specific socio-cultural and environmental contextual factors, and by the individual choices based on the specific personal determinants (knowledge, intention, self-efficacy, risk perception, attitudes, and norms). Therefore, intervention planning requires a clearer understanding of both the structural socio-cultural contextual influences of adolescents SRHR behaviours and the sociocognitive individual factors that result in adolescents making certain choices and decisions. A 
theory and evidence-based intervention development also requires an understanding of the relevant environmental decision-makers like parents, teachers, religious leaders, health workers and policy-makers whose personal beliefs, attitudes and perceptions towards teen sexuality play a crucial role in adolescent sexual health behaviours (Bartholomew Eldredge et al., 2016; Glanz, Rimer, \& Viswanath, 2015).

This dissertation reports on the results of different studies conducted to increase our understanding of the social cognitive determinants of safe sex behaviour among Ghanaian adolescents, focusing on why they fail to protect against STIs and especially, unintended pregnancies. It includes exploratory studies of their beliefs and perceptions related to contraceptive decision-making in their own daily socio-cultural, economic and political context, and an evaluation of the effectiveness of a context specific CSE programme Youth Supporting Peers and Encouraging Empowerment through Knowledge (SPEEK) among junior high school students in Ghana.

\section{Sexual and Reproductive Health of Ghanaian Adolescents}

As part of the universal normal process of human development, adolescents (age 10-19) represent a period of heightened curiosity, experimentation and exploration of the ideals of life, including sexuality and sexual life, which is frequently characterised by risk taking behaviours (Steinberg, 2008). However, many health problems can arise depending upon how the individual adolescent encounters this "normal" process of human development. For example, when sexual debut occurs too early (especially among girls), it is frequently associated with coerced sex (Kastbom, Sydsjo, Bladh, Priebe, \& Svedin, 2015; Pettifor, O'Brien, MacPhail, Miller, \& Rees, 2009). Also, these girls are more likely to engage in multiple intergenerational unprotected sexual partnerships (Moore, Awusabo-Asare, Madise, John-Langba, \& Kumi-Kyereme, 2007). In sub-Saharan Africa (SSA), early, coerced sexual debut is associated with higher risk of HIV and other STIs infections, and unintended teenage pregnancy compared to those who experience sexual debut in late adolescence (Moore et al., 2007; Stockl, Kalra, Jacobi, \& Watts, 2013). Also, when sexually active, most Ghanaian adolescents, do not use condoms or other family planning methods (contraceptives other than condoms) consistently to protect against STIs and unintended teenage pregnancies.

According to the Ghana demographic and health survey 2014, among sexually active unmarried women age 15 to 19 , only 45 percent were using a contraceptive method at the time of the study (GSS-DHS, 2015). Boamah, Asante, Mahama, et al. (2014) also showed that among sexually active adolescents age $15-19$ years $(N=793)$, only 22.9 
percent used contraceptives consistently. The result is that in 2014, 14 percent of women age 15-19 had begun childbearing, increasing to 31 percent at 19 years (GSS-DHS, 2015). Across SSA, teenage pregnancy rates remain high; 17.7 percent in Kenya in 2008, 25.6 percent and 22.8 percent respectively in Malawi and Tanzania in 2010, 23.8 percent in Uganda in 2011 and 47.4 percent in Zambia in 2007 (Birungi, Undie, MacKenzie, Katahoire, Obare, \& Machawira, 2015). Most of these pregnancies are unintended, unwanted and unplanned (Birungi et al., 2015). Unintended teenage pregnancies are the best indicator of unsafe sexual behaviours among adolescents.

In general, teenage pregnancy has negative social, psychological and health consequences for the victims, their partners, their families and for society as a whole. Girls initiating childbearing in adolescence is associated with the likelihood of not finishing high school and liable to end up in poverty in adult life compared to their peers who delay childbearing (Macleod \& Tracey, 2010). Children born to adolescent parents are also more likely to have poorer behavioural, educational and health outcomes in the course of their lifetime as compared to kids born to older parents (Cook \& Cameron, 2015; Marcotte, 2013). Among girls who drop out of school at the high school level in Ghana, 83 percent is related to unintended pregnancy, jeopardizing their future personal and professional development (Adams, Lemaire, \& Prah, 2013). Also, because most teen pregnancies are both unplanned and intended (Eliason, Baiden, Yankey, \& Awusabo-Asare, 2014), they often result in abortion. In Ghana abortion is only permitted under specific conditions: where pregnancy is the result of rape or defilement, the continuance of the pregnancy would involve risk to the life of the pregnant woman, and where there is substantial risk that if the child were born it may suffer from serious physical abnormality (Morhee \& Morhee, 2006). Therefore, unmarried girls' access to safe abortion services performed by qualified medical professionals is highly limited (Morhee \& Morhee, 2006). Consequently, among women who died from pregnancy-related causes in Ghana in 2010, 10.2 percent were between age 15 to 19 years and most of these resulted from unsafe abortion (Asamoah, Moussa, Stafström, \& Musinguzi, 2011).

Unsafe sexual behaviours also come with the risk of STI's infections, including HIV. Ghana's experience of the HIV epidemic is described as a generalized one - self-sustaining through heterosexual transmission (Djomand, Quaye, \& Sullivan, 2014). The Ghana AIDS Commission 2014 facts sheet on HIV puts the national prevalence at 2.0 percent and out of 11,356 newly infected people, 26 percent were young people between the ages of 15 to 24 years (GAC, 2014). Also, out of the 2,901 newly infected young people in 2014, 64 percent 
were females, meaning gender plays a crucial role in the dynamics of HIV transmission among young people in Ghana.

These statistics indicate that Ghanaian adolescents do face adverse SRHR outcomes. Unprotected sexual intercourse at an early age puts adolescents at higher risk of unintended pregnancies and STIs including HIV. Therefore, it is important to have a proper understanding of the social-cognitive determinants of their (un)safe sexual behaviours such as delaying sexual intercourse, using family planning methods and in particular, using condoms to be able to design CSE interventions that are responsive to their needs.

The practice of these safer sex behaviours (delaying sexual intercourse and consistently using condoms and/or other family planning methods) requires prior planning and forethought. Social cognitive theories and models help us to determine the important factors that can explain or predict these safer sex behaviours. The Theory of Planned Behavior (Ajzen, 1991) and its successor the Reason Action Approach (RAA; Fishbein \& Ajzen, 2010), Social Cognitive Theory (Bandura, 1998), the AIDS Risk Reduction Model (ARRM; Catania, Kegeles, \& Coates, 1990), and the Health Beliefs Model (HBM; Rosenstock, 1974) are frequently used to guide the selection of target determinants for SRHR interventions. The RAA (Fishbein \& Ajzen, 2010) holds that the intention to perform a given behaviour is the immediate antecedent of the actual performance of the behaviour. In turn, behavioural intention is influenced by attitudes, subjective norms and perceived behavioural control towards performing the behaviour. Attitudes are the overall evaluation of performing the behaviour (positive or negative) by the individual and are a learned disposition to respond in a consistently favourable or unfavourable manner on a given object. Subjective norms consist of an individual's beliefs about whether relevant reference persons think he or she should engage in the behaviour. The relevant reference persons are individuals or groups whose preferences regarding a person's behaviour are important to her or him.

The RAA has expanded the concept of perceived social norms to include two components: (a) the beliefs that the relevant reference persons such as peers, friends, teachers or parents are performing or not performing the behaviours is referred to as descriptive norms, and (b) beliefs that the relevant reference persons or groups approve or disapprove of performing the behaviour is describe as injunctive norms (Glanz et al., 2008, p. 67). Perceived behavioral control refers to people's perceptions of the degree to which they are capable of, or have control over, performing a given behavior. This includes their capacities - the belief that one can, is able to, or is capable of, performing the behavior (comparable to Bandura's concept of self-efficacy) - and autonomy, the perceived degree of control over performing the behavior. 
The ARRM was introduced to explain individuals' safe sex behaviours in response to the HIV epidemic in SSA. The model holds that safe sex behaviours towards HIV require that individuals: (a) recognise that a particular behaviour puts them at high risk of contracting HIV, (b) takes the necessary actions to reduce high-risk sexual contacts and engage in lowrisk activities, and (c) implement strategies to obtain safe sex behaviour goals. Finally, Rosenstock's HBM holds that where individuals perceived themselves as susceptible to a condition, believed that the condition could pose adverse consequences, think that a course of action available to them will help to reduce their susceptibility to the situation or severity of the outcome, and believed that the potential benefits of taking action outweigh the constraints to (or costs of) action, they are likely to take action that will reduce their risks.

These theories have been used to explain safe sex behaviours, also within the African context (Nyembezi, Ruiter, van den Borne, Sifunda, Funani, \& Reddy, 2014; Rijsdijk, Bos, Lie, Ruiter, Leerlooijer, \& Kok, 2012; Schaalma, Aarø, Flisher, Mathews, Kaaya, Onya, Ragnarson, \& Klepp, 2009; Sialubanje, Massar, Hamer, \& Ruiter, 2014). Because target populations and intervention contexts are seldom the same, the continuous use of these theories to study the socio-cognitive determinants of the intention to delay sexual intercourse or use condoms in an African setting is necessary to target interventions at the right determinants for change.

\section{Determinants of risky and safe sex practices in Ghana}

A number of studies have reported on the social cognitive determinants of initiating or delaying sexual intercourse among adolescents in Ghana, both at the individual level as well as at the environmental level. Kumi-Kyereme et al. (2007) reported on adolescent sexual and reproductive health from qualitative studies of different age groups within $10-19$ years across Ghana. The authors found that future aspirations and self-efficacy were important determinants of sexual delay. McQuestion, Ahiadeke, Posner, and Williams (2012) modelled primary abstinence and age at first sex in a cross-sectional sample of youth aged 17 to 22 years from 88 Municipalities across Ghana and found that among males, reproductive knowledge was negatively associated with abstinence but positively associated with abstinence among females. Also perceived permissive peer attitudes towards sex was not associated with knowledge but was a protective factor for sexual initiation for both sexes (McQuestion et al., 2012). Reporting from a national survey of adolescents, Awusabo-Asare, Biddlecom, Kumi-Kyereme, and Patterson (2006) found that perceived self-efficacy to negotiate safer sex, perceived self-efficacy to refuse sex and negative attitudes toward sex outside marriage negatively correlated with sexual intercourse. In a study of factors 
associated with sexual delay among adolescents in four sub-Saharan African countries that included Ghana, Kabiru, and Ezeh (2007) reported that gender, sex experience and being involved in romantic partnerships were significant predictors of sexual delay.

Regarding condom use, a number of determinants have been reported to significantly predict Ghanaian adolescents' condom use intentions and behaviours. These include exposure to a condom use demonstration (Bankole, Ahmed, Neema, Ouedraogo, \& Konyani, 2007), condom use self-efficacy and being able to communicate sexual wishes with a partner (Karim, Magnani, Morgan, \& Bond, 2003), perceived susceptibility to HIV infection, perceived self-efficacy to use condoms, perceived barriers to condom use, and perceived social support (Adih, \& Alexander, 1999), and subjective norms and perceived disadvantages of condom use (Bosompra, 2001). More distal variables like visit to health facility, marital status, place of residence, age, education, socioeconomic status, religion, household structure, sex communication at home and substance use have also been associated with condom use (Ahorlu, Pfeiffer, \& Obrist, 2015; Biddlecom, Awusabo-Asare, \& Bankole, 2009; KumiKyereme, Awusabo-Asare, Biddlecom, \& Tanle, 2007; Marrone, Abdul-Rahman, Coninck, \& Johansson, 2014). However, theoretically, it is expected that these distal factors are mediated by the psychosocial measures of attitude, subjective norm, and self-efficacy.

Across sub-Saharan Africa, social norms, perceived behaviour control, self- efficacy and attitudes towards condom use are reported to be significant predictors of intention to use condoms (Bryan, Kagee, \& Broaddus, 2006; Eggers, Aarø, Bos, et al, 2016; Gilles, Liddell, \& Bydawell, 2005; Mmari \& Sabherwal, 2013; Schaalma, Aarø, Flisher, et al, 2009). Also, Eggers, Aarø, Bos, Mathews, and de Vries (2014) reported that among high-school students in South Africa, self-efficacy failed to predict condom use directly but did so indirectly through intention. Comparing university students in South Africa and the US, Heeren, Jemmott, Mandeya, and Tyler (2007) demonstrated that attitudes and subjective norms explain less variance in condom use intentions among the South African sample than the Americans, but self-efficacy was more predictive of condom use intentions. In effect, these studies show that the psycho-social cognitive models can be used to identify determinants of intentions to use condoms in different geographical contexts, including the SSA context. These studies also show that the relative significance of the RAA variables can differ across context, behaviour, and populations. In addition, the relevant content of the determinant depends on the context: while peers may play a more important role in perceived social norms in a European context, what family members think may be the more important social norms in an African context (Giles, Liddel, \& Bydawell, 2005). Also, variables such as perceived risk, knowledge of risks of unprotected sex, unintended pregnancy and 
ways of HIV transmission which are constructs from other social cognition models (e.g., HBM, ARRM), seem to be important factors in explaining condom use in Ghana (AwusaboAsare et al., 2006). Bryan et al. (2006) showed that correct information about pregnancy and condom use for STIs prevention and high self-esteem significantly correlated with a positive attitude, perceived normative support towards condom use, and self- efficacy towards condom use.

\section{Contextual determinants of sexual behaviours}

In addition to the social cognitive factors, contextual determinants of sexual behaviour are also important in the context of SSA. An analysis of the demographic and health survey data from Burkina Faso, Ghana, and Zambia shows a huge diversity in sexual conduct by country, indicating mainly that the differences are due to varied social and economic determinants of sexual behaviour (Stephenson, 2009). The author concluded that although individual behaviour change is central to improving sexual health, efforts are also needed to address these socio-structural determinants. In the Ghanaian socio-cultural context, talking about sexual matters with young people is often considered a taboo subject. When teens ask sexuality related questions, they are suspected of being "bad boys or girls." This is regarded as one of the reasons why young people do not often consult health workers for SRHR services (Kumi-Kyereme, Awusabo-Asare, \& Darteh, 2014). Although a decentralized health care system that is robust to the district level is one of the priority areas of the Ghanaian government, young peoples access (both physically and psychologically) to SRHR services are still limited. Barries to services include fear, embarrassment, shyness, cost, less knowledge on the availability of services and distance to services (Biddlecom, Munthali, Singh, \& Woog, 2007). These barriers are common in other developing countries (ChandraMouli, McCarraher, Phillips, Williamson, \& Hainsworth, 2014).

In Ghana, socio-cultural and religious norms promote abstinence until marriage. However, as in many other societies, multiple standards concerning sexuality is common. Whereas the Society expects girls to be pious, modest, submissive and passive, boys are encouraged to behave in a manner that asserts their masculinity, autonomy, and ambition (Anarfi, \& Owusu, 2010; Ganle, 2015). Such sexual double standards constrain girls' sexual authority and self-determination while reinforcing boys' view of being in control of sexual relationships.

The economically disadvantaged position of most Ghanaian adolescents also has implications for sexual self-determination. Compared to other SSA countries, the prevalence of exchanging money and gifts in return for sex referred to as "transactional 
sex", is high in Ghana (Moore, Biddlecom, \& Zulu, 2007). Three-quarters of unmarried adolescent women said they had received gifts or money in exchange for sex (AwusaboAsare et al., 2006). Also, age-disparate relationships between adult men and younger women are prevalent in Ghana. Approximately 30 percent of 15-24 years old Ghanaian females are involved in (transactional) relationships with men who are at least ten years older (Baba-Djara, Brennan, Corneliess, et al., 2013). Inter-generational sex enhances risky sexual behaviour - such as non-use of condoms and having concurrent multiple sex partners. Some studies have addressed this issue, and Moore et al.'s (2007) review concluded that poverty and unequal power-relations force girls to have (unprotected) sex with older men. In such a socio-economic, religious and cultural context, the right to information and to make independent and informed decisions on safer sex choices by adolescents are hard to realise.

\section{Sex education in the Ghana context}

To make a well-informed decision to delay sexual intercourse until one is ready for it, and to prevent teen pregnancy or STIs by using condoms when sexually active are the reasons why sexuality education is a necessity. School-based sex education can help young people to make well-informed choices relating to their sexual and reproductive health. Worldwide, more and more youth experience sexual debut during their junior years in school. Within this period of early years in school, adolescents begin to respond to biological body changes by exploring sexuality. At the same time, the school environment provides an easy way to reach many adolescents with information regarding their sexuality. Therefore, school-based sex education programmes have the potential to address young peoples' SRHR challenges, reduce adolescents' sexual risk-taking behaviour and promote consensual, safe sexual behaviour (Kirby, 2011). With a primary school participation, net enrolment ratio of 83.9 percent and 84.8 percent for males and females respectively in Ghana (UNICEF, 2015), CSE at schools is an important strategy to address young peoples' SRHR needs.

Globally, there is a wide diversity of definitions and framing of sex education. In the US, CSE is mostly opposed to abstinence-only programmes (Kirby et al., 2006; Kirby, 2008; Bleakly, Hennessy, \& Fishbein, 2006). Thus, CSE is defined as "abstinence-plus" programmes that promote abstinence as the safest behaviour but also emphasise the use of condoms or other family planning methods for the sexually active teens (Kirby, 2008). However, since the International Conference on Population and Development (ICPD) placed reproductive health and gender equality as a human rights-based framework in the Cairo Programme of Action (UN, 1995), the rights-based approach towards sex education has emerged and has attracted 
more interest internationally. According to UNESCO (2009), CSE is more than abstinenceplus; it aims at "providing clear, well informed, and scientifically-grounded sexuality education based on the universal values of respect and human rights" (UNESCO, 2009). In this context, the notion that young people, regardless of gender, sexual orientation, economic status or geographic location, have sexual and reproductive rights is key. Therefore CSE places emphasis on human rights issues and power dynamics within sexual relationships and focuses on empowering adolescents, improving personal agency and selfrespect, and increasing satisfaction, communication, safety and health (Braeken \& Cardinal, 2008; UNFPA, 2010).

Until 1992, sexual and reproductive health was part of the social studies curriculum as family life education at the junior and senior high school levels in Ghana. In 1992, Ghana established the School Health Education Programme (SHEP). One key programme area of SHEP is adolescent reproductive health, within which teen pregnancies and related topics are expected to be addressed. However, the implementation of the SHEP programme has faced with some challenges. These includes the lack of SHEP programme materials, lack of trained teachers on SHEP topics, and no facilities for SHEP activities in schools and teachers' unwillingness to teach sex education (Akyeampong, Djangmah, Oduro, Seidu, \& Hunt, 2007; Awusabo-Asare et al., 2006). Also, as part of the Ghana Basic Education Certificate Examination (BECE), moral and religious classes address reproductive health and family life issues. These topics focus mainly on promoting delay of sexual intercourse until marriage (Awusabo-Asare et al., 2006). Similar trends have been reported elsewhere in Africa (Njue, Nzioka, Ahlberg, Pertet, \& Voeten, 2009). The resistance against CSE that includes condom use demonstration is based on the fear that condom promotion and sex education promote sexual promiscuity, a fear that is not supported by the available evidence (Kirby, 2007; Yeboah, \& Maticka-Tyndale, 2008). Sexuality education that places emphasis on abstinence-only messages is not reflective of the global recognition that adolescents are sexual beings with a right to self-determination, education, information, protection and participation as declared at the ICPD 1994 Programme of Action (UN, 1995). This Programme of Action included several formulations highlighting the responsibilities of Governments towards securing the rights of young people. One such responsibility is the obligation of the states to promote and protect adolescents' right to sex education, information and health services. Another example is the responsibility of the Government to establish, in collaboration with non-governmental organizations (NGOs) appropriate interventions, including training and empowerment of adolescents regarding gender equality, violence against children and women, responsible and safer sexual behaviour and reproductive health 
(UN, 1995).

\section{Effectiveness of School-based Sex Education}

Several reviews (Kirby, 2011; Kirby et al., 2006; Paul-Ebhohimhen et al., 2008; Ross, Dick, \& Ferguson, 2006) have pointed out that school-based CSE programmes can be effective in promoting safe sex behaviour among adolescent in both developed and developing countries. These reviews also show that comprehensive curriculum-based sex educational programs that promote condom use among young people do not result in early sexual debut or increase in sexual activity, as feared by critiques of CSE. To the contrary, several studies show that CSE leads to responsible safer sexual behaviour among young people (Kirby, 2007, 2008), also in SSA settings (Fonner, Armstrong, Kennedy, et al., 2014; Kristien, Matthew, Stanley et al., 2010).

Different authors and organisations (Albarracin, Gillette, Earl, Glasman, Durantini, \& Ho, 2005; Kirby, 2006; Kirby, 2008; Kirby \& Laris, 2009) have suggested critical characteristics of effective (curriculum-based) CSE and teen pregnancy prevention interventions. These features relate to the development, the content, and the implementation. Effective interventions are based on a logic model approach and involving members of the target community, especially adolescents, and involving people with different technical expertise, in theory, research, and health promotion. Critical at the design stage is that the plan of activities incorporates any existing community beliefs and available logistics (e.g., staff skills, staff time, facility space, supplies).

Regarding content, effective programmes have clear goals for preventing teen pregnancy and/or STIs and convey clear messages about specific change objectives related to these aims (Kirby \& Laris, 2009; Chandra-Mouli et al., 2015). Activities and teaching methodologies should be implemented in a way that creates a safe social environment for adolescents to participate, that are appropriate to the young people' culture, developmental stage, and sexual experience and helps them to personalize the information (Kirby, 2008; Rijsdijk et al, 2012). Effective sex-education programmes cover topics in a logical sequence, addressing social-cognitive risk and protective factors with evidence-based change methods and practical applications (Harrison, Newell, Imrie, \& Hoddinott, 2010). Apart from providing accurate messages about both abstinence and family planning methods, including condoms, effective interventions support young people in clarifying their individual, family, and societal values as well as in developing communication, negotiation and refusal skills (Albarracin et al., 2005; Albarracin, Durantini, \& Earl, 2006; Kirby, 2006). Also, effective implementation requires the 
support of appropriate stakeholders such as the health and education services, school authorities and existing community-based organizations as well as prudent selection and training of teachers, followed by continuous monitoring and support (Gallant, \& Matycka-Tyndale, 2004; Paul-Ebhohimhen et al., 2008). Finally, effective programmes implement all lessons with reasonable fidelity, dosage, and reach (Bartholomew Eldredge et al., 2016).

Review studies focusing specifically on the effectiveness of school-based CSE programmes in a Sub-Saharan African context (Gallant, \& Matycka-Tyndale, 2004; PaulEbhohimhen et al., 2008), shows more positive changes in knowledge and attitudes than on reported safer sexual behaviours. In another review, Harrison et al. (2010) suggested to consider the following factors to enhance intervention effectiveness: (1) identifying the social or structural risk factors (e.g., poverty or alcohol abuse) at the needs assessment stage, (2) using group-based delivery to change social norms, (3) relieving the burden on teachers by using additional personnel, and (4) focusing intervention activities at the school as well as individual level. Among the five school-based programmes that were reviewed, four encountered serious implementation challenges and questionable fidelity of implementation, which lead to a strong recommendation to pay attention to the implementation process to ensure that school-based intervention models are effective in SubSaharan context (Harrison et al., 2010).

\section{The SPEEK Program}

The Youth Supporting Peers and Encouraging Empowerment through Knowledge (SPEEK) was an initiative of the Youth Harvest Foundation Ghana (YHFG). The health goal of the program was to reduce the rate of unwanted pregnancies and STIs among young people aged 10 - 24 in 10 communities in the Bolgatanga Municipality of the Upper East region of Ghana. Until the initiation of the SPEEK program, the sexual health education program of the YHFG had been widely focusing on providing factual information to young people with the intention that they will use the knowledge to adopt behaviours that reduce the risk of STIs infections and unintended pregnancies. The original YHFG program was adapted into a more theory and evidence-based SPEEK program using the Intervention Mapping (IM) approach (Bartholomew Eldredge et al., 2016) to target adolescents in the Junior High Schools and other youth groups in the participating communities. Youth peer educators delivered the SPEEK program. 


\section{Overview of IM approach}

The IM approach is a systematic process to develop or revise health promotion programs based on theory and empirical evidence. The six steps of IM are designed in a way that makes each step providing a foundation for the next. Each step is composed of several tasks that lead to a clear end product. IM stimulates program planners to make decisions based on data and theory that have been shown to be most effective (Bartholomew Eldredge et al., 2016).

\section{IM step 1: Logic model of the problem}

In step one, the implementing team, in consultation with key actors in the health and education services, identified the relevant risk factors for unintended teenage pregnancies and STIs transmission among the youth in the participating communities. These were high unsafe sexual activities (mainly unprotected sex), lack of comprehensive knowledge on sexuality issues; negative attitudes (informed by myths and socio-cultural beliefs) towards contraception, lack of skills and self-efficacy to use the various contraception methods, low risk perception with regard to their sexual behaviors, and a perceived normative environment that do not support safe sexual practices.

\section{IM Step 2: Program outcomes and objectives}

Based on the initial assessment, the target behavioral outcomes in SPEEK were that the youth will: (1) delay sexual intercourse until only when they are ready for it, (2) those sexually active will correctly and consistently use contraceptives (including condoms) during sexual intercourse, and (3) go for HIV/STI testing to know their status and take appropriate measures. To make the behaviors more specific, we identified performance objectives, or sub-behaviors (Van Empelen \& Kok, 2008). The next task in the intervention development was to specify the determinants of the performance objectives. Determinants are factors that are associated with the fulfilment of the behaviors and that are presumed to predict the behavior. The selection of relevant and changeable determinants of the performance objectives was based on previous research in West African context (Meekers \& Klein, 2002; Godin, Tinka, Sow, Minani, \& Alary, 2008) and in other parts of the world (Armitage \& Conner, 2001). Personal determinants are factors within the individual; external determinants exist in the environment. SPEEK was designed to target only personal determinants, and the target determinants were knowledge, attitude, self-efficacy/skills, risk perception and social norms. The matrix of change objectives was developed by crossing each performance objective with each determinant. Change objectives consider the target adolescent population, the performance objective, and the determinant in a more specific 
measurable phrase. For example, adolescents (target group) express confidence (determinant: self-efficacy) in always having condoms with them when they go out (performance objective).

\section{IM Step 3: Program design}

The theory- and evidence-based intervention components of SPEEK were developed in step 3 of IM. A theoretical method is a general technique or process for influencing changes in the determinants of behaviors. The application is a specific technique of applying the theoretical methods in ways that fit the intervention population and the context in which the intervention will be conducted. We relied on the suggestions of Bartholomew, Parcel, Kok, Gottlieb, and Fernandez (2011) for possible methods of behavioral change objectives. For every determinant, various methods were discussed and finally decided based on their changeability and applicability within the context of northern Ghana. Methods were derived from theories and evidence in the literature that they might have the desired effect. However, for each method, we had to discuss the parameters or conditions under which the method had been shown to be effective and whether those conditions could be guaranteed in SPEEK implementation. The next task in step 3 was to translate the theoretical methods into practical applications, taking into consideration the target population, the context of northern Ghana and the peer educators who delivered the SPEEK program. We put the defined changed objectives within these applications and linked all strategies to one or more theoretical methods.

\section{IM Step 4: Program production}

At Step 4, the peer educators who were to implement the program had been recruited and trained to join the project team. The program scope, sequence and the needed resources were discussed. The applications were also carefully developed in line with the theoretical conditions of the underlying methods in Step 3. Most of the activities were tailored to characteristics of the adolescent population in the Bolgatanga Municipality. All applications and materials were pilot-tested and based on the ensuing discussions; the activities were adapted accordingly. The end product of IM step 4 was the SPEEK program manual, made up of 11 lessons: Lesson 1: Get to know each other, \& the male and female sexual body; Lesson 2: Menstruation, \& Wet Dreams; Lesson 3: Relationship, \& Sex; Lesson 4: Understanding pregnancy, \& abortion; Lesson 5: Understanding HIV, \& STIs; Lesson 6: High risk situations that can result in unintended and unprotected sex; Lesson 7: Personalizing Risk for Pregnancy, HIV, \& STIs, \& methods of protection; Lesson 8: Using protection part 1(condoms); Lesson 9: Using protection - part 2 (condoms); Lesson 10: 
Using protection - part 3 (Other contraceptives); Lesson 11: Sexual rights, setting personal limits and saying "no".

\section{IM Step 5: Program implementation plan}

According to the IM approach, when an intervention is being developed, the implementation has to be anticipated from the beginning. In SPEEK, implementation had three key decision makers: the peer educators who were to deliver the program, the education services authorities and the schools where the program was to be delivered, and the health services from which resource persons were to be drawn for both training and specific lessons. From the start of the project, the project team made engagements with the main actors, including all of these institutions. The successful participation of these organizations and their involvement in the planning process created an enabling environment for the implementation of the SPEEK program.

\section{IM Step 6: Evaluation Plan}

The SPEEK Project team identified prevention of unintended teen pregnancies and HIV/STIs as the final goals of the project. However, the matrices of change objectives and performance targets became the basis for the effect evaluation of the program, as reported in this dissertation.

As outlined above, effective interventions are not only theory and evidenced-based but also depends on a context-specific needs assessment that analyses the determinants of individual (safe) sexual behaviour decision-making processes and specific socio-cultural, religious and economic contextual factors that may influence these decisions (Bartholomew Eldredge et al., 2016). The studies that have been conducted in this Ph.D. project were aimed at analyzing the individual level determinants (knowledge, attitudes, perceived behavioural control, norms and their related beliefs and perceptions) and behaviours (sex experience, sex communication, condom use, relationship experiences) to inform effective intervention development targeting teenage pregnancy prevention in Ghana. This need assessment studies are limited to the target adolescent population (boys and girls) and do not include a detailed analysis of the determinants of their important referent persons such as parents, teachers and health workers or religious leaders.

\section{Outline of the thesis}

For different studies that have the combined objective of providing input to intervention development, the recommended approach is to first do qualitative studies to determine the most important factors, followed by a quantitative study to clarify the most significant factors that apply to the general population and then use the findings to develop the intervention 
(Bartholomew Eldredge et al., 2016). However, this sequence of studies may not happen in practice, which was the case in this dissertation. At the beginning of the Ph.D. project, we took advantage of a funded project to develop the SPEEK intervention because the urgent need for intervention to address teenage pregnancy in the study area could not be delayed. Therefore, the intervention reported in this dissertation was developed based on a review of the literature and preceded both the quantitative survey and the qualitative exploratory studies. However, for purposes of logical sequencing, the outline of the dissertation starts with the quantitative studies, followed by the qualitative studies and concludes with the evaluation of the intervention.

The first study (Chapter 2) discusses the socio-cognitive determinants of safe sex behaviour (i.e. intention to use condoms), including the difference between low and high intenders as compared with those with moderate intentions. A school-based sample was drawn from 21 junior high schools in the Bolgatanga Municipality of Northern Ghana. Participants $(N=2,018)$ completed a questionnaire measuring knowledge, attitudes, perceived behavioural control, social norms and self-efficacy beliefs regarding pregnancy, STIs and HIV and intentions to use condoms. Also, participants with and without previous sexual experience were compared.

The second study (Chapter 3) explored the factors associated with teenage pregnancy among girls with pregnancy experience in Bolgatanga, Ghana. Guided by themes (relationships, sex, pregnancy, family planning) and determinants (knowledge, attitudes, self-efficacy, norms, risk perceptions) derived from empirical studies and theories related to sexuality behaviour, we conducted semi-structured in-depth interviews with 21 pregnancy experienced teenage girls. The study discusses the need for open sex communication at home and the provision of CSE in school to address teenage pregnancies in Ghana.

The third study (Chapter 4) also explored the psychosocial and environmental factors influencing the sexual decision making of girls without pregnancy experience $(\mathrm{N}=$ 20) in Bolgatanga, Ghana. The aim was to find out how their contraceptive decision-making processes and beliefs differ from those with pregnancy experience studied in Chapter 3. Semi-structured in-depth interviews were guided by themes such as relationships, sex, pregnancy, family planning and psychosocial determinants (knowledge, attitudes, selfefficacy, norms, risk perceptions) derived from empirical studies and theories related to sexuality behavior. The study discusses protective factors at the individual, interpersonal, school and community levels that should be targeted for future intervention development. 
The fourth study reported in Chapter 5 looked at the particular forms of sexual behaviours among boys ( $N=20)$ living in Bolgatanga, Ghana. The aim was to explore boys' perceptions and beliefs towards sexual relationships and how their perceptions influence their contraceptives decision making. The semi-structured interview guide incorporated determinants related to knowledge, attitude, self-efficacy, risk perception, and social norms addressing topics such as relationships, sex experience, pregnancy, condom use, contraception, and sex communication. The study highlights the role of trust, fidelity and social norms in how boys negotiate condom use in sexual relationships and point out avenues for future research.

The fifth study (Chapter 6), aimed to assess the effects of SPEEK on the sociocognitive determinants of safe sex behaviour, including condom use intentions among Ghanaian junior high school students. This study was based on a randomised controlled design, involving participants belonging to intervention schools $(N=10)$ and comparison schools $(N=11)$. The students completed survey questionnaires at baseline $(\mathrm{N}=1822)$, at post-test $(\mathrm{N}=1805)$, and at six months follow-up $(\mathrm{N}=1959)$. The effectiveness of the SPEEK program on the social-cognitive variables is discussed.

The empirical chapters have been submitted as separate articles to peer-reviewed journals. The last chapter (Chapter 7) summarizes the most significant findings of the studies reported in this dissertation and discusses them in the context of the literature on adolescent SRHR. The chapter includes comments on the methodological limitations of the studies and highlights implications of the study results for the development of comprehensive sex education programs. The chapter concludes with some recommendations for future research on sex education for adolescents in a SSA rural context. 


\section{Chapter 2}

\section{Psychosocial correlates of condom use intentions among Junior High School students in the Bolgatanga Municipality of Ghana}

\section{Published as:}

Krugu, J.K., Mevissen, F.E.F., Debpuur, C., \& Ruiter, R.A.C. (2016). Psychosocial correlates of condom use intentions among junior high school students in the Bolgatanga Municipality of Ghana. International Journal of Sexual Health, 28, 96-110, doi: 10.1080/19317611.2015.1124162. 


\section{Introduction}

HIV (human immunodeficiency virus) and AIDS (acquired immune deficiency syndrome) had reached epidemic levels in most parts of Africa by the end of the last century. Current estimates are that half of all incidences of HIV occur in young people below 25 years, and $80 \%$ of AIDS cases worldwide affect those aged between 15 and 24 years, the majority of whom live in sub-Saharan Africa (UNAIDS, 2014). Among sub-Saharan countries in Africa, Ghana is one of the countries confronted with increasingly high rates of sexually transmitted infections (STI) among its adolescent population. Among sexually experienced young men and women aged 15 to 24 years, one out of four females and one out of seven males reported having ever been infected with an STI or having symptoms of STIs (Ghana Statistical Service, 2009). National HIV prevalence in Ghana was estimated at $1.3 \%$ in 2013, with prevalence in the Upper East region reaching 1.7\% (Ghana AIDS Commission (GAC), 2014). Moreover, with an overall HIV prevalence among sex workers estimated at $11.1 \%$ in 2011 (GAC, 2012), there is a significant reservoir of HIV that can easily spread to the general population.

Another problem affecting adolescents in Ghana is teenage pregnancies. According to the Ghana Health Service annual report, each year, approximately 750,000 teenagers between the ages 15-19 years get pregnant. In the Upper East Region, records from the Ghana Health Service indicate that in 2012, 13.3\% of girls had babies during their adolescent years. It has been acknowledged that teenage pregnancy not only increases health risks for the teenage mother and her (unborn) child (Awusabo-Asare, Abane \& Kumi-Kyereme, 2004) but also disproportionately disrupts girls' education in northern Ghana (Blunch, 2011; Sutherland-Addy, 2002; Tuwor \& Sossou, 2008 ).

Correct and consistent condom use, as compared to other forms of contraception, has been found to prevent both STIs and unintended pregnancies (Crosby, DiClemente \& Wingood, 2001; Steiner \& Cates, 2006). However, evidence shows that condom use remains low in Ghana. An analysis of data from the Ghana Demographic and Health survey showed that the proportion of women reporting condom use at last sexual intercourse was $15 \%$ in the urban areas and $10 \%$ in the rural areas (Baiden \& Rajulton, 2012). In another study conducted in four African countries, the proportion of urban young men reporting consistent condom use in the three months preceding the survey was $47 \%$ in Ghana. The authors of this study reported that age, school attendance, the level of sex education received in school, and exposure to radio were all significant predictors of condom use (Bankole, Ahmed, Neema, Ouedraogo, \& Konyani, 2007). 
In order to change behaviors and increase condom use among adolescents, thereby protecting them from STIs and unintended pregnancies, it is vital to gain insight into the factors that influence the use of condoms. The aforementioned study carried out by Bankole and colleagues (2007) illustrates that sex education does contribute to increased condom use, a finding in line with other publications (Eisenberg, Bernat, Bearinger, \& Resnick, 2008; Kirby, 2008). Our study explores the antecedents of condom use among adolescents in the Upper East Region of Ghana in order to guide the future development of theory- and evidence-based sexual risk reduction interventions (Bartholomew, Parcel, Kok, Gottlieb, \& Fernández, 2011).

A number of social cognitive theories have been used to explain sexual risk behavior, including within the African context (Nyembezi, Ruiter, van den Borne, Sifunda, Funani \& Reddy, 2014; Rijsdijk, Bos, Lie Ruiter, Leerlooijer, \& Kok, 2012; Schaalma, Aarø, Flisher, Mathews, Kaaya, Onya, Ragnarson \& Klepp, 2009; Sialubanje, Massar, Hamer \& Ruiter, 2014). Examples include the Theory of Planned Behavior (Fishbein \& Ajzen, 2010), Social Cognitive Theory (Bandura 1998), the AIDS Risk Reduction Model (ARRM; Catania, Kegeles \& Coates, 1990), and the Health Beliefs Model (HBM) (Rosenstock, 1974). These theories generally hold that behavior is primarily determined by motivation (intention) to undertake the behavior, and that intention is in turn determined by an individual's evaluation of the outcomes of the behavior (attitude), the behavior and opinions of important others (perceived norms), and personal control over performing the behavior (perceived behavioral control $\{\mathrm{PBC}\})$. Bandura's construct of self-efficacy places extra emphasis on the extent to which a person feels confident that he or she can successfully perform the target behavior. Both Rosenstock's HBM and Catania, Kegeles \& Coates' ARRM have emphasised the predictive value of perceived risk as a motivation for action related to sexual behavior.

Previous empirical research in West Africa has confirmed the role of these determinants in predicting condom use in young people (Adih and Alexander, 1999; Bosompra, 2001; Giles, Liddell \& Bydawell, 2005; Meekers \& Klein, 2002). However, as the number of studies is limited and/or data are outdated, there is a need for more up-to-date research to be carried out. Importantly, studies focusing on condom use among young people in Western Africa thus far seem to have neglected the powerful role of affect in influencing adolescent sexual behavior (Lawton, Conner, \& McEachan, 2009). Since discussing sex and buying or using condoms can elicit strong emotional responses from adolescents in a culturally inhibited environment, affective beliefs could be more potent predictors of both intentions and behavior than cognitive beliefs. In this study, we thus distinguish between affective or experiential attitude, which refers to an individual's 
emotional response towards performing a behavior, and cognitive attitude, which refers to beliefs, knowledge structures, perceptual responses and thoughts about the consequences of performing the behavior (Fishbein \& Ajzen, 2010).

Many studies exploring condom use have looked at determinants in terms of their broad conceptualisations: attitude towards condom use, self-efficacy towards condom use, etc. These more general psychosocial measures do not provide enough details for intervention development. The influence of these variables on condom use may well depend on the specific sub-behaviors involved, (such as buying condoms, having them available, and discussing condom use with a sexual partner), that either facilitates or inhibits the use of condoms (Bryan, Fisher, \& Fisher, 2002). Understanding the nature of these preparatory behaviors, and the practical obstacles that may prevent them being carried out, can further contribute to the development of empirically targeted interventions designed to promote such behaviors. Using behavior specific measures, the present study examined the antecedents of condom use intentions among junior high school students in the Bolgatanga Municipal area of Northern Ghana.

\section{Method}

The present study draws on the baseline survey of an effect evaluation of the SPEEK programme, a sexual health education program for Ghanaian youth (see Krugu, Mevissen, Debpuur, \& Ruiter, in progress). The baseline survey assessed the psychosocial determinants of adolescents' condom use intentions before the introduction of the SPEEK programme in September 2012.

Participants

Participants in this study were 2081 junior high school students (54\% female) from the Bolgatanga municipality, Upper East, Ghana. The mean age of the participants was 15.8 years ( $S D=1.89$ ). The majority of the respondents indicated their religion to be Christianity (79.6\%) followed by traditional worship (11.2\%), Islam (8.6\%), and $0.6 \%$ of respondents were affiliated with 'other' religions. In all, 617 respondents (29.6\%) indicated that they had had sexual intercourse, out of which $24 \%(N=148)$ indicated that they had used a condom the last time they had had sex. Another $28.4 \%(N=175)$ reported either having (had) a pregnancy or having impregnated someone. Among those with sexual experience, $65.8 \%$ had sexual debut at age 15 or below.

Procedure

All 21 Junior High Schools (JHS) in the 10 communities in the Bolgatanga municipality where SPEEK was to be implemented were approached and invited to participate in the 
survey. After consent from the Ghana Education Services authorities, approximately 2500 JHS students were invited to participate in the study. They were provided with background information about the study (including the voluntary, anonymous and confidential nature of their participation) and parental informed consent forms were provided for them to take home. Only those who returned completed parental informed consent forms were invited to complete the questionnaires. Those students who did not return parental consent forms were asked to stay outside the classroom during questionnaire administration. In total, 2356 (94.2\%) students returned completed parental consent forms and were then given child assent forms to complete.

Subsequently, 2324 students (98.64\%) returned completed child assent forms and were provided with questionnaires to complete in classrooms. Although we surveyed all participants attending junior high schools in the participating communities, the analysis is limited to respondents within the age range of 10 to 20 years - a range that covers most definitions of adolescence. As a result, $9(0.39 \%)$ participants outside the desired age range were excluded from analyses.

During data cleaning, we found that 165 participants had missing data for the background variables of age, gender, religion and sexual experience, and 69 participants had more than $20 \%$ missing data in the theoretical constructs (intention towards condom use, PBC towards condom use, etc.). These participants $(\mathrm{N}=234)$ were also excluded from analyses, leaving a final sample of 2081 participants to be included in the analyses. Logistic regression analyses were done to check for selective dropout on the theoretical constructs using the percentages of the missing values as an outcome measure (with 0 representing students less than $20 \%$ drop out and 1 representing those with more than $20 \%$ drop out). The analyses showed no selective drop out based on age, gender, religion or sex experience $(p ' s>.08)$.

Participants received a half-page brief description of the project, the survey, and the voluntary nature of their participation. The description outlined the project aim of reducing sexual risk behaviors and emphasized the anonymity and confidentiality of participation. In addition to this, the project and the survey were further explained to participants by trained research assistants. To ensure the students' privacy, school teachers were not present in the classrooms during survey administration, and each student sat at a separate desk. Research assistants (not personally known to the students) were present to ensure that students did not discuss questions among themselves, and to explain the questions both in English and in the local language (Gurune). The study was approved by the Ethics Review Board of 
Maastricht University in the Netherlands and the Ghana Health Services ethical committee in Accra.

Measures

The measures were derived from a survey previously used in South Africa and Uganda to measure condom use intentions among adolescents (Rijsdijk et al., 2012). The development of the original survey was based on the same psychosocial theories mentioned earlier in our introduction and the social-psychological constructs matched those found in the reported empirical studies. To assess how easy it would be for participants to understand the questions included in the survey, it was pre-tested on a representative sample of adolescents $(\mathrm{N}=50)$ from a school in Bolgatanga. This pre-test data was not included in the final study. The pre-test resulted in minor changes being made, such as the rephrasing of certain questions to make their meaning clearer.

The survey included items assessing socio-demographic variables, sexual experience, and psychosocial measures. For the demographic measures, an open question: "How old are you?" required the participants to provide their age. Participants were asked to tick the options male or female to indicate their sex. With regard to religion, they were asked to select from: Traditional worship, Islam, Christianity or Other. The answer options for religion were recoded into a binary scale with 1 representing Christianity (biggest group) and 0 all others.

Past sexual experience was measured by the item: "Have you ever had sexual intercourse?" $(0=$ No; 1 = Yes). We defined sexual intercourse for participants as "when a man or boy inserts his penis into a woman's or girl's vagina." For those with sexual experience in accordance with this definition, additional questions were asked about their age at sexual debut (How old were you when you had sexual intercourse for the first time?), their use of condoms ('Did you use a condom the last time you had sex?': $0=$ Never; $1=$ Always), and pregnancy experience (Have you ever been pregnant or made someone pregnant?; $0=$ None; 1 = Once; $2=2$ times or more; $3=I$ don't know, which was recoded into $0=$ No or don't know; 1 = Once or more than once. The answer options "never" and "always" for the question on condom use experience was later detected to be inappropriate (a better option would have been a simple "yes" or "no") and therefore condom use experience was excluded from the analyses. No questions on sexual orientation or anal sex were included because no honest answers were expected based on the high stigma associated with homosexuality and anal sex in the study area (AED, 2008).

Table 1 provides an overview of the psycho-social measures; including the items, and reliability scores (the full questionnaire is available from the first author upon request). The 
psychosocial measures included cognitive- and affect-oriented measures and used 5-point Likert scales, except for the knowledge items which were measured on a three point scale: true, false and don't know. Psychosocial items comprised of: knowledge [actual \& perceived], attitude [cognitive and affective] towards condom use and its availability, perceived behavioral control [PBC] towards condom use, buying condoms, and dealing with negative feelings when buying condoms, perceived STI risk, perceived norms [both injunctive and descriptive], and intention towards condom use. These psychosocial items were recoded such that higher scores reflected a stronger presence of the variable in question. Knowledge items were recoded into $0=$ false answer or don't know, $1=$ correct answer, and combined in sum scores. For psychosocial measures consisting of more than one item, reliability analyses were performed. For each measure, scores on items that showed sufficient internal consistency (Cronbach's alpha $\geq .60$ for three or more items; Pearson correlation coefficient $>.30$ for two items) were averaged into one single index. Mean scores for measures were calculated for each participant if more than half of the items that made up one measure were answered. No data imputation was done to retain the missing items in a measure for a specific participant. 


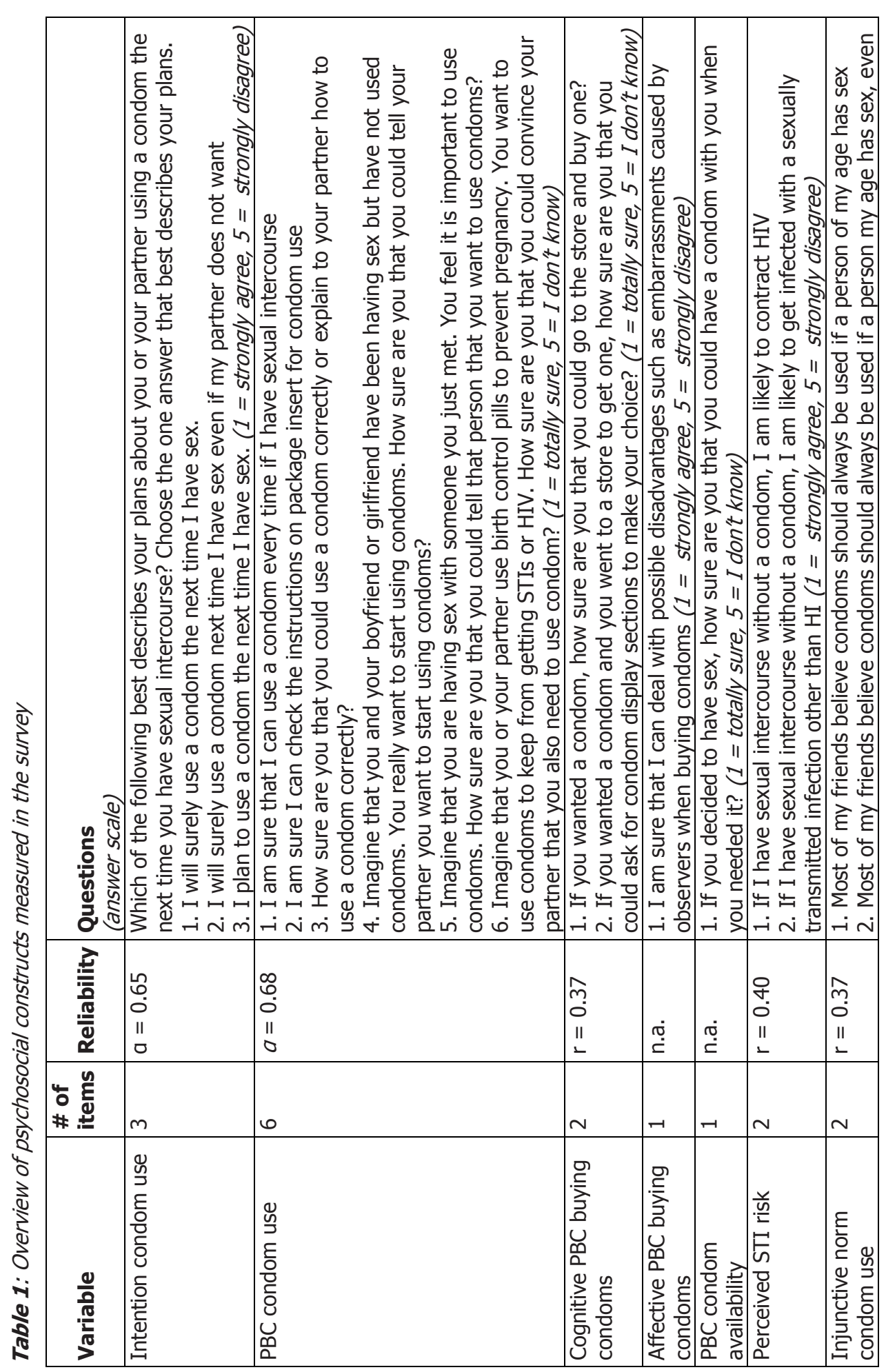

m 


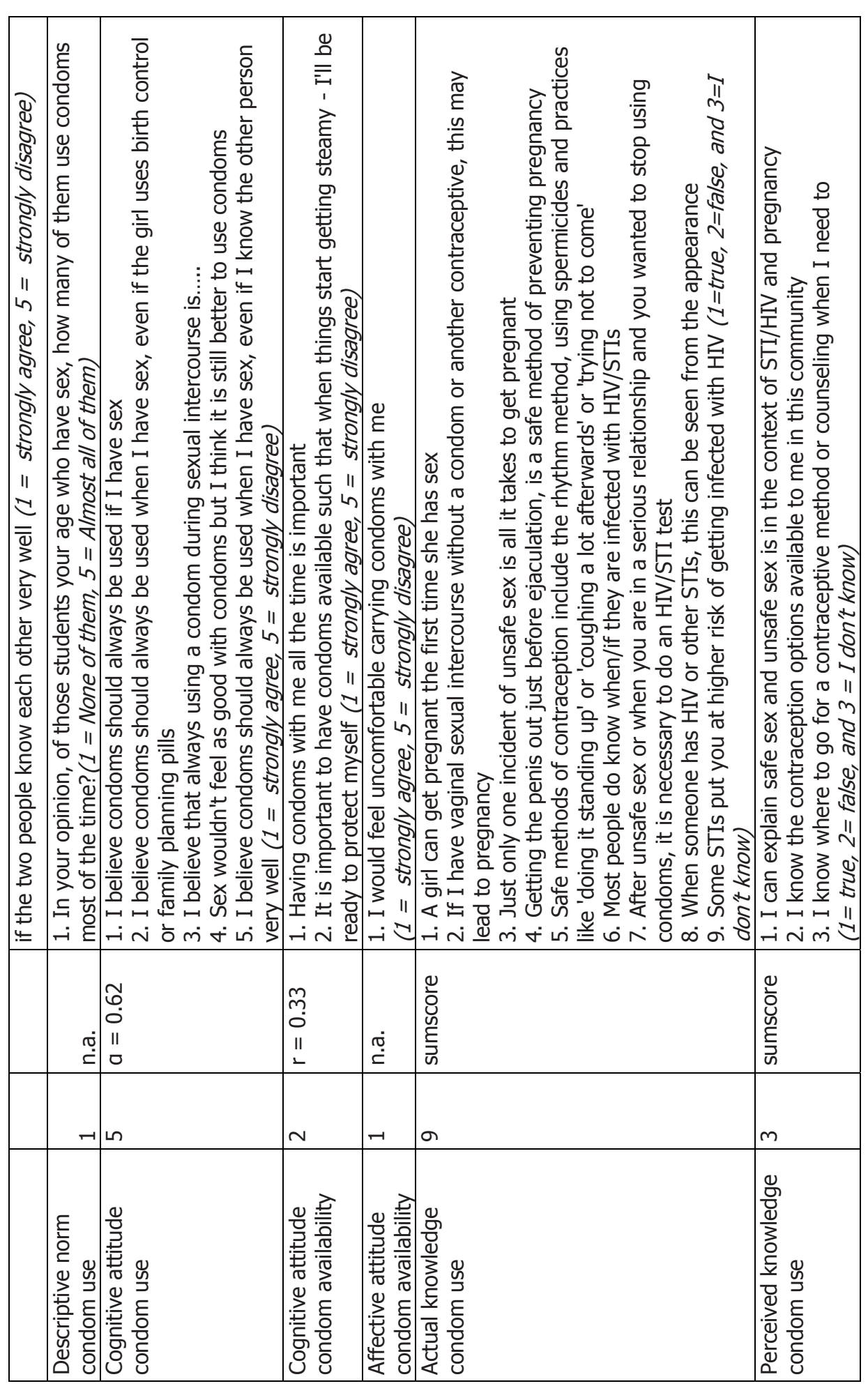




\section{Data analysis}

SPSS Version 21.0 was used for the data analysis. First, descriptive analysis, frequencies, and mean scores were calculated. The Bivariate associations among sociodemographic, psychosocial, sexual experience and intention measures were calculated using Pearson correlation coefficients. Variables that showed significant univariate associations with intention to use condoms ( $p$ 's $\leq .01$ ) were included in a multinomial logistic regression analysis to identify the effect of the independent variables on the probability of: (1) having no intention to use condoms vs not having made a clear decision about condom use, and (2) having high intention of using condoms vs not having made a clear decision about condom use. This intention measure was created based on tertile split scores for the original intention measure following its u-shaped distribution. The respondents were split into three groups: those with no/low intention to use condoms (intention towards condom use score < 3.00; $\mathrm{N}$ $=469)$, those expressing no clear decision about condom use ( $3 \leq$ intention towards condom use < 4; $N=489$ ), and those with high intention to use condoms (intention towards condom use $\geq 4.00 ; N=626$ ). To explore possible differences between female and male participants in the predictors of intention to use condoms, the correlation and regression analyses were repeated for each gender group.

Blockwise multinomial logistic regressions were conducted in order to assess the contribution of socio-cognitive variables (Model 1), additional affective beliefs (Model 2), and past behavior and demographics (Model 3 ) in explaining condom use intention. To demonstrate differences in classification accuracy, the Nagelkerke index was chosen (Cohen, Cohen, West \& Aiken, 2003). In light of the relatively large number of participants resulting in high statistical power in the analyses, results were considered significant at $p<.01$.

\section{Results}

Bivariate analyses

Table 2 presents the bivariate associations found among the psychosocial and demographic measures using Pearson r correlations ${ }^{1}$. With the exception of religion, age at sexual debut, and condom use, all items included in the analyses significantly correlated with the intention to use condoms, with $r=.10-.23$ indicating a small effect, $r=.24-.36$ indicating a moderate effect, and $r \geq .37$ indicating a large effect (Cohen, 1988). The strongest associations with intentions to use condoms were found for perceived risk of STI

\footnotetext{
${ }^{1}$ Repeating the correlation analyses with scales in which participants with more than $20 \%$ missing items (69
} participants) were included did not reveal any significant differences in results 
infection, perceived behavioral control towards condom use and injunctive norms towards condom use. Cognitive attitude towards condom use, cognitive attitude towards condom availability, cognitive perceived behavioral control towards buying condoms and perceived behavioral control with regard to condom availability all moderately correlated with condom use intention. Small effect sizes were noted for both actual and perceived knowledge towards condom use, affective attitude towards condom availability, perceived behavioral control towards dealing with negative feelings when buying condoms, descriptive norm towards condom use, as well as gender, sex experience, and pregnancy experience. All significant correlates related positively to intention except for pregnancy experience.

Separate correlation analyses for female and male participants found no differences between both groups in the pattern of findings. 


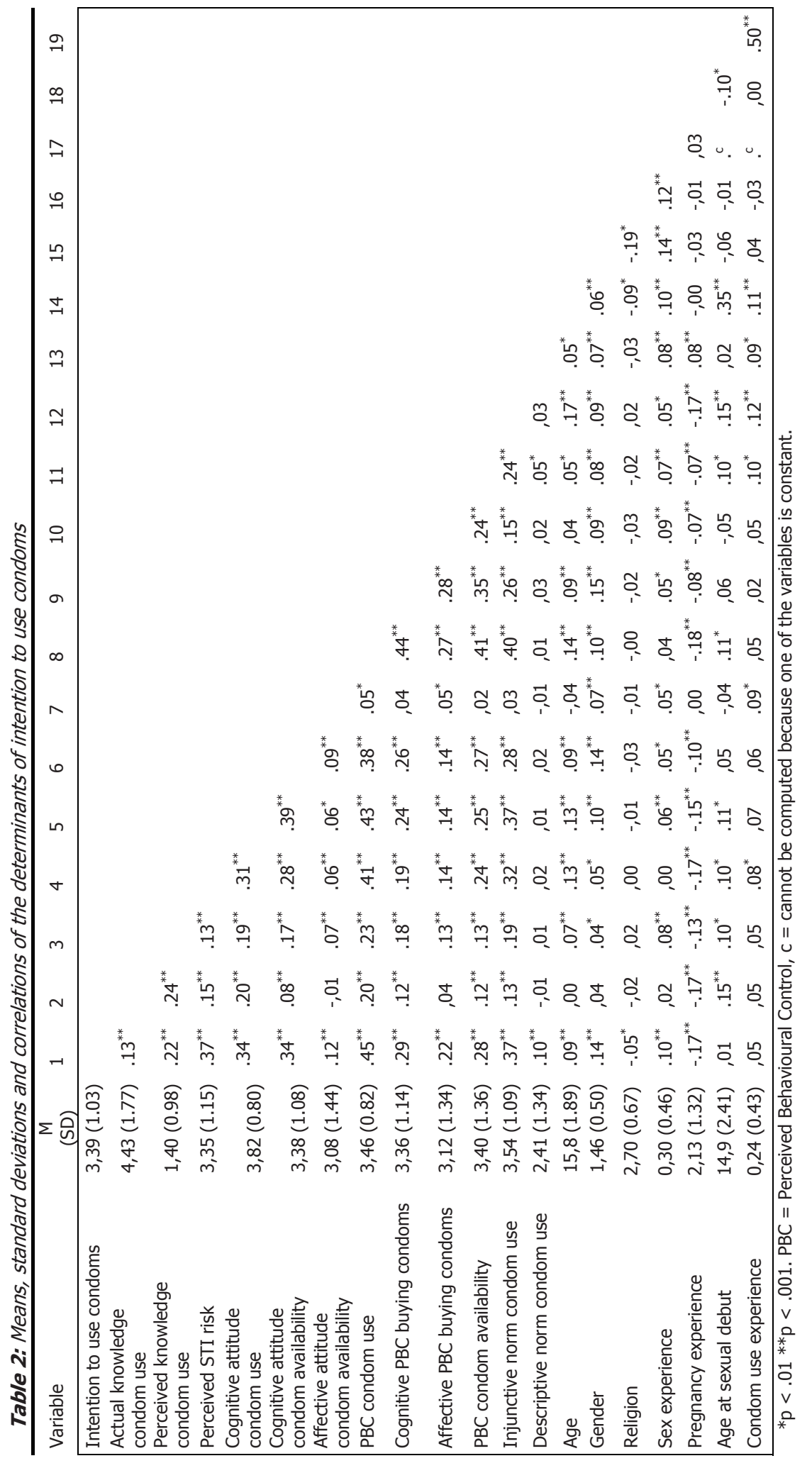




\section{Multivariate analyses}

Multivariate logistic regression analyses were conducted to explore the unique contributions of the study variables, and the influence of these variables on intention to use (or not use) condoms. The results of the regressions are shown in Table 3a (total sample), Table 3b (females), and Table $3 c$ (males) ${ }^{2}$. Significant results $(p<.01)$ of the final model are described, first for the total sample and then for the two gender groups.

No intention to use condoms vs no clear decision about condom use.

Participants were more likely to have no intention to use condoms, than they were to be undecided about condom use when they reported a lower injunctive norm towards condom use and when they reported weaker affective attitudes towards condom availability. Furthermore, participants without sex experience were significantly more likely to have no intention to use condoms as compared to those with sex experience.

Separate analyses for male and female participants found for females a unique additional contribution for descriptive norm towards condoms use $(b=-.18$, SE $=.07, p=$ .01 ), with lower descriptive norms making it more likely that girls have no intention to use condoms, whereas the contributions of injunctive norm $(b=-.22, \mathrm{SE}=.10, p=.02)$, affective attitude $(\mathrm{b}=-.16, \mathrm{SE}=.06, p=.02)$ and sexual experience $(\mathrm{b}=-.53, \mathrm{SE}=.22, p$ $=.02$ ) approached significance at the $p<.01$ level. For male participants, the contributions of injunctive norm $(\mathrm{b}=-.31, \mathrm{SE}=.11, p=.01)$ and affective attitude $(\mathrm{b}=-.27, \mathrm{SE}=.08, p$ $<.01)$ remained significant, whereas sexual experience had no significant contribution $(b=-$ $.45, \mathrm{SE}=.23, p=.06)$.

High intention to use condoms vs no clear decision about condom use.

Participants were more likely to have high intentions to use condoms than be undecided about condom use if their risk perceptions towards getting infected with an STI were high, had positive cognitive attitudes towards condom availability, and reported higher ratings of perceived behavioral control towards both buying condoms and condom use. For female participants the same pattern of findings was found with significant contributions of perceived STI risk $(b=.30, \mathrm{SE}=.09, \mathrm{p}<.01)$, cognitive attitude towards condom availability $(\mathrm{b}=.30, \mathrm{SE}=.10, \mathrm{p}<.01)$, and perceived behavioral control towards using condoms $(b=.44, \mathrm{SE}=.15, \mathrm{p}<.01)$. The contribution of perceived behavioral control towards buying was no longer significant $(b=.16, \mathrm{SE}=.09, \mathrm{p}=.09)$. For male participants, the findings changed with no longer significant contributions for perceived STI risk $(b=.06$,

\footnotetext{
${ }^{2}$ Repeating these regressions using scales in which participants with more than $20 \%$ missing items (69 participants) were included resulted in the effect of sex experience, risk perception, and perceived behavioral control towards buying condoms no longer being significant, p's > .02, for the total sample)
} 
$\mathrm{SE}=.09, \mathrm{p}=.53)$, cognitive attitude towards condom availability $(b=.06, \mathrm{SE}=.10, \mathrm{p}=$ $.59)$, and perceived behavioral control towards buying condoms $(b=.19, \mathrm{SE}=.10, \mathrm{p}=.04)$. The contribution for perceived behavioral control towards condom use remained significant $(b=.58, \mathrm{SE}=.16, \mathrm{p}<.01)$. In addition, a significant contribution was found for perceived knowledge about condom use $(b=.27, \mathrm{SE}=.10, \mathrm{p}=.01)$ indicating that higher perceived knowledge was associated with a higher likelihood of having a strong intention to use condoms.

The multinomial logistic regression across the total sample using socio-cognitive, past sexual experience and demographic variables as predictors showed a classification accuracy of $55.5 \%$ (pseudo $\mathrm{R}^{2}=.33$ ). For female participants only, the classification accuracy was $55.2 \%$ (pseudo $\mathrm{R}^{2}=.33$ ), for male participants, $53.8 \%$ (pseudo $\mathrm{R}^{2}=.29$ ). 


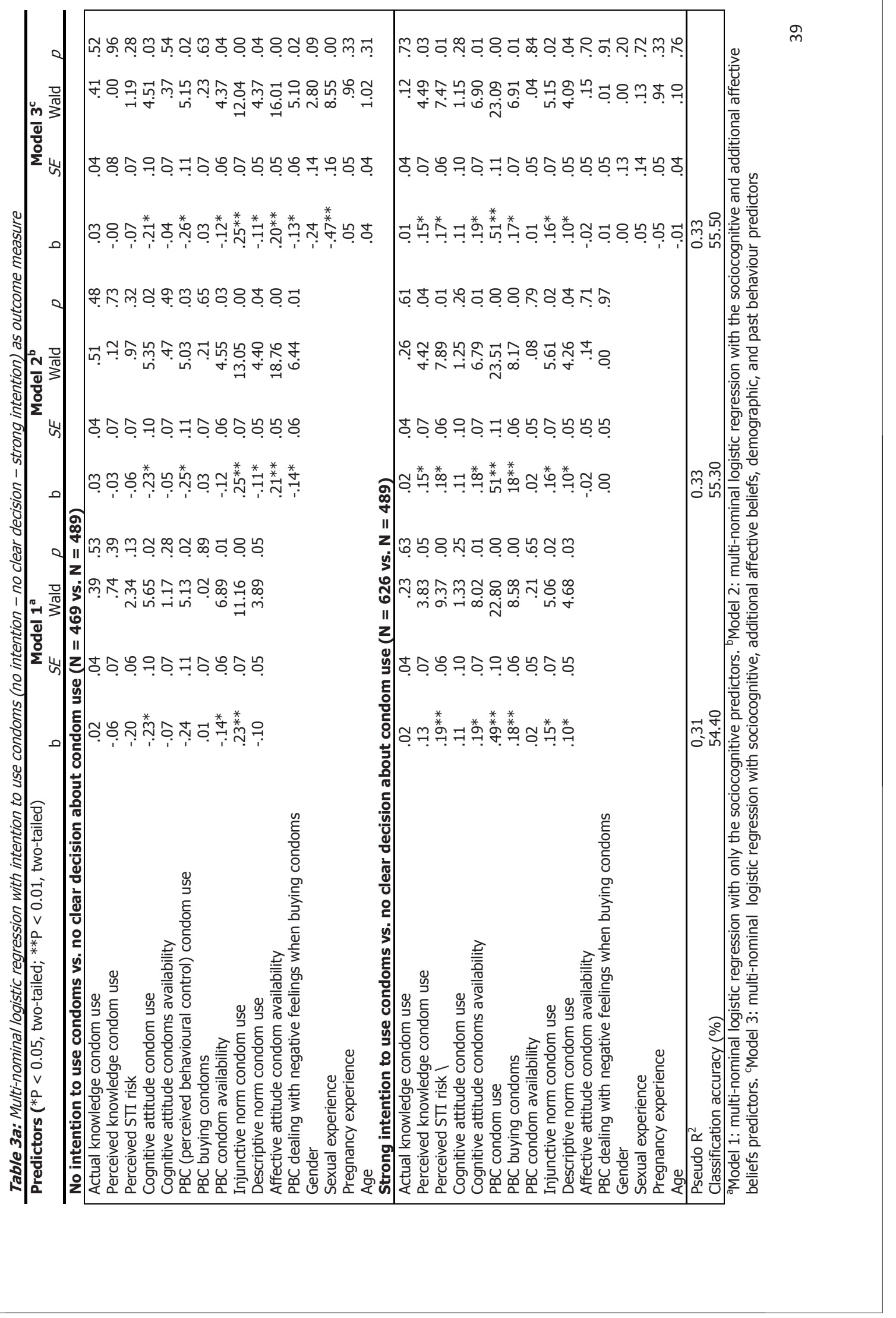




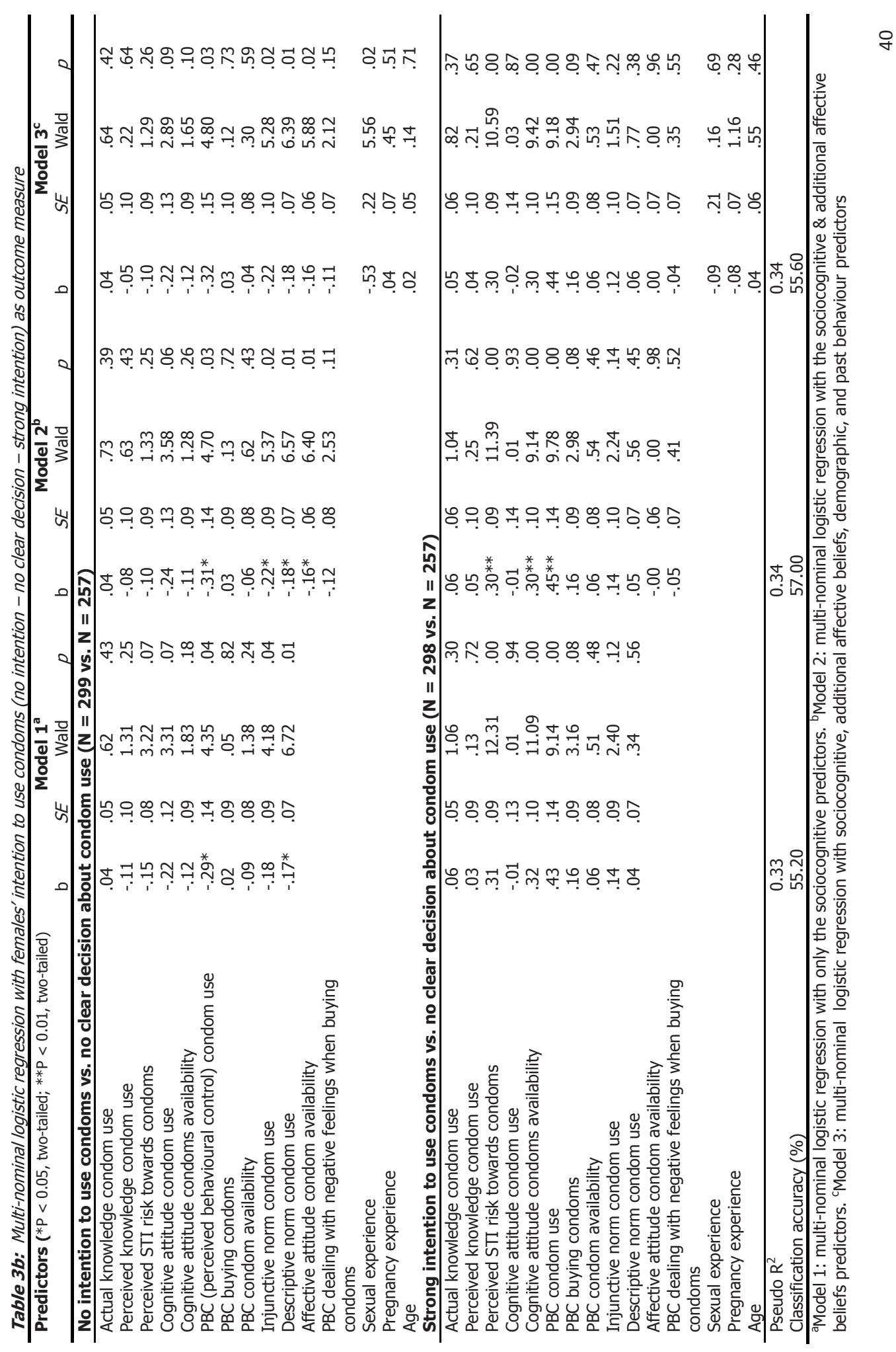




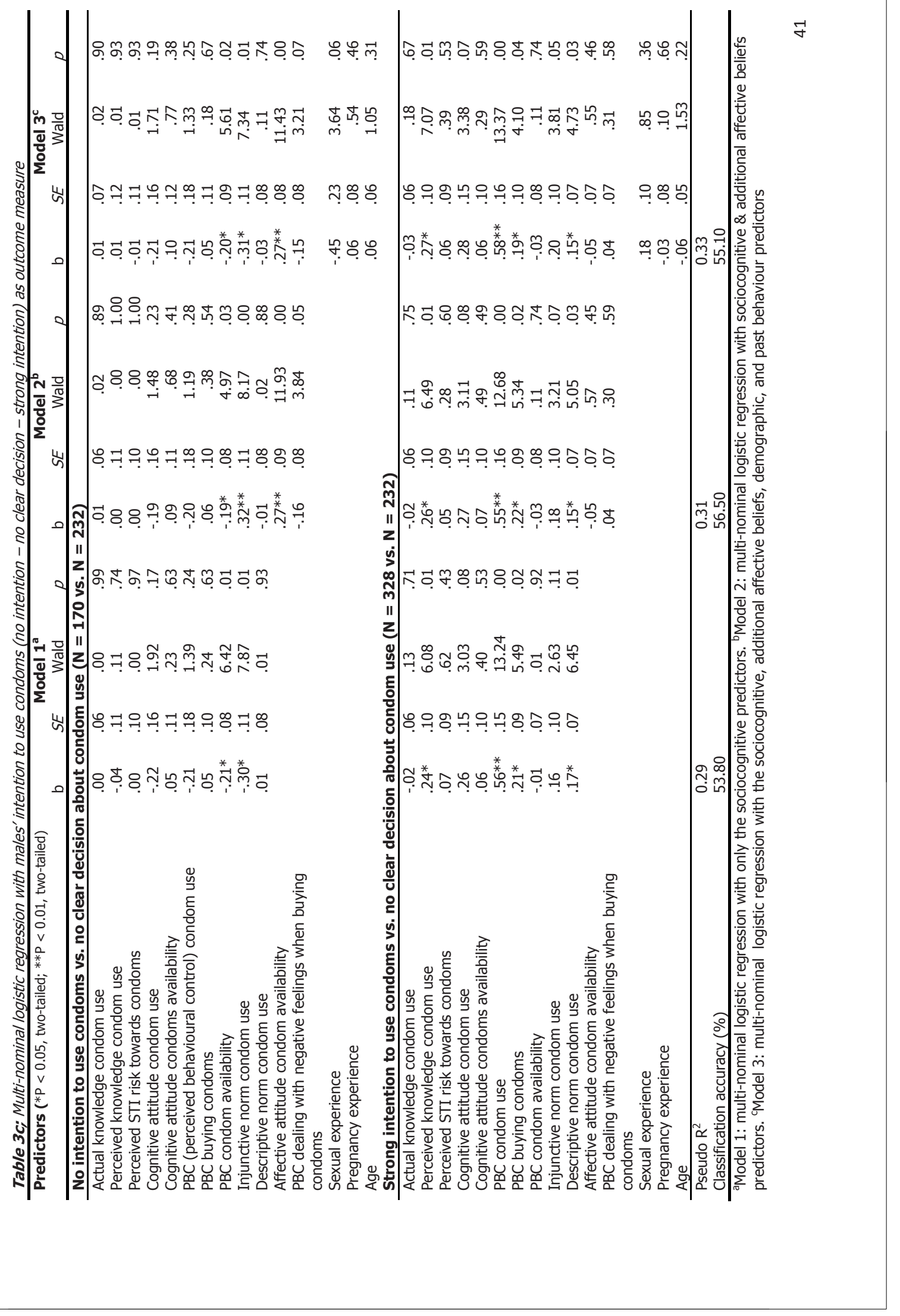




\section{Discussion}

Understanding predictors of adolescents' condom use intentions is a critical step in the development of interventions aimed at reducing STI transmission and preventing unintended teen pregnancies. This study investigated the antecedents of adolescents' intentions to use condoms in the Bolgatanga Municipal area of Ghana - an area where the lack of empirical data on condom use still poses serious challenges to researchers and programme planners alike. Bivariate analyses showed that perceived susceptibility towards STIs, perceived behavioral control towards condom use, and the injunctive norm towards condom use were the strongest correlates of condom use intentions among Ghanaian adolescents.

The additional multivariate analyses revealed that having no sex experience, having negative feelings towards carrying condoms, and not strongly perceiving that peers believe that condom use is always a good idea specifically predicted the intention to not use a condom. In addition, higher risk perceptions, positive attitudes towards condom availability, and higher PBC towards buying condoms, as well as towards condom use, specifically predicted high intentions to use a condom. Altogether, our results show that interventions designed to increase condom use in Ghana may not be effective if they fail to target perceived susceptibility towards STIs, injunctive norms, attitudes and feelings towards having condoms available, and perceived behavioral control towards buying and using condoms.

Our findings are consistent with the findings of studies that have been conducted in other parts of Africa that have shown that confidence and skills regarding condom use are among the most important predictors of the intention to use condoms (Giles et al., 2005; Hendriksen, Audrey, Sung-Jae , Coates, \& Rees, 2007; Meekers \& Klein 2002; Taffa, Klepp, Sundby, \& Bjune, 2002). In a review of behavioral interventions designed to reduce the incidence of HIV, STDs, and pregnancy among adolescents, Robin and colleagues (2004) reported that skills-building activities (including negotiation skills, communication skills, problem solving skills and decision-making skills that increase behavioral control towards condom use) were all crucial to program effectiveness and success. Other methods used to increase self-efficacy and behavioral controls -- such as guided practice and enactive mastery experience -- have been developed (Bartholomew et al., 2011, pp. 342-344). Enactive mastery experience refers to the successful performance of the target behavior, which should enhance perception of efficacy, while failure to perform the behavior should undermine it (Bandura, 1988). A recent review of the best way to increase self-efficacy in order to promote lifestyle and recreational physical activities found that interventions that 
included enactive mastery experiences as well as feedback on past or others' performance produced the highest levels of self-efficacy (Ashford, Edmunds, \& French, 2010).

In order for people to be motivated to change their behavior, they must first acknowledge their own personal risk in terms of the specific threat (Floyd, Prentice-Dunn, \& Rogers, 2000). Although there is an ongoing debate about the importance of risk perception in motivating safe sex practices (see Brewer, Chapman, Gibbons, Gerrard, McCaul \& Weinstein, 2007; Sheeran \& Taylor, 1999), our study clearly shows that perceived risk is strongly related to condom use intentions. Though caution should be exercised when using fear-related messages to influence risk perceptions (Mevissen, Ruiter, Meertens, \& Schaalma, 2010; Peters, Ruiter, \& Kok, 2013) various effective theory-based methods, such as the use of personalized risk information or scenario-based risk information to target STI-related risk perceptions, can be found in the scientific literature (DiClemente, Crittenden, Eve, Sales, Wingood, Crosby et al., 2008; Mevissen et al., 2010; Mevissen, Meertens, Ruiter, Zimbile, \& Schaalma, 2011). For a review of additional methods and practical applications that can be employed to increase PBC and raise the awareness of risk towards behavior change, see Bartholomew et al (2011: pp. 325-377).

That cognitive as well as affective attitude towards condom availability strongly predicted condom use intentions in our study is perhaps not surprising, in light of available evidence regarding the influence of attitudes on human behavior. However, the finding is contrary to the argument that cognitive attitudes, as a subject of value clarifications, are less developed in adolescence and, would therefore have a limited role in explaining young people's (sexual) behavior (Ajzen, 2001). The stronger predictive role of cognitive attitude as compared with affective attitude towards condom availability is in contrast to our expectation; since discussing sex in a culturally inhibited environment such as Northern Ghana can elicit strong emotional responses from adolescents, we expected affective beliefs to more strongly predict condom use intentions than cognitive beliefs. However, we interpret this contrast with caution because the affective attitude construct contained only one item scale. Future research should explore the role of affective attitudes on adolescents' intentions towards condom use in Ghana.

In addition, these results show that feeling comfortable with carrying condoms, and finding it important to have them available, are important prerequisites for condom use. The importance of condom availability makes it clear that initiatives attempting to increase condom use may have a good chance of success if they include dealing with how to obtain condoms from public stores, and how to carry them around without feeling embarrassed. Efforts to make condom displays visible and easy to approach in local stores or health 
facilities, or supplying free condoms in relatively anonymous places such as wash rooms may help to overcome such barriers. Initiatives like placing free condoms in washrooms have been shown to increase the number of condoms acquired, carried around and used by individuals showing high-risk sexual behavior (Moore, Dahl, Gorn \& Weinberg, 2006). However, given the strong religious and socio-cultural negative beliefs about pre-marital sexuality in Northern Ghana (Takyi, 2003), further research is necessary to determine the feasibility of such initiatives.

With regard to normative influences on intention, the reason for the relatively weak predictive value of descriptive norms as compared to injunctive norms is unclear. The results of research carried out thus far are not consistent; while some studies are reporting medium to strong relationships (Rivis \& Sheeran, 2003), others obtained similarly weak associations (Rimal \& Real, 2003). From a theoretical perspective, we expected descriptive norms to more strongly predict intention because of evidence suggesting that adolescents are more susceptible to social influence than adults (Clark \& Lohéac, 2007; Steinberg \& Monahan, 2007). Adolescents are therefore particularly susceptible to peer pressure, and more likely to conform to pressures related to both real and perceived social norms, as they tend to model peer behaviors in order to gain group recognition (Kiesner, Cadinu, Poulin, \& Bucci, 2002; Lapinski \& Rimal, 2005; Newman \& Newman, 2001; Pedlow \& Carey, 2004). In essence, descriptive norms should weakly correlate with intentions to use condoms only if the sample is from a population where people do not define themselves in terms of the group norm. However, this cannot be the case in our sample - a population where the interpersonal relationships and ties are strongly embedded in the social system and determine the norm (Acquaah, 2007). Future research should therefore use more rigorous measures of social norms to explore the associations between descriptive norms, group identification, and condom use intentions in order to arrive at a more definite conclusion. However, from the mean scores of the two norm constructs, it is clear that the students expect their peers to be positive about condoms (injunctive norm) but not to use them (descriptive norm). This is in line with what is expected from adolescents in Ghana (Awusabo-Asare, Biddlecom, KumiKyereme, \& Patterson, 2006) and it might explain the low correlation between the two constructs of perceived social norms.

In line with existing evidence (Berten \& Van Rossem, 2009), both perceived and actual knowledge subscales correlated weakly with condom use intentions, and failed to contribute in the regression equation. This is one more finding confirming the view that simply disseminating information about HIV/STIs or teenage pregnancies, as is current 
practice in Africa, will not induce condom use intentions. Instead, intervention planners should focus on variables such as PBC, risk perception and attitude.

The finding that participants without sex experience have no intention of using condoms confirms the findings of previous studies which showed that young people with no sex experience (and therefore no condom use experience) in the past are unlikely to intend to use condoms in the future (Hendriksen et al., 2007; Sheeran \& Taylor, 1999). These findings could be of interest to intervention planners involved in promoting condom use as they suggest that young people may be using their past behavior as a guide to their future plans regarding condom use, rather than basing their intentions on attitudes and subjective norms.

From the regression equation, our findings show that cognitive and affective psychosocial constructs can, in part, explain the prerequisites for increasing intentions to use condoms among West African adolescents, a finding which is in line with other studies conducted in Africa (Giles et al., 2005; Schaalma et al., 2009; Sheeran \& Taylor, 1999). Schaalma and colleagues (2009) also included geographic, socio-economic and condom access factors as predictors of condom use in their study among adolescents in Uganda, which resulted in a high level of explained variance. Such environmental factors are especially important in intervention contexts where few resources are available. As reported by Macphail \& Campbell, (2001), contextual factors determining young peoples' condom use behaviors in Africa include negative and unsupportive adult attitudes to young peoples' sexuality; restricted availability of condoms, the broader social issues related to the social construction of gender, and the economic constraints that young people face. Future research should take into account environmental determinants in order to clarify the contextual factors that can explain adolescent sexual behaviors in northern Ghana.

Our results also suggest that factors influencing condom use intentions are slightly different for adolescent girls and boys, which is in line with previous findings (Boer \& Mashamba, 2007; Pearson, 2006). Future intervention planners should examine ways to address gender differences within program components.

The present study also has some limitations. First, it is possible that adolescents may not provide honest responses to questions about sensitive topics (Mensch, Hewett \& Erulkar, 2003; Plummer, Ross, Wight, Changalucha, Mshana, Wamoyi et al., 2004). However, we do think the procedure we used in collecting the data (separate seats, anonymous data collection) maximized our chances of receiving honest responses from the students. Second, this is a cross-sectional design and therefore the "effects" of the psychosocial measures on the intention measure are not necessarily causal (Fishbein \& Yzer 2003). Third, the 
generalizability of our findings may also be limited by the relatively low alphas of the scales, and the fact that some scales only contained one item. Also, due to the high stigma related to homosexuality in the region where the study was conducted (AED, 2008), our measures of sexual experience were limited to questions regarding heterosexual intercourse. Finally, although the students in our study did not have difficulties stating their age, whether the ages provided were accurate, we are unable to tell. Validity checks are also difficult; if an individual does not know his/her exact age, it is likely that his/her parents will not know it either.

Aside from these limitations, the overall results show that psychosocial variables with regard to perceived risk, attitude, social norms, and behavioural control can explain the intention to use condoms among adolescents living in the Bolgatanga Municipal area in Northern Ghana. For the purposes of intervention planning, we recommend providing a comprehensive sex education program to adolescents with an emphasis on enhancing perceived behavioral control, addressing negative attitudes and feelings towards carrying condoms, and raising perception of risk/susceptibility to STIs. The results from the present study suggest that this will increase behavioral intentions which should in turn facilitate the likelihood of actual condom use.

\section{Funding}

The SPEEK sex education project was funded by the Sir Halley Stewart Trust, UK. Data management and analysis was supported by NUFFIC PhD fellowship grant nr. NFP-PhD.11/ 806.

\section{Acknowledgements}

We wish to acknowledge Ms. Linda Anaabah, Project Coordinator of the SPEEK sex education project for coordinating the surveys. We are also grateful to all the SPEEK peer educators, Dutch volunteers (Tes Schmeink \& Jennifer Hollenberg), and the school health teachers who supervised the completion of questionnaires by the students in the participating schools. All staff of the Youth Harvest Foundation Ghana who played various supportive roles in the conduct of the study are acknowledged accordingly. 


\section{Chapter 3}

\section{Beyond Love: A qualitative analysis of factors associated with teenage pregnancy among girls with pregnancy experience in Bolgatanga, Ghana}

Published as:

Krugu, J.K., Mevissen, F.E.F., Münkel, M., \& Ruiter, R.A.C. (2016). Beyond Love: A qualitative analysis of factors associated with teenage pregnancy among young women with pregnancy experience in Bolgatanga, Ghana. Culture, Health and Sexuality.

http://dx.doi.org/10.1080/13691058.2016.1216167 


\section{Introduction}

Globally, and largely in low and middle-income countries, an estimated 16 million girls aged 15 to 19, and about a million girls under 15 give birth every year (Dick \& Ferguson 2015). Each year, about 14 million pregnancies occur across sub-Saharan Africa, with nearly half occurring among women aged 15-19 years (UNFPA 2013). In Ghana, 14 percent of women age 15-19 had begun childbearing in 2014 (GSS-DHS 2015).

Adolescent childbearing (intended or not) has adverse effects at the individual, community, and societal level. Compared with their peers who delay childbearing, teen girls who have babies are less likely to finish high school, more likely to be poor as adults, and more liable to have kids who have poorer behavioral, educational, and health outcomes over the course of their lives than do children born to adult parents (Cook \& Cameron 2015; Marcotte 2013). Babies born to teen mothers also face a substantially higher risk of dying than those born to women aged 20 to 24 (WHO 2014). In addition, adolescent pregnancies are more likely to be aborted (UNFPA, 2013). In Africa, where pre-marital sex is not accepted, especially for girls, unintended pregnancies mostly happen outside marriage. This often implies secret, unsafe abortions under unhygienic conditions performed by people who lack the necessary skills and in places that do not meet minimal medical standards (WHO 2011).

Teenage pregnancies could be avoided by using condoms or other contraceptives (the latter often referred to as 'family planning'). Most sexually active adolescents in Ghana, however, do not use contraceptives: among those who are sexually active, $31 \%$ were not using any contraceptive method at their last sexual encounter (Doku 2012). If the majority of the pregnancies among teenagers are unwanted, this questions the reasons why adolescents are not protecting themselves. Findings of three reviews of studies conducted in sub-Saharan Africa (Macleod 1999a, 1999b; Macleod \& Tracey 2010) indicate that adolescent girls' use of contraceptive methods is limited by several factors including violent and coercive sexual relationships, lack of knowledge, limited access to contraceptive methods, lack of control over contraception decisions, and concerns over side effects of family planning methods (Macleod \& Tracey 2010; Wood \& Jewkes 2006). In the particular case of condom use, ever received sex education in school, ever attended school, exposure to the radio, condom use self-efficacy, perceived social norms, attitude towards condom use, positive behavioural control beliefs and positive outlook on life have all been reported to predict the intention to use condoms among adolescents in different African settings (Boer \& Mashamba 2007; Macleod \& Tracey 2010; Rijsdijk, Bos, Lie, Ruiter, et al. 2012). 
In Ghana, knowledge of the existence of contraceptives and where to obtain them seems to be high among the adolescent population (Awusabo-Asare, Biddlecom, KumiKyereme \& Patterson 2006). For example among those aged 15-19, 76\% of the girls and $88 \%$ of the boys were aware of at least one method of contraception (Awusabo-Asare, Abane \& Kumi-Kyereme 2004). However, this knowledge seems superficial as evidence shows that $21 \%$ of the girls and $46 \%$ of the boys who knew the pill did not know that it has to be taken daily for it to be effective (Awusabo-Asare et al. 2006). Beyond the knowledge gap, studies show that contraceptive usage in Ghana is also influenced by girls feeling too inhibited and ashamed to seek contraception services or because contraceptives are not easily available (Adjei, Sarfo, Asiedu \& Sarfo 2014; Apanga \& Adam 2015).

However, the situation in Ghana is still understudied. The specific factors and beliefs that lead to contraceptive non-use remain obscure and up to date, evidence-based data on personal (e.g. knowledge, attitudes, and skills) and environmental (i.e. social and structural influences such as social support, reinforcements and access to contraceptives) determinants of teenage pregnancy are lacking. This paper makes a contribution by exploring the factors underlying adolescents' decisions and beliefs relating to the use of protection for pregnancy prevention in rural Ghana using qualitative interviews with girls who have experienced pregnancy.

The use of individual in-depth interviews is well matched to understanding the experiences of inconsistent contraceptive use among teen mothers in a rural setting. Therefore, the results can support efforts to promote contraceptive use among young people in northern Ghana, and to decrease ultimately, teenage pregnancies in the country.

\section{Methods}

The study used individual in-depth interviews guided by a semi-structured interview protocol. The Ethics Committee of the Ghana Health Services and the Ethics Review Board of Maastricht University in the Netherlands granted ethical approval.

\section{Study setting}

The study was conducted in the Bolgatanga Municipality in the north of Ghana covering a total land area of $729 \mathrm{sq} \mathrm{km} 2$. It has an estimated population of 131,550 with $52.3 \%$ being female, $44 \%$ below 18 years and a growth rate of $3.0 \%$ (GSS 2012). Bolgatanga is traditionally home to the "Frafra" people, although its current status as a regional capital has brought other tribes ( 2\%) to the Municipality. They are organized along family and clan lines, and polygamy is widespread. The Municipality is predominantly agricultural in nature and is among the poorest districts in the country with $35 \%$ of its 
population living on less than the World Bank's threshold of $\$ 1.25$ per day (Amanor-Boadu, Zereyesus, \& Asiedu-Dartey 2013). The health system in the Municipality comprises of one regional hospital, nine Health Centres, and several Community-based Health Planning and Services (CHPS) compounds.

\section{Participants}

Twenty-one (21) young women aged between 14 and 19 years $(M=17.5, S D=$ 1.32) with a pregnancy experience, living within the Bolgatanga Municipality, were interviewed. Pregnancy experience was defined as having been or being pregnant or having a child at the time of the study. One interview was excluded from the analysis due to poor recording sound quality. Most girls had left their high school due to the pregnancy $(N=11)$, a few returned $(\mathrm{N}=2)$, or are planning to go back after delivery $(\mathrm{N}=3)$. Of the twenty girls included in the analysis, the average ages for sexual debut and first pregnancy were 15 and 16 years respectively. Seven were pregnant at the time of the interviews, two of them pregnant for the second time after experiencing stillbirths with their first pregnancies, and the other thirteen had already given birth with an average age of their babies at 17 months. For some girls, the pregnancy ended their last relationship because the boy denied paternity and 'run away.' Seven (7) girls were married to the father of the child after they became pregnant, of which the majority ( $N=6$ ) were living with their husband's family, and the remaining 13 were single mothers. All the married girls were either 18 or 19 years old. The participants included eighteen Christians and two Muslims.

Recruitment \& procedure

Participants were recruited through a purposeful homogeneous sampling technique (Palinkas, Horwitz, Green, Wisdom, et al. 2013). An A5-sized summary of the study was advertised on the walls of public buildings, including schools and health facilities where adolescents with pregnancy experience were likely to visit. The summary included stating the purpose of the study, the voluntary nature of participation, confidential handling of information, and how to register to participate. Also, participants were recruited by nurses through the health centres. The study summary was provided to the nurses, who in turn, explained the study to attending teenage mothers and pregnant girls both in English (the official language in Ghana) and in the local language (Gurene).

In total, 26 girls signed up for the study (11 via the advertisements and 15 by the nurses) of which 21 met the criteria of being adolescent ( $\leq 19$ years old) and having pregnancy experience. The 21 girls were then requested to sign a consent form. For participants under age 18 years $(\mathrm{N}=8)$, additional parental approval was obtained either by providing them with information and forms for their parents or by having research assistants 
visiting their homes to explain the study. All 21 girls provided their consent, with the additional parental consent given by those less than 18 years. No consent of husbands was required. Participants were not compensated for participation. Where necessary, the transport cost was paid, and all participants received a soda drink.

Because of the sensitive nature of the topic of sexuality in northern Ghana, participants were repeatedly assured through the recruitment and interview process that all information would be treated confidentially and that their identities would not be disclosed in any future reference to the study. To secure anonymity, specific details that could reveal their identities were omitted in transcribing the interview recordings. At the beginning of each interview, participants were reminded that they had the right not to answer questions and to stop the interview at any point necessary. To avoid socially acceptable responses, research assistants stressed the non-judgmental nature of the interview and assured that the only interest was in their personal stories. The interviews were conducted in English or the local language. A trained interpreter was available to translate questions and responses between research assistants and participants when necessary.

The interviews were held at different locations as per the convenience of each participant. After interviewing nineteen girls, saturation was achieved and after two more interviews, the data collection ended. The average length of an interview session was about an hour.

\section{Research instrument}

The interview protocol was a semi-structured interview guide based on the empirical literature on sexual health, contraceptive use, and teenage pregnancies in West Africa. In addition, it was guided by social cognitive theories of human behavior, among which the theory of planned behavior (TPB) and the health belief model (HBM) (for an overview of these theories, see Glanz, Rimer \& Vasnawath 2008).

Interviews were conducted by two young trained women; a local Ghanaian with prior experience in sex education and a German graduate student from Maastricht University. Data analysis

All 20 transcripts in MS Word documents were exported into NVivo 10.0 software for qualitative analysis. An inductive approach based on grounded theory techniques (Corbin \& Strauss 2015) was used to identify emerging sub-themes from the central themes by delving deep into the contents and grouping all the similar statements made under the respective themes. We conducted a comparative form of analysis to allow themes to emerge in accordance with the suggestion of Cho and Lee (2014).

At level one coding, we examined transcripts line-by-line to identify specific factors 
that seem to influence the participants' risky sexual behaviour that led to them becoming pregnant against their will; these factors were used as codes. At level two coding (axial coding), we examined open codes to understand the role each theme played in the adolescents girls' contraceptive decision-making processes. We then used selective coding (level three) to summarize the codes into the central thematic areas. In the process, multiple sub-themes emerged from the data, and these are described below under the respective central themes of the study. The second author checked the reliability and validity of the coding, and in cases where disagreement existed, reasons for differences in coding were discussed with the first author to reach an agreement.

\section{Results}

The results are presented as individual factors (relationship experience, sexual history), environmental factors (sexual communication and education), and social cognitive determinants of both contraceptive use and teenage pregnancy (knowledge, attitudes, selfefficacy and normative beliefs). It is worth noting that difficulties were encountered in getting the girls real thoughts and feelings on the specific topics. They did comment on factual behaviours extensively, but to find out how they felt about it was difficult. If questioned, they remained silent, laughed, or only gave very brief responses. Also, it seemed they found it difficult to talk about sexual issues; either they were not used to it or not used to providing their opinion in general. However, different techniques such as asking one question at a time, verifying unclear responses, avoiding leading questions, and using followups and probes were used in combinations to elicit in-depth responses from the participants.

\section{Individual factors}

\section{Relationship experiences}

The girls seemed to have all had more than one boyfriend at different times but not all relationships involved sexual intercourse. Reasons for no-sex were: not liking the boy, not being married, or fear for unwanted pregnancy.

The participants had difficulties commenting on the nature of their relationships. Most of them mentioned financial benefits or academic support as reasons for a relationship and did not seem to perceive a relationship as something that could be fun or enjoyable.

I: and what is important for you in your relationship with him? P: like when I need help, he helps me financially and in school when they give me work, and I don't understand he helps me. I: and what kinds of feelings do you have for him? P: ahh, feelings? No, I don't have feelings for him. (19 years with three years old child) 
One participant described a previous relationship as a bad one (quarrelsome). Another participant said that her relationship needs were "beyond love," explaining that being supported financially to cater for basic needs were her main reason for accepting to be in a relationship. Only one participant stated that love and trust are the most important in a relationship. Most of the single mothers were no longer interested in a relationship either because of the difficulty with the pregnancy/baby caring or because they wanted to pursue other life goals:

I: and are you in a relationship with someone at the moment? P: I do not want to be in a relationship again I: why? P: Why? Do you know how difficult taking care of this child is? (16 years with one-year-old child)

General sex experiences

With few exceptions, the girls had previous multiple sexual experiences before the one that resulted in the pregnancy. They mentioned that physical pressure (beating, pushing) and verbal pressure (boys saying they would die or suffer if they cannot release or saying they want a proof of fertility) was used to force them into sex. Only one participant indicated to have had sex only once and became pregnant. Forced sex is rather common (11 girls, two within marriage context) and almost all of them were left sad, unhappy, and angry:

\section{I: How did you feel when he forced you? \\ P: I feel sad. (18 years with one-year-old child).}

Some did find ways to avoid forced sex by terminating the relationship or crying for help, which attracted the attention of others.

First-time sex experience

The participants described their first-time sex experience as unplanned and painful. One girl was beaten up by her boyfriend before she gave into sex but because her relationship with the boy was not known to her parents, she could not report the incident. Some said they had wanted to have sex, but only one person seemed to have had a pleasant experience. Those who mentioned their age at first-time sex mostly said 15; one girl said 13. Some girls expressed fear during sex because of the risk of getting pregnant or because the school had apparently told them that they should not have sex:

I: How was your first-time sex experience? P: It was painful.

I was afraid because in school they advised us not to do it. (18 years, nine months pregnant).

\section{Condom use experience}

The girls said using condoms is the responsibility of the boys. Some did use condoms 
before, but such usage was irregular. Reasons mentioned for not using or inconsistently using condoms included non-availability of condoms at the point of need, being confused at the point of sexual intercourse, being unaware that the boy was not using condoms, unable to negotiate condom use, the boy promising to marry them or the girl wanting to marry the boy, or "it just happened". Some girls cited (the boy complaining about) not getting enough feelings with condoms, need to prove fertility after an STI infection, a 'need to have a child for her father', or trust in the partner as reasons for not using condoms resulting in pregnancies. None of them were using other family planning methods. They believed that they can use their menstrual cycle to prevent pregnancy and, therefore, do not need to use condoms. However, at the same time they had limited knowledge on their menstrual cycles as in:

I: When do you decide to use it and not to use it? P: When I am in my dangerous period I normally use a condom. I: And what is the dangerous period? P: I don't know. (18 years with one-year-old baby).

\section{Reactions to the pregnancy}

Except some few who were happy with the pregnancy because either they wanted a baby or the pregnancy was a proof of their fertility, all others were shocked, saddened or unhappy to hear the news of their pregnancy:

P: I was sad because I would not attend school again that is why I was sad. (18 years, nine months pregnant).

Moreover, their parents reacted in similar manner of despair:

I: So what did your parents say? P: My mother was crying that I was pregnant. (18 years, with three-year-old daughter)

However, some parents were happy to learn of their daughters' pregnancy because they wanted a baby from her before she could go into marriage - participants explained that expecting a daughter to give birth before marrying is a cultural practice among the 'Frafra' tribes, which becomes necessary when the parents do not have a male child to inherit the family heritage. For some girls, when the boys denied the pregnancy, they contemplated abortion but did not do it because other referent persons caution against it.

\section{Environmental factors}

\section{General sex communication}

The girls indicated that they do not talk about sex at home; not with their mum, not with anybody else. They were afraid to talk to their parents for fear of becoming an object of scorn, or for being beaten, or because it is embarrassing: 


\section{P: I don't talk this in my house because my father would think}

I am a bad girl that is why I don't want to talk about sex. (18 years, 8-month pregnant,)

Only one person indicated talking to her mother about sex and another girl said she talked to her friends about sex. Two girls reported 'talking about pregnancy' with their partner but this did not seem to be in-depth.

Experience with sex education in the formal sector

The girls' experiences with sex education in school were limited to moral and religious admonitions to abstain from sex, or with a focus on how to use the menstrual cycle to prevent pregnancy. Some did not get any form of sex education. Others did receive a resemblance of sex education (at least with the inclusion of condom use), but either they were educated after becoming pregnant or had no access to condoms. One girl got sex education from a nurse through a virgin club but admitted to having been unable to use that knowledge to prevent pregnancy:

P: That nurse was there, and we had a virgin club [...] and we asked questions on whether and when you get your menstruation at what point you can get pregnant. I: And you apply what you learned with your boyfriend to not get pregnant? P: No.

(19 years, second time pregnant)

On sex education from the health services, some girls said they never went to a health clinic to talk about sexuality-related things, though they did express the need. No clear reasons were given for not going to the health facilities; only one said she did not know how to explain herself to the nurses. Those who had visited a health center indicated that they were more comfortable and confident to talk to the nurses on their family planning needs. In general, it seemed the girls had no negative perception towards the health clinics

\section{Social Cognitive Determinants}

Knowledge of contraceptives

Mostly, the girls indicated that they had heard about condoms before their pregnancies. Most mentioned that condoms could protect against pregnancy and diseases. However, whether they actually knew how to use condoms was unclear - while one girl clearly claimed she knew how to use condoms, others seem to have no idea. Some girls seemed only to have heard about condoms without any clear picture of what they look like and one girl did not even know that one can get pregnant without using condoms. The girls had no knowledge of the female condom. Even though some girls stated that they knew of family planning, it seemed that clear knowledge about family planning was lacking. They have either only heard of family planning or know in general about it as a way of preventing 
pregnancy. Most girls' knowledge on family planning methods was limited to the injectable method.

Perceived Behavioural Control (PBC) towards buying, carrying and negotiating condom use

The girls indicated that they were ashamed to buy condoms and believed it is the responsibility of boys to buy and have condoms available at the point of need:

I: So who is responsible for carrying condoms? P: Only my boyfriend. He is responsible. (18 years, with one-year-old child)

Having safe sex partly seems to depend on the boy having condoms available. The girls did not openly express levels of PBC towards negotiating condom use. When asked for reasons for not using condoms, or not talking about sex with their partners, they mostly remained quiet or laughed. Only a few girls, after persistence of the interviewer, expressed fear or some kind of uncontrollability for negotiating condom use:

P: I wanted him to use a condom, but I do not know why he didn't use. I: But did you insist? P: No I didn't force him I: Why you didn't force him? P I was afraid to force him. (18 years with one-year-old child)

Attitude towards contraceptive use, teenage pregnancy, sex and abortion

Most of the girls did not comment extensively on their attitude towards condom use. For those who did speak, some indicated that condoms are good protection against unintended pregnancies but either preferred the injectable contraception to condoms (because 'it is safer') or their partners felt condoms reduce sexual feelings. In general, the girls had a perception that family planning will lead to infertility and therefore were not positive about it. Some of them said they would never use family planning methods for fear of their partners' disapproval.

The girls did not consider abortion as a good option for their pregnancy. Various reasons were given, including the fear of destruction of the womb or death:

P: He insisted that I should go for abortion, and I also didn't agree. So he asks me why? I said I can go for abortion, and lose my life or my womb forever, so I can't go for it. (18 years seven months pregnant)

Some believed that abortion was a kind of 'killing' and thus against the will of God. For others, their boyfriends put pressure on them to abort the baby, and their refusal to heed to the pressure resulted in the boy denying the pregnancy.

After going through pregnancy and childbearing (some), the girls did not want to get pregnant again, except those who were married. The unmarried girls preferred to get pregnant again but only when they grow up (become more mature), or after school, or when they finish a vocational training: 


\section{I: Do you want to get pregnant again? P: No, I want to finish my job before [complete vocational training]. (18 years, with one-year-old child).}

Some indicated that sex was no longer important to them because of the painful firsttime sex experience, sex leading to their dropping out of school, and embarrassing negative beliefs associated with sex:

I:...and now is sex important for you? P: no. I: and why is it not important?

$P$ : because I learn the lesson now because all my friends in school and I am now here, so sex is not important for me. (17 years with one-year-old baby).

Others said they still do have sex as an obligation in marriage or towards their boyfriend and only two girls mentioned sex in relation to love.

Risk perception towards pregnancy and intention to use contraception

It was mostly not clear what the girls' risk perceptions towards getting pregnant were. Some expressed having been 'afraid of getting pregnant' which could be interpreted as perceiving a risk. However, it is not clear if the girls have any idea on the probabilities of getting pregnant when having unprotected sex. Many seem to have complete faith in using the 'time-of-the-month' calculation to determine the risk of having unsafe sex, which could be interpreted as having a low-risk perception for getting pregnant and a high feeling of control over (not) getting pregnant. It was the same with some girls just being sure 'it won't happen' to them as in:

I: You said the boys sometimes used condoms and sometimes not and you didn't ask why?

P: I didn't ask them why they do not use condoms. I: And were you not afraid of getting pregnant? P: It will not happen to me. (16 years with one-year-old child).

For the girls, a common phrase such as 'pregnancy prevention/condom use was not in my mind' defines their low perception of conception risks. It also appears that some girls do have superficial ideas of risks towards pregnancy.

I: How is your sex life now? Do You use condoms? P: No, only the injection.

$$
\text { (18 years with one-year-old child). }
$$

Not all of the single mothers had plans to do family planning to prevent future pregnancy but those who did preferred the injection method, either because it is perceived to be safe or because its use does not involve negotiating with the boyfriend. Some do not believe pregnancy can happen to them unexpectedly again or just do not have an idea of what to do to prevent the next pregnancy.

Social norm towards teen sex, pregnancy and child-bearing

A few girls $(\mathrm{N}=3)$ became pregnant intentional to get a baby boy for their parents (their parents did not have any sons to keep family inheritance). Some girls indicated that 
their parents and other relations were not happy to hear that they were pregnant because they had brought disgrace to the family. For this reason, some had to hide their pregnancy for fear of becoming objects of social scorn or the fear of being forced to marry the boy. One shared her family's reaction as follows:

My parents were sad with me when I got my pregnancy because I was still a small girl and got my pregnancy. My \{elder\} sisters are still there and are not married, and they were also sad too. (17 years, pregnant).

Concerning normative beliefs towards teen sex in general, some girls shared their perceptions of how important others in their life expected them to behave sexually; for example, mothers or teachers expected them to abstain from sex.

\section{Discussion}

In the present study, we explored the main individual, environmental and social cognitive factors that put young girls at risk of pregnancy in Ghana. The results suggest that a poor environment full of sexual taboos and abstinence-only sex education, together with limited negotiation skills are shaping the sexual decisions and behaviours of the girls. The participants had limited knowledge of contraception, low self-efficacy to obtain contraceptive methods such as condoms, and they lacked the skills to negotiate condom use. The latter seemed to be partly driven by economic reasons (e.g., pay for school supplies). Also, the girls appeared to have low awareness of the likelihood of getting pregnant when having sex without contraception. They exhibited a strong negative attitude towards hormonal contraceptives because they believed it causes infertility. The girls' sex experiences were often limited to coercive, painful early sexual debut, and they frequently practice unsafe sex, including inconsistent contraceptive use.

The reported lack of sex communication, neither with parents nor with other family members or friends, is not surprising. Studies in sub-Saharan Africa have reported significant barriers to communication about sex (Bastien, Kajula \& Muhwezi 2011). Parents are reluctant to discuss more than biological issues and adverse consequences of sexual activity, and maternal communications about sex are frequently restrictive and moralistic in tone and limited to few topics such as abstinence, menstruation, and HIV/AIDS (Bastien et al. 2011; Macleod and Tracey 2010; Manu, Mba, Asante, Asare and Odoi-Agyarko , 2015). In some western societies, a more open communication and pragmatic view of adolescent sexuality have positively influenced the success of interventions aimed at reducing teenage pregnancy (Weaver, Smith \& Kippax 2005). The socio-cultural landscape of Ghana may not yet permit an open communication on sexuality. However, as concluded by Bastien et al. (2011), 
parents in sub-Saharan Africa may be more open to talking to their children about sexuality if given the appropriate support, including the necessary knowledge and skills to do so. Therefore further qualitative research involving parents to understand how parents communicate with their children, their concerns regarding sexuality communication and how to address those concerns in interventions aimed at enhancing parent-child sex communication is necessary.

The finding that some participants became pregnant to prove their fertility or to get a child to their parents as a cultural practice highlights the way culture is shaping the dynamics of teenage pregnancy in northern Ghana. Even within a context where premarital childbearing is highly stigmatized, parents and their teenage daughters can still decide to have children outside marriage. It portrays two conflicting moral standards in this society; while the remaining patriarchal believers of the African traditional religion can accept sex outside marriage when it is to provide them with a baby boy; those who have converted to Christianity or Islamic faith are completely against pre-marital sex of any kind (Adongo, Philips, Kajihara, Fayorsey, et al. 1997; Macleod \& Tracey 2010). Jewkes and Christofides (2009) extensively discussed the cultural value of fertility in Africa and concluded that the importance attached to fertility and procreation puts women of all ages in most African societies under pressure to have children. Our finding confirms these earlier works and suggests that success in preventing teen pregnancy could be challenging in contexts where the socio-cultural beliefs surrounding fertility remain high.

Another significant finding is the girls' (perceived) inability to obtain condoms and negotiate its use to prevent unwanted pregnancies. Within Ghana, Opoku (2010) and Hindin, McGough and Adanu (2014), reported similar barriers to condom use, such as shyness in buying contraceptives, the cost of contraceptives, and non-youth friendly health services being barriers to adolescents' accessing contraceptives. Two recent reviews showed the critical importance of changing self-efficacy and behavioural control beliefs to increase adolescents' condom use (Gottschalk \& Ortayli 2014; Mavedzenge, Doyle \& Ross 2011). Our results suggest that changing skills and self-efficacy beliefs towards buying and negotiating condom use among girls should be the focus of interventions aiming at preventing teen pregnancies in Ghana. However, evidence also shows that girls' condom use self-efficacy is related to the general culture of communication on sexuality (Sayles, Pettifor, Wong, MacPhail, et al. 2006). Indeed, placing emphasis on communication with friends and partners regarding the risks of pregnancy and the use of condoms may be an important additional component of interventions aimed at improving self-efficacy and skills on condom use among girls in Ghana. 
The finding on the girls reporting negative attitudes towards family planning and strongly ceding condom use responsibility to their male partners make girls very depended on their partners when it comes to pregnancy prevention. While condom use requires negotiating with possibly unwilling partners, family planning methods like the oral pills (if access can be guaranteed) can give young girls more control over pregnancy prevention. Since there seems to be much misunderstanding about these methods, there is a need for programme planners to explain fully to adolescents how these methods work. Such discussions should include the unreliability of 'safe period of the month', the fact that development of severe health consequences and significant side effects by using family planning are rare, and point out the risks associated with carrying a pregnancy to term compared with using family planning (Grossman, Fernández, Hopkins, Amastae \& Potter 2010).

Our participants expressed fear of potential health problems following abortion or believed that it was morally wrong to do so. Ghana's abortion law is relatively liberal; safe abortion services on medico-social grounds are permitted (Morhee \& Morhee, 2006), yet abortion-related deaths are responsible for an estimated $11 \%$ of all maternal deaths and over $17 \%$ for those age 15-19 years (GSS, 2012). Sundaram, Juarez, Bankole \& Singh (2012) reported that health care providers' biases and negative attitudes can serve as a major barrier to adolescents seeking abortion services. Future research that explores the individual attributes of health care providers and it impacts on pregnant adolescents' attitude towards abortion in Northern Ghana is warranted.

A revealing feature of the girls' narratives is that love as an aspect of relationships, and/or sex was hardly ever mentioned. It appeared that the girls' motivations to start relationships with boys or to succumb to sexual advances were "beyond love". Studies conducted in South Africa (Bhana \& Pattman 2011; Harrison, Cleland \& Frohlich 2008) and in Malawi (Poulin 2007) have pointed out a long tradition in poorer societies where young people's sexual partnership is more about economic gain rather than love. Our finding supports the conclusion of Brook, Morojele, Zhang, and Brook (2006) that family poverty and deviant peers are directly related to risky sexual behaviours. These reports are suggestive that as long as young women do not have sufficient means to live their lives independent of men, they will always engage in unwanted/forced relationships. Therefore, interventions aimed at preventing teenage pregnancies need to incorporate elements of economic empowerment to support young women earn income and be able to make independent decisions on their sexual choices. 
Our results suggest that in schools, sex education is limited to moral admonitions to abstain from sex. Abstinence-only messages are not only morally problematic by withholding information and promoting inaccurate personal opinions (Kohler, Manhart \& Lafferty 2008), but are also a threat to fundamental human rights to health, information, and life. Evidence show no positive association between teaching about contraception and increased risk of teen sexual activity, and rather those who received comprehensive sex education had a lower risk of pregnancy compared to adolescents who received abstinence-only or no sex education (Kohler et al. 2008). Interventions that go beyond moral education and take an approach towards comprehensive sexuality education (CSE) both at home and in school, could help girls better handle their sexuality and consequently reduce the incidence of teenage pregnancies. But despite the overwhelming evidence in support of CSE, implementing it in the Ghanaian context requires a bigger environmental change. Therefore more implementation research on other important stakeholders (teachers, community leaders, religious leaders) is necessary to effect change. Efforts to introduce CSE in Ghana can also benefit from recent nation-wide CSE scale-up experiences of Senegal and Nigeria (Chau, Seck, Chandra-Mouli \& Svanemyr 2016; Huaynoca, Chandra-Mouli, Yaqub Jr \& Denno 2014).

We acknowledge the following limitations. First, our procedure required participants below the age of 18 to seek parental consent. The sample could be slightly biased if only parents who found it acceptable for their daughters to talk about their private lives agreed. Second, as our sample was small, the results are not generalizable to the adolescent population in Ghana. Third, we interviewed girls who are not used to discussing sexuality openly and exhibited shyness and reluctance during the interviews. Follow-up probing to clarify details was mostly not fruitful which resulted in part of the data lacking depth. Also, it is possible that they provided socially acceptable comments in parts of the interviews.

In conclusion, this study highlights important individual, environmental and social cognitive factors negatively influencing adolescent girls' ability to use contraception to prevent unwanted pregnancies in rural Ghana. Although most girls prefer a later pregnancy, the economic and cultural situation, including taboos surrounding sex communication and limited sex education in school leave girls vulnerable in many ways. For mostly economic reasons, they engage in sexual relationships with low self-efficacy to obtain and negotiate condom use, low-risk awareness towards unsafe sex and negative attitudes towards hormonal contraceptives - all making it difficult to prevent unwanted pregnancies. Poverty and long-held cultural and religious beliefs towards adolescent sexuality perpetuate these barriers. 
Given the controversial nature of sex education in Ghana, intervention planners may find it challenging to implement and sustain an effective, CSE programme unless it fits with local needs, values, and can engender discussions on socio-cultural beliefs surrounding sex communication. Developing a broad base of community involvement in assessment, planning, and implementation may enhance the likelihood of community buy-in and programme effectiveness (Bartholomew Eldredge, Markham, Ruiter, Fernández, Kok \& Parcel, 2016). An ecological orientation that addresses gender and poverty issues, and some understanding of theory and evidence-based methods to change the determinants of decision-makers such as politicians and education authorities as well as personal determinants of adolescent girls' sexual behaviours, can boost programme planners' capacity to engage essential community-level involvement and enhance programme success towards preventing teenage pregnancy in Ghana.

\section{Acknowledgements}

We acknowledge the girls who participated in this study, and also our research assistant, Martha Atule for her dedication. The study was funded by NUFFIC Ph.D. fellowship grant nr. NFP-PhD.11/ 806 with additional support from Maastricht University and the Youth Harvest Foundation Ghana (YHFG). 


\section{Chapter 4}

\section{Who's that girl? A qualitative analysis of adolescent girls' views on factors associated with teenage pregnancies in Bolgatanga, Ghana}

Published as:

Krugu, J.K., Mevissen, F.E.F., Prinsen, A., \& Ruiter, R.A.C. (2016). Who's that girl? A qualitative analysis of adolescent girls' views on factors associated with teenage pregnancies in Bolgatanga, Ghana. Reproductive Health, 13:39. Doi: 10.1186/s12978-016-0161-9. 


\section{Background}

The present generation of adolescents is the largest in history. Nearly $90 \%$ live in low-andmiddle-income countries where they constitute a far greater proportion of the total population because of the higher fertility rates as compared to high-income countries (Sawyer, Afifi, Bearinger, Blakemore, Dick, \& Ezeh, 2012; Skirbekk, 2008). Most of these youngsters are sexually active (Dick \& Ferguson, 2015; Sedgh, Finer, Bankole, Eilers, \& Singh, 2015), thus putting a significant number of the world population at risk for getting infected with sexually transmitted diseases or getting pregnant unintentionally.

Adolescent pregnancy is a recognized public health concern that has diverse consequences for the individual, the family, and society as a wholee (Harden, Brunton, Fletcher, \& Oakley, 2009; WHO, 2014). Across sub-Saharan Africa, it is estimated that 14 million unintended pregnancies occur every year, with almost half occurring among women aged 15-24 years (Hubacher, Mavranezouli, \& McGinn, 2008). In Ghana, the Reproductive and Child Health Department of the Ghana Health Services reported a rise in adolescent pregnancies among those aged 15 to 19 years from 43,465 in 2009 to 83,917 in 2013, representing $12.3 \%$ of all pregnancies in the country (GHS, 2013). In rural areas like the Upper East Region, $21.7 \%$ of adolescents aged 15 to 19 years had begun childbearing in 2014 as compared to $8.3 \%$ in the Greater Accra region (GSS, 2015).

Teen pregnancy contributes significantly to the high maternal mortality rate of 920 deaths per 100,000 live births in Africa (WHO, 2014). Among the 14.3 million adolescent girls that gave birth in 2008, one out of three was from sub-Saharan Africa and pregnancyrelated morbidity and mortality rates are particularly high in this group (UNFPA, 2012). The bodies of adolescent girls are not yet sufficiently developed to deal with pregnancy in a healthy way, and this age group is twice as likely to die in childbirth as women aged 20 or over (Ahman \& Shah, 2010). Also, across Africa, one-quarter of the estimated 6 million unsafe abortions and 22,000 abortion-related deaths each year occur among women aged 15-19 years, showing that most of the pregnancies among teenagers are unwanted (WHO, 2014).

While the use of effective contraception can prevent unwanted or unplanned pregnancies $u$, few sexually active adolescents use contraceptives methods such as hormonal contraceptives (often referred to as 'family planning') and condoms. For example, among sexually active Ghanaian adolescents age 15 to 19 years, $80 \%$ of girls and $63 \%$ of boys were not using any contraceptive method at their last sexual encounters (Kumikyereme, Awusabo-Asare, \& Biddlecom, 2007). An earlier report also showed that only $10-$ 
$12 \%$ of adolescents' aged $15-19$ years who were not using contraceptives intended to do so in the next 12 months (Karim, Magnani, Morgan, \& Bond, 2003).

Addressing the high rate of teenage pregnancies and non-contraceptive use in Africa requires a context-specific understanding of why teen pregnancy is so high among adolescents while a significant group does seem to manage to prevent getting pregnant. Previously identified barriers to contraceptive use among adolescents in sub-Saharan Africa include inadequate sexual knowledge and risk perceptions, lack of skills to negotiate safer sex options, ambivalent attitudes towards sex, lack of access to educational and health services, and negative social norms around premarital sexual activity and pregnancy [Krugu, Mevissen, Münkel \& Ruiter, under review; Macphail, \& Campbell, 2006; Mushwana, Monareng, Richter, \& Muller, 2015). Other empirical reports also indicate that young girls may engage in unsafe sex because they have not considered contraception (Gomes, Speizer, Oliveira, Moura, \& Gomes, 2008; Krugu et al., under review), are afraid of possible side effects (Abiodun, \& Balogun, 2009), are more worried about the safety of contraceptives than preventing an unintended pregnancy (Warenius, Pettersson, Nissen, Höjer, Chishimba, \& Faxelid, 2007), or are not adequately informed about the risk of pregnancy or disease posed by unsafe sex (Adedimeji, Omololu, \& Odutolu, 2007).

However, most of these studies have focused on pregnant girls and those with pregnancy experience - following the general long held practice of merely focusing on people with the health problems. There is limited work on never-pregnant adolescent girls' perceptions regarding pregnancy prevention. Gaining an understanding of adolescent pregnancy from the perspective of never-pregnant teenage girls can play a major role in identifying factors that influence sexual decision-making in young women regarding initiating sexual activity and preventing pregnancy. Studying girls without pregnancy experience could also provide pointers on the capacity and needs that girls with pregnancy experience are lacking, which, in turn, facilitates the development of intervention goals. Knowledge of the perceptions, beliefs and behaviors of never-been-pregnant adolescent girls is, therefore, necessary to guide the content of future teenage pregnancy prevention programs.

To fill this gap, we conducted the present study as part of a larger research project exploring the behavioral, environmental and psychosocial factors influencing adolescent sexual and reproductive health behaviors. More specifically, the project was initiated to create a comprehensive picture of factors associated with the high teenage pregnancy rates in Northern Ghana and to inform future prevention strategies. After a study focusing on teenage girls with pregnancy experience in Bolgatanga, Ghana (Krugu et al., under review), the current study reports on the qualitative interviews conducted among adolescent girls 
without pregnancy experience. The aim was to explore the psychosocial and environmental factors influencing their sexual decision-making, which seems to put them not or less at risk of unintended pregnancies as compared to their peers with pregnancy experience.

\section{Methods}

\section{Study design}

The study used semi-structured individual in-depth interviews to explore the behavioral, environmental and psychosocial determinants of sexual choices of adolescent girls who do not have pregnancy experience. The semi-structuring helped to ensure consistency across interviewers and interviewees. The Ethics Committee of the Ghana Health Services in Accra and the Ethics Review Board of Maastricht University in the Netherlands approved the study.

\section{Study setting}

We conducted the study in the Bolgatanga Municipality in northern Ghana. Bolgatanga is located $743.83 \mathrm{~km}$ to the north of Accra (capital of Ghana) and covering a total land area of $729 \mathrm{sq} \mathrm{km} \mathrm{km}^{2}$. Females make up $52.3 \%$ of an estimated population of 131,550 and $44 \%$ are below 18 years with a growth rate of 3.0\% (GSS, 2012). Agriculture is the main economic activity in the Bolgatanga Municipality, and it is among the poorest districts in the country with between 22 to $35 \%$ of its population living on less than the World Bank's threshold of $\$ 1.25$ per day (Amanor-Boadu, Zereyesus, \& Asiedu-Dartey, 2013). The healthcare system in the Municipality includes a Regional Hospital, nine Health Centres, and several Community-based Health Planning and Services (CHPS) compounds.

\section{Study population}

Our final sample included 20 adolescent girls between the ages of 14 and 19 years $(M=17.3, S D=1.59)$ with no pregnancy experience and living in the Bolgatanga Municipality of the Upper East region of Ghana. Six participants reported sex experience; 3 of them were 18 years of age and the other 3,19 years. The girls came from families engaged in peasant farming or doing petty trading businesses. The girls lived together with siblings in larger families - an average of 5 children per family. Two girls had lost their fathers, and one had lost her mother. One girl came from a polygamous family, and another one had a Burkinabe father and a Ghanaian mother. All the participants were still in various stages of high school. The sample included 5 Muslims and 15 Christians, and all of them indicated that religion was important to them. Although all the girls were from the low socioeconomic background, they all had clear goals and hopes of a better future career and indicated their preparedness to work towards such goals. 


\section{Recruitment and Procedures}

The study used a purposeful homogeneous sampling technique to recruit the participants (Palinkas, Horwitz, Green, Wisdom, Duan, \& Hoagwood, 2013). A short description of the study, including the purpose, the voluntary nature of participation and how to register to participate, was advertised in schools and other public places in Bolgatanga where young girls are likely to visit. Also, research assistants visited schools to recruit girls. Interested participants confirmed their participation by completing an informed consent form and those below the age of 18 years took the form home for parental consent before they could participate. Participants were enrolled day-by-day until thematic saturation was reached.

In all, 28 girls signed up for the study, of which 25 met the criteria of being adolescent ( $10 \leq$ years old $\leq 19)$ and having no pregnancy experience. The 25 girls were then asked to complete informed consent forms and for those below age 18 years $(\mathrm{N}=8)$, research assistants visited their homes to explain the study and secured additional parental consent. In the end, we interviewed 23 girls who returned completed forms to participate. We did not compensate for participation, but where necessary, participants' transport costs were paid, and all received a soda drink at the beginning of each interview. The interviews lasted between 45 minutes and 1 hour. All interviews were audiotape recorded, and after transcription, the tapes were erased.

Researching sensitive issues such as sexuality in a culturally inhibiting environment like northern Ghana necessitated an ethical awareness in the development of the research method. Anonymity and voluntary participation was warranted by not documenting identifiable details of participants and not applying any persuasion regarding participation. Also, the research team, was conscious of concerns that young girls in northern Ghana are in a position of both economic and social vulnerability (Alhassan, 2013). To ensure that hierarchical research methods did not exploit the girls, the research assistants were trained to pose questions as supportive as possible and the interviews terminated if signs of distress were observed. At the beginning of each interview, participants were also assured of the confidential handling of the data to avoid that they provide socially acceptable responses. Finally, participants were informed of the option to quit the interview at any time necessary without having to provide an explanation.

Since the participants were all high school students who could speak and understand English, the interviews were mostly carried out in English; both the questions posed by the interviewer as well as the responses given by the participants. However, sometimes the research assistant (who spoke English but also was a native speaker of 'Frafra') had to 
translate questions posed in English by the lead interviewer for participants who could not understand some of the English formulations or questions. Also, sometimes participant's responses were in Frafra if they had difficulties finding the correct English expression. These responses were also translated in the same manner to the lead interviewer, and we recorded both languages for the transcription. The first author, who speaks the local language as well, validated the transcriptions by listening to the voice recordings and made minor corrections where necessary. The participants determined the locations of the interviews. Out of the 23 individual interviews conducted, 3 were excluded from the analysis because of bad recording quality and/or interview stopping half-way because participants had to attend to parental calls.

Research instrument

We used a semi-structured interview guide that was developed based on theoretical concepts and literature review. The interview protocol included themes related to knowledge, attitude, self-efficacy, risk perception, and social norms addressing topics such as relationships, sex experience, pregnancy, contraception, and sexuality communication. Table 1 presents the main themes and topics of the interview instrument. Two young trained women, a Ghanaian with prior training in youth peer sex education and a Dutch graduate student from Maastricht University, conducted and transcribed the interviews. The corresponding author validated the transcripts by listening to the interviews and making minor corrections where necessary. 
Table 1: Interview protocol showing the themes and topics that guided the data collection

\begin{tabular}{|c|c|c|}
\hline Theme/Topics & Examples of subtopics & Examples of questions \\
\hline $\begin{array}{l}\text { Introduction } \\
\text { Background } \\
\text { variables } \\
\text { Demographics }\end{array}$ & $\begin{array}{l}\text { Age, background, school/work, } \\
\text { family, life, religion, ethnic } \\
\text { group. }\end{array}$ & $\begin{array}{l}\text { Can you tell me something about yourself? What does } \\
\text { your life look like? Do you go to school, work? What do } \\
\text { you like to do in your free time? Can you tell me a bit } \\
\text { about your family? Would you consider yourself being } \\
\text { religious? What role does religion play in your life? }\end{array}$ \\
\hline $\begin{array}{l}\text { Pregnancy/mothe } \\
\text { rhood }\end{array}$ & $\begin{array}{l}\text { Pregnancy } \\
\text { Motherhood } \\
\text { Important others include: } \\
\text { mother, father, brother/sister, } \\
\text { friends, boys/girls in your village } \\
\text { or at your school, the teachers, } \\
\text { and church leaders? Health } \\
\text { centre workers? }\end{array}$ & $\begin{array}{l}\text { How do you think about pregnancy? What would be a } \\
\text { good time to become pregnant/ a mother according to } \\
\text { you? How would you feel if you found out you were } \\
\text { pregnant now? What would you do if you figured out you } \\
\text { were pregnant now? Do you know anyone of your age who } \\
\text { got pregnant? What do you think of that? How do } \\
\text { important others in your surrounding think about teenage } \\
\text { pregnancy in general? How do you feel about their } \\
\text { opinion? }\end{array}$ \\
\hline $\begin{array}{l}\text { Femininity/mascul } \\
\text { inity }\end{array}$ & & $\begin{array}{l}\text { What does it mean to be a woman? What do you think are } \\
\text { the main differences between men and women of your } \\
\text { age? How do important others think about women? }\end{array}$ \\
\hline Relationships & $\begin{array}{l}\text { Current relationships } \\
\text { Past relationships } \\
\text { First relationship }\end{array}$ & $\begin{array}{l}\text { Are you in a relationship at the moment? How did your } \\
\text { relationship start? How would you define your current } \\
\text { relationship? Where do you meet your partner? } \\
\text { What do important others think about your relationship? }\end{array}$ \\
\hline Sex experience & $\begin{array}{l}\text { Attitude towards sex } \\
\text { Positive/negative experiences }\end{array}$ & $\begin{array}{l}\text { Did you ever have sex? Why/why not? How many } \\
\text { partners? If you have sex, where (At home? Church? } \\
\text { Bushes? Parties? School?) How would you describe your } \\
\text { sex life/ how are your sex experiences? } \\
\text { (positive/negative experiences) Do other people know you } \\
\text { have sex? (why/why not). What do you think important } \\
\text { others think about you having sex? }\end{array}$ \\
\hline Safe sex & $\begin{array}{l}\text { Definition and importance of sex } \\
\text { Definition of safe sex } \\
\text { Contraceptive use } \\
\text { Condom use } \\
\text { Where/ how do they get } \\
\text { condoms/other contraception }\end{array}$ & $\begin{array}{l}\text { What do you consider safe sex? Do you use condoms? } \\
\text { (how often?) Do you use other types of contraception? } \\
\text { Which one? What are reasons for using/not using condoms } \\
\text { (or other forms of contraception)? Who do you think is } \\
\text { responsible for contraception? What are advantages and } \\
\text { disadvantages of contraception? What do you prefer } \\
\text { (condom or other contraceptives) and why? Should } \\
\text { men/women carry them around? }\end{array}$ \\
\hline $\begin{array}{l}\text { Safe sex } \\
\text { negotiation with } \\
\text { partner }\end{array}$ & & $\begin{array}{l}\text { People don't always want the same with sex. For example } \\
\text { some want to use condom others don't. Or some like sex } \\
\text { in one way and others like it in different way. What do you } \\
\text { do / would you do if partner want something else? What if } \\
\text { you want to use a condom but he doesn't? Have you ever } \\
\text { persuaded a man to practice safe sex? Can you describe } \\
\text { how you discussed it with him? What was the reason for } \\
\text { not discussing? }\end{array}$ \\
\hline $\begin{array}{l}\text { Communication } \\
\text { about (safe) sex } \\
\text { with partner }\end{array}$ & $\begin{array}{l}\text { Topics of communication with } \\
\text { partner, aboo topics } \\
\text { Communication }\end{array}$ & $\begin{array}{l}\text { Which topics can/can't you discuss with partner? } \\
\text { Do you ever talk about sex with your } \\
\text { friends/sisters/parents? }\end{array}$ \\
\hline $\begin{array}{l}\text { Sex education/sex } \\
\text { communication }\end{array}$ & Information sources & $\begin{array}{l}\text { Did you learn about sex? How/ by whom? Did you have } \\
\text { sex education at school? What did you think of it? Do you } \\
\text { ever talk about sex, contraceptives, motherhood at school, } \\
\text { with your friends, family? Do you think you know all you } \\
\text { need to know about sex/safe sex? If you have questions } \\
\text { (e.g. on contraception/pregnancy) where would you go? } \\
\text { Did you have to go to health clinic for sex-related issues? } \\
\text { What is your experience? }\end{array}$ \\
\hline
\end{tabular}




\section{Data analysis}

After validity checks and proof-reading, the 20 transcripts in MS Word documents were exported into NVivo 10.0 qualitative software for analysis. The analysis took the form of thematic exposition -- identifying the dilemmas, fears, and beliefs within the narratives (Walsh, \& Downe, 2006). A thematic exposition allows the researcher to determine categories and construct concepts using a grounded theory approach (Corbin, \& Strauss, 1998). The analysis employed a three-level coding system. At the first level, the transcripts were repeatedly read to identify phrases which could be coded into general themes. We grouped these initial codes into smaller themes at the second level coding (axial coding or pattern coding). At the third or selective coding level, we reviewed level one and two codes to confirm the various thematic categories. The second author checked the three levels of codes (Birks, Chapman, \& Francis, 2008) against the original transcripts and discussed a few little parts that were not covered under the right topics back-and-forth with the first author to reach an agreement. The thematic categories were then summarized and used as the basis of subordinate and secondary analysis of the determinants of adolescent girls' sexual health decision-making processes in the Bolgatanga area as viewed from the perspective of unmarried teenagers without pregnancy experienced.

\section{Results}

Table 2 presents the main themes that emerged from the data, and the number of girls who reported on the various thematic areas. We have classified the results according to behavioral factors, environmental factors, and psychosocial determinants related to sex and sexuality, contraceptive use, and teenage pregnancy. It seems there were some overlapping patterns in the girls' responses. For example, those who reported a positive relationship with their parents also did express a desire to stay in school and had clear intentions to make safer sex choices to safeguard future plans. 
Table 2: A matrix of the main themes that emerged from the data and the number of participants who reported those themes

\begin{tabular}{|ll|}
\hline Main theme & $\begin{array}{l}\text { Number } \\
\text { of girls } \\
\text { reporting }\end{array}$ \\
& 10 \\
Buying condoms & 16 \\
Carrying condoms and condom use & \\
responsibility & 17 \\
Attitude towards condoms and condom & \\
Use & 20 \\
Knowledge on condom use & 19 \\
Risk perception towards both pregnancy & \\
\& STIs & 15 \\
Intention to use and negotiating condom & \\
use & 18 \\
Life situation of the girls (occupation, & \\
economic situation) & 17 \\
Knowledge on family & \\
planning/contraception & 19 \\
Attitude towards school/education & 9 \\
Attitude towards sex & 6 \\
First time sex experience & 4 \\
Experiences with forced sex & 10 \\
Social norms towards pregnancy & 8 \\
Sex education at the health facility & 17 \\
Sex education in school & 14 \\
Sex education/communication at home \\
Social norm towards adolescent sexuality \\
General relationship experiences \\
General sex experiences & 13 \\
Condom use experience & 6 \\
Future goals \& its influence on safer sex \\
choices
\end{tabular}

\section{Behavioural factors \\ Relationship experience}

Half of the girls mentioned that they had experienced relationships with boys and had pleasant and steady relationships lasting between one to six years. For most of them, their relationships were not secret but known to others, including their parents and they perceived that others were positive about the relationship. The girls indicated that not keeping the relationship secret was important to them because the boys cannot deny responsibility if they mistakenly get pregnant. One girl put it this way:

P: We always do it plain, so people know. In that way, there can be no denying if anything happen

\section{$\{18$ yrs Muslim in Senior High School\}}

Some of the girls are in a relationship because of potential help (material gain) from the boys as in: 
P: Like anytime I want money to do [anything] at school, he will give me the money, and I like him

$\{19$ yrs old Christian in Senior High School\}

\section{Sex experience}

The six girls with sex experience were mostly one year older than those without sex experience, and most of them had been in the relationship for an average of one year before initiating sex. Concerning sexual debut, they reported mixed experiences. Some girls described their sexual debut as "good" or "somehow good" and for this category they had planned for it and also used condoms:

I: When did you have sex for the first time? P: The first time it was a year of the day we met, that was our one year celebration. I: Did you talk about it with your boyfriend before? P: Yes I: Was it a good experience? P: Somehow good.

$\{19$ yrs Christian in Senior High School\}

Others had bad experiences such as forced sex and painful intercourse:

I: Can you tell me a bit about your first sexual experience? P: Oh it was very painful, very painful. I: how old were you when you had your first sexual experience? P: 16 years. \{18 yrs Christian in Senior High School\}

The girls who were sexually active said they initiated sex because of the perception that their peers were doing it. Some girls also indicated that they had encountered forced sex, and some had sex with their boyfriends' because the boys' had threatened to end the relationship if they did not yield to their request for sex. Some few girls also added that they had been approached by teachers demanding to have sex with them and they refused. They believed that most teachers are making similar advances towards young girls.

\section{Condom use experience}

All sexually experienced girls indicated using condoms consistently. Also, they all stated that they discussed sex and condom use with partners before sex. The girls were clear of the need to use condoms and they negotiated for it:

P: Yes, I am using condoms with my partner because he has not married me yet and so far as he loves me, we can have sex. But if we do not use a condom, it is too bad. We have to use condoms to avoid unwanted pregnancy.

$\{19$ yrs, Christian in Senior High School\}

\section{Environmental factors}

(Sex) communication with parents and peers 
The girls' reported an attuned and warmth relationship with their parents (mostly mothers) at home. The cordial home environment seemed to have resulted in a relatively open mother-daughter communication. They also discussed exuality-related topics with their mothers. However, such discussions centered on moral advice and abstinence-only messages, except for a few girls who reported receiving safe sex practices advise. Many of them indicated that their parents discouraged them from thinking and talking about sexuality issues. When asked why they think their parents showed little interest in talking about sex with them, the majority indicated that their parents harbored fears that talking about sex will encourage them to practice more sex. One girl put it as follows:

P: It is up to them, I don't know. They think we shouldn't be in love. (19 yrs Christian in Senior High School)

The girls reported that their mothers continuously admonished them to delay entering into sexual relationships or use protection against pregnancy. In general, the girls were not happy with the emphasis on abstinence-only messages from their mothers, but those who had more extensive advice on relationship and sex were glad to have such talks:

P: she said that when you are having sex, you have to use condoms. I feel great that someone is concerned about my life.

$\{19$ yrs Catholic in Senior High School\}

At the same time, some girls expressed their desire to discuss sexuality issues with their parents, but they missed such discussions:

P: It is good they talk but when they don't talk, what can you do? You cannot go and tell them, come here and sit and talk with me!

\section{$\{17$ yrs Christian in Senior High School\}}

Some girls preferred to discuss matters of sexuality with peers instead of talking with their parents who will only preach morality to them. Among peers, the discussion often centered on advising each other about the "good and bad" side of their sexual lives:

P: We talk about the bad effects of sex; we speak about the good part and the bad part. I: Hm, what are the good parts and what are the bad? P: The good part is when you marry and give birth to children then you are fulfilling God's promise like that, but the bad effects is that you maybe a teenager too, you have it, and you get pregnant, who can take care of the child, that Is on the wrong side.

\{18 yrs Christian in Junior High School\}

Experience with and Attitude towards sex education 
The majority of the girls received sex education in school, which seemed to be skills-based and included condom use demonstration. They shared positive experiences with the schoolbased sex education:

P: It was good, they told us about AIDS and teenage pregnancy and gonorrhea, syphilis, all this kind of disease, [...] so they taught us all the things in school, including how to use condoms, yes.

\{19 yrs Catholic in Senior High School\}

And:

It was good [. ..] if you are even at my age, and you want to have sex and they even teach you how to prevent yourself from those sickness, you now know how to keep yourself and how to have safe sex with a man.

$\{15$ yrs Muslim girl in Junior High School\}

On the other hand, some of them got abstinence-only messages and one never got sex education at all. For some, nurses from the health education unit came to teach them in school and for others; it was either their teachers or peer educators from NGOs. On seeking information via health services, the majority of the girls had either already gone to the health facility for sex education or indicated that if they needed information on sexuality, they would go to the health center.

\section{Psychosocial determinants}

\section{Determinants related to condom use}

Except one girl who indicated her lack of knowledge, the girls reported that they were relative ly knowledgeable about condoms. In general, they knew about condoms and its use as a protection against unwanted pregnancies and STIs:

P: Yeah, I told him that as young as we are, we have to use protectives like condoms, to avoid ourselves from being pregnant and he said okay. He also decided that we should use condoms, so that is why we use condoms

\{19 yrs Catholic in Senior High School\}

Almost all the girls also seemed to know how to use condoms and, also, some knew that family planning (other contraceptives besides condoms) can also be used to prevent pregnancy. Most girls indicated that it was important for both boys and girls to carry condoms with them to be prepared for any unplanned sex:

I: And what do you think if a girl carries condoms with her? P: I will think she wants to protect herself because you don't know. Anything can happen at any time, so in case she is forced to have sex and want to protect herself, she can use it 


\section{\{17 yrs, Christian in Junior High School\}}

However, none reported ever buying condoms, including the girls with sex experience. While some of them do know that they can buy condoms at the drugstores, others seemed not to know exactly where to obtain condoms. The main reasons for not attempting to buy condoms included the belief that it is the boy's responsibility to buy condoms or the perception that the store attendants will ridicule them:

P: Because she'll say who is this small girl coming to buy condoms, what are you going to use it for? But she'll not ask you whether it's for you or it's not for you, they will just start saying that look at this small girl, and you are buying this thing to do what

\{14 yrs Muslim in Junior High School\}

Regarding perceived behavioral control concerning negotiating condom use, the girls believed they were able to negotiate condom use with their partners by pointing out unwanted pregnancy and STIs as reasons why they must use condoms. They were prepared to stop the relationships if their partners do not agree to use protection. The following quote sums up the girls' readiness to negotiate for condom use:

P: When it happened that way I told him no condoms, no sex and he had to go out and bring one

$\{17$ yrs old Christian at Senior High School\}

A common phrase "no condom, no sex" depicted how they were not willing to compromise on negotiating to use condoms.

The majority of the girls were positive about condoms and also about using condoms. They were clear about the importance of using condoms to protect against both pregnancy and STIs:

P: Because if you use them well, you will not get pregnant and you will not get HIV/AIDS that is why I think condoms are good

$\{18$ yrs, Christian girl in Junior High School\}.

Some gave reasons why other people may not be comfortable using condoms, such as a reduced sexual pleasure. The majority of the girls, including those without sex experience, were clear in their intentions to use condoms, and were prepared to negotiate for it or stop the relationship if the partner refuses (or would refuse) to use condoms:

P: Okay, if it happens.... I don't think I'll agree to have sex without condoms, and if he doesn't agree too, I'll walk away from him $\{17$ yrs old Christian girl in Senior High School\}

The reasons for clear intentions to use condoms included being able to continue their education to achieve their goals, not wanting to become a disgrace to their family, and not 
wanting to live in poverty. In general, the girls were conscious of the risk that any girl can get pregnant at any time. The following quotes indicate their high level of perception of risk:

P: me like this, I'm having my boyfriend. At this my age, maybe it can come to a mistake, then we sleep together, then I can get that pregnancy. But if you protect yourself, you'll not get pregnant, but if you don't protect yourself, if the boy release on you, you will get pregnant.

$\{18$ yrs Catholic girl in Junior High school\} A common phrase "it can happen to any girl"defined their perception of risk of pregnancy.

All the girls had clear goals towards the future, and the majority indicated they were concentrating on taking measures to ensure unintended pregnancy do not keep them from achieving their life goals. They wanted to become teachers, nurses, lawyers, doctors or business women. They reported measures such as using condoms and avoiding male friends to stay focused on achieving their goals.

P: If you don't stay away from boys now, but at my age like this, as of now I don't have anything, I don't have any work, then if I follow the boys in the end I'll not get anything in the future, and my hope of becoming a nurse will fail. Maybe they can impregnate me now, and I'll drop out from school.

\section{$\{18$ yrs, Christian in Junior High School\}}

All the girls were very firm in their statements that they will only allow themselves to become pregnant and have children when they achieved their goals around the age of 25 to 30 years.

\section{Determinants related to family planning}

The girls defined family planning as contraceptives other than condoms. Thus, condom use was viewed separately from other family planning methods. All the girls were aware that condoms and family-planning can protect against unwanted pregnancy and, in the case of condoms, STIs as well. However, none of the girls was using a family planning method, and almost all of them believed that family planning is not right for unmarried girls. They gave reasons ranging from high potential of becoming infertile, growing slim or too fat, and falling sick to destroying your womb as in:

P: I hear people talking about it that if you are doing it, it can destroy your womb, so you can't give birth again, but they even said that it is only meant for those who are married.

\{18 yrs Catholic girl at Junior High school\}

Determinants related to sex and pregnancy

The attitude of the girls towards sex is varied. To some, sex is a good thing 


\section{I: When did you have sex the first time? P: Last year I: Okay, how was the} experience? P: It was good experience, sex is good

\section{$\{19$ yrs Christian girl in Senior High School\}}

To others, sex is only for married people based on what they heard from their parents or the church:

P: Okay, as at my age, sex is not a good thing to me, but if you are a married woman, and honest, you have to have sex before you can give birth.

$\{18$ yrs Catholic girl at Junior High school\}

Some of them said although sex is for married people, when they are not able to resist the urge and should have sex, they will protect themselves against pregnancy. Regarding social norms towards teenage pregnancy, the majority of the girls think that the important referent people in their lives consider teenage pregnancy as a bad thing to happen:

P: They will say oh, look at this girl, she is pregnant, they will even be talking, everywhere about you, you are having pregnancy and what and what, your friends will now be afraid of you and not follow you again, now that you are a bad girl, that is why it is not good.

\section{$\{16$ yrs Muslim girl in Junior High school\}}

On social norms towards girls being in sexual relationships, some of the girls indicated that other important referents to their lives, including their parents, were open to adolescent sexuality and relationships. They clearly indicated that their parents were aware that they are in sexual relationships, and some got advice on protection against pregnancy from their mothers. Other girls were of the view that their parents and other relative do not want to hear that they are in a relationship or have sexual relations with boys:

P: It's up to them, I don't know. They think we shouldn't be in love

$$
\text { \{19 yrs Catholic girl in Senior High School\} }
$$

\section{Discussion}

Knowledge of what makes girls without pregnancy experience differ from girls with (unintended) pregnancy experience can greatly enhance the development of effective pregnancy prevention programs. In this study, we interviewed adolescent girls living in communities with high teenage pregnancy rates but without pregnancy experiences themselves. The results suggest that the girls had a cordial and positive relationship with their parents and did talk about sexuality with their mothers and friends. Although much of the mother-daughter communication was largely limited to moral advice to abstain from sexual relationships, some girls received more extensive advice, including safer sex practices 
to avoid unwanted pregnancy. In school, the majority of the girls seemed to have received sex education with the inclusion of condom use. The girls also reported high awareness of the risk of pregnancy through unprotected sexual intercourse. They were also positive about carrying condoms (some girls) and using condoms. All the girls also indicated strong selfefficacy beliefs towards negotiating condom use. On the other hand, the girls believed that it is the boys' responsibility to buy condoms, and they had negative attitudes towards so-called family planning (contraceptives other than condoms). There were some overlaps in the narratives of the girls. However, conclusions cannot be made base on these overlapping reporting of only 20 qualitative interviews. Whether there are potential relationships between the reports of the girls among the emerged themes will require a quantitative survey involving a statistically significant sample.

The results also suggest that the girls had clear future goals regarding educational levels and careers they want to achieve, combined with clear plans on how to achieve them. The latter mostly focused on preventing any pregnancy before having finished education and before having a proper job by staying away from boys or refusing any sex without condoms. All the girls had clear intentions for future condom use and those who were sexually active reported consistently using condoms to avoid pregnancy until the achievement of their plans.

Our participants' experiences of frequently receiving advice on sex and relationship issues from their mothers are contrary to what was reported by Krugu et al. ( under review), where the pregnancy experienced girls had no form of sex communication at home. Parents who keep the communication lines open all the time have been reported to have a closer and more connected relationship with their children, which allows them also to discuss sexuality topics (Biddlecom, Awusabo-Asare, \& Bankole, 2009; Crichton, Ibisomi, \& Gyimah, 2012). Although some of our participants' experiences were largely that of being dissuaded from having sex, those who received more extensive advice, including condom use discussions, reported being happy to know how to "have sex with a man". Which might explain why they could avoid unwanted pregnancy as compared to the pregnancy experienced girls of Krugu et al. (under review). Past research suggests that motheradolescent discussion about condoms before adolescent's sexual initiation was associated with more use of condoms at sexual initiation and could set the stage for later consistent condom use (Nadeem, Romo, \& Sigman, 2006). However, factors such as lack of time, lack of knowledge, not being comfortable and perceiving that their daughters are not at risk of pregnancy or STIs have been reported to inhibit mother-daughter communication on safe sex practices (Crichton, Ibisomi, \& Gyimah, 2012; Wamoyi \& Wight, 2014). Further 
exploration into the influences of mother-daughter sex communication is necessary to support family based interventions to address teenage pregnancy in North Ghana.

In contrast, to the girls with pregnancy experience (Krugu et al., under review) the girls in the current study all reported having had some form of school-based sex education that included lessons on the use of condoms. Across Africa, formal school-based sex education programs focus on promoting abstinence-only messages (Paul-Ebhohimhen, Poobalan, \& van Teijlingen, 2008). However, comprehensive programs also provide information on birth control methods and condoms to prevent both pregnancy and STIs (Kirby, 2008). These different topics included in sex education across schools could explain the differences in safer sex choices made by the girls without pregnancy experience as compared to the girls with pregnancy experience. Systematic reviews suggest that the effects of abstinence-only programs in reducing sexual risk behaviors have been minimal (Bennett, \& Assefi, 2005; Smoak, Scott-Sheldon, \& Johnson, 2006; Underhill, Montgomery, \& Operario, 2007). Rather, adolescents who received comprehensive sex education had a lower risk of pregnancy than those who received abstinence-only or no sex education (Kohler, Manhart, \& Lafferty, 2008).

The girls in this study reported positive attitudes towards condom use, exhibited high condom use self-efficacy, high-risk perceptions towards pregnancy, and had clear intentions towards condom use as compared to the girls who became pregnant against their wish (Krugu et al., under review). Some studies across Africa have demonstrated the role of attitude, self-efficacy beliefs, risk perception and subjective norm in shaping young people's intention to use condoms (Bryan, Kagee, \& Broaddus, 2006; Molla, Astrøm, \& Berhane, 2007; Schaalma, Aarø, Flisher, Mathews, Kaaya, Onya, Ragnarson, \& Klepp, 2009). Future research that seeks to confirm the relevance of these personal determinants in condom use decision-making among the adolescent population in northern Ghana is necessary to guide intervention development.

The girls in this study mentioned specific plans such as using condoms to prevent unwanted pregnancies that may threaten future goals. This is in contrast to Krugu et al.'s (under review) study of girls with pregnancy experience. The girls with pregnancy experience often described and perceived themselves as being subordinate to boys. They also seemed not to have specific future goals. The current finding adds a potential new dimension to the efforts to prevent teenage pregnancy in Ghana. Several studies have shown the positive effects on health behavior and decision making of having clear future goals or purpose for living (Kim, Strecher, \& Ryff, 2014; McKnight, \& Kashdan, 2009; Ryff, 2014; Steger, Frazier, Oishi, \& Kaler, 2006). Our finding suggests that the proactive 
pregnancy preventive behaviors of adolescent girls to fulfill their aims could influence whether or not they will become victims of unintended pregnancy. Thus, it could be useful to get young girls to relate safe sex with life goals that they can forfeit by the outcomes of unsafe sexual activities (Bartholomew Eldredge, Markham, Ruiter, Fernández, Kok, \& Parcel, 2016). At the same time, however, within the African context, goal-setting as a strategy to increase health-related decision making of girls may be difficult to accomplish. Across rural Africa, the choices of young women are often constrained by their narrow range of experiences, and they frequently project for themselves a life similar to that of their mothers, which is often characterized by low income, and limited economic opportunities (McFerson, 2010) .

A concerning finding is that, similar to the girls with pregnancy experience (Krugu et al., under review), the girls in the current study also had strong negative attitudes towards family planning (i.e. using other methods of contraception besides condoms) and believed that boys are responsible for buying and carrying condoms. These beliefs mostly put boys in control of safer sex choices. Therefore, although the girls in this study reported clear intentions to use condoms, they may, in the end, fail to act by their intentions. Programs aimed at promoting condom use need to stress that the importance of being prepared and in control or having condoms available is also important for girls. In addition, the 'double Dutch' approach (using another contraceptive method in addition to condoms) has been shown to be safer for pregnancy prevention than only relying on condom use (Ferguson, Vanwesenbeeck, \& Knijn, 2008). Future research should explore strategies to change girls' negative beliefs about using family planning outside marriage context.

\section{Study Limitations}

Since all the girls belong to the 'frafra' ethnic group living in Bolgatanga, the findings are not necessarily generalizable to other African populations. However, the findings offer interesting perspectives to the discourse on adolescent girls' sexual behaviors in Ghana and should be further confirmed through quantitative methods. Also, fearing that age difference between interviewers and participants may inhibit open discussion on sexuality, we used young women to collect the data. The interviewers had limited experience in conducting indepth interviews on sensitive topics like sexuality. They might have had difficulty in determining whether or not a participant was responding in a socially desirable manner. More experienced interviewers could have enriched the data through the right follow-up questions or further probing. Also, the context in which we conducted the interviews could have influenced the results. A few times, interview sessions had to be moved to a more quiet location in the course of interviewing and the disruption led to some questions remaining 
unanswered. Our recruitment procedure required participants less than 18 years of age to obtain parental consent. It is possible that only parents who accepted that their daughter's can discuss sexual topics openly consented, thus causing a bias in the generalizability of our sample. The recruitment procedure also ended up with only school-going girls as participants as well as with a sample of which only a limited number had sexual experiences. Both could have influenced our findings. Since the school setting can define the sexual socialization of girls in different ways (Stromquist, 2008), it is possible that the results would have differed if out of school girls were included in the sample. For girls without sexual experience, the answers on how they would deal with actual sex-related situations are therefore hypothetical.

\section{Conclusion}

This study suggests that a more positive mother-daughter communication at home may be one of the protective factors in the sexual decision-making processes of girls. Since previous research also showed that mothers seem to be important socializing agents in adolescent sexual decision-making (Bankole, Biddlecom, Guiella, Singh, \& Zulu, 2008; Biddlecom, Awusabo-Asare, \& Bankole, 2009), interventions may focus on helping the maternal parent become skilled, comfortable and open in discussions about sexuality with their daughters. Also, it seemed that access to school-based sex education that includes condom use information made a difference between the girls with pregnancy experience and those reported in this study. Therefore, the parental contribution could also include engaging in school policy development to ensure that school-based sexuality education goes beyond abstinence-only messages to equip adolescents for safer sexual choices.

Our results also point out how the attitude towards contraception, risk perception towards pregnancy, and girls condom use self-efficacy can influence the performance of action specific sub-behaviors necessary for girls' safer sex practices. Preparatory subbehaviors such as buying and carrying contraceptives and skills to communicate contraceptive use wishes are vital to enable girls to make safer sex choices (Van Empelen, \& Kok, 2008). Future intervention planners should first examine which cognitive beliefs are more important in addressing specific preparatory behaviors related to condom use. Such efforts may consider the 'double-dutch' approach of promoting the combined use of both condoms and hormonal contraceptives to enable girls to take full control of their sexuality (Ferguson, Vanwesenbeeck, \& Knijn, 2008).

Finally, this study suggests that girls with higher purpose may tend to use more pregnancy preventive measures to avoid unintended pregnancy and stay focused on achieving their life goals. Intervention studies designed to improve goal-setting and 
experiences of purpose in life may be warranted. Doing so could offer new avenues for girls' increased use of pregnancy preventive measures, thereby decreasing the chances that they will become pregnant against their wish.

\section{Acknowledgement}

We are grateful to all the girls who participated in this study, and also to our research assistant, Belinda Akolgo for her dedication. The study was funded by NUFFIC Ph.D.

fellowship grant nr. NFP-Ph.D.11/806 with additional support from Maastricht University and the Youth Harvest Foundation Ghana (YHFG). 


\section{Chapter 5}

\section{Girls cannot be trusted: Perspectives of adolescent boys on contraceptive decision-making in sexual relationships in Bolgatanga, Ghana}

Manuscript submitted as:

Krugu, J.K., Mevissen, F.E.F., Flore, K.A., Ruiter, R.A.C. Girls cannot be trusted:

Perspectives of adolescent boys on contraceptive decision-making in sexual relationships in Bolgatanga, Ghana. 


\section{Introduction}

Globally, an estimated 16 million births occur annually to young women aged 15 to 19 years, representing $11 \%$ of all births (Sawyer, Fifi, Bearinger et al., 2012). Almost all (95\%) of adolescent births take place in developing countries, and 50\% occur in sub-Saharan Africa (Patton, Coffey, Cappa et al., 2012; Neal, Matthews, Frost et al., 2012). Early childbearing is associated with higher maternal mortality and morbidity rates (Ganchimeg, Ota, Morisaki et al., 2014) and increased likelihood of induced, mostly illegal and unsafe, abortions (( Åhman \& Shah, 2010 ). Adolescent pregnancy is independently linked to increased risks of delivering babies with low birth weight, preterm delivery, severe neonatal conditions, and early neonatal death (Ganchimeg et al., 2014). Out of the estimated 22 million unsafe abortions that occur every year, 15\% occur among young women aged 15 to 19 years (WHO, 2011). Teen pregnancies also result in adverse social outcomes for the victims and their partners, including lower educational achievements than their peers, being more likely to being unemployed, earning less and living in poverty (Cook \& Cameron, 2015).

These high rates of teen pregnancies in sub-Saharan Africa represent a high rate of unsafe sexual practices among the adolescent population, which in turn also puts them at risk for STI (Bearinger, Sieving, Ferguson, \& Sharm, 2007). Indeed, recent meta-analysis of risky sexual behaviour among male youth in developing countries including some within Africa found that the proportion of higher-risk sex among male youth aged 15-19 years was nearly $90 \%$ in most countries, and the odds ratio for African male youth was higher than that for the non-Africans (Berhan \& Berhan, 2015). In Ghana, among adolescents aged 1519 years who had multiple partners in the past 12 months preceding a survey, only $15 \%$ (females), and 34\% (males) reported using a condom during their last sexual intercourse (GSS-DHS, 2015). Another recent study by Yidana, Ziblim, Azongo \& Abass (2015) indicated that only $20 \%$ of sexually active Ghanaian adolescents' age 14 - 19 years had ever used condoms. Considering the low use of contraception among Ghanaian youth as compared to their peers in some developing countries, it is not surprising to find these high rates of pregnancies among Ghanaian girls.

Effective use of condoms and other contraceptive methods (often referred to as family planning) can avoid both STIs and teen pregnancies. Therefore promoting adolescent sexual and reproductive health and rights (SRHR) requires an understanding of the specific factors and beliefs that influence their non-use of contraceptives. These factors can be similar but also different for boys and girls. For example, while girls may not use family planning methods due to fertility concerns (Krugu, Mevissen, Prinsen \& Ruiter, 2016), boys may consider getting girls pregnant as a mark of masculinity and therefore harbour 
ambivalent attitude towards contraception (Bhana \& Nkani, 2014; Shefer, Kruger \& Schepers, 2015). Also, while girls may engage in multiple sexual partnerships for economic reasons (Krugu, Mevissen, Münkel \& Ruiter, under-review), boys may behave the same manner but for different reasons (Jewkes \& Morrell, 2010). In the context of Western Africa, the specific factors influencing the contraceptive decision-making of adolescent boys is less studied. Efforts in this direction have mainly focused on teenage girls and teenage mothers.

However, adolescent boys play a crucial role in impeding or discouraging condom use in heterosexual relationships (Shai, Jewkes, Nduna \& Dunkle, 2012), and can play an equally important role in promoting healthy behaviours. In the broader context of sub-Saharan Africa, studies focusing on adolescent boys and young men's roles in safe and unsafe sexual practices have pointed out that despite a high awareness of sexual risks and the acknowledgement of the protective value of condoms, boys exhibited high risky behaviours, including having multiple sexual partnerships, and not using condoms to protect against pregnancy or STIs (Berhan \& Berhan, 2015; Bhana \& Nkani, 2014; Bhatasara, Chevo \& Changadeya, 2013; Harrison, Cleland, Gouws \& Frohlich, 2005; Izugbara, 2004; Jewkes \& Morrell, 2010; Shai et al., 2012; Shefer, Kruger \& Schepers, 2015). These studies also reported boys' reasons for non-use of contraceptives, including boys stressing the risk of pregnancy rather than the risks of STIs and therefore relying on girls' use of hormonal contraceptives to prevent pregnancy, boys perceiving that wearing condoms decreases sexual pleasure, and boys reporting that the frequent 'heat of the moment' nature of their sexual encounters made it difficult to incorporate condoms use. Among the few studies targeting boys within West Africa, Oyediran, Feyisetan and Akpan (2011) in Nigeria reported that economic status index (ESI) and mass-media exposure were associated with the use of condoms at last sexual encounter with lower ESI and lower mass-media exposure negatively influencing condom use. A study on predictors of young males' exposure to family planning messages in Ghana by Darteh and Amo-Adjei (2012) also reported that fear of effects of methods still presents a considerable obstacle to acceptance and use of contraceptives. Recent data on boys' perceptions and beliefs towards safe sex and how their perceptions influence their condom use decision making is lacking.

To understand the personal and environmental factors influencing the sexual behaviour of boys living in Bolgatanga, Ghana, and the processes and contexts through which they occur, a qualitative method is useful. In the context of only a handful collection of quantitative research on condom use, and almost no qualitative studies of boy's sexual relations, in-depth interviewing was selected as the approach to use. Semi-structured 
interviews were undertaken to explore boy's sexual practices and the underlying meanings attached to their socio-sexual relations.

\section{Methods}

\section{Study design}

The study used individual in-depth interviews that provided the opportunity for the participating boys to share their feelings, perspectives, and attitudes about their experiences and perceptions of girls and heterosexual relationships. The Ethics Committee of the Ghana Health Services in Accra and the Ethics Review Board of Maastricht University in the Netherlands gave approval for the study.

Study setting

We conducted the study in the Bolgatanga Municipality, which also serves as the capital town of the Upper East region of Ghana. Bolgatanga is located $743.83 \mathrm{~km}$ to the north of Accra, Ghana's capital and has an estimated population of 131,550; males constitute $47.7 \%$, and 44\% (entire population) are below 18 years (GSS, 2012). The predominant tribal group in the Municipality is the "Frafra" people, who are primarily engaged in agriculturerelated activities and are among the poorest in the country with between $22-35 \%$ of the population living on less than the World Bank's threshold of $\$ 1.25$ per day (Amanor-Boadu, Zereyesus, Asiedu-Dartey, 2013). The "Frafra" are organized along family and clan lines, and polygamy is widespread, although this is fast changing due to the influence of the Christian religion. Extended families live in compounds next to each other. There is one regional hospital in Bolgatanga that also serves as a referral hospital for the other 12 districts in the region. The health system includes nine Health Centres and several Community-based Health Planning and Services Compounds (CHPS). The key players in the adolescent sexual and reproductive health and rights-related issues include the Ghana Education Services (GES), Ghana Health Services (GHS), community and traditional leaders, and youth-focused nongovernmental organizations (NGOs).

\section{Recruitment and Sampling techniques}

We recruited the participants of the study using a purposeful homogeneous sampling technique (Denzin \& Lincoln, 2011). We prepared an A5-sized summary of the study and advertised on the walls of public buildings, sporting fields, schools, clinics, and places where adolescent boys were likely to visit. The summary explained that the study was being conducted to explore factors contributing to adolescent pregnancy and strategies to reduce its occurrence in the Bolgatanga Municipality, the fact that participation is purely voluntary, and how one can register to participate. In addition, the summary indicated that 
participation was limited to adolescent boys' age 14-20 years living within the Bolgatanga Municipality. We also gave the study summary to teachers, who in turn explained the study to their students both in English (the official language in Ghana) and in the local language (Gurene). After a week, the research assistants went back to the schools and collected the list of participants who were recruited by the teachers and arranged individual appointments. In all, 14 boys were recruited through public adverts and 7 through teachers in schools. One boy was later detected to be 23 years and was thus excluded, leaving 20 participants included in the analysis. Getting teachers to talk to potential participants directly in schools enabled the recruitment of those who did not get the chance to see the adverts.

Participants

The ages of the 20 participants included in the analysis were between 14 and 20 years $(M=18.43, S D=1.81)$. They included 12 Christians, 7 Muslims, and one pagan. All of them reported that religion was an important factor in their life choices. Eight of the boys were still in various stages of high school, 7 had just completed high school, 2 were pursuing tertiary studies, and three boys had earlier dropped out of school for financial reasons. Eleven boys came from relatively smaller, single-parent families while 9 were from households with an average size of six. Thirteen boys had sex experience, and the mean age of sexual debut was 14.5 years. Three boys had experience impregnating 17 -year-old girls each, and one of them persuaded the girl to abort the pregnancy; for the other two, one was married to the girl, and the other was currently taking care of the babies together with the girl. The two boys' sexual relationships with the girls ended after the pregnancy either because the parents of the girl did not agree to a marriage proposal from the boy or both considered the pregnancy a mistake and wanted to proceed with their lives in different directions.

\section{Procedures}

Two research assistants, a Ghanaian young man who had previous training in peer sex education and a Dutch graduate student from Maastricht University, conducted and transcribed the interviews. The research assistants took the boys who were willing to participate in the interviews through an informed consenting process, including explaining the purpose of the study, the voluntary nature of participation, confidential handling of information and anonymity of identities to them. When they were convinced that a participant had understood the study, he was requested to sign a consent form and be interviewed. Research assistants also provided parental informed consent forms to participants below age 18 years to take home for their parents' consent. They followed up after one week and recruited those who secured their parental approval to participate in the 
study. We did not provide compensation for taking part in the study. However, where necessary, the cost of transportation was reimbursed and at the beginning of the interviews, participants received a soda drink.

Throughout the recruitment and interviewing process, research assistants repeatedly assured the participants of the confidential treatment of the information, including assuring them that their identities would not be disclosed in any future reference to the study. Subsequently, we anonymized the names of the participants and excluded any specific details that could reveal their identities from the interview recordings. At the start of each interview, participants were reminded of their inherent right to stop the interview anytime and refused to answer any question without having to give a reason. On average, each interview session lasted for about an hour. The interviews were conducted both in English and in the local language for those who could not speak English. For the local language interviews, a trained interpreter was available to translate questions and responses between research assistants and participants.

The participants determined the location and timing of their interviews. Research assistants thanked the participants at the end of each interview and gave them the opportunity to ask questions. After interviewing 17 boys, saturation was achieved and with additional three interviews, recruitment was stopped. Research assistants recorded all interviews and transcribed them intermittently between separate interviews, which made it easier to determine the saturation point. The corresponding author listened to the voice recordings of the interviews, checked against research assistants field notes and made minor corrections in the transcripts.

\section{Research instrument}

We used a semi-structured interview guide based on social cognitive theories, including Fishbein \& Ajzen's Theory of Planned Behavior (TPB) (2010), Bandura's Social Cognitive Theory (1998), the AIDS Risk Reduction Model (ARRM) by Catania, Kegeles \& Coates (1990), and the Health Beliefs Model (HBM) (Rosenstock, 1974). These theories have already been used to explain risky sexual behavior within the African context (Krugu, Mevissen, Debpuur \& Ruiter, 2015; Nyembezi, Ruiter, van den Borne, Sifunda, Funani \& Reddy, 2014; Rijsdijk, Bos, Lie, Ruiter, Leerlooijer, \& Kok, 2012; Sialubanje, Massar, Hamer \& Ruiter, 2014). The TPB hold that motivation or intention to undertake a behavior precedes actual behaviour, and that in turn, intention is determined by a person's evaluation of the outcomes of the behavior (attitude), the expectations of important reference person (perceived norms), and personal control over performing the behavior (perceived behavioral control $\{\mathrm{PBC}\}$ ). Together with Bandura's construct of self-efficacy which holds that 
performing a given behaviour partly depends on how an individual feels confident of successfully performing the behavior and both Rosenstock's HBM and Catania, Kegeles \& Coates' ARRM construct of perceived risk as a motivation for action related to sexual behavior were used to guide the design of the interview guide. The guide incorporated determinants related to knowledge, attitude, self-efficacy, risk perception, and social norms addressing topics such as relationships, sex experience, pregnancy, condom use, contraception, and sex communication.

Data analysis

We saved the transcribed files as password protected MS Word documents. The first author read each transcript alongside listening to the original interview recording to validate the transcripts and corrected the notable minor mistakes. After validity checks and proofreading, we exported all transcripts into NVivo 10.0 for further analyses. We used thematic exposition which allowed us to identify the dilemmas, fears and beliefs within the narratives, and construct categories using a grounded theory approach (Denzin \& Lincoln, 2011; Walsh \& Downe, 2006).

We employed a three-level coding system (Weston, Gandell, Beauchamp et al., 2001). At level one, we read each transcript repeatedly to identify phrases which we could organise into general themes. The meanings assigned to these topics enabled us to engage the data further, immersed ourselves in the data and explored the meanings that the data holds (Birks, Chapman \& Francis, 2008). At level two (axial coding or pattern coding), the initial codes were grouped into smaller themes. We used axial coding to fine-tune theoretical categories by (a) establishing the terms of the condition that gives rise to each category; (b) delineating the embedded context; (c) outlining the interaction strategies; and (d) highlighting potential consequences of such strategies (Walker \& Myrick, 2006). At level three (selective coding), we reviewed all codes to confirm the various thematic categories. The second author checked the three coding levels against the original transcripts and with the agreement of the first author, corrected some aspects of the codings. We then linked the thematic categories through logical deductions to achieve the highest degree of validation for the central summarized thematic areas. The summaries formed the basis of the final analyses of the determinants of adolescent boys' perceptions on relationships and sexual health decision-making processes in Bolgatanga, North of Ghana.

\section{Results}

We present the results as behavioural factors, environmental influences, and personal determinants of boys' sexual practices and contraceptive decision-making processes. The 
boys did talk a lot during the interviews. In some cases, it was not very clear whether they were simply excited to talk about sexuality issues or, for some topics like sexual partners, whether they exaggerated their experience such as the number of sexual partners as a way of raising their masculine social status.

\section{Behavioural factors}

\section{Perceptions towards girls and relationships}

There is a general belief among the boys that "girls cannot be trusted" to be faithful in a relationship:

For guys, you don't have to trust a girl because she can disappoint you at any time. Unless maybe when you are married, then you have to trust your wife. (20 years).

They believed that girls are only looking for money and when the next more resourceful guy comes around; they will abandon their existing boyfriends and go for the new guy. They said because girls cannot be trusted, boys engage in multiple sexual relationships, besides their 'main' girlfriend as a relationship security measure:

Because nowadays the girls are no more trusted, so maybe if I have one girlfriend then she changed her mind, because girls are easily convinced. Maybe someone comes to convince her, and she changes her mind; it will be very hard for me. However, if I have about two or three girlfriends, then she even break up, it will be normal because others are there. That way you still move on. So that is just the main reason. (19 years).

The boys said they frequently break up relationships with girls because of the same issue of trust and perceived unfaithfulness:

Girls... they are intelligent, but you cannot trust them. That is the problem. They are intelligent, but they are not faithful, yeah. (19 years).

The boys reported that among peers, not having a girlfriend was not acceptable. Thus, having multiple girlfriends or reporting to have multiple girlfriends was partly related to the status of being a boy. In most cases, the boys hide their relationship with the other girls from their 'serious' girlfriend because they think her knowledge of him having multiple partners will ruin the relationship. At the same time, they will break up with their girlfriends if they discover that she is dating other guys:

I: Does your girlfriend know about these other girls? P: No, if she knew she would leave, so I know I have to hide to do those things. I: Would you leave her if she had other boyfriends? P: Yeah, I would leave her. (20 years).

The majority of the boys believed that girls accept their proposals for friendship because of the hope of getting money or other material gifts from them. Because of the belief that girls 
are looking for money, the boys often invest material resources in maintaining a relationship:

P: Girls are deceitful and also spoil guys. You can be in a relationship where you will be giving the girl money and everything you have and one day she will go after another boy and leave you. (18 years).

Only a few boys reported positive boy-girl friendship experiences, but such experiences were atypical. Some of the boys also believed that God created boys to be superior to girls and help encourage them. Frequently, they describe girls as not equal to males, being quite emotional or having a "small brain":

Anyway, I think the lady, or should I say, girl, the brain system of a girl [...] is very small. I see it as very small because it can be manipulated at any time- at any point in time. Girls are very much emotional, so anything you tell them can influence the steps they will take the following day. (19 years).

It was, therefore, common to hear the boys stating that they need to advise girls on how to organise their lives better or how to have a more 'stable mind.' The boys exhibited a superior masculine posture towards girls in a relationship context. Some reported that they expected their girlfriends to obey their request to have sex or risk a breakup of the relationship, which was also partly related to the fact that they had spent money on the girl or had given gifts to the girl.

\section{Condom use experiences}

Among the sexually active boys, only a few of them reported consistent condom use, mostly to protect against STIs rather than pregnancy. The majority have had unprotected sex. The reasons for not using protection includes not wanting to use condoms because it reduces feeling, wearing of condoms affecting sexual libido, and lack of preparation (not having condoms available). Other reasons were using the so-called 'safe period' of the girls menstrual cycle, not having money for condoms, using the withdrawal technique or because they trust the girl and felt no need to use condoms:

P: Sometimes I do not use condoms. However, it depends on whom I am going to have sex with. Some girl, if I trust her, I don't use a condom. (20 years).

P: I use condoms when I meet different girls that I don't know, but to my girlfriend, I know when she is always not safe for pregnancy, so when she is not safe, I use a condom. However, when she is safe, I use raw. (17 years).

Responsibility towards pregnancy prevention 
In general, the boys believed that it is their duty to have condoms available and to protect against impregnating girls. When asked why they think the responsibility lies with males, some responded as follows:

$P$ : Because you are the one who releases the sperms into her and the sperms form to a child, so you are the one because a girl cannot [laughs]. (18 years).

$P$ : Because it is you the guy who want the sex and can get her pregnant, so you have to take responsibility for your actions. (18 years).

Although a few believed that the responsibility for contraception lies with the two partners, others acknowledged that it is harder for girls to buy condoms because of the general expectation that girls have to abstain from sex until marriage. They believed that boys must take the responsibility to make sure condoms are available at the point of sex because girls may use fear of pregnancy to decline sexual advances from boys. One of them puts it this way:

The girls are now wise, so if you are having sex with them without condoms, they don't feel happy and may even refuse to have sex. So when you know you are planning for sex, I suppose you carry a condom. (17 years).

Some of them also said even though both partners are responsible for condom use, they will like to make sure they have a condom available to be in control or "master the situation."

\section{Environmental factors}

\section{Sex communication}

It was evident from the interviews that much of the sex communications among the boys took place when they were together as peers and when asked what they talked about among the peer groups, some of them said:

By all means you like to friend a girl, so when we gather we talked. This boy will bring his idea, what he likes, or this girl, he loves her and you too also... after that we are now going to tell you what to do. (18 years).

and

Maybe sometimes you have a problem with your girlfriend. Then you just seek your friends for advice. Maybe "what should I do? And maybe you seek an opinion from your friends. Among the options, I choose the one which I think is most appropriate (18 years). Some boys also indicated that part of the sex communication with peers was about putting pressure for those who do not have girlfriends or are not yet sexually active to get into relationships as a way of fulfilling peer group norms. 


\section{P: If you don't have a woman, they consider you to be a woman because a man will}

have a girlfriend. (19 years).

For most of the time, peer talks included joking a bit about girls and sex or boasting about their sexual experiences. Others, however, stated that they do have serious talks about sexrelated issues like warning each other of potential risks.

The boys also reported to have an open communication with at least one of their parents when it was about general life issues but when it was about sexuality they mostly received moral messages. For example, one boy mentioned that his mother once advised him to avoid impregnating a girl or contracting an STI by abstaining from sex. For those who had discussed sexuality issues with their parents, it was largely the mother advising that they should stay away from girls to avoid pregnancy and disease or for religious reasons:

P: my mother always tells me to take time, like I should take time with girls. I should take time, that's all, she does not tell more. (18 years).

Very few of them seemed to have very open and in-depth communication about sexuality with their mothers at home. They mentioned that their mothers did encourage them to use protection if they should have sex and one of them reported receiving advice on how he should also take care of "pleasing the girl." The reasons for the lack of sex communication at home included not being comfortable discussing sex with parents, fear of being regarded as "a spoilt" boy or having the perception that parental discussion on sex is limited to caution statements. Only a few boys mentioned talking with a teacher, girls or girlfriends about sexrelated issues.

Experiences with formal sex education

More than half of the boys got sex education in school, but the exact content often remains vague or diverse. It seems they mainly received basic information and warnings about the need to protect against impregnating girls or contracting STIs. Part of the information they receive at school also seems incorrect, as advice to use 'withdrawal' was for example mentioned as a safe sex technique learned at school. Most of them received sex education at the age of 16 years. The content of the sex education they received differed widely; for some, sex education was part of the science lessons in class and for others, NGO staff or peer educators came to teach them in school. A few explicitly stated they received training in how to use a condom from nurses. Some indicated to have learned a lot through sex teachings in class:

Yeah, [...] I never knew about contraceptives, so it was just in classes that I got to know about contraceptives, including how to use the pill, withdrawal, and condoms. (18 years). 
A few others said they got sex education through the media (television), and two boys reported that they got sex education through health workers, either at the clinic or during health promotion outreach programmes. Only a few boys indicated that they had no experience with sex education at all.

As for me, they didn't teach me about sex. (17 years).

\section{Personal determinants}

Knowledge towards teenage pregnancy and contraception

In general, the boys talked a lot about their perceptions of the risk and consequences of impregnating a girl or contracting STIs if one engaged in unprotected sex. Only a few of them explicitly expressed their knowledge on teenage pregnancy and contraception. They were fairly aware of the negative consequences of teenage pregnancy, especially how it affects both partner's education and life in general. Their knowledge of safe sex and contraception is frequently limited to condoms:

Apart from condoms, I don't know about the rest. (20 years).

Some of the boys mentioned that besides condoms, they will also use the withdrawal method and the girl's 'safe period of the month' method for contraception. They are aware that girls can use other contraceptives, but none could be specific beyond the emergency pill and the female condom. Mostly, they refer to hormonal contraceptives as "some drugs" or "other family planning methods" that girls can use to avoid pregnancy or to "urinate out the sperms after sex". On the question of knowledge of where to obtain condoms, all of them made reference to the drugs stores as the primary source to buy condoms.

Attitude towards safe sex practices, teenage pregnancy \& abortion In general, the boys' had a varied attitude towards teen sex; on the one hand, some stated that is not good to have sex with "small girls," while others think the teenage years should be invested in education and not sex. On the other hand, they admit having early sexual debut:

At that age, you know, you've got to concentrate on studies. Even though I started having sex at this age, I see it as bad. (17 years).

It appears that negative beliefs about teen sex are an extension of parental, or teachers, or religious leader's advice and not the actual attitude of the boys because most of them were sexually active by age 15 years.

Also, the boys expressed a clear negative attitude towards teenage pregnancy. They all used the expression "teenage pregnancy is very bad". They believed it is not suitable for both young partners and society does not accept it either. Almost all of them mentioned 
school dropout and not being able to care for family, resulting in a life of misery for both teenage parents as some of the adverse impacts of early pregnancy. They considered protection during sex as important to prevent teenage pregnancy and STIs.

Regarding condoms, the attitude of the boys can be described as ambivalent. While some of them indicated that condoms are necessary to prevent STIs, others reported bad experiences with condoms such as friction resulting in pain to the girl, condoms causing bruises or making their penis failing to erect. For these participants, they preferred to "go raw" or "flesh to flesh" and some said it was their girlfriends who requested the raw sex.

The boys seemed to be divided on their attitude towards abortion. Half of them thought that abortion was evil and constitute a kind of "killing." So for this group, if they mistakenly impregnate a girl, they will prefer that she give birth rather than abort. Their religious beliefs had an influence on their attitude towards abortion:

Actually, in my religion it is a dangerous thing to [...] it means that you are killing a human being, in my religion, which I don't think I am supposed to do. (19 years).

The other half were of the view that abortion is the inevitable choice for them should they make a girl pregnant.

\section{Self-efficacy related to buying, carrying and using condoms}

Almost all the boys said they felt shy to buy condoms when they were much younger but now in their upper adolescent years, they have no problems going to buy condoms at the drugstores. One of them explained why boys can purchase condoms from the stores as compared to girls.

You know when condoms came, adult men were feeling shy to go and buy them. They always sent small, small boys to buy condoms. By doing that, they made us (boys) get used to buying condoms. So now, if I go to buy condoms, the stores attendant will be thinking that I am just buying it to give it to somebody else. Because of that, I am not afraid to go and ask for condoms. (19 years).

\section{Risk perceptions towards pregnancy and STIS}

In general, the boys perceived themselves to be at risk of contracting STIs if they have unprotected sex. Their perception of the risk of STIs is related to how they perceive the behaviour of girls; most of them do think that girls go around having sex with different guys and are therefore agents of STIs. One put it this way

A condom is very important. Some other girls don't prefer using condoms. They just want to sleep in that way. It is dangerous to do that. If you don't trust the girl, you don't have to have sex with her without condoms because nowadays the girls go around sleeping with so many guys. Without a condom, you are going to put yourself in trouble. (18 years). 
At the same time, some of them thought that if they do not have bruises or sores on their penis, then they feel safe and can have unprotected sex. Again, condom use to protect against perceived risks in multiple relationships is related to whether a girl can be trusted or not. It was common to hear the phrase "When I trust a girl, I don't use protection" across the interviews. When asked how one can assess whether or not a girl can be trusted, the responses were related to the behaviour and physical appearances of the girls:

You look at a girl then you can tell, just like the saying 'show me your friend and I'll tell you your character". Yeah, you see the girl, the friends that she is with, you can tell. And the way that she dresses, you can tell the kind of girl she is. (18 years).

Also, it seemed that the boys' perception of the risk of unprotected sex is more related to STIs and less about the girls becoming pregnant. In some instances, they even differentiated the perceived risk of unprotected sex between boys and girls:

Both partners have to think about safe sex. The girl may have in mind that she doesn't want to become pregnant at that age and therefore need to use a condom. And the boy may also say oh, I don't want to engage myself in infections. I also try to buy a condom and do it safely. (17 years).

Perceived Social norms towards teen sexuality and pregnancy

All the boys indicated that they were expected by parents, religious leaders, and community members to abstain from sex until marriage. Because of the negative social expectation towards teen sexuality, they have always dreaded the risk of impregnating a girl and suffering the social scorn. The boys also admitted that it was difficult to go by the social expectation of not having sex, especially when peers tell them of their experiences with dating girls;

Most churches, they preach, or they teach against immorality. They say sex is immoral, maybe unless you are married, then you are supposed to have sex. But if you are not married, you are not supposed to go into that. But so far, you're also a guy, then most of your friends are dating, so you also have to carry yourself in those shoes. (18 years).

Some of them believed that boys engage in multiple sexual relationships because their peers expect them to do so and doing it enhances their social status among peers:

I think some people normally befriend one girl to another, thinking that they are 'niggers' or they put themselves ahead of others. [...] some of them just think that they are men if their girlfriends are many. Maybe a year or it will not even reach a year; then he will leave her and go to another. Maybe that one too a year or a month, he will also drop that lady and go to another because they think they have some men like 'niggers, 'they now put this kind of pose up on them. (19 years). 
Others also acknowledged that peers put pressure on them to have unprotected sex because it is "cool" to have raw sex:

$P$ : Yes, there is some of my friends they don't like using condoms, they always like to do raw, yeah, it is cool that way- which will bring them problems, yeah I do talk about that. I: Do you think your friends expect you also to use raw? P: Yeah, they are trying to convince me. (17 years).

While others indicated that they come under pressure to date girls or have sex to fulfil peer norms:

If you don't have a woman, they consider you to be a 'woman' because a man will have a girlfriend. (19 years).

Intention towards condom use

Most of the boys have clear intentions to use condoms to protect against both STIs and to impregnate their partners. Most of them also said they will use condoms when the girls insist and make condom use a condition for sex:

I: what kind of girl would make you use a condom? P: [laughs] Maybe if I have tried sometimes to have the girl and the girl doesn't give in, then the only option for me is to use a condom. That's when I would try to use one (18 years).

However, a few of them shared situations where they may not use condoms - like when they think they are safe:

P: I just try to see whether I have some bruises on my penis. Before I have that, maybe I just use soap then see whether I have some sores on my penis and if I am not feeling any pains. And if I think that I'm safe, I will just go in. That's what I do; that is the only thing I do. (18 years).

\section{Discussion}

In this study, we interviewed Ghanaian adolescent boys living in communities with high teenage pregnancy rates to understand factors influencing their (safe) sexual decisionmaking processes. One of the main findings is that the boys have a very negative perception of girls in general and about (sexual) relationships with girls in particular. It was often mentioned that girls cannot be trusted, are not faithful in sexual relationships, and are mostly interested in material gains rather than the need for intimacy in a relationship. These perceptions, together with normative standards on manhood, seem to influence their sexual and relational decisions: they engaged in multiple sexual relationships (labelling one as "serious relationship" the others as 'spare girlfriends') to avoid a situation where they could become a laughing stock among peers for not having a girlfriend, since "a man must have a 
girlfriend". The boys exhibited double standards towards relationship fidelity; they engage in multiple sexual relationships themselves, but, they will end their relationship with a girl if they found her dating other boys. The need to exhibit masculine character is so strong that they come under considerable peer pressure to engage in multiple sexual partnerships to conform to peer norms.

Our results also show that although the boys reported clear perception of the risk of STIs and awareness of the severity and possibility of teenage pregnancy when having unsafe sex, they still frequently engaged in unprotected sex. Their reasons for such risky behaviours included feeling safe with so called 'girls that can be trusted,' believing that the girl was in her 'safe period of the month' or not having condoms available at the point of need. Additionally, the boys hardly talked about sexuality topics at home and in school, and their experience of sex education was limited. Their biggest space for sex communication is among peers, where "they advise each other about sex". Their knowledge of contraception is mostly limited to condoms, the withdrawal technique and the girls' safe period of the month while the drugs store is their primary source for obtaining condoms.

Our participants reported engaging in multiple sexual partnerships to ensure that even if some of their partners stop the relationship, others will still be there to fulfil their relationship needs. This finding is a valuable addition to efforts towards understanding sexual behaviours of adolescent boys in Ghana. Such aberrant expectations of appropriate male sexual behaviours encourage boys to assume some form of patriarchal ownership over girls. In this way, hegemonic masculinity inevitably links having multiple sexual partners with the subordination of girls to boys' control, if necessary with the use of violence (Jewkes \& Morrell, 2010). For example, while our participants extolled themselves for engaging in multiple sexual partners, they were quick to condemn girls who have more than one boyfriend. Such adolescent boys' retrogressive gender notions are grounded in traits which have the potential to increase their risk of making girls pregnant or leaving them vulnerable to STIs (Varga, 2001). In such relationships, the male partner mostly controls sexual activity, and their posture may constrain young women's ability to practice safer sex.

Another interesting finding of this study is the links between condom use, relationship type, fidelity, and trust of the sexual partner. Participants were fully aware of the protective value of condoms for both STIs and pregnancy prevention. However, trust and condom use were often discussed as mutually exclusive (when I trust a girl, I do not use condoms). Among study participants, a decision to (not) use a condom was based on trusting a girl, which in turn, was judged according to physical appearance or diffidence in social relations and sexual fidelity. Previous studies on heterosexual sex and sexual relationships have 
shown that, just like young women, young men also consider 'trust' and 'love' as central in defining the meaning of sexual involvements and contraceptive use (Bauman \& Berman, 2005; Corbett, Dickson-Gómez, Hilario \& Weeks, 2009; Harrison, Cleland \& Frohlich, 2008). What is interesting in this study is the contrast of the boys demanding commitment from their "main girlfriends" against the realities of keeping several "spare girlfriends." This contrast makes condom use necessary even in 'faithful 'relationships, but unlikely. The boys are looking for girls who can be trusted in a monogamous relationship, but their behaviours reflected the opposite: they have other 'secret' partners. Therefore, adolescent boys in committed relationships behave towards their partners as though they were monogamous (and therefore no need to use condoms), but keeping 'secret spare' girlfriends is not uncommon. So the question is which partner should be trusted.

Another surprising finding in this study is the absence of love and intimacy in the constructions of sexual relationships and safe sex behaviours. Previous research linked young heterosexual men non-use of condoms to a desire to cultivate a loving and meaningful relationship, at all cost, including risk to their health (Corbett et al., 2009; Harrison et al., 2008). However, trust rather than love was the central theme of the narratives of the boys of this study. The finding shows that understanding heterosexual adolescent boy's (un)safe sex require considerable knowledge of how relationships are constructed and given meanings. When the boys interviewed here have unsafe sex with their 'spare' or 'main' partners, they interpret it in a manner which has only been partially explored in existing literature in West Africa. Given the small sample size, it cannot be claimed that the observed patterns can be generalized to all heterosexual boys in Ghana, let alone to their peers in other countries and cultures. However, the possibility that these configurations of meaning and practice are present in similar forms in the lives of other boys deserves further research. There is also the need for interventions to address precisely the issues of trust and emphasize that STI testing within "faithful" relationships may not be comfortable but necessary.

The discussions on attitude towards condoms also revealed a gap between intentions to use condoms and actual behavior. Our participants frequently stated their intentions to use condoms with casual partners, but they often failed to do so "at the heat of the moment." The finding points to the need for programs aiming at promoting condom use among adolescent boys to address self-efficacy to use condoms in difficult situations, safe sex communication, and negotiation skills. Equally important is the need to emphasised carrying condoms when going out for social functions so as to "be ready." 
Our study participants were unanimous in their beliefs that girls' motivation for a sexual relationship is limited to economic reasons. Indeed, studies among African adolescent girls have shown that social norms and economic motivation encourage teenage girls to be sexually active before marriage and to engage in multiple sexual partnerships (Krugu, Mevissen, Münkel \& Ruiter, under review; Moore, Awusabo-Asare, Madise, John-Langba \& Kumi-Kyereme, 2007; Poulin, 2007). Especially economic motivation can cause young women to engage in intergenerational sexual relationships, increasing their risk for both STIs and unintended pregnancy (Moore, Biddlecom \& Zulu, 2007). Also, with deteriorating economic conditions in most African countries, the use of premarital multiple sexual relationships as a means of economic survival is more likely to increase. Under such environmental conditions, the promotion of contraceptives (including condom use) as pregnancy prevention programs are more likely to achieve the desired outcomes than programs aimed at reducing the number of sexual partners, because to adolescent girls, that would be equivalent to their social and economic demise. Also, the finding highlights the need for interventions aiming at promoting safe sex practices among adolescent girls to incorporate economic empowerment components. In this regard, the report by Bandiera, Buehren, Burgess et al. (2012), on their evaluation of the Empowerment and Livelihood for Adolescents (ELA) programme in Uganda is a good example. In the ELA intervention, a combination of sexual risk reduction and economic empowerment activities led to $50 \%$ increase in condom use, $26 \%$ decrease in the probability of teenage pregnancy and the share of girls reporting sex against their will dropping from $21 \%$ to almost zero. The interesting part is that the ELA intervention included a broad range of income generating activities, including hairdressing, tailoring, computing, agriculture, poultry rearing and small trades operation, which are all implementable in other African settings

Our participants reported that among peers, the pressure to engage in sexual relationships is unyielding, which could be the reason why most of them experienced early sexual debut. Several studies have reported that boys frequently experience pressure to prove manliness by engaging in a sexual relationship (Reidy, Smith-Darden, Cortina, Kernsmith, Kernsmith, 2015; Richardson, 2010). In South Africa, Selikow, Ahmed, Flisher, Mathews \& Mukoma (2009) found that if boys are perceived as not being sexually active, they risk being excluded from their peer group. Blum (2007) review of trends and outcomes related to young people sexual and reproductive health across sub-Saharan Africa reported that both girls and boys do experience significant peer pressure to be sexually active. Susceptibility to peer pressure differs among young people, but adolescent boys appear to be more susceptible than teenage girls (Rosenberger, Bell, McBride, Fortenberry \& Ott, 
2010; Suleiman \& Deardorff, 2015). Peer pressure is however, not necessarily a negative influence. Positive examples set by friends and role models can promote safer sexual behaviour (Suleiman \& Deardorff, 2015). Such positive peer influences have been cited as the basis for the effectiveness of youth peer sex education programmes (Sriranganathan, Jaworsky, Larkin et al., 2010). Thus, it is important to ensure that adolescents have access to the right role models and correct sexuality information so that their influence over each other can be in a positive direction. This is particularly so because, among boys, sex communication largely occur with peer groups.

Limitations

In future reference to this study, the following limitations should be acknowledged. Since this is a report from qualitative interviews of boys from rural Ghana, the findings may not be generalizable to other African populations and cultures. Also, the interviews were conducted by two young people (male and female). It is unclear whether the boys provided answers that were meant to sound impressive or socially acceptable to the female interviewer. Also, both interviewers being young themselves, meant that they had limited experience in conducting qualitative interviews. Perhaps, more experienced researchers would have detected socially acceptable responses and probed further for clarity. Also, our sample included some boys without sex experience. For these boys, their responses on how they will handle actual situations within sexual relationships are therefore hypothetical.

Conclusion

This study has pointed out the critical need to decouple condom use and infidelity in the minds of young people. Especially, for adolescents who want to prevent pregnancy, more messages on dual protection (using condoms in addition to other safe sex practices) could help de-stigmatize condoms within faithful relationships. Also, adolescents need to understand that "being faithful" only protects them from STIs if they are faithful to one mutually monogamous, non-infected partner and being faithful still requires attention to pregnancy prevention. The double standard of boys' expecting fidelity from 'main girlfriends' but keeping 'secret' spare girlfriends means adolescents in 'faithful' relationships will always need to assess their risk of STIs and consider condom use, and repeat STIs testing within their relationships. Also, these findings suggest the need to give particular attention to the matter of trust and fidelity in intervention planning. Efforts to promote consistent condom use among boys should project it as a positive, progressive and healthy quality of a 'cool' masculinity, along with the promotion of gender equity and male participation in sexual and reproductive health. 
This study has pointed out that adolescent boys' exposure to sexuality discussions largely occur within peer groups. It is, therefore, important to expand access to comprehensive sexuality education for all young people. When they are all well-equipped with the right information and skills, their influence on their peers and advice in peer discussions are likely to be positive towards safer sex behaviours

The findings of this study also point to interesting avenues for future research. Future efforts to investigate some of the complexities and contradictions that are inherent in adolescent boys' heterosexual relationships is warranted. Such efforts may also specifically examine the social construction of types of partners and how inconsistent condom use vary according to partner type. Reports on these topics will provide valuable information to inform the development of effective programs that addresses the cultural norms and peculiar needs of adolescent boys.

\section{Acknowledgement}

We are grateful to all the boys who participated in this study, and also to our research assistant, Thomas Ayine for his dedication. The study was funded by NUFFIC Ph.D. fellowship grant nr. NFP-Ph.D.11/806 with additional support from Maastricht University and the Youth Harvest Foundation Ghana (YHFG) 


\section{Chapter 6}

\section{SPEEK: Effect evaluation of a Ghanaian School-based and Peer-led Sexual Education Program}

Manuscript in preparation as:

Krugu, J.K, Mevissen, F. E.F., Van Breukelen, G., \& Ruiter, R. A.C. SPEEK: Effect evaluation of a Ghanaian School-based and Peer-led Sexual Education Program. 


\section{Introduction}

Unsafe sexual practices among adolescents is widespread, resulting in high rates of sexually transmitted infections (STIs) and high incidence of unintended teen pregnancies (ChandraMouli, Svanemyr, Amin, Fogstad, Say, Girard \& Temmerman, 2015; Slater \& Robinson, 2014). For example, a worldwide incidence of 170-190 million new cases of T. vaginalis infection is reported each year, with prevalence as high as 50-60\% among adolescent girls and commercial sex workers (Gewirtzman, Bobrick, Conner \& Tyring, 2011) and 58\% among adolescent males at high risk for STIs (Johnston \& Mabey, 2008). Both STIs and unplanned teen pregnancies have adverse consequences (WHO, 2014).

Ghana's largely youthful population (median age $=20$ years) are sexually active by age 15 and due to high unmet need for contraception, $37 \%$ of all pregnancies of unmarried women is unintended (GSS, 2012; GSS -DHS, 2015). Pregnancy and childbirth complications are the leading cause of death in adolescence in Africa(UNICEF, 2012). Also, stillbirths and death in the first month of life are $50 \%$ higher among babies born to mothers younger than 20 years compared to babies born to mothers aged 20-29 years (UNICEF, 2012).

Unintended pregnancies and STIs can be prevented by use of contraception. However, in Ghana, among sexually active $15-19$-year-olds, $80 \%$ of females and $63 \%$ of males do not use any method of contraception(GSS-DHS, 2008). There is a reported decrease in condom use at last sexual intercourse; $24.4 \%$ of women and $40.3 \%$ of men used condom at last sexual intercourse in 2008 compared to $33.5 \%$ of women and $46.2 \%$ of men in 2003 (GSS-DHS, 2008).

A number of factors have been reported as determinants of adolescent sexual behaviours in Ghana, including transactional sex involving the exchange of money or gifts for economic reasons(Tenkorang \& Owusu, 2012), the social expectations with regard to sexual behaviours (girls needing to proof their fertility too early and boys needing to show their sexual prowess), lack of knowledge on sexuality and contraception, as well as lack of self-confidence to put knowledge into practice (Krugu, Mevissen, Debpuur \& Ruiter, 2015).

An effective sex education program addressing the determinants of adolescent's condom use behaviours can prevent both unplanned teen pregnancies and STIs (Kirby \& Laris, 2009). However, school based sex education remains a grey area in the curricula of many African countries, despite convincing evidence showing that schools present good settings for delivering sex education (Ajuwon, \& Brieger, 2007; Ogunfowokan \& Fajemilehin, 2012) . Systematic reviewers have also expressed concerns on the limited number of rigorously designed school-based evaluation studies of sexuality education in Africa, despite the enormity of the HIV epidemic as well as the high rates of teenage pregnancies on the 
continent (Gallant \& Maticka-Tyndale, 2004; Paul-Ebhohimhen, Poobalan \& vanTeijlingen, 2008) . In recent times, a few more promising evaluations have been reported (Udegbe, Fayehun, Isiugo-Abanihe, Nwagwu, Isiugo-Abanihe \& Nwokocha, 2015; van der Geugten, van Meijel, den Uyl \& de Vries, 2015). The present study adds to these efforts and presents the effects of a comprehensive sex education program known as Supporting Peers and Encouraging Empowerment through Knowledge (SPEEK) in northern Ghana. It is one of the few large-scale evaluation studies of a school-based comprehensive sex education program targeting junior high school students conducted in a West African rural setting.

The SPEEK Program

In 2012, the Youth Harvest Foundation Ghana (YHFG) and Maastricht University adapted the comprehensive sex education program, SPEEK, using Intervention Mapping (IM). IM is a comprehensive approach to the systematic planning and development of theory- and evidence-based health promotion interventions (Bartholomew Eldredge, Markham, Ruiter, Fernández, Kok \& Parcel, 2016). IM can also be used to adapt already existing programs to give them a stronger theory and evidence-based grounding (Leerlooijer, Ruiter, Reinders, Darwisyah, Kok \& Bartholomew, 2011; Schaafsma, Stoffelen, Kok \& Curfs, 2013). An extensive description on how the old version of the YHFG's sex education program was systematically adapted into a new theory and evidence-based SPEEK using IM is available through the first author. In this paper, the end product will be described.

The SPEEK program is a skills-based interactive sex education program aimed at Junior High School students aged 10 to 24 years. The program is aimed at empowering and supporting young people in making their own informed decisions about sex. The main program goals are that young people aged $10-24$ years living in ten communities in the Bolgatanga Municipality of Ghana: 1) Delay initiating sexual activities until they are ready for it; 2) Correctly and consistently use condoms, and other contraceptives to protect against STIs/unintended pregnancies, and 3) Undertake HIV/STI testing and counseling to know their status, and take measures if necessary.

The foundations of SPEEK was based on empirical literature and four psychological theories of individual behaviour change: the integrative model of behavioral prediction - the latest formulation of the theory of planned behavior, that is the reasoned action approach (Fishbein, 2008; Ajzen \& Fishbein, 2010), the health belief model (HBM) (Ronsenstod, 1974) and the AIDS Risk Reduction Model(Catania, Kegeles \& Coates, 1990) . The RAA/TPB describe how the intention to perform a given behaviour is influenced by attitudes (cognitive or affective), subjective norms (descriptive or injunctive), and perceived behavioural control (PBC) or self-efficacy (Bandura, 1977). These concepts, together with 
the HBM's and the AIDS Risk Reduction Model's concepts of perceived risk were used as basis for the development of the SPEEK program. For an overview of the program, including goals and content, see table 1.

The program was delivered on a lesson per week basis by youth peer educators aged 16-24 years. Peer educators received a week long intensive training before the start of implementation and a three-day refresher training mid-way into the implementation. The use of peer education was based on the rationale that peers have a strong influence on individual behavior and as members of the target group, peer educators are assumed to have a level of trust and comfort with their peers that allows for more open discussions of sensitive topics (Medley, Kennedy, O'Reilly \& Sweat, 2009). To evaluate the intervention's effectiveness, scores on targeted psychosocial determinants of adolescent sexual behaviours of students in schools receiving the program were compared with students in control schools (not receiving SPEEK). It was hypothesized that students in the intervention group will score significantly better than students in the comparison group on determinants of knowledge, attitudes, perceived social norms, self-efficacy, risk perception and intention regarding sexual delay, undertaking HIV/STI testing, and consistent use of condoms.

\section{Methods}

\section{Study design}

Participating schools were randomly assigned ${ }^{3}$ to one of two study conditions: 1) experimental schools receiving the SPEEK program $(\mathrm{N}=10)$ and 2$)$ waiting-list control schools, which were to receive the program after the evaluation was finished $(N=11)$. The same self-administered questionnaire was completed by all participants during all three time points at baseline (TO), post-test (T1), and six months follow up (T2). Approval for the study was obtained from the Ethical Review Committee Psychology and Neuroscience at Maastricht University and the Ghana Health Service ethical committee in Accra.

\section{Recruitment}

The participants were recruited in August 2012, a month before the introduction of the SPEEK program. The regional director of the Ghana Education Services wrote a letter to the schools supporting the implementation of the program. All 21 schools that received the letter agreed to participate in the intervention and evaluation. No special incentives were provided for participation in the evaluation study.

\footnotetext{
${ }^{3}$ Using simple random sampling technique (every object has the same probability of being chosen), all 21
} participating schools were assigned to the two study arms. 
After the agreement to participate, research assistants visited the schools, introduced the SPEEK program and explained the evaluation design to the teachers (i.e., mentioning that the evaluation would require participation of intervention schools and waiting-list control schools and would include a baseline measure, direct post measure, and a 6 month follow up). During these visits, the teachers were provided with parental informed consent forms to be given to students to take home for their parents' consent to participate in the evaluation. In addition, students received similar assent forms for their own consenting. The information on the forms (including information on ethical approval, the right not to participate, the voluntary nature of participation, the anonymity and confidentiality of handling data, and the duration of completing the questionnaires and follow up surveys being approximately 45 min.) was thoroughly discussed with the students, for their own understanding as well as for helping them explaining it to their parents. All students attending these schools (in total, about 2500 students in grades $1,2 \& 3$ were invited to obtain parental consent to join in the study. Of these, 2356 (94.24\%) obtained parental consent, out of whom 2324 students (98.64\%) additionally signed the assent forms to participate in the evaluation surveys. Reasons for no approval of the parents included avoiding additional burden of their children completing survey questionnaires and not being sure of the benefits of participation in the evaluation. Reasons for not willing to participate for the students were not being comfortable completing questionnaires in a manner perceived as similar to exams conditions.

At the point of data collection, among those who provided parental consent and child assent, 1934 of them (83.2\%) completed the baseline survey (TO). The rest $(\mathrm{N}=390)$ were not in class to complete the questionnaires. At post-test, 1805 (85.4\%) completed the questionnaires (T1) and 1959 (92.7\%) completed the six months follow up (T2). At T2, few students who were not part of the baseline $(N=25)$ took part in the survey and this made it difficult to link individual participants across all three time points. Participants with missing values in the demographic variables of age, gender, religion and sex experience, and those with missing values more than $20 \%$ in the outcome variables in each time measurement (all together, $\mathrm{N}=112$ ) were excluded from the analysis, leaving $1822(94.2 \%)$ of the baseline participants in the final analyses.

Participants

At baseline ( $\mathrm{N}=1822), 892$ boys (48.95\%) and 930 girls (51.04\%) between 10 and 21 years old $(M=15.84$ years; $S D=2.07)$ participated. The majority were Christian (75.2\%), followed by traditional worshippers, (13\%), Muslims, (9.9\%), and 0.9\% responding for other religions. For past sexual behaviours, 367 (20\%) indicated having been involved in 
sexual intercourse before. Also, 317 participants indicated either having experienced pregnancy before (girls) or having made someone pregnant before (boys).

Procedure

All questionnaires were completed in the classroom within approximately 45 minutes under the supervision of two research assistants who could guide the students in answering the survey if necessary. Confidentiality was secured by requesting the teacher to leave the class during survey completion and having the students seated at separate tables. In addition, students did not have to enter personal information such as name and age by which the survey could be linked to them personally. However, other background information including sex, class, birth month and number of siblings (dead or alive) were collected to link participants across time, but this did not work out fully. One week after finishing TO, students in the intervention group started receiving the 11 lessons of SPEEK on weekly bases, one lesson per week. In the same time period, the control group did not receive any regular sexuality education, except when teachers discussed the biology of the reproductive systems during science lessons. Three months after TO, and after all 11 lessons had been delivered in all intervention schools, both the intervention and the control schools received the T1 survey and T2 6 months after T1. The same procedure as was described above for TO was used for completing T1 and T2.

\section{The Intervention}

The SPEEK program included 11 lessons designed to influence the knowledge, attitude, self-efficacy/skills, risk perception and normative beliefs of the students related to their initiation of sexual activities, using condoms or conducting HIV/STIs test. Theory and evidence-based methods were selected to target these determinants. See Table 1 for an overview of the program. Each lesson took approximately one hour to be completed. Lesson one focused on bodily anatomy and the functions related to the various body parts. This was followed by lesson two that introduced the students to the biological processes resulting in menstruation in girls and wet dreams in boys. Lesson three then introduced students to the concept of entering into a relationship (both sexual and platonic), followed by the discussions on how certain sexual behaviours can result in pregnancy in lesson four.

Lesson five introduced students to STIs and provided the opportunity to explain safe sex in the context of preventing both STIs and pregnancy. In lesson six, the students discussed various context specific high risk situations that can lead to unplanned and unprotected sexual intercourse. Lesson seven tried to make the risk of getting pregnant or contracting an STI more personal to the students and it served as an introduction to the discussions on safer sex using condoms for protection in lessons eight and nine. Lesson ten took the 
discussion on contraception beyond condoms and exposed the students to the various methods of contraception options. Finally, in lesson eleven, the students learned of their sexual rights and responsibilities and the skills necessary to enjoy one's sexual rights. 


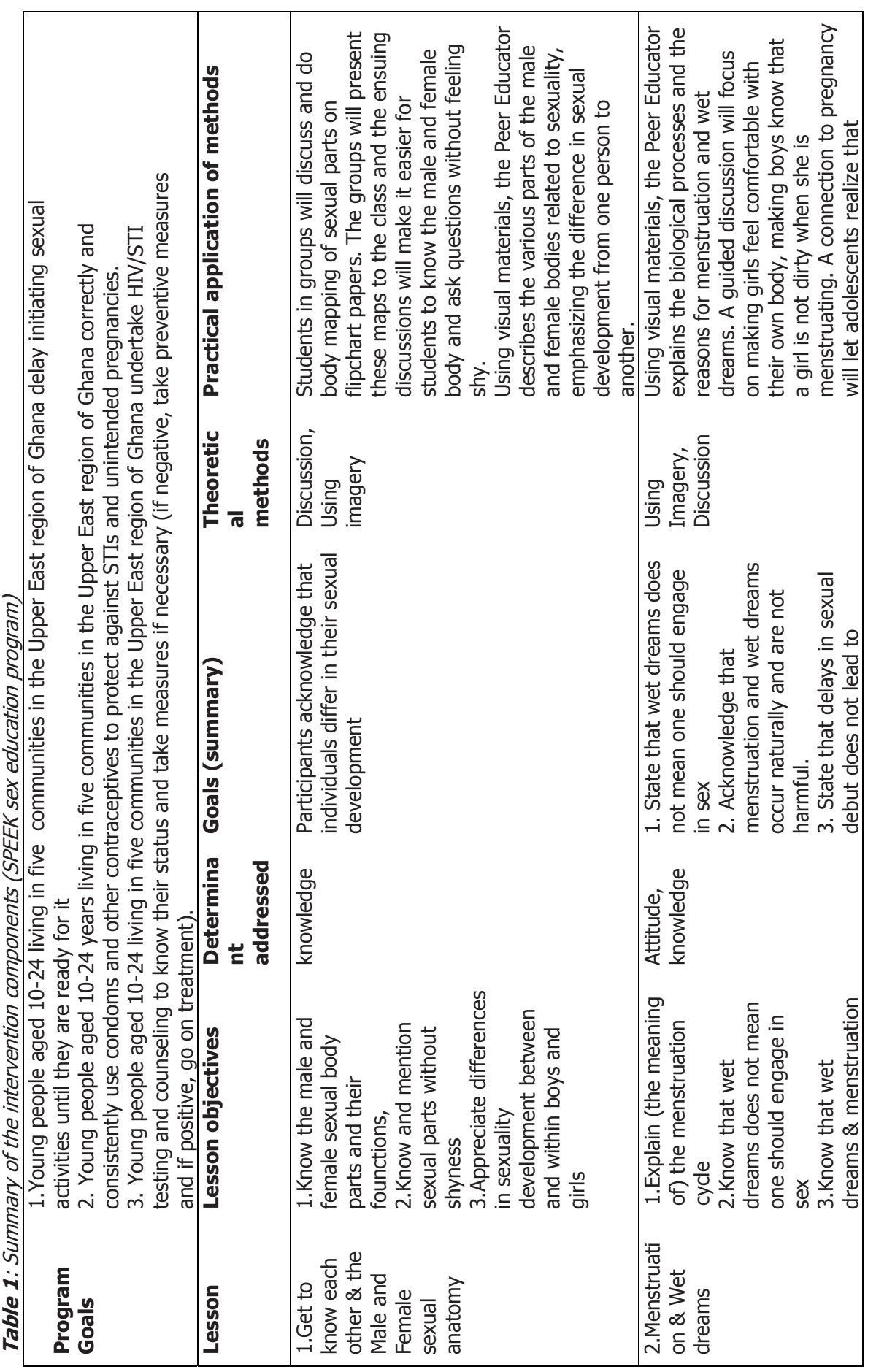




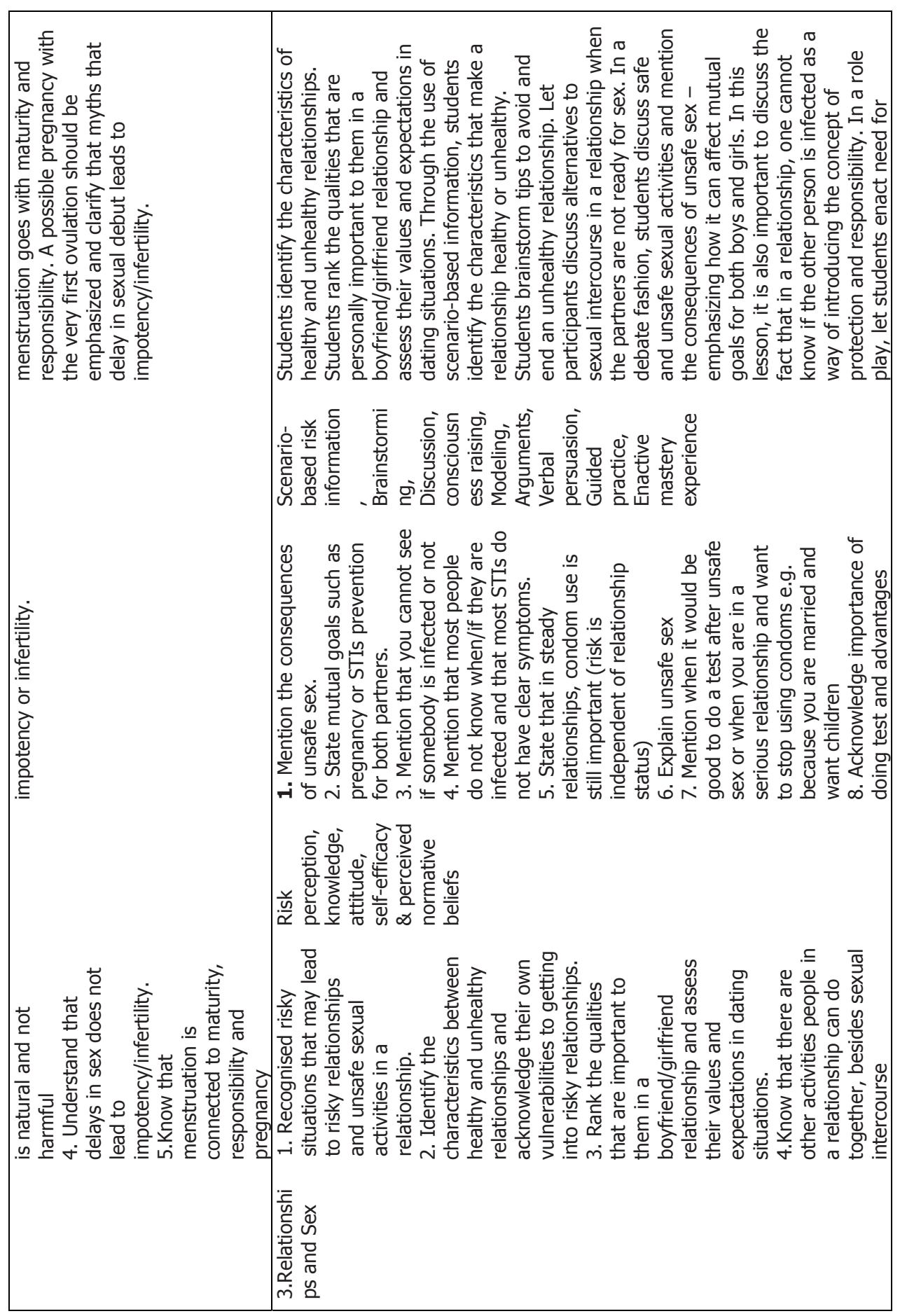




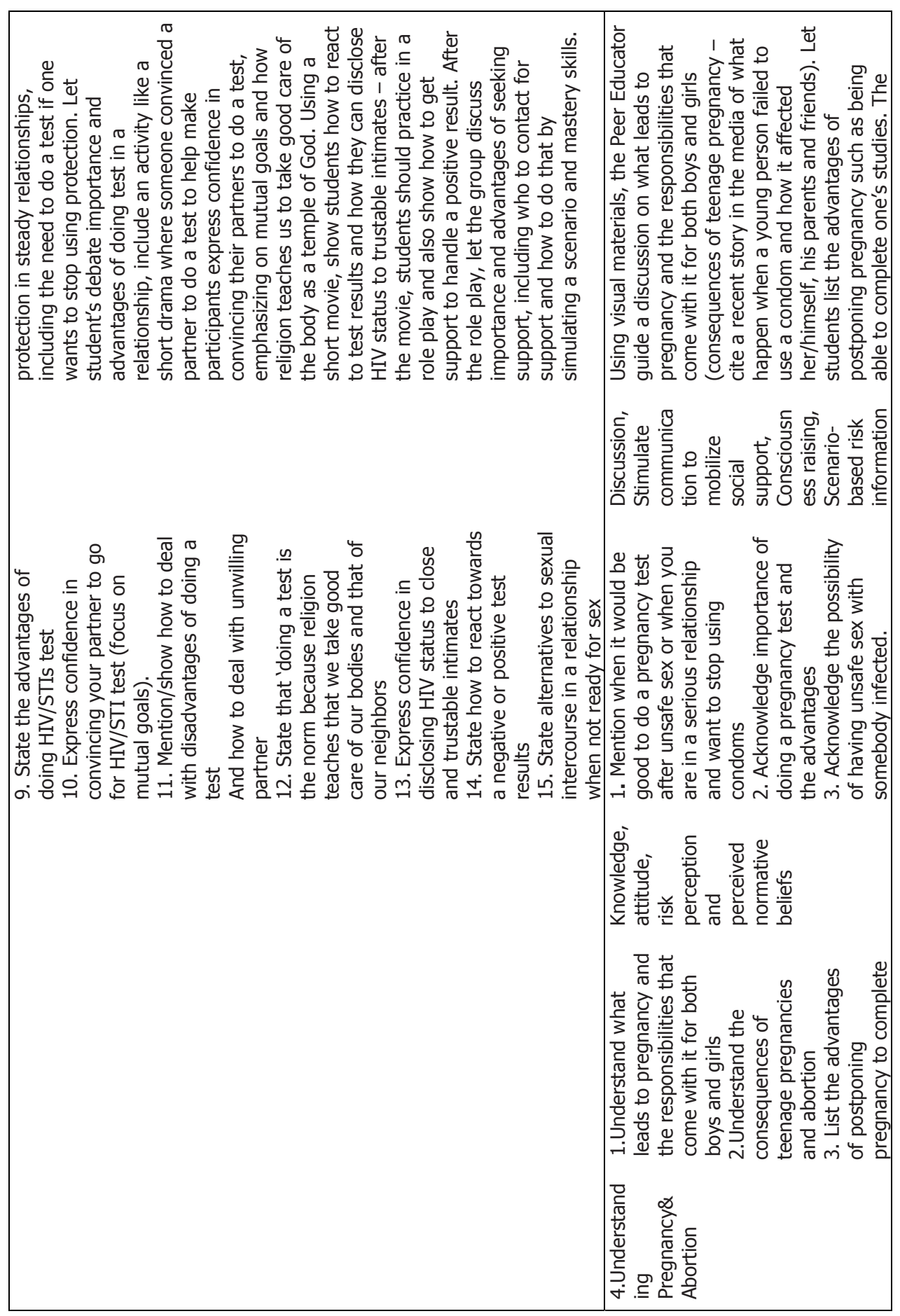




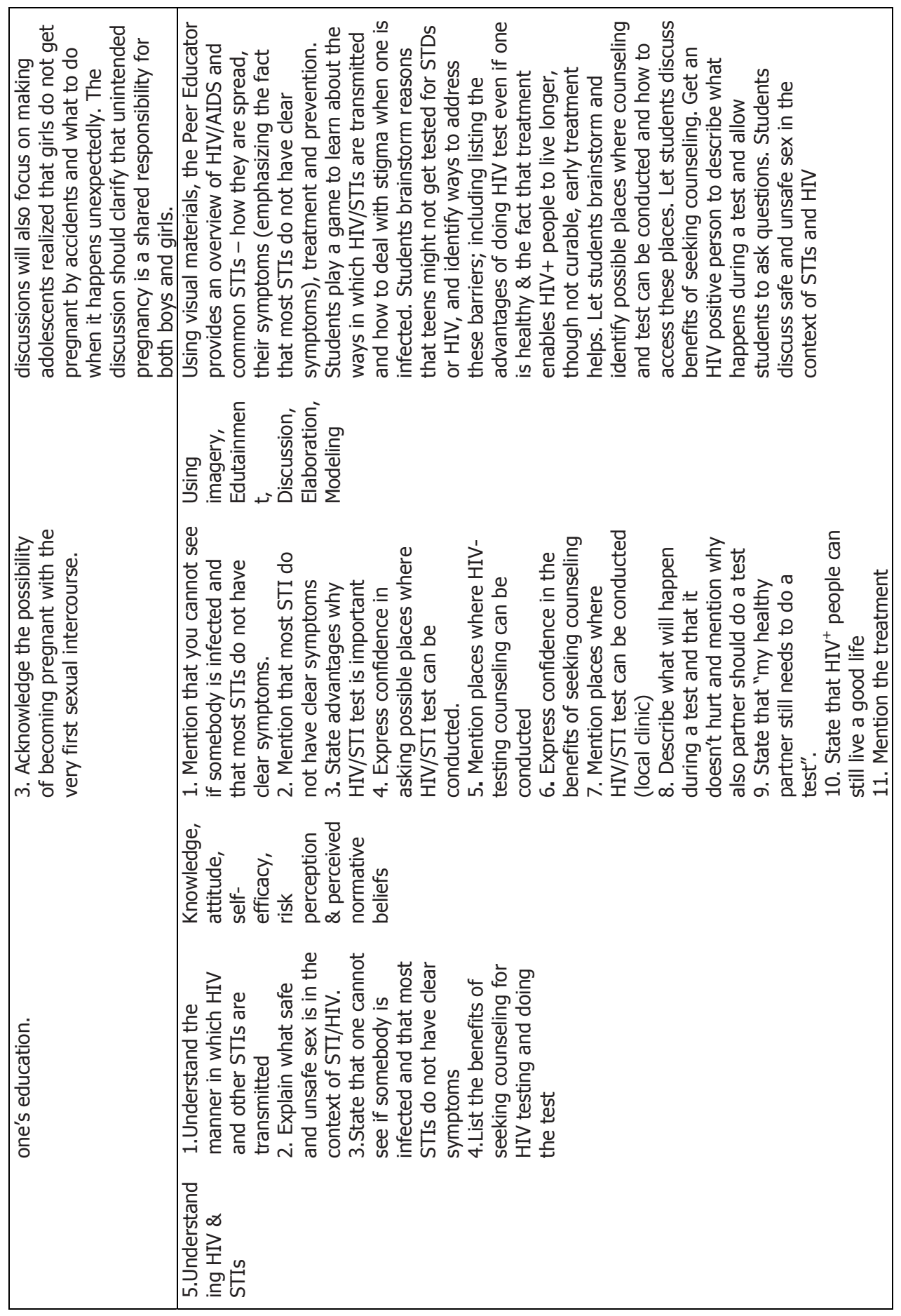




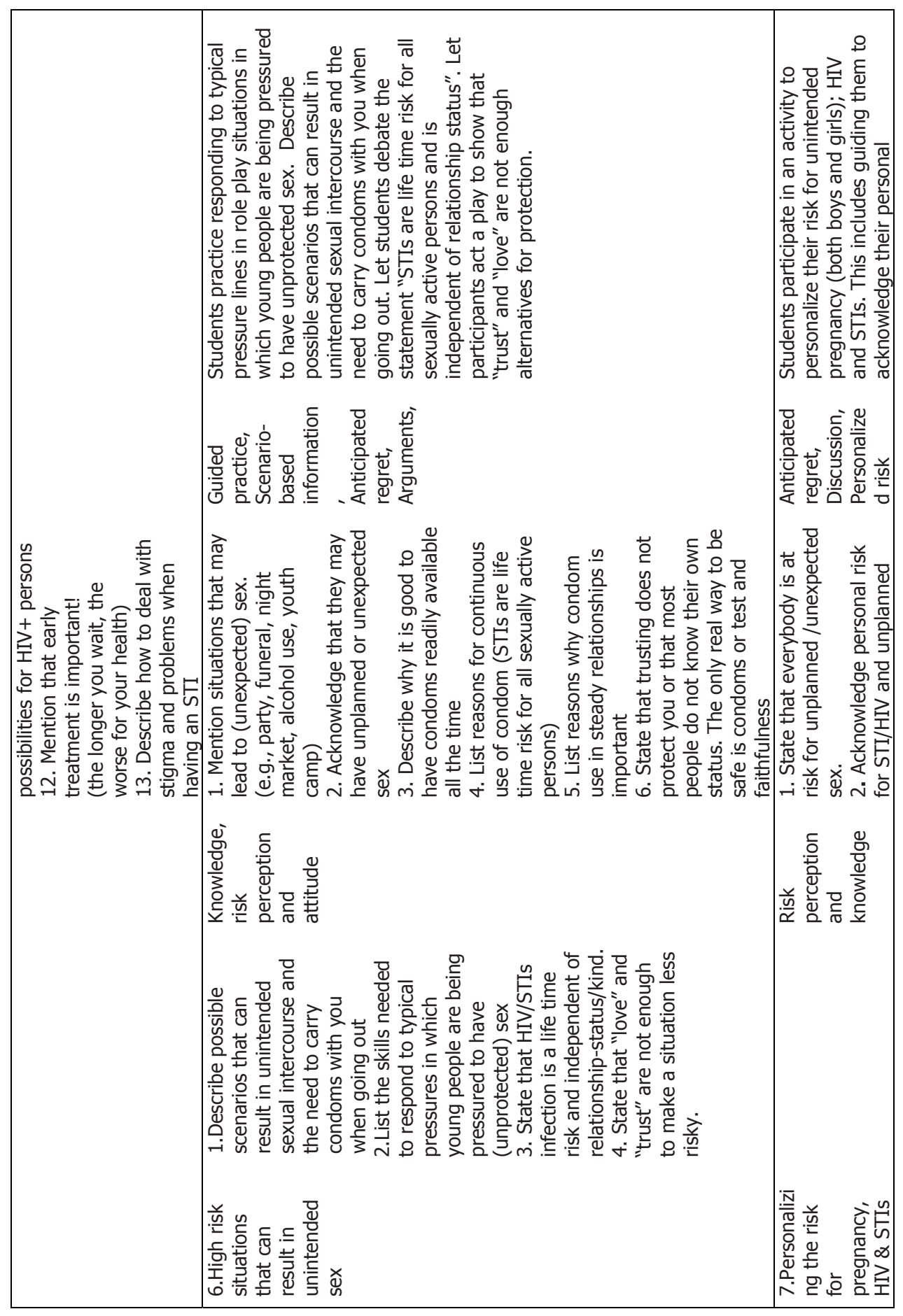




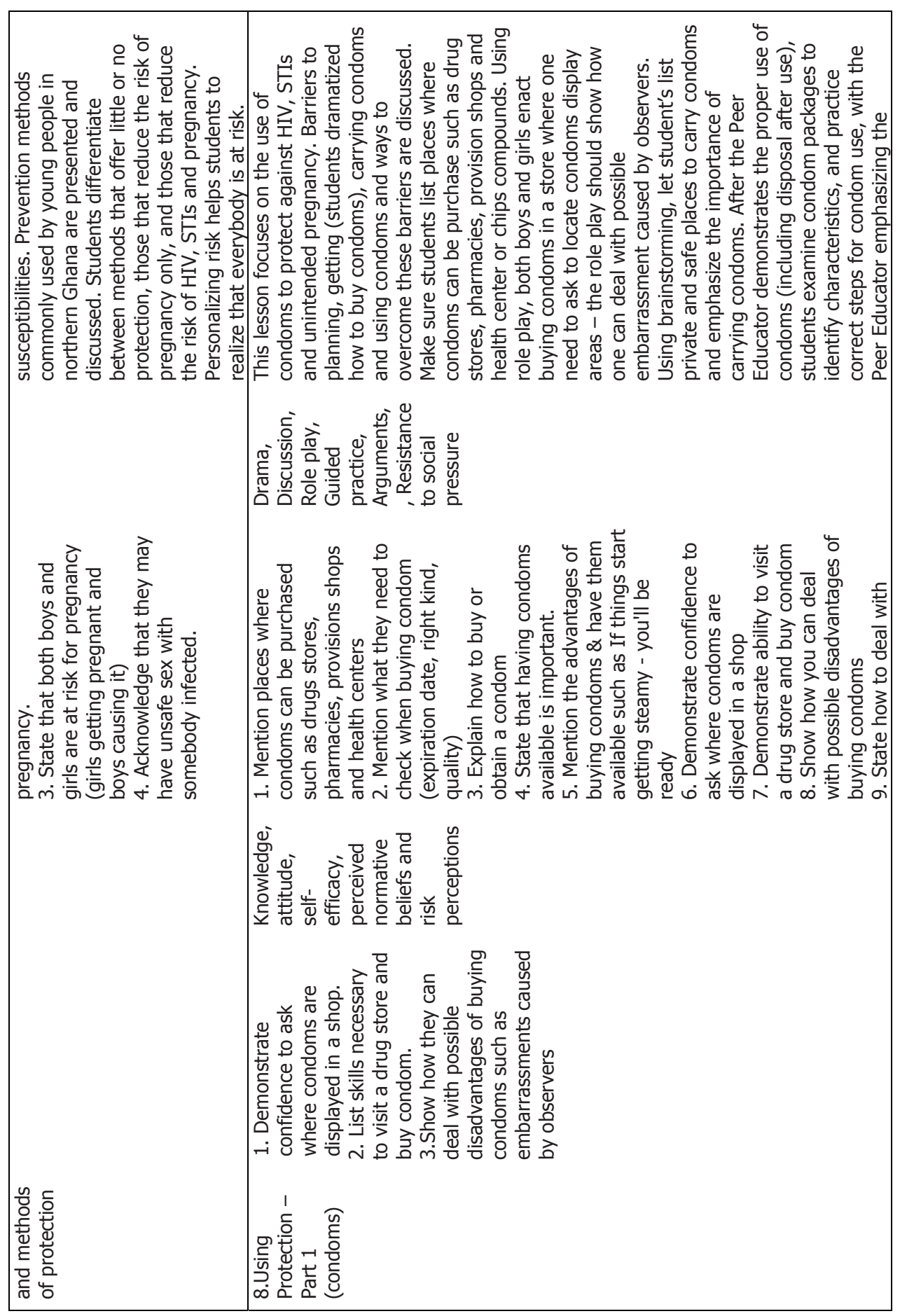




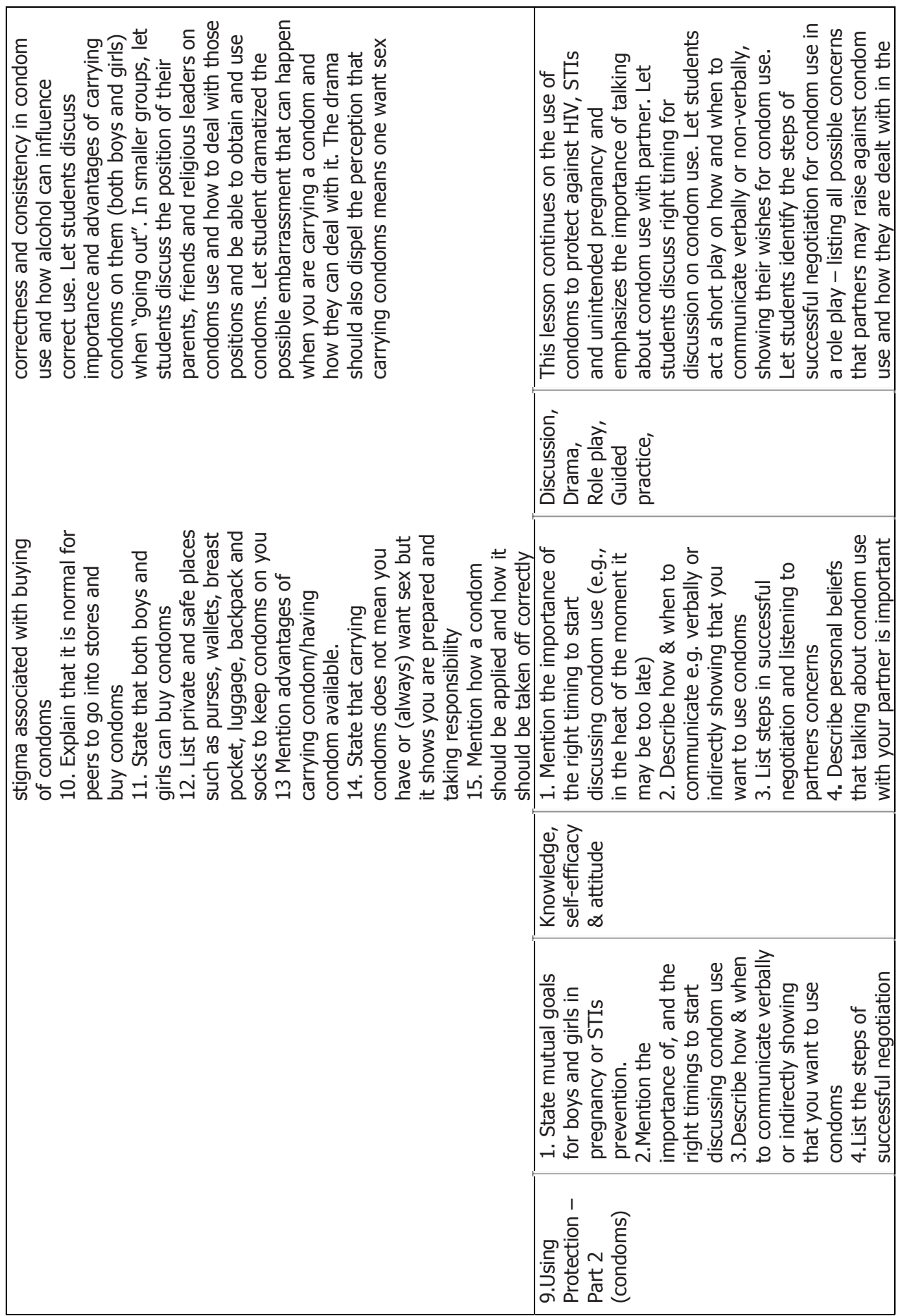




\begin{tabular}{|c|c|}
\hline 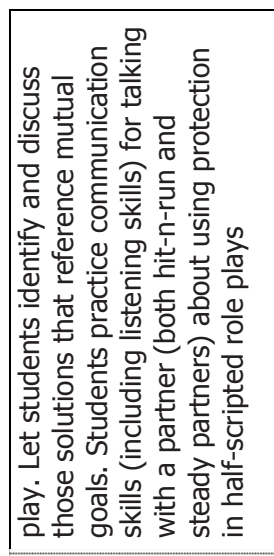 & 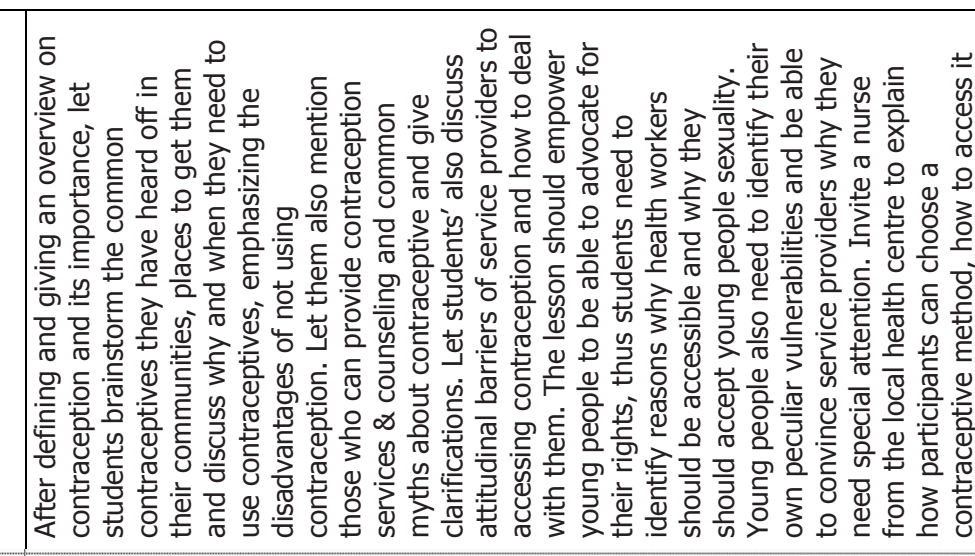 \\
\hline & 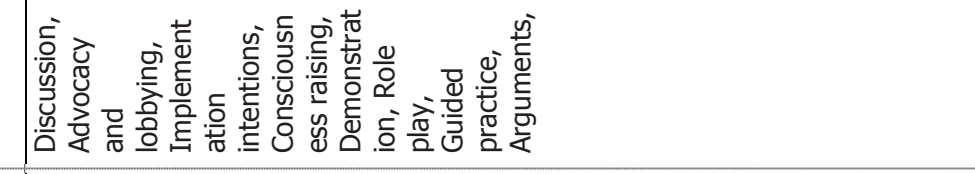 \\
\hline \multirow[t]{4}{*}{ 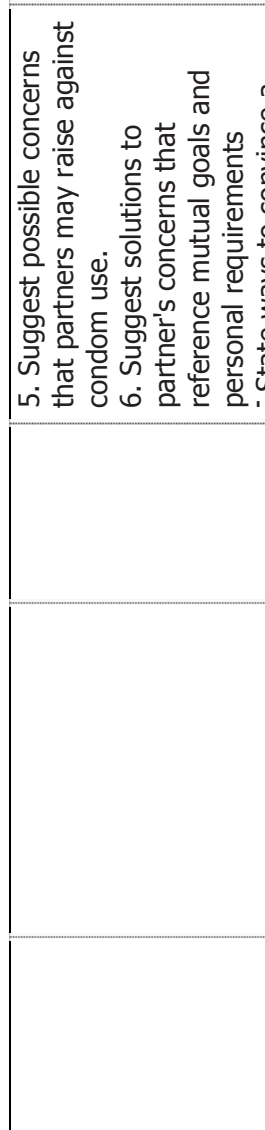 } & 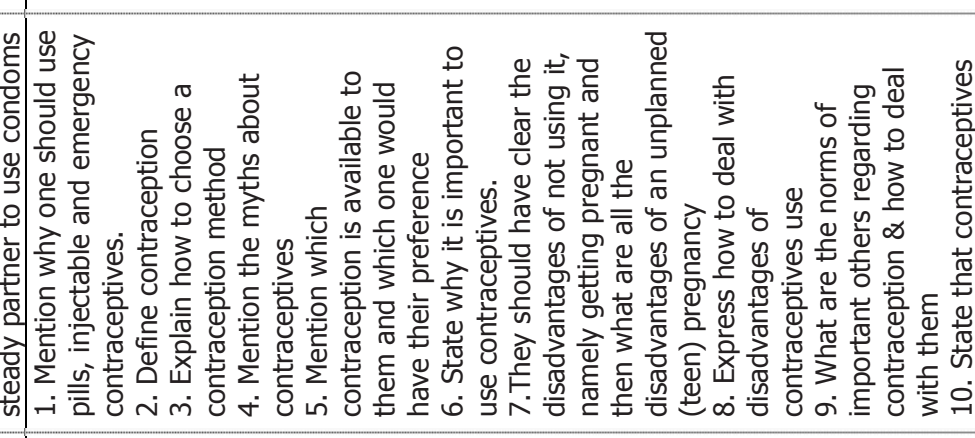 \\
\hline & 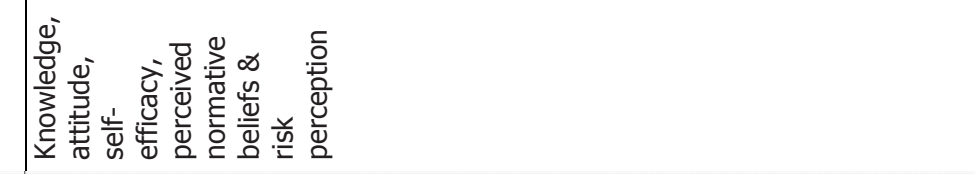 \\
\hline & 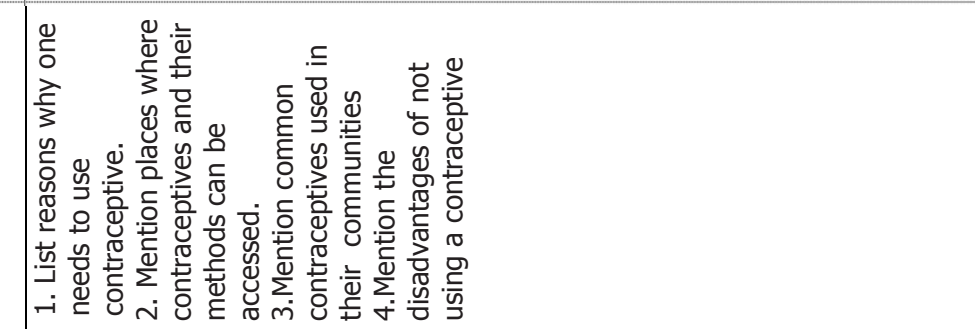 \\
\hline & 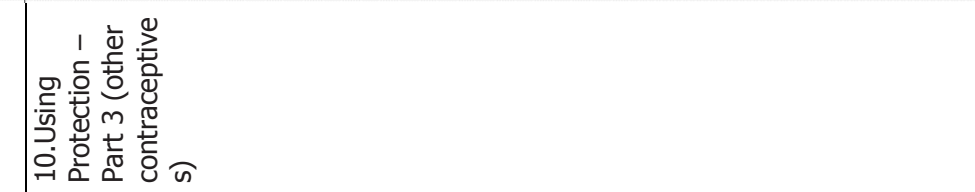 \\
\hline
\end{tabular}




\begin{tabular}{|c|c|}
\hline 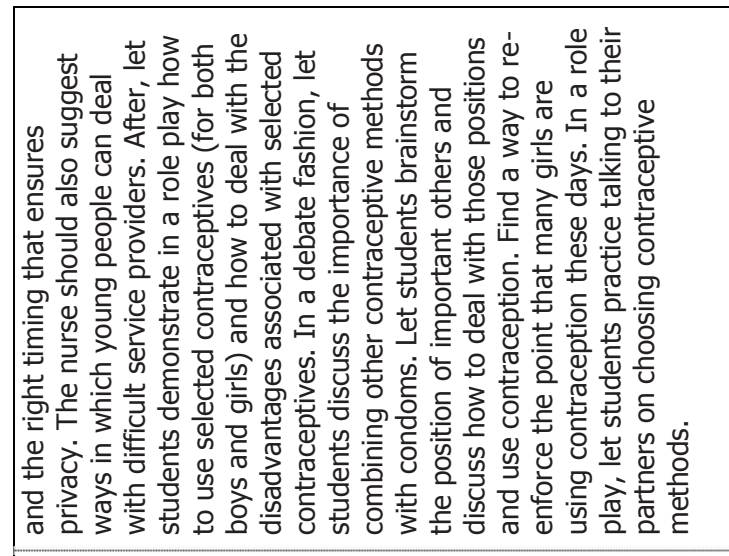 & 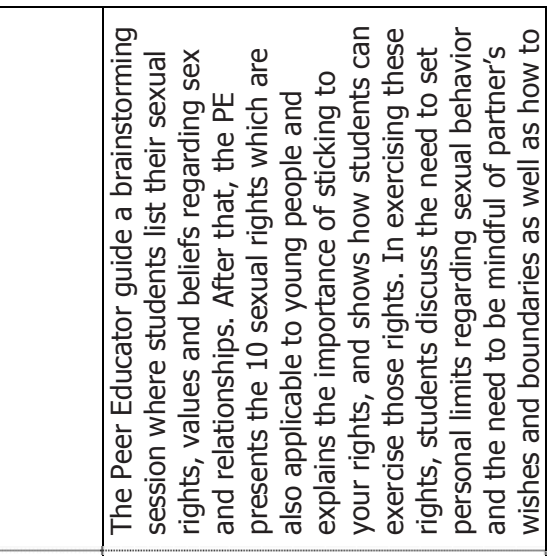 \\
\hline & 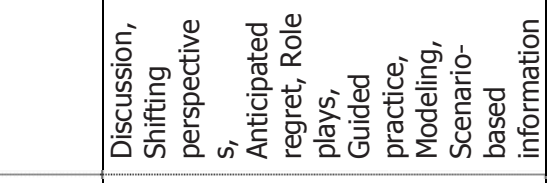 \\
\hline \multirow[t]{4}{*}{ 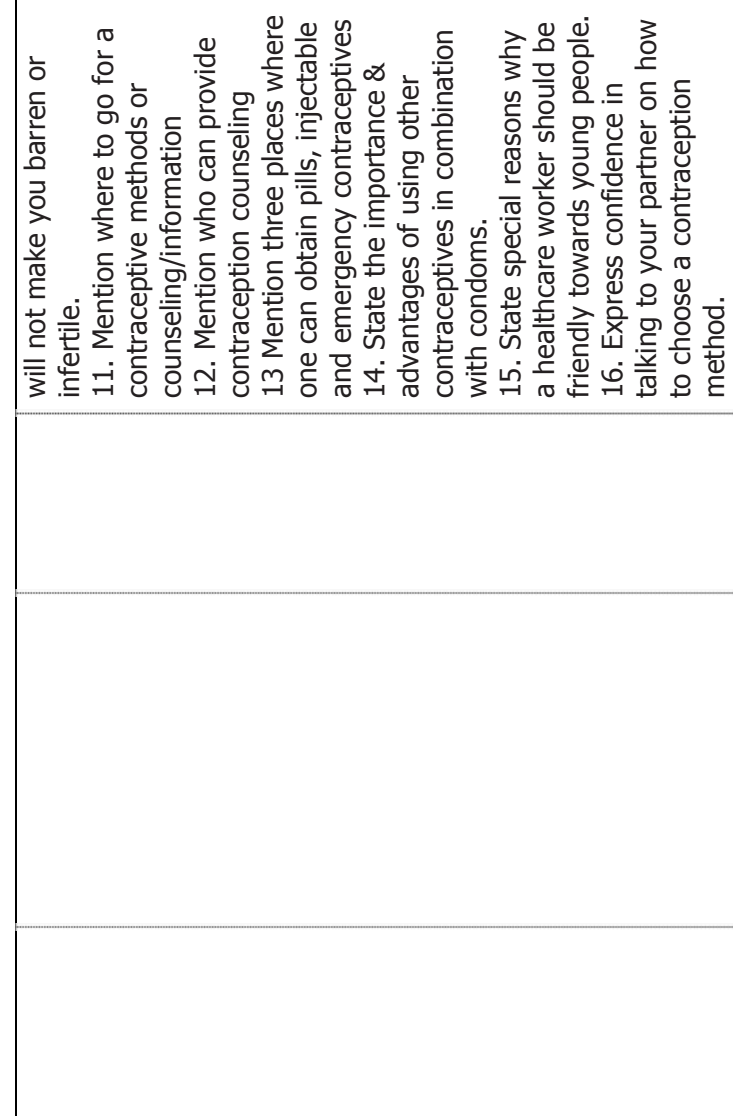 } & 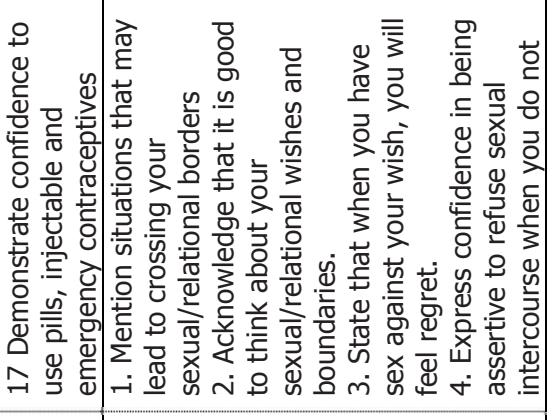 \\
\hline & 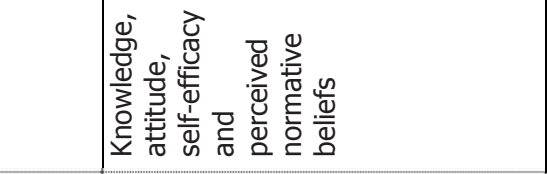 \\
\hline & 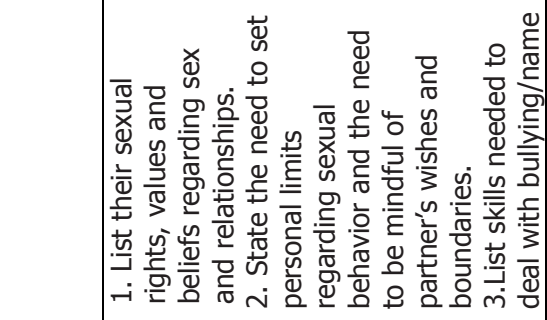 \\
\hline & \\
\hline
\end{tabular}




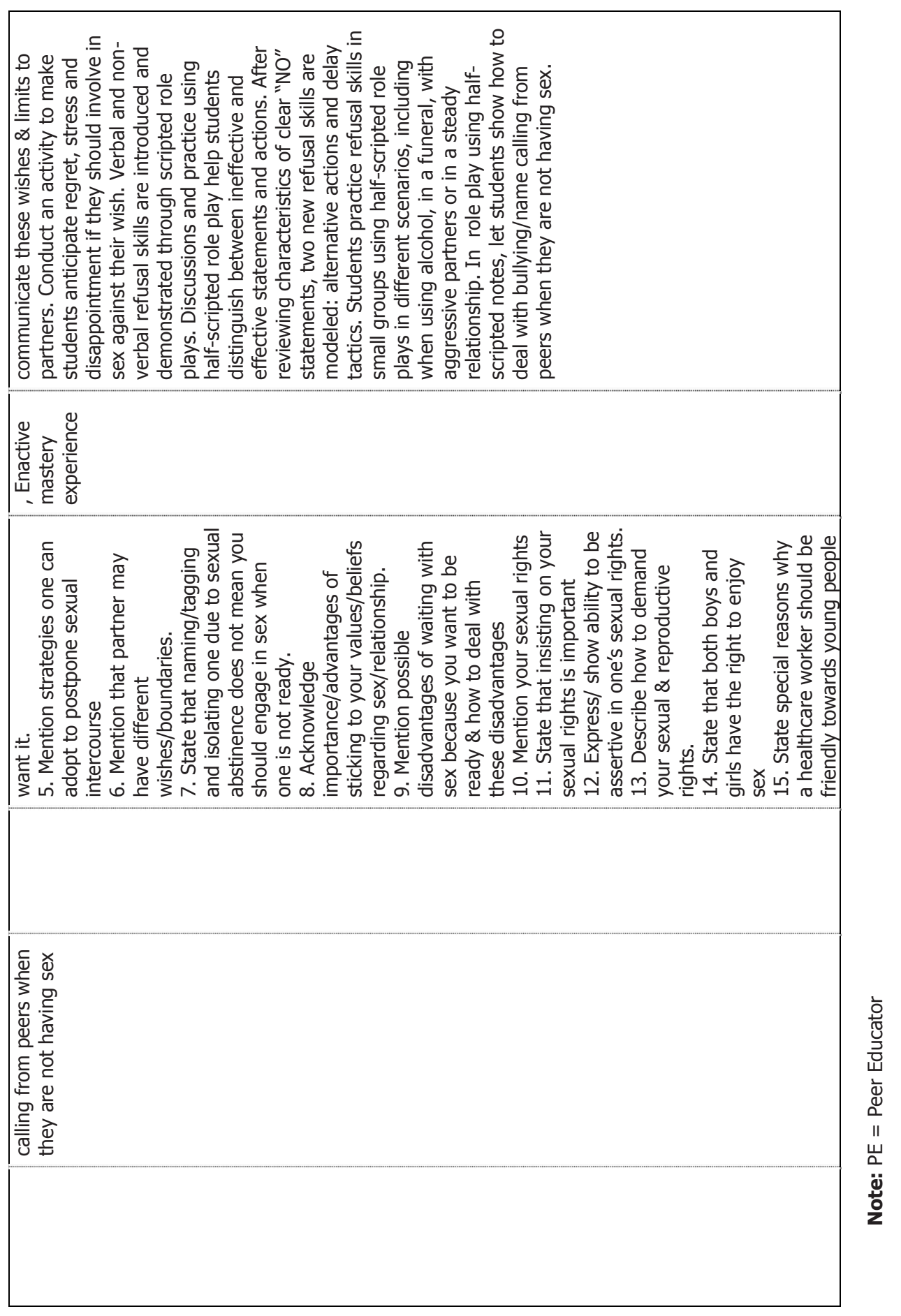




\section{Measures}

The measures were based on measures used in previous research in an African context (Rijsdijk, Bos, Lie, Ruiter, Leerlooijer \& Kok, 2012). The same psychosocial theories mentioned earlier in our introduction were also used to guide the development of the original survey which showed acceptable reliability scores of $r \geq .30$ for two-item scale or $a=.70$ for a scale with three or more items. The survey was pilot tested among a representative sample of Ghanaian adolescents from a school in Bolgatanga $(N=50)$. Following the pretest, minor corrections were made to the phrasing of the questions to enhance understanding by the students.

The survey included items on socio-demographic variables (age, gender, and religion), sexual experience (yes vs. no), condom use during last time sex (never vs. always) and pregnancy experience ( $0=$ No or I don't know, $1=$ once or more). For sexual behavioral measures, by mistake no time reference point had been included in the phrasing of the question (e.g. 'ever in your life', 'over the past two months'). Therefore, the behavioral measures, including condom use experience could not be included in the effect analyses.

In addition, 29 psychosocial determinants of condom use, STI testing and stating sexual boundaries were measured. Except knowledge that was measured with 3-point scales, the psychosocial measures used 5-point Likert scales. All items were recoded such that higher scores reflect a higher presence of the concerned variable. For each measure, scores on items that showed sufficient internal consistency (Cronbach's alpha $\geq .60$ for three or more items) or Pearson correlation coefficient ( $r>.30$ for two items) were averaged into one single construct for each participant if more than half of the items making up a construct were answered by that participant at that time point.

For the psychosocial variables, we used specific subscales of knowledge, perceived risk, attitudes, perceived behavioural control (PBC), perceived social norm and behavioural intention related to condom use, pregnancy prevention and stating sexual boundaries. The details of these measures, including example questions, number of items and their reliability test scores are presented in Table 2 (the full questionnaire is available from the first author upon request). 


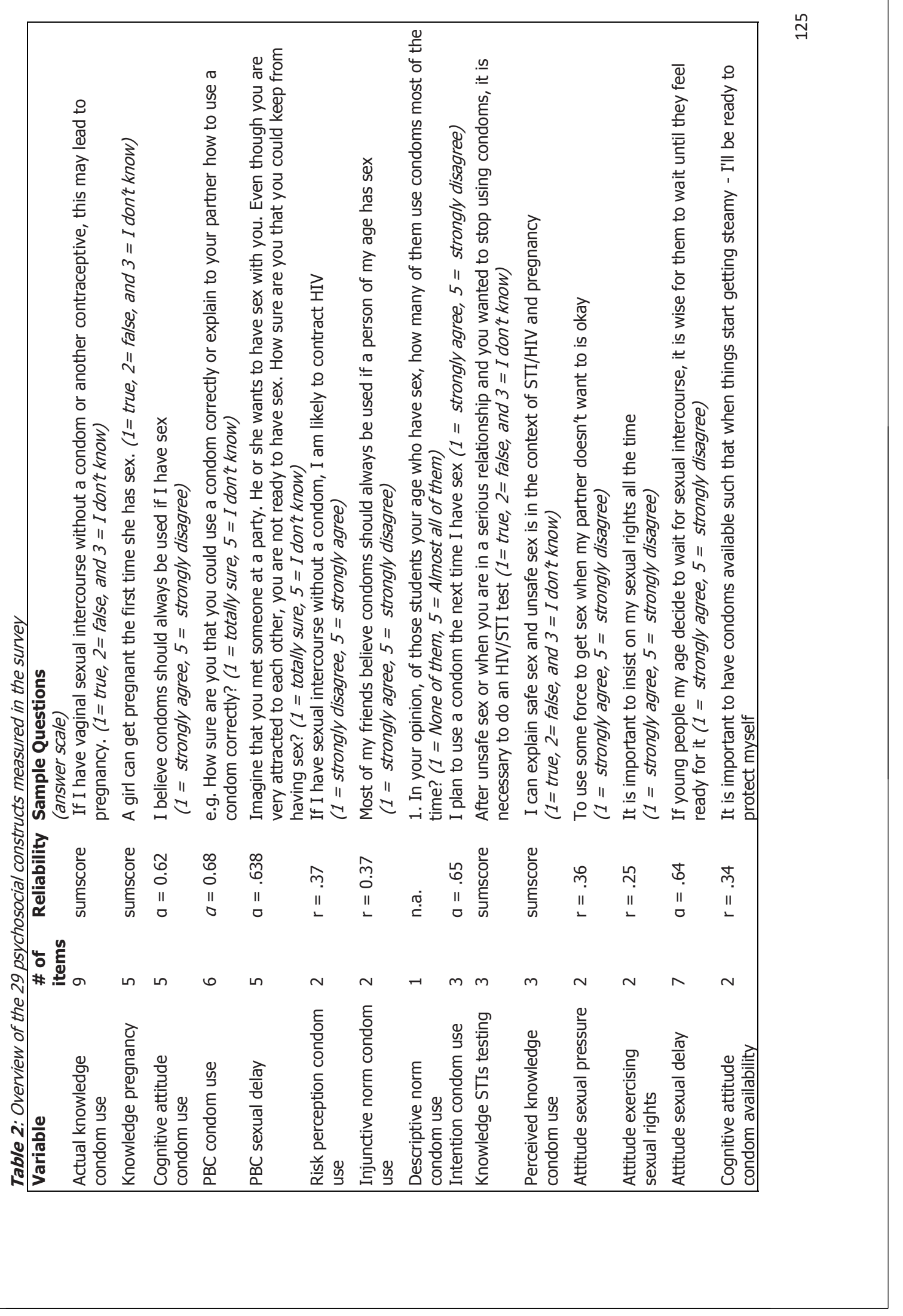




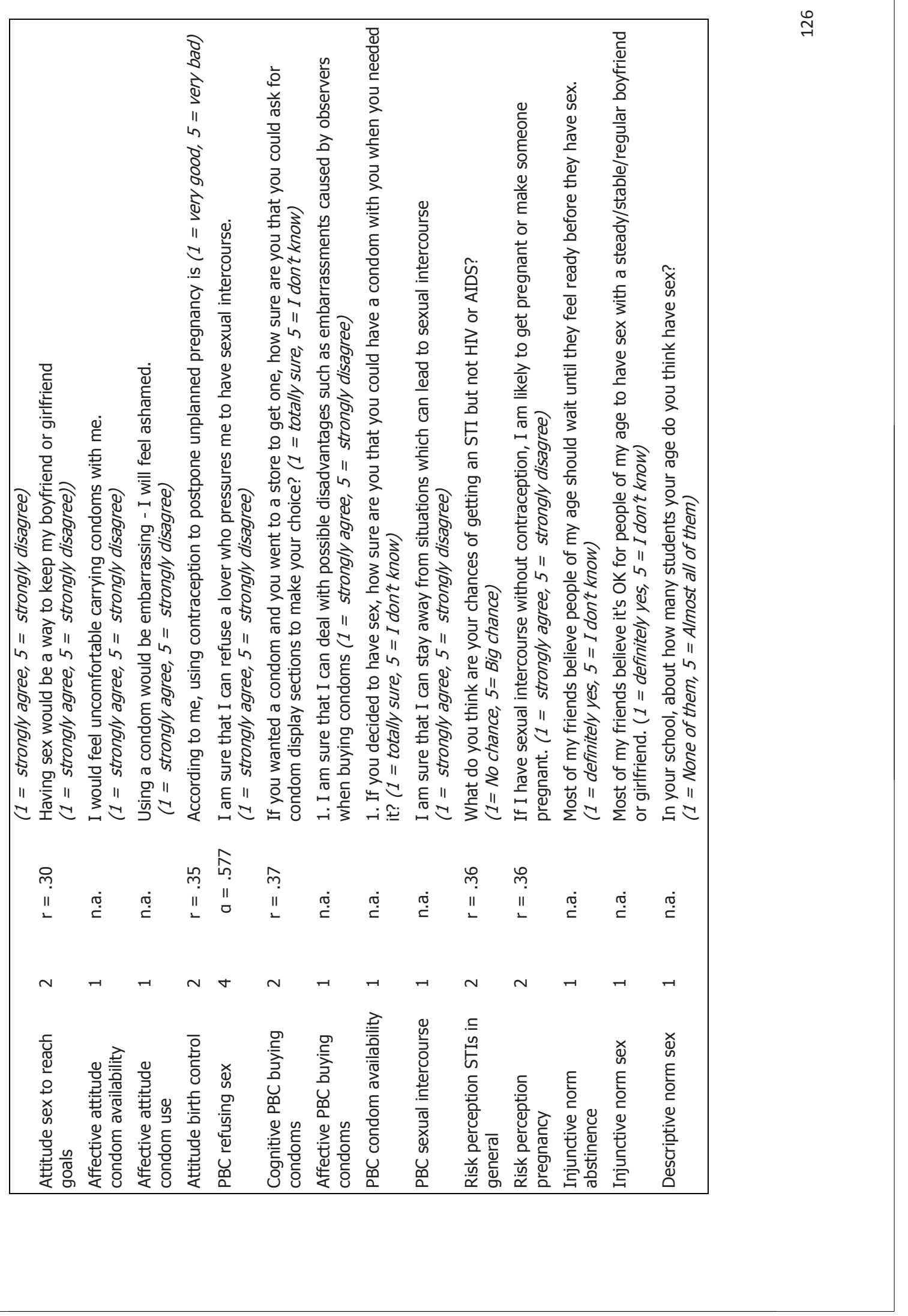




\section{Data analysis}

Data were analysed using IBM SPSS 21.0. To measure the effects of the SPEEK program on the psychosocial variables, mixed multilevel regression models were used to cater for the nested hierarchical structure of the design (repeated measurements over time points nested within students who are nested within schools), by allowing the intercept to vary randomly between schools, and assuming an unstructured covariance matrix for the three repeated measures, although not all participants could be matched across all three time points of measurement. The predictors were condition ( $0=$ control, $1=$ intervention) and time of measurement (with dummy-indicators for post-test (T1) and follow-up (T2), and baseline (TO) as reference category).

Because of the large number of outcome variables (29), a Bonferroni correction was applied. In doing this a distinction was made between primary outcome variables - variables that have a direct bearing on the goals of the SPEEK sex education program and thus received more attention during lessons- and secondary outcome variables - variables that received less attention because they are remotely related to the goals of the program. In the end, actual knowledge condom use, knowledge on pregnancy, cognitive attitude condom use, PBC condom use, PBC towards sexual delay, risk perception towards STIs in relation to condom use, injunctive norm condom use, descriptive norm condom use and intention towards condom use ( 9 variables) were considered as primary variables with effect being significant if $p<.01$. All other variables were considered secondary and Bonferroni correction was applied by dividing the a-level $(p=.05)$ by the total number of outcome measures (29) resulting in a $p$-value of $.05 / 29=.0017$ for the secondary variables. However, as the Bonferroni correction is an overcorrection, we rounded it off to .002 . Effect sizes were calculated using Cohen's $d=\beta / \sqrt{ }$ var2 for the $T 1 *$ condition interaction and $d=$ $\beta / \sqrt{ }$ var3 for the $T 2 *$ condition interaction ${ }^{4}$.

Age, gender, religion and sexual experience were included as covariates into the mixed model to gain power by reducing residual outcome variance, as well as to adjust for chance imbalance between treatment and control with respect to these variables (which can occur in spite of randomization due to the small number of randomized schools). The inclusion of the covariates did not change the conclusion from the basic interaction model that only included the Time $x$ Condition interactions. We did not correct for class level because in the

${ }^{4} \beta=$ estimated effect size, var $2=$ estimated group $\mathrm{x}$ time interaction effect at $\mathrm{T} 1$ and $\mathrm{Var} 3=$ estimated group $\mathrm{x}$ time interaction effect at $\mathrm{T} 2$ 
participating schools, classes correspond with age groups and not different levels. To report the result, the model was re-run using ML instead of REML.

\section{Results}

Table 3 shows the mean scores on the 29 dependent variables at baseline (TO), post-test (T1) and at six month follow-up (T2) for both intervention and control group.

Table 4 also shows the significance ( $p$-values) and effect sizes (Cohen's $d$ ) of the condition $\mathrm{x}$ time interaction effects. 


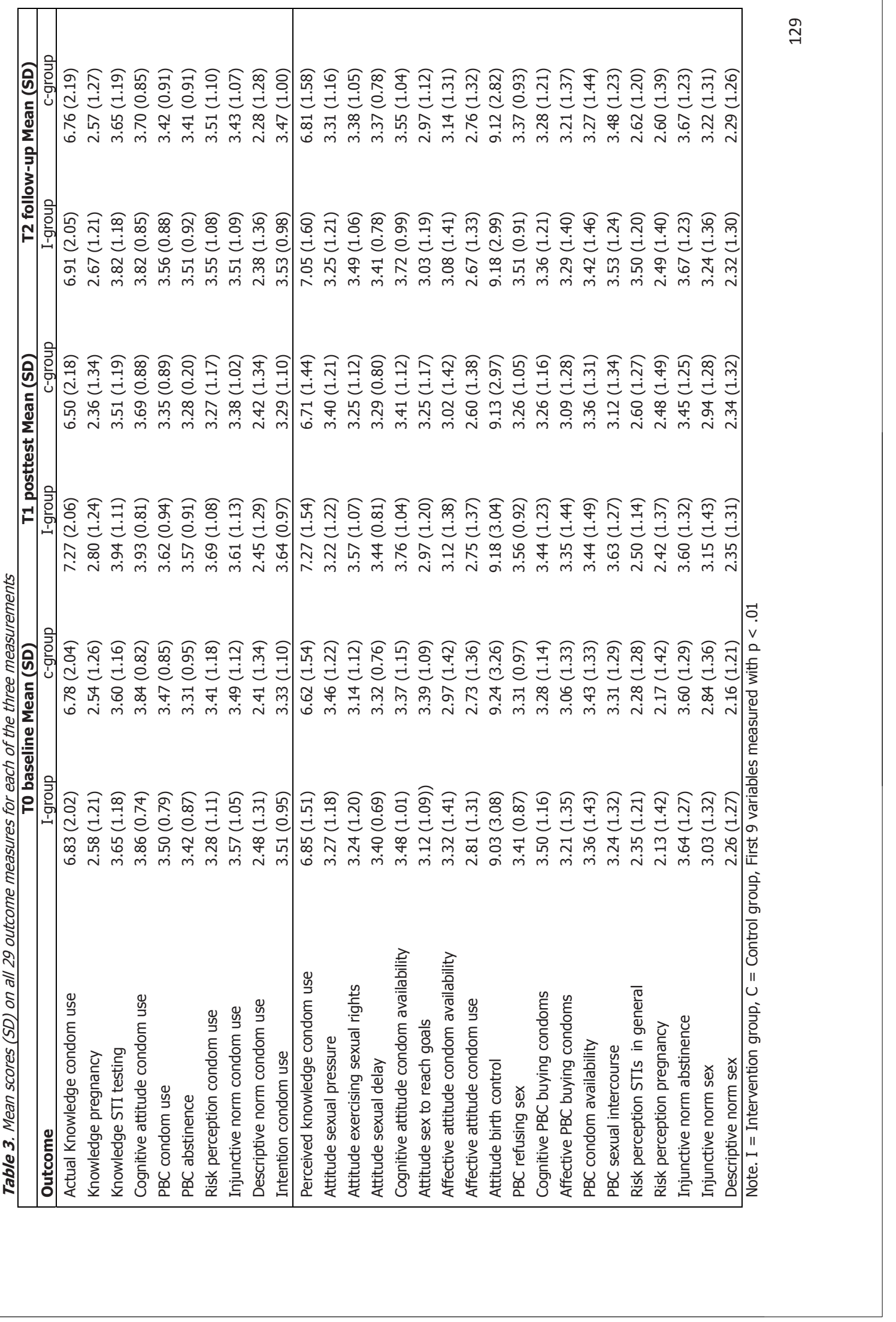


Table 4: significance ( $p$-values) and effect sizes (Cohen's d) of the condition $x$ time interactions

\begin{tabular}{|c|c|c|c|c|}
\hline \multirow[t]{2}{*}{ Outcome } & \multicolumn{2}{|c|}{ Condition*T1 } & \multicolumn{2}{|c|}{ Condition*T2 } \\
\hline & $p$ & $d$ & $p$ & $d$ \\
\hline Actual Knowledge condom use & .00 & .30 & .08 & .12 \\
\hline Knowledge pregnancy & .00 & .24 & .15 & .09 \\
\hline Cognitive attitude condom use & .00 & .25 & .01 & .12 \\
\hline PBC condom use & .00 & .28 & .01 & .15 \\
\hline PBC sexual delay & .00 & .20 & 61 & .03 \\
\hline Risk perception condom use & .00 & .48 & .01 & .16 \\
\hline Injunctive norm condom use & .03 & .17 & .74 & .02 \\
\hline Descriptive norm condom use & .84 & .04 & .71 & .09 \\
\hline Intention condom use & .02 & .20 & .23 & .02 \\
\hline Knowledge STI testing & .00 & .29 & .05 & .10 \\
\hline Perceived knowledge condom use & .00 & .20 & .60 & .04 \\
\hline Attitude sexual pressure & .86 & .01 & .08 & .06 \\
\hline Attitude exercising sexual rights & .00 & .19 & .52 & .06 \\
\hline Attitude sexual delay & .18 & .09 & .70 & .00 \\
\hline Cognitive attitude condom availability & .00 & .24 & .21 & .10 \\
\hline Attitude sex to reach goals & 67 & .02 & .00 & .20 \\
\hline Affective attitude condom availability & .02 & .16 & .00 & .26 \\
\hline Affective attitude condom use & .35 & .11 & .05 & .08 \\
\hline Attitude birth control & .22 & .07 & .15 & .08 \\
\hline PBC refusing sex & .00 & .17 & .25 & .05 \\
\hline Cognitive $\mathrm{PBC}$ buying condoms & .69 & .00 & .16 & .13 \\
\hline Affective PBC buying condoms & .27 & .11 & .57 & .09 \\
\hline PBC condom availability & .10 & .10 & .01 & .14 \\
\hline PBC sexual intercourse & .00 & .42 & .06 & .13 \\
\hline Risk perception STIs in general & .05 & .11 & .01 & .16 \\
\hline Risk perception pregnancy & .86 & .03 & .26 & .04 \\
\hline Injunctive norm abstinence & .17 & .12 & .87 & .02 \\
\hline Injunctive norm sex & .61 & .03 & .08 & .10 \\
\hline Descriptive norm sex & .29 & .08 & .31 & .00 \\
\hline
\end{tabular}

First 9 variables measured with $\mathrm{p}<.01$ 
The results show that at post-test, the experimental group scored significantly higher than the control group on the psychosocial variables of actual knowledge on condom use, actual knowledge on pregnancy, actual knowledge on STIs testing, perceived knowledge on condom use, attitude towards exercising sexual rights, cognitive attitude towards condom use, cognitive attitude towards condom availability, PBC towards sexual delay, PBC towards condom use, PBC towards sexual intercourse and perceived risk towards STIs in relation to condom use. However, the experimental and control groups did not differ significantly in attitude towards sexual pressure, attitude towards sexual delay, attitude towards sex to reach goals, affective attitude towards condom availability, affective attitude towards condom use, attitude towards birth control, cognitive PBC towards buying condoms, affective PBC towards buying condoms, PBC towards condom availability, intention towards condom use, perceived risk towards STIs in general, perceived risk towards pregnancy, and all the normative beliefs subscales, with p's $\leq .002$ (see table 3).

For the long-term impact survey at six month follow up, the analysis did not find any significant treatment effect for the determinants measured in the study except attitude towards sex to reach goals $(p=.000)$ and affective attitude towards condoms availability $(p=.000)$, both of which were not significant at post-test (see table 3 ).

\section{Discussion}

This study is one of few studies reporting on a large scale effect evaluation of a school-based sex education program targeting high school students in rural West Africa. A Ghanaian school-based and peer-led sex education program was evaluated in a randomized controlled trial. Although the long-term results showed limited effects, short term effects as measured directly after program delivery is encouraging: the students who received the SPEEK program were significantly better able to explain how to use a condom in addition to a strong perceived knowledge on condom use, better able to explain how pregnancy occurs and how to conduct an STI test compared with the comparison group. At post-test, the students in the intervention arm were also more positive towards exercising their sexual rights and considered it more important to carry condoms with them when going out for social activities compared with students in the control group. In addition, the students in the intervention group had a higher perception of being able to decide when and with whom to have sexual intercourse, being able to delay sexual intercourse until they are ready for it and were more confident of their ability to use condoms in the future compared with the comparison group. The short-term impact results also showed that the students who 
received the SPEEK program perceived themselves to be more at risk of contracting STIs if they have sex without using condoms compared with the control group.

The important role of school-based comprehensive sex education programs such as SPEEK in changing psychosocial determinants and promoting safe sex behaviour in developing country context has been demonstrated in different studies and reviews (Gallant \& Maticka-Tyndale, 2004; Kirby, 2007; Paul-Ebhohimhen et al., 2008). The evaluation of SPEEK confirms these findings and indicates that peer education interventions that employ more evidence based and more active learning methods can produce desired results, contrary to the conclusion by Chandra-Mouli, et al. (2015) that peer education do not work. However, implementing peer-led interventions at the national level will have cost implications, and their cost-effectiveness should be considered against teacher-led interventions. Teacher-delivered interventions formally incorporated into the school curriculum, with time allocated for it and motivation of both teachers and students secured has been shown to be effective (Kirby, Obasi \& Laris, 2006).

Also, our results support evidence that teaching about contraception in schools is not associated with increased risk of adolescent sexual activity (Kohler, Manhart \& Lafferty, 2008). But rather, adolescents who receive comprehensive sex education have lower risk of pregnancy than those who receive abstinence-only or no sex education (Eisenberg, Bernat, Bearinger \& Resnick, 2008). In the Ghana context where public opinion is erroneously against sex education in schools for fear of promoting sexual promiscuity (Stephenson, 2007), the results of this study can make a significant contribution to advocacy for the inclusion of sex education in the school curriculum.

The significant increase in the knowledge of the students agree with the results of previous studies of secondary school students in Africa that knowledge can change after any educational intervention (Gallant \& Maticka-Tyndale, 2004). Although knowledge alone is proven not to be sufficient in itself to produce behaviour change (McCluskey \& Lovarini, 2005), the improvement in the students' knowledge after three months is desirable because acquiring the requisite knowledge is often the first stage in the process of behaviour change (Glanz, Rimer, \& Viswanath, 2008 p-77).

Changing attitude is often considered a difficult behavioural task (Petty, Brino \& DeMarree, 2007). But within three months of implementing the SPEEK program, there was a significant change in the attitude of the students towards exercising their sexual rights and towards having condoms available with them to be prepared when the need to use arises. School-based sex education interventions have been reported to have additional benefits of promoting reporting of sexual violence, sexual coercion and stigma (Chin, Sipe, Elder, 
Mercer, Chattopadhyay, Jacob et al., 2012; Rijsdijk et al., 2012). However, such outcomes cannot be achieved unless adolescents have the right attitude towards exercising their sexual rights (Glasier, Gülmezoglu, Schmid, Moreno, \& Van Look, 2006). It is therefore encouraging to see that attitude towards exercising sexual rights increased positively by $33 \%$ in three months among the intervention group as compared with only $11 \%$ among the control group (see table 2).

After receiving the SPEEK program, students of the intervention group had a significant increase in their perceived ability to delay sexual activities, felt more in control of their behaviour related to sexual intercourse, and also felt more in control of condom use decision-making. Self-efficacy beliefs or a perception of behavioural control has been shown to strongly predict condom use intentions, also among Ghanaian adolescents (Krugu, Mevissen, Debpuur, \& Ruiter, 2016). Therefore, the positive effects of the SPEEK program on these determinants within the Ghana context are important.

In line with previous studies, all observed effects of the SPEEK program on the intervention group at immediate post-test disappeared at the six months follow up. In two systematic reviews (Medley, Kennedy, O'Reiily \& Sweat, 2009; WHO, 2006), positive outcomes on actual condom use and reported increase in practice of abstinence were not present in follow up tests. The lack of long-term impact could indicate that repeated doses of intervention components may be needed to sustain effects. Skill-based and lengthier interventions, offering the opportunity for repeated exposure is associated with sustained effectiveness (Gallant \& Maticka-Tyndale, 2004). However, the socio-cultural context of sexuality in Ghana - religious leaders constantly preaching against sexual activities outside marriage and too closed parental monitoring of adolescents' sexual activities impacting negatively on their sexual behaviours (Osafo, Asampong, Langmagne, \& Ahiedeke, 2013 might have also contributed to the lack of sustained positive effects of the SPEEK intervention. For the determinants of condom use in particular, factors such as its availability to students in the rural communities of northern Ghana may also have influenced the findings: it might have been difficult for students to obtain condoms after the intervention phase had elapsed since condoms were only more accessible through peer educators during the implementation period.

Our results also show that the SPEEK program could not change the behavioural intentions of the students to use condoms $(\mathrm{d}=.20, \mathrm{P}>.01)$. Evidence indicates that changing intentions regarding safe sex, especially intention to use condoms, is more difficult (Fishbein \& Yzer, 2003). Thus, our findings support the view that actual condom use may require more than knowledge and positive attitudes towards condom use, especially in West 
Africa where the traditional and cultural beliefs limits sexual activities to marriage context (Amuyunzu-nyamongo, Biddlecom, Ouedraogo, \& Woog, 2005). To change behavioural intention towards condom use, the need to include skills-based activities as part of the program components and also target the wider community or school environmental factors has been emphasised (Kirby, 2006; Bartholomew Eldredge, et al. 2016, pp. 243) .

The absence of significant effects in close to half of the psychosocial variables (see table 2) could be due to different reasons. Bartholomew et al. (2016) suggested that an evaluation may fail to prove effectiveness if the intervention includes many variables that were not equally addressed by the program or if needs assessment of the target population was not properly done or if the program was not implemented strictly as was designed. Although the design and implementation of the SPEEK program as guided by the IM approach (Bartholomew Eldredge, et al., 2016), was rigorous, the lack of positive effects in some measures require further research.

Limitations of the study

First, the scales recorded relatively low alphas and some measures used single items, which leaves room for further improvement on reducing error variance due to better measurement. Second, the time period between the three measures at baseline, immediate post-test and follow-up test was relatively short, which limits the possibility of detecting behavioural changes. Therefore we only measured changes at the determinants level, but including measures of behavior at (longer follow-up) could be helpful to see whether despite the non-significant effects at follow-up, the intervention nevertheless induced behavior changes. Third, the results are based on self-reported questionnaires completed by junior high school students. In responding to sensitive topics such as sexuality, adolescents may not be honest (Plummer, Ross, Wight, Changalucha, Mshana, Wamoyi et al., 2004). It is therefore impossible to rule out potential biases due to self-report. However, the rigorous design and data collection procedures (anonymity and confidentiality measures) could have elicited honest answers from the students. Finally, at the six months follow up survey, some students who were not part of the baseline $(\mathrm{N}=25)$ sneaked in and participated in the survey, adding to the difficulty of matching participants across all three time points. Therefore we had to ignore the correlation between the repeated measures and this might have slightly biased the results.

Conclusion

The SPEEK evaluation results confirmed the importance of school-based interventions aimed at changing determinants of sexual behaviours in a West African setting. Within a period of three months, SPEEK was able to positively change about $40 \%$ 
of the behavioural determinants measured in the study. The study was a randomised control trial with outcomes measured at three different time points, with school as the unit of randomisation and the clustering of students within schools, and of repeated measures within students, accounted for during data analyses. Such rigour in design makes our findings an important addition to the literature on school-based programs to reduce STIs rates and unintended teen pregnancies in sub Saharan Africa. Our results therefore suggest that evidenced- and theory-driven, school-based, peer-led interventions with interactive skills development components can positively change psychosocial determinants of sexual behaviours and may, ultimately reduce risk-taking behaviours related to STIs and pregnancy prevention.

Acknowledgements

The SPEEK sex education project was funded by the Sir Halley Stewart Trust, UK with data management and analyses supported by NUFFIC PhD fellowship grant nr. NFP-PhD.11/ 806. We acknowledged Ms. Linda Anaabah, who supervised the SPEEK sex education project and coordinated the surveys. We are also grateful to all the SPEEK peer educators, Dutch volunteers (Tes Schmeink \& Jennifer Hollenberg), and the school health teachers who supervised the informed consenting process. All staff of the Youth Harvest Foundation Ghana who played various supportive roles in the conduct of the study is acknowledged accordingly. 
Chapter 7

General Discussion 


\section{Introduction}

The main objective of this dissertation was to increase our understanding of the personal and environmental factors and psychosocial determinants that influence adolescents' sexual and reproductive health and rights (SRHR) behaviours, with a focus on why they fail to use contraception to protect against teenage pregnancy and STIs. In addition, this thesis aimed to apply Intervention Mapping (IM) to the adaptation of a program to promote safe sex behaviours (sexual delay and correct and consistent use of contraceptives). These studies are necessary to address the high rate of teenage pregnancies and STIs, that are not only negatively affecting the individual young people and their future aspirations but also has adverse effects on families, communities, and society as a whole (GSS-DHS, 2015).

This concluding chapter presents a discussion of the results of the various studies as presented in this thesis and juxtaposes the findings in the context of the available literature. First, the social cognitive predictors of condom use as reported in Chapter 2 are discussed. Next, the discussion examines the individual factors, beliefs, and perceptions of the target population (adolescent girls and boys) in their contraceptive decision-making processes as reported in Chapter 3,4 and 5. This is followed by a discussion on the environmental and behavioural factors that enables or disables adolescents' self-determination and choice of safe sex behaviours (also reported in Chapter 3, 4 and 5). Finally, the effect evaluation of the SPEEK sex education program and its impact on the social cognitive determinants of safe sex behaviours as reported in Chapter 6 is discussed. The chapter concludes with a discussion of the methodological limitations of the different studies, the practical implications for intervention planning, and suggestions for future research about teen pregnancy prevention in Ghana.

\section{Socio-cognitive predictors of condom use intentions}

Chapter 2 described the socio-cognitive correlates of predictors of safe sex behaviour (i.e. condom use intentions) among adolescents in Ghana. The unique strength of this study lies in the fact that we measured the main socio-cognitive variables of the RAA (attitude, subject norm, and perceived behavioural control) and variables of the HBM and ARRM (perceived risk and perceived susceptibility) at the specific sub-behaviour levels of condom use: to buy, to carry, and to use condoms consistently. The study found that perceived susceptibility towards STIs, injunctive norms towards condom use, both cognitive and affective attitude towards carrying condoms when going out, and perceived behavioural control towards buying and using condoms are the unique predictors of condom use intentions among Ghanaian adolescents. 
These results are in line with findings from studies in the Western context (Albarracin, Johnson, Fishbein, \& Muellerleile, 2001; DiLorio, Dudley, Kelly, et al., 2001; Peters, Wiefferink, Hoekstra, Buijs, ten Dam, \& Paulussen, 2009), but also within the SSA context (Boer \& Mashamba, 2007; Bryan, Kagee, \& Broaddus, 2006; Giles, Liddel, \& Bydawell, 2005; Heeren, Jemmott, Mandeya, \& Tyler, 2007; Molla, Åstrøm, \& Brehane 2007; Rijsdijk et al., 2012; Schaalma et al., 2009). Our findings show that in addition to the three primary cognitive variables of the RAA, perceived susceptibility towards STIs also explains condom use intentions of Ghanaian adolescents. We did not measure perceived barriers, but an earlier report in Ghana showed that both perceived barriers and perceived susceptibility predicted adolescents condom use (Estrin, 1999). These findings confirm previous conclusions that in SSA, condom use may be impeded by factors related to the availability and accessibility of condoms (Agha, Kusanthan, Longfield, Klein, \& Berman, 2002). Therefore, it is necessary for program planners to place emphasis on personal susceptibility to STIs while addressing ways to overcome barriers to access condoms.

In general, in the SSA context, subjective norms have been shown to predict condom use strongly among adolescents (Bosompra, 2001; Fekadu \& Kraft, 2002; Giles et al., 2005). It may be because the community influence and group behaviours are still more important in African societies compared to the West where decision-making is more a matter of the individual (Benefo, 2010; Yeboah \& Maticka-Tyndale, 2008). However, a more interesting perspective from our study is that while injunctive norms significantly predicted condom use intentions, descriptive norm failed to contribute. The predictive value of injunctive norm may be because Ghanaian parents raise their children in a more moralistic and authoritative manner (Mawusi, 2013) such that adolescents are more likely to do what the 'important' others expect them to do rather than what others are doing. Therefore, interventions that focus on changing beliefs in subjective norms may have a chance of success if they raise awareness that other important reference individuals expect adolescents to use condoms to protect against pregnancy and STIs.

Both cognitive and affective attitude towards carrying condoms when going out, and perceived behavioural control towards buying and using condoms strongly predicted intention to use condoms in our sample. The role of these RAA variables in predicting condom use among adolescents is nearly universal (Schwarzer, 2014). Therefore, we contend that it is a fruitless endeavour to fail to assess how these variables are manifested in a particular target population before developing program components aimed at promoting condom use. 
In addition to the predictors reported in this study, many other distal factors do influence adolescents' safe sex behaviours. Age of sexual debut and marital status (Lagarde, Pison, \& Enel, 1996); the culture of sex communication at home (Benefo, 2010) and the nature of sex education in school (Peters et al., 2009; Schaalma et al., 2004) have been reported to be associated with higher intentions to use condoms. Also, girls from poorer socio-economic background not only experienced earlier sexual debut but also used condoms less consistently compared with those from higher socio-economic families (Madise, Zulu, \& Ciera, 2007). Therefore, future surveys should measure all other potential factors that can help define the target factors to consider in addressing teenage pregnancy in Ghana. Although our findings support the RAA as a model to understand the factors associated with the intention to use condoms among Ghanaian adolescents, the explained variance in the condom use intention measure $\left(R^{2}=.33\right)$ was lower than is generally found in studies conducted in a Western context. In their meta-analytic review, Armitage and Conner (2001) found an average of $39 \%$ variance in predicting the intention of behaviours derived from TPB constructs in a Western context. Studies conducted in Africa tend to show less to similarly low (as in our study) explained variance in intention to use condoms, often within a range of 22\% - 36\% (Boer, \& Mashamba, 2007; Bosompra, 2001; Molla, Åstrøm, \& Brehane, 2007; Taffa, Klepp, Sundby, \& Bjune, 2002). However, two studies conducted in the African context have been exceptional in reporting $67 \%$ and $77 \%$ explained variance in the intention to use condoms (Giles et al., 2005; Schaalma et al., 2009). The Schaalma et al. study also included, next to the RAA/TPB constructs, geographic variables, socioeconomic factors and access to condoms in the explanatory model, which may account for the high explained variance.

Based on the findings of the study reported in chapter 2, we support the view that health behavioral models with a Western history like the RAA, HBM, and ARRM are usefull also in non-Western contexts however the relative relevance of variables may vary according to the behaviour, the target population, and the socio-cultural, economic and political context in which that behaviour is performed (Ajzen, 1991; Fishbein, 1998). Furthermore, although the study reported in chapter 2 showed the relevance of these theoretical models to explain (at least partly) the intention to use a condom in a Ghanaian context, future research should also include other environmental and socio-economic factors to explain safe sex behaviour among Ghanaian adolescents. Behavioural models that incorporate environmental and structural opportunities and assesses access to safe sex commodities such as condoms could be more useful additions to the more individual focused theoretical models (Kaufman, Clark, Manzini, \& May, 2004; Glick \& Sahn, 2008). Also, since conceptual factors and intervention characteristics can moderate the intention-behaviour change causal path (Albarracin, 
Durantini, \& Earl, 2006), future studies should use longitudinal designs to come to more firm conclusions than a cross-sectional study that only shows correlates instead of real predictors.

\section{Individual factors, beliefs, and perceptions}

Chapter 3, 4 and 5 of this dissertation described the qualitative analysis of the perceptions, beliefs and experiences of adolescent girls without pregnancy experience (Chapter 3), those with pregnancy experience (Chapter 4), and adolescent boys (with and without pregnancy experience) (Chapter 5). The results of these studies show that among both groups of girls and the boys, buying, carrying and using condoms are believed to be the responsibility of boys or their heterosexual partners. Also, all the girls were explicit that contraceptives other than condoms (referred to as "family planning") can cause infertility. These beliefs of girls present several challenges for pregnancy prevention. First, although the use of family planning methods requires advanced planning and expectation of sexual activity, it does not need further action at the point of sexual intercourse. Conversely, condom use may require less prior planning but involves enacting safer sex practices and discussions while in the midst of sexual activity. Girls, who enter into sexual relationships for different reasons other than love (see Chapter 4), may find it particularly challenging to negotiate condom use during ongoing sexual activities. Second, the narratives from both groups of girls confirm a common theme among adolescents' stories of first intercourse - "it just happened" (Tolman, 2002). Therefore, girls' negative attitude towards family planning and putting responsibility for condom use on boys must be a worry to efforts towards addressing rising rates of teenage pregnancy. Intervention planners have a responsibility to help girls personalize the risk of pregnancy and accept that they are ultimately responsible for pregnancy prevention.

Both groups of girls in our sample also reported never buying condoms. Using condoms require these preparatory sub-behaviours such as buying, carrying and negotiating use during the actual sexual act (de Vet, Gebhardt, Sinnige, et al., 2011). Girl's carrying condoms or insisting on their use during sex is often viewed as a sign of promiscuity, infidelity, or HIV infection (Macleod \& Tracey, 2010) which explains them not carrying condoms. By not being prepared themselves, girls are depending on boys for their sexual safety. The additional negative perceptions of other family planning methods, as well as the heavily relying on the "safe period of the month" calculations, which the boys also seemed to believe as a means of preventing unwanted pregnancy show that girls are frequently exposed to the risk of pregnancy.

Almost all the pregnancy experienced girls and a few of those without pregnancy experience reported a forced and painful sexual debut. Similar experiences of sexual violence 
by young women have been reported (Stöckl, March, Pallitto, \& Garcia-Moreno, 2014). Violent and coercive sexual relations are associated with early sexual debut and early pregnancy (Dunkle, 2004; Jewkes \& Abrahams, 2002). Also, the gender dynamics underpinning coercive sex enforces double standards in behaviour and inhibits the ability of young women to negotiate with a partner (Shai, Jewkes, Nduna \& Dunkle, 2012). We did not explore sexual violence in-depth in the studies reported here. However, the fact that all the pregnancy experienced girls reported some sexual abuse means the role of sexual violence in perpetrating teenage pregnancy in Ghana cannot be underestimated. Future research should explore the manifestations of sexual abuse in adolescent sexual relationships and how girls can deal with coercive sex to prevent teenage pregnancies.

Except few girls who were culturally motivated to become pregnant, all other girls got pregnant unintended. Chapter 3 paints a clearer picture on why the girls with pregnancy experience might have failed to prevent unintended and unwanted pregnancies. These girls reported limited negotiation skills, low self-efficacy to obtain contraceptive, low awareness of the risk of getting pregnant through unsafe sex, ambivalent attitude towards condom use, no clear intention for future condom use or family planning (single mothers), and they are surrounded by negative social norms towards teen sexuality. Many studies have confirmed the role of the theoretical variables in explaining adolescent (un)safe sex behaviours (see Chapter 2). However, the girls also reported not being thoughtful about the possibility of engaging in sexual intercourse that could lead to pregnancy ("it just happened") and therefore not taking preventive measures which requires further attention. Indeed, such a variable could not have been explained by the RAA because it is not a "planned" as in TPB or "reasoned" activity as in the RAA. In this case, the girls harbored an attitude of denial of their sexuality or the belief that pregnancy could not happen to them. The finding is consistent with adolescent intellectual, emotional, and psychological development, which involves the formation of a stable self-image and a sexual identity (Steinberg, 2005). As this process does not always unfold sequentially (Miller, Miceli, Whitman \& Borkowski, 1999), adolescent girls may not always see themselves as sexually active when they have had intercourse only once or twice (Lemay, Cashman, Elfenbein, \& Felice, 2007). Our findings suggest that "not thinking about having sex" may contribute to the non-use of contraception before first pregnancy. Therefore, before menarche signals the possibility of fertility, young girls need information on how pregnancy occurs and on pregnancy risk awareness. Girls also need to acknowledge their sexuality and sexual development at an earlier age.

Next to similarities, also differences were found between girls with and girls without pregnancy experience. Contrary to their pregnant peers, the girls without pregnancy 
experience was relatively knowledgeable about condoms, seemed to be aware of the risk of pregnancy posed by unsafe sex, were positive towards carrying and using condoms (although they did not see it as their responsibility), exhibited strong self-efficacy beliefs toward negotiating condom use, and had clear future goals including plans on how to achieve them. These girls also had clear intentions for future condom use and frequently indicated that they will end the relationship if their partners attempt to have unprotected sex. Although we cannot impute causality from these qualitative interviews, the literature is conclusive that the beliefs of these girls might have contributed to them not falling victim to teenage pregnancy. In a review of sexual risk and protective factors affecting US teen sexual behaviors, Kirby and Lepore (2007) concluded that the strongest protective factors are teens' own sexual beliefs, values, attitudes, skills, and intentions. In a review of the most important risk and protective factors shaping adolescent reproductive health in developing countries, Mmari and Blum (2009) found a positive association between condom use self-efficacy and actual condom use. Also, in a review of studies in developing countries, with $60 \%$ conducted within the SSA context, Mmari and Sabherwal (2013) concluded that being able to discuss sexual wishes and borders with a sexual partner was the strongest protective factor for safe sex behaviours of adolescent girls. Sexual risk and protective factors are particularly important for several reasons. First, they are well supported by a variety of social psychological theories (Conner \& Norman, 2005). Second, they are more strongly related statistically to some types of sexual and contraceptive behaviors, indicating their relative importance over other factors. Third, some of these factors form the basis for many sex and STIs/HIV education programs because they have been found to be important in predicting behaviour and methods to change them are specified (Bartholomew Eldredge et al., 2016). We recommend extensive quantitative surveys to confirm the role of these determinants on predicting safe sex behaviours of adolescents to guide future intervention development to address teenage pregnancy in Ghana.

Across the gender domain, the boys' narratives present an opportunity to see the common beliefs of both sexes (similarities as well as differences), how boys perceive girls and sexual relationships and the most important factors to consider in the engagement of young males towards addressing teenage pregnancies and STIs in Ghana. Just like their female counterparts, the study presented in chapter 4 shows that the boys' knowledge of contraception was mostly limited to condoms and their risk perception towards both getting a girl pregnant and getting infected with STIs remain questionable since they also believed in the girls 'safe period of the month' method. The boys also provided different perspectives to our understating of adolescent sexual behaviours as compared to both groups of girls. 
Prominent among these were the boys' negative perception of girls and relationships with girls such as their strong belief that girls cannot be trusted to be faithful in sexual relationships, and that girls are only interested in material gain in relationships and not love. The boys also believed that God created them to be superior to girls and, like their female counterparts, they had the perception that it is boys' responsibility to carry and use condoms so as to "be in control of the situation." Masculinity and gender-based hegemonic beliefs also seemed to put pressure on boys to engage in multiple sexual relationships to conform to peer-norms.

Across SSA, similar beliefs of boys regarding girls and sexual practices have been reported (Bhana, \& Nkani, 2014; Izugbara, 2004; Nzioka, 2001). The ideology of a double standard, in which males feel morally and physically dignified by having multiple sex partners and view females as morally demeaned by the same behaviour was observed among the boys in this study. Therefore, a fruitful direction for future research would be to focus on the gender ideologies and sexual health of males. To what extent does internalizing traditional ideas about masculinity impact on boys' sexual health? It is possible that while boys high in masculinity ideology may not view it as their responsibility to prevent pregnancy, they may take more seriously concerns about preventing the transmission of STIs (Tolman, Spencer, Harmon et al., 2004). Future research could also determine whether there are different dimensions of masculinity ideology that are associated with the various forms of protection among adolescent boys in Ghana.

Perhaps most important, the qualitative findings of both girls and boys illustrate the complex and dynamic interrelationships between partnership type, duration, and infidelity. The boys in this study sample described widespread sexual networks, claiming it is because girls cannot be trusted. At the same time, the boys strongly perceived that girls were only interested in material gains when they engaged in relationships. On the other hand, while the girls confirmed the economic motivations for engaging in relationships, they put condom use responsibility on the boys. These relationships, conducted over time, form the basis for overlapping, or concurrent, sexual partnership patterns. Little emphasis has been placed on research to date on the temporal and spatial dimensions of young people's sexual partnerships and its relation to sexual risk, although the links between the economic basis for sexual networking has been extensively studied (Luke and Kurz 2002; Dunkle, 2004; Hunter 2002; Poulin 2007). In this study, the combination of data from multiple sources provides insight into how and why these patterns occur, as well as important gender differences. For instance, many of the young men who had multiple relationships had overlapping partnerships, whereas young women who had multiple relationships were more 
likely to have serial relationships, with overlap frequently occurring in the context of partner change, often at the start of a new relationship (see Chapter 3). These partnering patterns can further put girls at risk for unintended pregnancy and therefore future research should explore how such patterns of sexual partnerships are assign meaning and how safe sex can be practice within such complex of relationship dynamics.

\section{Environmental and Behavioural factors}

All the participants of our qualitative interviews came from low-income families who are either engaged in peasant farming or involved in small-scale trading enterprises. The girls with pregnancy experience reported engaging in sexual relationships to get financial support to meet basic "girls needs" such as sanitary pads or to pay for school supplies. This was in line with the reports from the boys in our sample who firmly believed that girls are only interested in money and other materials gains when they engage in a relationship. Across SSA, widespread poverty increases girls' vulnerability to sexual exploitation (Mabala, 2006). Therefore, income generating skills that enable adolescent girls to earn money are crucial in empowering them to take independent decisions on their sexual wishes and desires. Pregnancy prevention programmes that combine safe sex promotion activities with economic empowerment components have indeed been found to be more effective than those focusing on health promotion only (Bandiera et al., 2012).

As depicted in Chapters 3, 4, and 5, the narratives of all the three groups of respondents point out to two other critical environmental conditions that are shaping the sexual behaviours of both adolescent boys and girls: a normative home environment continues to make sexuality a taboo subject and a school environment where sex is not thought at all or limited to abstinence-only messages. Both environmental conditions seem to be shaped by religious and cultural beliefs regarding sexuality. The high social norm towards abstinence until one is married together with a sexual double standard for boys and girls lead to internal struggles and lack of self-determination, in particular for girls (Barker \& Ricardo, 2005; Muhanguzi, 2011; Wolff, Blanc, \& Gage, 2000). From the findings, it can be concluded that both religion and culture create confusion for girls sexual identity and self-determination (see also Muhanguzi, 2011). This may lead to the situation where girls who engage in pre-marital sex will fail to use condoms because they are not prepared (Agha, Hutchinson, \& Kusanthan, 2006; Chatterji, Murray, London, \& Anglewicz, 2004). 
Rights-based CSE, focusing on rights within relationships in a culturally acceptable manner and incorporating skills development, is regarded as an important strategy to ensure that young people receive the necessary information and education to take well-informed decisions on sexual behaviours. However, implementation of such programmes in the Ghana context, remains challenging. As our results show, teachers, parents and religious leaders still place emphasis on abstinence-only messages. Moreover, CSE in the national school curriculum is only possible if there is an official political decision and commitments for its implementation. It is therefore important to know the socio-cognitive factors influencing the decision-making processes of these stakeholders to be able to target them with interventions aimed at getting their support for the implementation of CSE in Ghanaian schools.

Based on the results of chapter 3-4-5 the most significant behavioural factors deserving attention for purposes of intervention planning are multiple sexual partnerships and not- or inconsistent condom use and non-use of other family planning methods. While the girls engaged in multiple sexual relationships for economic reasons, with less selfdetermination to insist on condom use, the boys, on the other hand, reported that the normative requirement of "being a man" includes having multiple sexual partners to avoid the unacceptable position of being without a girlfriend. The manifestation of these three behaviours together puts adolescents at high risk of both STIs and teenage pregnancies (Kotchick, Shaffer, Forehand \& Miller, 2001; Da Ros \& Schmitt, 2008). The need to empower adolescent girls economically to enable them to take independent and self-determined decisions regarding sexuality has been emphasised in different parts of this dissertation. Given the influential role of peers in boy's intimate relationships, addressing peer relations and building skills to identify and deal with peer pressure in healthy and acceptable ways would be very useful.

\section{Effect Evaluation of the SPEEK sex education program}

The aim of the effect evaluation (Chapter 5) was to assess the effects of SPEEK on the targeted socio- cognitive determinants of safe sex behaviour (sexual delay, consistent condom use, and undertake STIs test). Multivariate analysis was done on data derived from a randomised controlled design, comparing an intervention group with a waiting list control group at post-test and six months follow-up. The development of the intervention followed a systematic approach in which clear target determinants for change, based on the literature (Boer \& Mashamba, 2007; Bryan, et al., 2006; Giles, et al., 2005; Rijsdijk et al., 2012; Schaalma et al., 2009) were created. 
Overall, at immediate post-test, the results show that SPEEK had a significant positive effect on 6 out of the 9 primary outcome measures and 7 out of the 20 secondary outcome measures targeted by the intervention activities. The intervention was effective in enhancing the students' knowledge regarding condom use, getting to know how pregnancy occurs, and on how to go for an STI test. Also, SPEEK was effective at changing negative beliefs concerning exercising sexual rights and carrying condoms into positive beliefs. In addition, the intervention increased the students' perception of being able to decide when and with whom to have sexual intercourse, of being able to delay sexual intercourse until they are ready for it and of being confident in their ability to use condoms in the future compared with the comparison group. For some determinants, no effects were found, and almost all effects disappeared at six months post-test, which could be due to the general socio-cultural context within which SPEEK was implemented - the general emphasis on abstinence only messages both at home and in school (see Chapters 3,4 and 5), might have affected the outcome. Another explanation for the loss of effects at the long-term, especially for the condom use related determinants could be due to the fact that other determinants more important in this population were not measured in the survey. The empirical studies reported in Chapters 3-5, have shown that other factors such as the economic situation of girls, perceptions related to future goals and, trust and relationships fidelity are important determinants of condom use but were not targeted by the SPEEK program because the studies were not conducted before the adaptation of the program. In the future, it is important to conduct such needs assessments studies and use the results to inform intervention development.

In general, the results on intervention effects are in line with results from previous studies conducted in SSA context (Kaaya, Flisher, Mbwambo, et al., 2002; Koenig, Lutalo, Zhao, et al., 2004; Rijsdijk et al., 2012). Two systematic reviews of studies of curriculumbased sexual health interventions in SSA concluded that programs that are rigorously designed to suit the African context can positively change knowledge and attitude towards STIs, HIV, and pregnancy prevention (Gallant \& Maticka-Tyndale, 2004; Paul-Ebhohimhen, Poobalan, \& van Teijlingen, 2008). In line with these reviews, but contrary to the findings of Rijsdijk et al. (2012), is the lack of positive effects of SPEEK on the intention to use condoms. According to reviews mentioned above, changing intentions regarding safe sex, especially (intention of) condom use, is more difficult in a context where the social norm dictates abstinence until marriage. The finding suggests that the promotion of condom use and skills among Ghanaian adolescents may not be effective if condoms are not widely available at a reasonable cost, or for free. It also re-enforces the point that there is the need 
to take a more ecological approach to intervention development, targeting key players, including schools and religious organisations as well as policymakers at different levels.

\section{Methodological considerations: strengths and weaknesses}

Since the findings of this dissertation have clear implications for intervention development and future research, a reflection on the quality of the methodology used in the various studies is necessary.

Primarily, the strength of this dissertation lies in the fact that the findings are based on the results of mixed methods designs including both quantitative and qualitative approaches. A mixed method design provides a comprehensive overview of the research topic because of the added advantage of data triangulation that enhances the validity of the findings (Robson, 2011). In addition, both the qualitative studies (Chapter 3-5) as well as the quantitative study (Chapter 2 ) involved large samples. For the qualitative studies, saturation was reached.

In addition, this dissertation contributes to the data gap on the specific sociocognitive predictors of condom use intentions involving a broad cross-section of young people in an SSA context. Again, the health problem was not studied from the perspective of only one specific group but includes different explorative studies among Ghanaian adolescent girls with and without pregnancy experience, and specifically among adolescent boys. All together this makes the results of these studies representative for the Bolgatanga youth population These studies provided both commonalities and differences in perspectives, which greatly enhanced our understanding of the structural socio-economic, cultural, political, and individual factors influencing adolescents' sexual behaviour in Ghana. Finally, we not only report on needs assessment studies but also on findings from a randomised controlled effect evaluation of a systematic adaptation of a CSE intervention implemented in junior high schools in a West African rural setting. Such rigour in design and evaluation of school based sex education programs are not common in Africa (Kaaya et al., 2002; Michielsen, Chersich, Luchtersa, et al., 2010; Paul-Ebhohimhen et al., 2008).

The context within which the studies were conducted also presented some challenges. For the determinant study (Chapter 2), the main limitation is the cross-sectional nature of the data, which does not allow drawing conclusions about causality. In the intervention study (Chapter 5), the background information of the students (age, school, class, community and mother's last name) were used to form codes meant to link the same participants across three-time measurements. During follow-up surveys, the students might have had changes in their ages or misinterpreted a question on their number of siblings, 
which caused changes in what was supposed to be a unique participant code, which in turn, made it difficult to match participants across the three-time points. The effect of this limitation on the results may be minimal because it was considered in the choice of the statistical model for the analysis. Also, the questionnaire used among students had some limitations. First, the questionnaire was in English. Since English is the second language for all respondents, some questions may have been difficult to comprehend. By training the research assistants who were present in the classrooms to give explanations to individual students who had difficulties understanding certain formulations of questions, the negative consequences of this limitation were addressed. Second, the questionnaire was too long. It took respondents up to 1.5 hours to complete. The survey included so many measures, including items not based on validated constructs, to be able to measure determinants at the specific sub-behaviour level to specify target change objectives for intervention development. Both the English language used and the fact some items were not based on validated constructs, could account for the low reliability of most of the scales used. When the Cronbach's alpha was below 0.60 , two items and single-item constructs were used instead, which reduces certainty about the underlying construct that was measured as individuals might have different interpretations of the same item. Finally, the data is from self-reported questionnaires completed by junior high schools students in a context where sexuality is rarely discussed at home. This was the best option to ensure anonymity and confidentiality, but it could be that the students provided socially acceptable responses. We tried to reduce this possibility as much as possible by creating a more private situation in the class room: separate tables and teachers out of the class rooms.

The qualitative data reported in Chapter 3, 4 and 5 also had some limitations. First, generalising the findings to all Ghanaian adolescents may be limited by the fact most girls in the study area were not willing to speak openly on sexuality. May be only those who dared to speak were in the sample and therefore, the actual situation may be worse. Also, it could be that girls in more rural communities did not get hear of the study. However, such indepth qualitative studies are necessary to gain insight into the nuances surrounding adolescent sexuality. Second, because of the sensitive nature of sexuality and the fact that age difference between interviewers and interviewees could inhibit open discussion; young people conducted the in-depth interviews. Irrespective of the extensive training, their limited experiences in conducting qualitative interviews could have affected the depth of the data. Also, for the qualitative study reported in chapter 3 , the recruitment procedure ended up with only in-school adolescent girls. It is possible that the responses would have been different if out-of-school girls were included in the sample. 


\section{Recommendations and future research}

The findings of the studies reported in this dissertation contribute to our understanding of the correlates of safe sex behaviour of Ghanaian adolescents and of how the socio-cultural and economic context in which the sexual behaviour of adolescents take place can inhibit or enable the enjoyment of the right of young people to complete and accurate information and sexual self-determination. Also, the findings add to the understanding of which personal and environmental factors influences a failure of adolescent girls and boys to protect against unwanted pregnancy and STIs in Ghana. Finally, the study on the effectiveness of SPEEK adds to our understanding of what changes at the level of determinants such interventions can make within the Ghanaian context. We make recommendations to support future intervention development, target change objectives and environmental conditions to consider in support of the implementation of comprehensive sex educational programs, such as SPEEK. Also, recommendations for future research towards promoting adolescents safe sex behaviours are proposed.

\section{Intervention development}

Based on the context in which adolescents SRHR takes place (Chapter 2 - 5) and on the conclusions from the effect evaluation (Chapter 6), it is recommended that interventions aimed at promoting adolescent safe sex behaviours target different stakeholders at the various levels of the Ghanaian society. At the national level, the Ministry of Education, Ministry of Health, Ministry of Justice and Ministry of Gender, Children and Social Protection are important stakeholders to engage in creating supportive sexual health and sex education policies and laws. Media also play a major role in providing information on SRHR and media representatives at both national as well as regional and community level should be involved in intervention development to ensure that what they feed to the public is accurate and appropriate.

At the community level, local religious and political leaders, (youth) NGOs, parents, teachers, health workers and school authorities are relevant social change agents. Their supportive socio-cognitive determinants towards adolescents' sexuality and rights-based CSE, including condom use demonstration and gender equality, are decisive for a supportive and conducive environment for the promotion of adolescent SRHR. To reduce teenage pregnancy significantly, communities may have to address many factors, beliefs and opinions among different groups (e.g., adolescents, their families, schools, religious groups and communities), and they may have to address both the limited access to sexuality education 
and nonsexual factors such as the economic empowerment of girls. In practice, this may mean that a patchwork of programs can be effective if each targets different populations to address a specific set of factors that in the aggregate improve the sexual self-determination and safe sex choices of adolescent girls. For example, a combination of programs designed to improve open and positive sexuality communication at home with those promoting access to comprehensive sexuality education in school may still not be enough if girls are not economically empowered through income generation activities to be in a stronger position to negotiate safe sex practices.

At the school level, although the benefits of SPEEK are based on the delivery of lessons by peer educators, for sustainability reasons, we recommend teachers as the main implementers of school-based sex education. As concluded by Rijsdijk et al. (2012), teachers know best the implementation context and can assess the feasibility and acceptability of proposed intervention methods and strategies. Also, students should participate fully in intervention development aimed at them because it is their right to do so (IPPF, 2010), but also because they can provide valuable feedback on practical methods to change behaviour.

Given that a large number of factors are linked to teen pregnancy, creating programs to reduce teenage pregnancy substantially in Ghana can be challenging. The fact that many important factors are manifestations of social disadvantages related to poverty and genderbased stereotypic beliefs (which are difficult to change) makes the challenge even greater. Consequently, it is not likely that there are any simple, easy-to-implement prevention programs - "magic bullets" - that will substantially change adolescent sexual behavior and teen pregnancy rates in Ghana. Therefore, efforts should be geared towards implementing different programs that address the various factors related to the teenagers, their parents, their access to CSE in school, and their economic situation. Addressing these different social determinants will require a multi-sectoral approach at the national level.

\section{Target change objectives}

Because adolescents' sexual knowledge, attitudes, emotions, perceived norms, perceived behavioural control beliefs or self-efficacy, and intentions are strongly associated with sexual and contraceptive behaviors and because these socio-cognitive determinants can be changed, pregnancy prevention initiatives should include interventions that address these determinants as effectively as possible. Given that adolescents' sexual beliefs, attitudes, and behavior are affected by the behaviours and expectations of parents, peers, teachers and health workers, pregnancy prevention initiatives should also target the socio-cognitive 
determinants of these groups to ensure that adolescent gets the necessary supportive environment to enjoy their sexual rights.

\section{Environmental conditions to consider for intervention development}

The findings from the exploratory studies on adolescents' beliefs and perceptions on pregnancy prevention show that CSE needs to provide complete and accurate information on sexual and reproductive health issues, including how to address trust and fedelity issues in relationship context. Although correct knowledge alone is not enough to effect positive behaviour change (Peters et al., 2009), it is a necessary prerequisite for safe sex behaviour and one of the fundamental basic sexual rights of adolescents (IPPF, 2010). Adolescents can only make informed choices about their sexuality if they have access to complete and reliable knowledge.

Boys and girls should be educated to challenge the existing socio-cultural, political and religious norms and practices and appreciate the two sexes as co-equals. It is important to involve both sexes in these discussions, including a discussion of the genderspecific realities of both genders such as on issues of masculinity, relationship fidelity, and trust. A review of interventions that have included a discussion of the gender-specific realities of adolescent boys showed that a gender-based perspective is a very promising approach to engaging boys in SRHR issues and pregnancy prevention (Barker \& Ricardo, 2005). In Ghana, the importance of targeting both boys and girls in sex education programmes cannot be overemphasised, as the focus has too much been on girls, aiming at their empowerment or promoting virginity values and disciplining them to abstain from sex. It is recommended to make mixed peer discussions a regular part of CSE, enabling the students to critically discuss and challenge existing values, norms, and cultural beliefs. Many existing sexuality values, attitudes, norms, beliefs, and practices are associated with gender-power relations (Muhanguzi, 2011). For instance, as reported in this dissertation, there is the norm that girls ask presents and money from boys or men and, in return, they come under extreme pressure to engage in sex (Nyanzi, Pool, Kinsman, 2001; Wagman, Baumgartner, Geary, et al., 2009). CSE programs should include topics that address transactional sex and its impact on the sexual health of girls.

Furthermore, many factors, such as restrictive social and religious norms regarding adolescents' sexuality and condoms use, sex and power dynamics combined with the economically disadvantaged positions of teenage girls, impact upon their SRHR. Therefore, to be effective, CSE should be implemented alongside with interventions aiming at supportive political, socio-economic, community and school management contexts (Bonell, 
Allen, Strange, et al., 2006; Matthews, Boon, Flisher, \& Schaalma, 2006). Examples of interventions aiming at the political context are advocacy interventions aimed the Ministry of Education to include condom use promotion as a recommended sex education strategy. Supportive economic contexts can be achieved by implementing interventions in the school settings to create small businesses for adolescents, especially girls to make them less vulnerable to intergenerational and transactional sexual practices.

\section{Future research}

There is the need for research that can shed more light on the relative relevance of sociocognitive factors in predicting safe sex behaviour in SSA context, in combination with the most structural factors, such as socio-economic, community, cultural, religious, gender and political context. More research on how sexual violence is manifested in adolescent sexual relationships and how it impacts on teenage pregnancy is warranted.

The firm belief of girls that the use of family planning methods, besides condoms, causes infertility require further research specifying the factors that continue to entrenched such beliefs and how such fears among girls can be laid off. Also, more research involving boys is necessary to increase understanding of their safe sex behaviours and choices. In particular, the kind of masculinity ideologies and beliefs that are associated with their decisions to engaging in sexual activities is important to inform interventions aimed at promoting condom use to prevent teen pregnancies and STIs. Again, the socio-economic empowerment of girls seems to be crucial in their sexual self-determination and their ability to negotiate safe sex choices. Since in the SSA context, resource limitations can make it difficult to implementing different gender-based programs with different goals, more research on the effectiveness of combining sexual health information with economic empowerment activities in the same program is necessary.

Finally, since adolescents safe sex choices are mostly influenced by relevant referent persons such as parents, teachers, health workers and religious leaders, we recommend research involving these groups to identify the social cognitive determinants shaping their beliefs, perceptions, and opinions towards adolescent sexuality.

\section{Conclusion}

This dissertation has discussed the socio-cognitive determinants of safe and unsafe sex behaviour among Ghanaian adolescents, explored the personal beliefs and the environmental factors influencing adolescent boys' and girls' contraceptive decision-making processes, and assessed the effectiveness of SPEEK, a skills-based CSE program. Together, the studies have 
specified the important socio-cognitive determinants for intervention targets and identified the personal factors (beliefs, perceptions) and environmental conditions related to families, communities, and schools that should be considered for intervention development. Also, the findings show that systematic and rigorous development of CSE programs guided by evidence and theory can be effective at changing psychosocial determinants of safe sex behaviours of adolescents in Ghana.

The results of this dissertation give valuable input to the systematic design and implementation of rights-based and skills-based CSE programs in a Sub-Saharan African rural context. In particular, CSE programs need to incorporate interactive skills development activities to build confidence and empower adolescents (especially, girls) to negotiate safe sex choices. Also, the effective implementation of such skills-based CSE programs depends on the support and participation of key stakeholders including parents, teachers and health workers. Therefore, SRHR programs need to be planned from an ecological perspective, in close collaboration with all relevant stakeholders including adolescents to create ownership and adapt activities to fit their specific needs and context. Programs that include advocacy components to secure the support of these key stakeholders are more likely to achieve community effectiveness towards preventing both teen pregnancies and STIs prevention. Also, CSE is likely to be most effective when it is guided by theory- and evidence-based needs assessments that delineate the relevant determinants, followed by clear-cut change objectives at the sub-behaviour levels as part of the intervention components.

Finally, this dissertation has highlighted the critical need for girls to take control over their sexuality and sexual agency. For this to happen, parents (in particular mothers) need to initiate open and positive sex communication with their daughters at home. In addition, programs that include economic empowerment activities for girls can enable them to earn income and be able to make independent, informed choices on their sexuality. Future research should explore mothers' needs regarding open sex communication as well as the effectiveness of programs that combine sexuality information with economic empowerment activities to inform intervention development towards teenage pregnancy prevention in Ghana. 
Valorization 
This valorisation section describes the social value of this dissertation project by outlining the relevance of the project, the people, and organisations that may have an interest in the findings besides the scientific community, the emerging activities informed by the conclusions and how such activities can be implemented for the benefit of the wider society.

\section{Relevance}

Ghana's population is largely youthful. While some have the knowledge, understanding and skills to care for themselves and access support when they need it, this dissertation has shown that many others are neither equipped nor supported to make the transition from childhood to adulthood. Further, some adolescents are especially vulnerable because they are growing up in homes and communities where they are neither protected nor nurtured. There has been substantial investment over many years in child survival resulting in impressive declines in childhood mortality. However, the Ghanaian society has been slow to respond to the pressing needs of adolescents. Consequently, adolescents face many challenges in their attempt to navigate their way through the transition to adulthood. These include engaging in risky sexual behaviours that lead to unintended and unwanted pregnancies and sexually transmitted infections.

Besides the health consequences, teenage pregnancy presents many social problems. Girls who become pregnant as teens drop out of school, resulting in low educational attainment and an adult life of poverty. Also, many girls who become pregnant end up in child marriage. Given the linkage of teenage pregnancy to child marriage, the factors driving early childbirth also become relevant. These include limited sexual and reproductive health education, low access to contraceptives and low girls' empowerment. This is the gap that the findings of this dissertation seek to contribute solutions to fill. Amongst others, this work has highlighted the need for comprehensive sexuality education (CSE) to help young people better to understand their bodies, feelings, and personal integrity. The work has shown how CSE can enable young people to make informed choices about sex and relationships, and counters myths and misconceptions about sexuality. It has also demonstrated how CSE can help to counteract gender stereotypes and address masculinity norms. The work has also pointed out how access to contraceptives is a means for young people to make empowering decisions about their life course, such as education. Apart from using the empirical findings to highlight the need for CSE, this dissertation provides an excellent example of how CSE programs can be systematically adapted to include interactive skills components to make it effective at positively influencing the factors that determine young people safe sexual choices Finally, since CSE 
is still not yet incorporated into the Ghanaian school curriculum, the findings of this dissertation also contributes to the evidence base upon which civil society groups can embark on advocacy actions for the inclusion of CSE into the national curriculum.

\section{Target groups}

The findings of this dissertation are of interest to many institutions and agencies working in youth development and the empowerment of young people. First, the Government of Ghana is concerned about the high rates of teenage pregnancy and sexually transmitted diseases among the youth. Therefore, the relevant ministries, including the Ministry of Gender, Children and Social Protection, the Ministry of Education and the Ministry of Health are constantly formulating various policies and programmes aimed at addressing unsafe sexual behaviours among adolescents. These ministries require evidence to be able to convince government at the highest level to invest in the implementation of such policies. The findings of this dissertation contribute to the work of these ministries in a significant manner.

The results of this work may also be very useful to civil society groups, including NGOs working directly to provide services to meet the sexual and reproductive needs of adolescents as well as those advocating for policy and legal changes to expand access to youth friendly health and educational services. To be taken seriously by decision-makers, NGOs need to show credibility and support their advocacy arguments with concrete evidence. For example, in Ghana, to get stakeholders to support the implementation of CSE in schools, strong proof that abstinence-only messages do not empower young people to able to make informed decisions on their sexual choices and that CSE does not necessarily promote sexual promiscuity is crucial. Thus, civil society groups and human rights activist will find the findings of this dissertation a valuable addition to their advocacy work.

Also, in poor settings like northern Ghana, many young people live in poverty and discrimination. These people can gain a voice and participate in civil society or other avenues for engagement. This dissertation shows adolescents themselves why they may lack the means to achieve change and areas in which changes need to take place to enjoy sexual and reproductive health.

\section{Activities}

A number of activities can be developed based on the results of this dissertation to promote adolescent sexual and reproductive health in Ghana. These includes using the effect evaluation of SPEEK as a guide to design sex education programs targeting junior high 
school students, using the evidence from the qualitative analysis to engage stakeholders to gain support for the teaching of CSE in schools and using the qualitative narratives of the girls and boys to engage parents on the need for an open and positive sex communication at home. The results may also be used to develop clear advocacy messages to engage decision makers at various levels for the inclusion of CSE in the school curriculum. Finally, the results point out new directions for further research to gain more insight into the factors influencing the safe sex choices of adolescents in Ghana.

\section{Innovation}

There are many governmental and non-governmental organisations and institutions that are making efforts at different levels to promote adolescent sexual and reproductive health in Ghana. Much of these efforts are not informed by empirical data. The results of this study are innovative in how it provides comprehensive empirical evidence on the personal factors influencing adolescents' family planning decision-making processes. In particular, this dissertation provides evidence in changing determinants at the specific sub-behaviour level. For example, to increase condom use, we have discussed how to influence changes in preparatory sub-behaviours such as buying condoms, carrying or having condoms available, negotiating condom use and how to be consistent in condom use. Such a discussion on specific preparatory sub-behaviours that culminate in the performance of the actual desirable health behaviour is novel in the literature in Ghana.

\section{Implementation}

As the author works for the Youth Harvest Foundation Ghana (YHFG) that provided the platform upon which the research was conducted, the results put into operation the YHFG's commitment towards promoting the sexual and reproductive health of young people in northern Ghana. It will guide our resource mobilization, the content of our programming and grant applications, as well as our annual planning. It will also guide us in the development of human resources - identify capacity building needs and assist us when recruiting new staff. The findings will be rolled-out and presented internally in YHFG, to its partners, key allies, and donors. The results will inform how the organization's work is presented on our website and in all our printed material. Depending upon availability of funding, the results will inform a revision and scaling up of the SPEEK sex education programme to include income generating activities to empower many girls to take control over their sexuality and life choices. 
Summary 
Ghana's youthful population is sexually active and most of them are not or inconsistently using contraceptives which results in high rates of teenage pregnancy and sexually transmitted infections (STIs). Both teenage pregnancy and STIs pose serious adverse health and social consequences for the victims, their families, and for society as a whole. Promoting safe sex behaviours among adolescents and young people require a clear understanding of the personal and environmental factors as well as the social cognitive determinants influencing the sexual and reproductive health choices of teenagers and their decisionmaking regarding contraception. The studies reported in this dissertation have been conducted to gain more insight into the sexual choices of adolescents and suggest ways to promote safe sex behaviours towards preventing teenage pregnancy and STIs among adolescents in Ghana.

Chapter 2 presents a cross-sectional study on the antecedents of adolescents' intentions to use condoms in Bolgatanga, Ghana. The goal of this study was to increase our understanding of the predictors of adolescents' condom use intentions to assist intervention development towards reducing STI transmission and preventing teenage pregnancy. The study found that a perception that one is susceptible to STIs, a perception of behavioral control towards using condoms, and a belief that other relevant referent persons expect one to use condoms when engaging in sexual activities were the strongest correlates of condom use intentions among Ghanaian adolescents. Further analysis of the data showed that having no sex experience, being uncomfortable to carry condoms and not believing that peers expect one always to use condoms precisely predicted the intention not to use a condom. On the contrary, high-risk perceptions, positive attitudes towards carrying condoms, and high perception of behavioural control towards buying and using condoms specifically predicted strong intentions to use a condom.

The results show that programs that aim at promoting condom use among adolescents in Ghana are more likely to succeed if they target perceived susceptibility towards STIs, injunctive norms, attitudes and feelings towards having condoms available, and perceived behavioral control towards buying and using condoms. Targeting these determinants with the valid evidence and theory-informed methods that are applied under the required conditions for effectiveness may increase behavioral intentions, and ultimately, actual condom use.

Chapter 3 describes a study that used in-depth qualitative interviews involving girls with pregnancy experience and living in the Bolgatanga Municipality of Ghana. The aim of this study was to gain more insight into the individual, environmental and cognitive factors that put teenage girls at risk of pregnancy in Ghana. The study found that the girls were 
from low-income families and did struggle to meet basic needs such as school supplies. At home, sex remains a taboo subject and in school, they are exposed to abstinence-only messages. The girls' knowledge of contraceptives was limited to condoms, and they were unable to obtain contraceptives and negotiate their use with sexual partners. Also, the girls seemed to have little awareness of pregnancy risk and believed that contraceptives other than condoms, often referred to as family planning methods, are linked to infertility. Regarding past sexual behaviours, the girls shared experiences of coercive, painful sexual debut and they often failed to use contraceptives to protect against unintended and unwanted pregnancy.

It was concluded that even though the majority adolescent girls do not want to become pregnant, the lack of a positive and open sex communication at home, the emphasis on abstinence-only messages at school, together with the poor economic situation of the families make it difficult for girls to make independent choices to prevent unwanted pregnancies. From a vulnerable position, they enter into sexual relationships without selfdetermination and agency to obtain contraception and negotiate for safe sex. The girls also seemed to have little awareness of the risk of pregnancy resulting from unprotected sex and had negative beliefs towards family planning methods. The girls' sexual and reproductive health behaviours were also partly shaped by generational cultural and religious beliefs.

The results highlighted the need to expose young girls to open and positive sex communication at home and comprehensive sexuality education in school. However, the Ghanaian society, with its embedded cultural and religious beliefs, may not be prepared for an open discussion on sexuality topics. Therefore, any sustainable solution ought to start with the engagement of community key stakeholders, including parents, teachers, health workers and religious leaders to secure broad support for the implementation of CSE in schools. An ecological approach that includes objectives to change gender-based norms and incorporate activities to help girls earn income to be able to make independent and informed decisions may help to prevent teenage pregnancies in Ghana.

Chapter 4 also describes data from individual in-depth interviews but with never been pregnant girls living in the Bolgatanga Municipality of Ghana. The goal of the study was to find out the differences in beliefs and perceptions towards contraceptive decision-making between girls with and without pregnancy experience. The study discovered that contrary to their peers with pregnancy experience (Chapter 3 ), these never pregnant girls came from a home environment where they could more easily discuss sexuality issues with their mothers and friends, and some girls had received safe sex advice to prevent unintended pregnancy. These girls also received sex education beyond abstinence-only messages at school. They 
exhibited protective factors such as high awareness of pregnancy risk through unprotected sex, positive attitudes towards carrying and using condoms, and they indicated high selfefficacy beliefs towards negotiating condom use with a sexual partner. In addition, the girls narratives also showed that they had clear future goals, including staying longer in school and coming out with successful learning outcomes. They also seemed to have formulated clear plans towards achieving their goals, including plans to use protection against unintended pregnancies that may derail their future goals. However, similar to their pregnancy experienced peers, the never been pregnant girls also believed that boys were responsible for buying condoms, and they also had high perceptions that the use of family planning methods will lead to infertility.

The results suggest that a positive attitude towards contraception, high-risk perception towards getting pregnant and high condom use self-efficacy are important protective factors in girls contraceptive decision-making processes. These factors can enable girls to take specific actions such as carrying condoms and initiating discussions towards condom use in a relationship. Therefore, a successful intervention may require prior assessment of the particular cognitive beliefs that can influence the performance of action specific sub-behaviours that will culminate in the performance of the actual safe sex behaviours such as using condoms. It may also be more effective to encourage the 'doubledutch' approach: the combined use of both condoms and other family planning methods among girls to secure full protection against both teenage pregnancy and STIs. Also, since there seems to be a link between working towards a clear future goal and using protection to avoid unintended pregnancy until the goal is achieved, programs that include goal-setting activities may have a higher chance of succeeding in preventing teenage pregnancy.

Chapter $\mathbf{5}$ describes another in-depth qualitative study but this time the participants were boys living in the Bolgatanga Municipality of Ghana. The aim of the study was to understand the personal, environmental and social cognitive factors that shape boys contraceptive decision-making processes and how the sexual behaviours of boys may impact on girls' failure or success to use contraception to protect against teenage pregnancy. An unexpected result was that love was hardly mentioned as a reason for engaging in a sexual relationship. At the some time, the study found that boys believed that girls are mostly interested in material gain and cannot be trusted to be faithful and fidel in a relationship. The boys also shared that they do engage in multiple sexual relationships to ensure that when one or two of their girlfriends leave for the next more resourceful guy, they can still have girlfriends to fulfill masculine social requirements always to have a girlfriend. 
The study also showed that despite boys high perception of STIs risk and high awareness of the consequences of impregnating a girl, the boys reported failing to use protection on regular basis, citing several reasons, including feeling safe without protection, trusting that the girl was in her 'safe period of the month', not have condoms available at the point of need or using the physical appearance of the girl to decide whether protection was necessary or not. Similar to both groups of girls in Chapter 3 and 4, the boys' knowledge of contraception was also limited to condoms, and they mostly relied on the 'withdrawal method' or the girls 'safe period' of the month for contraception. Also, the boys' experiences of sex communication at home and sex education in school were limited. Mostly, sex communication occurred within peer groups.

The double standards of boys expecting girls to be fidel and faithful in sexual relationships but at the same time they (boys) are engaging in multiple sexual partnerships puts young people at risk of not only pregnancy but higher risk of STIs, since they may not be able to maintain consistent condoms use across the different partners. Boys and girls need to know that even in faithful relationships, family planning or condom use is still necessary to prevent teenage pregnancy. Also, the boys' sexual behaviors are partly driven by masculinity beliefs and the pressure from peers to conform to the social construction of the African man, who must have a girlfriend or remain a laughing stock among colleagues. Therefore, efforts to promote consistent condom use among boys should project it as a positive, progressive and healthy quality of a 'cool' masculinity, along with the promotion of gender equity and male participation in sexual and reproductive health. Also, since among boys, much of sex communication occurs within the peer group, peer education may be an important strategy to reach boys with correct and accurate information on safe sexual practices. Future research that explores the social construction of masculinities among the adolescent population in northern Ghana and how such hegemonic beliefs influences safe sex choices will be a valuable addition to efforts to prevent teenage pregnancy in Ghana.

Chapter 6 describes a systematically re-designed skills- and rights-based comprehensive sexuality education (CSE) program based on both empirical evidence and theories of sexual behaviours. The goal of the study was to find out whether a rigorously designed peer-led CSE, using the Intervention Mapping approach to planning health promotion programs, can positively change specific social cognitive factors towards the performance of safe sex behaviours of adolescents in Bolgatanga. Intervention Mapping is a theory-guided approach that supports intervention planners to design evidenced based health promotion programs, taking into consideration the local culture and context. A 
randomized controlled trial (RCT) was used including intervention schools and waiting-list control schools.

Although no significant effects of the SPEEK sex education program on the social cognitive factors of the participants were detected after a six-month follow-up survey, the immediate post-test measure showed that the intervention group scored significantly higher in over $40 \%$ of the social cognitive determinants of safe sex behaviours targeted by the intervention. In particular, students in the intervention group had significant higher scores on their ability to explain condom use, their perceived knowledge of condom use, actual knowledge on pregnancy and STIs testing as compared with the students in the control group. Also, at posttest, the students in the intervention group were significantly more confident of exercising their sexual rights, more likely to carry condoms with them when going out for social activities, perceived themselves more capable of deciding when and with whom to engage in sexual activities, perceived themselves more able to delay sexual intercourse until they were ready for it and were more confident towards future condom use compared with the control group. Also, at posttest, students who received the SPEEK sex education program perceived themselves to be more at risk of contracting STIs through unprotected sex compared with students of the control group.

The evaluation study confirmed that theory and evidence-based CSE, that is systematically designed to incorporate interactive skills development activities such as condom use demonstration can positively change the determinants of adolescents safe sex behaviours in African rural settings. Advocacy actions to convince decision-makers at the Ministry of Education to include theory-driven CSE in the school curriculum is a major step towards addressing the high rates of teenage pregnancy and the spread of STIs among young people in Ghana.

Finally, Chapter 7 summarized and discussed the findings of the various studies, made recommendations for further intervention development towards addressing the high rate of teenage pregnancy and STIs among young people, and suggested directions for future research to generate more evidence to support the promotion of adolescent sexual and reproductive health in Ghana.

First, it is important for programs aimed at promoting condom use among adolescents to do a thorough needs assessment to identify the specific target determinants to change and carefully select evidence-based methods, taking into consideration the necessary parameters for the effectiveness of those methods to guarantee program success. Second, a positive and open communication on sexuality topics is very necessary to prepare children at home towards sexual self-determination and safe sex negotiation. Third, besides 
the fact that young people have a right to CSE, they need it to be able to make independent and informed choices in responding to their sexual and reproductive health needs and development. Fourth, besides condoms, supporting girls to change from a negative perception towards other family planning methods to using hormonal contraceptives for pregnancy prevention may help them to take full control of their sexual wishes and boundaries. Fifth, sexual health information alone may not be enough to secure girls sexual self-determination and autonomous decision-making on contraception. CSE programs may have to combine sexual health messages with income generating activities to empower young girls to avoid transactional and intergenerational sexual activities for economic reasons - a situation that makes it difficult for them to negotiate for safe sex. Sixth, effective CSE programs require a systematic design, using the best available evidence, guided by theoretical concepts and implemented with a reasonable fidelity and dosage.

Finally, Ghana may not be able to address the high rates of teenage pregnancy without context-specific evidence to ensure that intervention efforts have broad acceptance and participation by key stakeholders such as parents, school authorities, religious leaders, and community-based health workers. Future research should explore the social cognitive determinants of the behaviour of these important reference people towards adolescent sexuality. Such knowledge will provide a more comprehensive picture on the best entry points for interventions aimed at preventing teenage pregnancy and STIs spread among young people in Ghana. 
References 
Abiodun, O.M., Balogun, O.R. (2009). Sexual activity and contraceptive use among young female students of tertiary educational institutions in Ilorin, Nigeria. Contraception, 79(2), 146-149. doi:10.1016/j.contraception.2008.08.002.

Acquaah, M. (2007). Embeddedness and immigration: Notes on the social determinants of economic action. American Journal of Sociology, 98, 1320-1350.

Adams, F.H., Lemaire, M.B., \& Prah, K.A. (2013). Factors affecting girls' completion of senior high schools in Sekondi Takoradi Metropolitan Area. Journal of Education and Practice, 4(6). Retrieved from: http://iiste.org/Journals/index.php/JEP/article/view/4815.

Adedimeji, A.A., Omololu, F.O., Odutolu, O. (2007). HIV risk perception and constraints to protective behavior among young slum dwellers in Ibadan, Nigeria. Journal of Health, Population, and Nutrition, 25(2), 146-57.

Adih, W. K., \& Alexander, C. S. (1999). Determinants of condom use to prevent HIV infection among youth in Ghana. Journal of Adolescent Health, 24, 63-72.

Adjei, D., Sarfo, J.O., Asiedu, M., \& Sarfo I.A. (2014). "Social cognitive factors affecting contraceptive usage: A case of unmet needs in Ghana." European Scientific Journal, 10 (15): 84-93.

Adongo, P., Phillips J.F., Kajihara B., Binka F.N., Debpuur C., \& Fayorsey C.K. (1997). "Cultural factors constraining the introduction of family planning among the KassenaNankana of northern Ghana." Social Science \& Medicine, 45(12), 1789-1804.

AED (Academy for Educational Development). (2008). How to implement HIV/AIDS interventions targeting men who have sex with men (MSM) in a hostile socio - political environment: 10 Lessons learned from Ghana. Operational Research Report. Retrieved from www.aedsharp.org/sites/default/files/documents eg.pdf.

Agha, S., Hutchinson, P., \& Kusanthan, T. (2006). The effects of religious affiliation on sexual initiation and condom use in Zambia. Journal of Adolescents Health, 38(5), 550-555.

Agha, S., Kusanthan, T., Longfield, K., Klein, M., \& Berman, J. (2002). Reasons for non-use of condoms in eight countries in sub-Saharan Africa. Washington, D.C., Population Services International [PSI], Research Division, Working Paper No. 49.

Ahman, E.L., \& Shah, I.H. (2010). Contraceptive use, fertility, and unsafe abortion in developing countries. The European Journal of Contraception \& Reproductive Health Care, 15 Suppl 2, 77-82. doi:10.3109/13625187.2010.533004.

Ahorlu, C,K., Pfeiffer, C., \& Obrist, B. (2015). Socio-cultural and economic factors influencing adolescents' resilience against the threat of teenage pregnancy: a cross-sectional survey in Accra, Ghana. Reproductive Health, 12:117 DOI 10.1186/s12978-015-0113-9.

Ajzen, I. (1991). The Theory of Planned Behavior. Organizational Behavior and Human Decision Processes. 50, 179-211.

Ajzen, I. (2001). Nature and operation of attitudes. Annual Review of Psychology, 52, 27-58. 
Akyeampong, K., Djangmah, J., Seidu, A., Oduro, A. \& Hunt, F. (2007). Access to basic education in Ghana: The evidence and the issues. CREATE country analytic review. Winneba/ Brighton.

Albarracin, D., Durantini, M. R., \& Earl, A. (2006). Empirical and theoretical conclusions of an analysis of outcomes of HIV-prevention interventions. Current Directions in Psychological Science, 15, 73-78.

Albarracín, D., Gillette, J. C., Earl, A. N., Glasman, L. R., Durantini, M. R., \& Ho, M. H. (2005). A test of major assumptions about behavior change: A comprehensive look at the effects of passive and active HIV-prevention interventions since the beginning of the epidemic. Psychological Bulletin, 131(6), 856-897.

Albarracin, D., Johnson, B.T., Fishbein, M., \& Muellerleile, P.A. (2001). Theories of reasoned action and planned behavior as models of condom use: a meta-analysis. Psychological Bulletin, 127, 142-161.

Alhassan, E. (2013). Early marriage of young females: A panacea for poverty in the Northern Region of Ghana? Research on Humanities and Social Sciences, 3(12), 18-31.

Amanor-Boadu, V., Zereyesus, Y., \& Asiedu-Dartey, J. (2013). A district-level analysis of the prevalence of poverty in Northern Ghana. Retrieved from http://www.metss-ghana.kstate.edu/research-briefs/Poverty-Analysis-by-Districts-Final-3-11-2014.pdf.

Amuyunzu-Nyamongo M, Biddlecom AE, Ouedraogo C, Woog, V. (2005). Qualitative evidence on adolescents'views on sexual and reproductive health in sub-Saharan Africa, Occasional Report No. 16, New York: The Alan Guttmacher Institute.

Anarfi, J.K., \& Owusu, A.Y. (2011). The making of a sexual being in Ghana: The state, religion and the influence of society as agents of sexual socialization. Sexuality and Culture, 15, 1-18. doi:10.1007/s12119-010-9078-6.

Apanga, P.A., \& Adam, M.A. (2015). "Factors influencing the uptake of family planning services in the Talensi District, Ghana." Pan African Medical Journal, 20 (12), 1-9. doi:10.11604/pamj.2015.20.10.5301.

Armitage, C.J., \& Conner, M. (2001). Efficacy of the Theory of Planned Behaviour: A metaanalytic review. British Journal of Social Psychology, 40, 471- 499.

Asamoah, B.O., Moussa, K.M., Stafström, M., \& Musinguzi, G. (2011). Distribution of causes of maternal mortality among different socio-demographic groups in Ghana; a descriptive study. BMC Public Health, 11, 159. doi: 10.1186/1471-2458-11-159.

Ashford, S., Edmunds, J., \& French, D.P. (2010). What is the best way to change selfefficacy to promote lifestyle and recreational physical activity? A systematic review with meta-analysis. British Journal of Health Psychology, 15, 265-288.

Awusabo-Asare, K., A.M. Abane \& A., \& Kumi-Kyereme, A. (2004). "Adolescent sexual and reproductive health in Ghana: A synthesis of research Evidence." New York. www.guttmacher.org. 
Awusabo-Asare, K., Biddlecom, A., Kumi-Kyereme, A., \& Patterson, K. (2006). Adolescent sexual and reproductive health in Ghana: Results from the 2004 national survey of adolescents, occasional report no. 22, New York: The Alan Guttmacher Institute.

Baba-Djara, M., Brennan, A., Corneliess, C., Agyarko-Poku, T., Akuoko, K., Opoku, K.B., Yaw Adu-Sarkodie, Y. \& Beard, J. (2013). what you have to get what you want": Vulnerability to HIV and prevention needs of female postsecondary students engaged in transactional sex in Kumasi, Ghana: A qualitative study. Operations Research among Key Populations in Ghana. Retrieved from: http://www.bu.edu/cghd/files/2014/01/.pdf.

Baiden, P., \& Rajulton, F. (2011) Factors influencing condom use among women in Ghana: An HIV/AIDS perspective. Journal of Social Aspects of HIV/AIDS Research Alliance/SAHARA, 8, 46-54.

Bandiera, O., Buehren, N., Burgess, R., Goldstein, M., Gulesci, S., Rasul, I., Sulaimany, M. (2012). "Empowering adolescent girls: evidence from a randomized control trial in Uganda". Retrieved from: http://econ.Ise.ac.uk/staff/rburgess/wp/ELA.pdf

Bandura, A. (1998). Health promotion from the perspective of social cognitive theory. Psychology and Health, 13, 623-649.

Bankole, A., Ahmed, F.H., Neema, S., Ouedraogo, C., \& Konyani, S. (2007). Knowledge of correct condom use and consistency of use among adolescents in four countries in SubSaharan Africa. African Journal of Reproductive Health. 11, (3), 197-220.

Bankole, A., Biddlecom, A., Guiella, G., Singh, S., \& Zulu, E. (2008). Sexual behavior, knowledge and information sources of very young adolescents in four Sub-Saharan African countries. African Journal of Reproductive Health, 11(3), 28-43.

Barker, G., \& Ricardo, C. (2005). Young men and the construction of masculinity in sub Saharan Africa. Washington DC: World Bank Social Development Papers.

Bartholomew Eldredge, L.K., Markham C.M., Ruiter, R.A.C., Fernandez, M.E., Kok, G., \& Parcel, G.S. (2016). Planning health promotion programs: An Intervention Mapping Approach, 4th ed, San Francisco, CA: Jossey-Bass.

Bartholomew, L. K., Parcel, G. S., Kok, G., Gottlieb, N., \& Fernández, M. (2011). Planning health promotion programs: An Intervention Mapping Approach (3rd ed.). San Francisco, CA: Jossey-Bass.

Bastien, S., Kajula L.j., \& Muhwezi, W.W. (2011). "A review of studies of parent-child communication about sexuality and HIV/AIDS in Sub-Saharan Africa." Reproductive Health, $8(1)$, 25. doi:10.1186/1742-4755-8-25.

Bauman, L.J., \& Berman, R. (2005). Adolescent relationships, and condom use: trust, love and commitment. AIDS and Behavior, 9:2. doi: 10.1007/s10461-005-3902-2.

Bearinger, L.H., Sieving, R.E., Ferguson, J., \& Sharma, V. (2007). Global perspectives on the sexual and reproductive health of adolescents: patterns, prevention, and potential. Lancet, 369, 1220-1231. 
Benefo, K.D. (2010). Determinants of condom use in Zambia: A multilevel analysis. Studies in Family Planning, 41(1), 19-30.

Bennett, S., \& Assefi, N. (2005). School-based teenage pregnancy prevention programs: a systematic review of randomized controlled trials. Journal of Adolescent Health, 36(1), 72-81. doi:10.1016/j.jadohealth.2003.11.097.

Berhan, Y., \& Berhan, A. (2015). A meta-analysis of risky sexual behaviour among male youth in developing countries. AIDS Research and Treatment, 580961-9. http://dx.doi.org/10.1155/2015/580961.

Berten, H., \& Van Rossem, R. (2009). Doing worse but knowing better: An exploration of the relationship between HIV/AIDS knowledge and sexual behavior among adolescents in Flemish secondary schools. Journal of Adolescence, 32,1303-1319.

Bhana, D., \& Pattman, R. (2011). "Girls want money, boys want virgins: the materiality of love amongst South African township youth in the context of HIV and AIDS." Culture, Health \& Sexuality, 13(8), 961-972, doi: 10.1080/13691058.2011.576770.

Bhana, D., Nkani, N. (2014). When African teenagers become fathers: culture, materiality, and masculinity. Culture Health \& Sexuality, 16(4), 337-350. doi: $10.1080 / 13691058.2014 .887780$.

Bhatasara, S., Chevo, T., \& Changadeya, T. (2013). An exploratory study of male adolescent sexuality in Zimbabwe: The case of adolescents in Kuwadzana Extension, Harare. Journal of Anthropology, 11: 298670. http://dx.doi.org/10.1155/2013/298670.

Biddlecom, A., Awusabo-Asare, K., \& Bankole, A. (2009). Role of parents in adolescent sexual activity and contraceptive use in four African countries. International Perspectives on Sexual and Reproductive Health, 35(2): 72-81. doi:10.1363/3507209.

Biddlecom, A.E., Munthali, A., Singh, S., \& Woog, V. (2007). Adolescents' views of and preferences for sexual and reproductive health services in Burkina Faso, Ghana, Malawi and Uganda. African Journal of Reproductive Health, 11(3), 99-110.

Birks, M., Chapman, Y., Francis, K. (2008). Memoing in qualitative research: Probing data and processes. Journal of Research in Nursing, 13(1), 68-75. doi: $10.1177 / 1744987107081254$.

Birungi, H., Undie, C., MacKenzie, I., Katahoire, A., Obare, F., Machawira, P. (2015). Education sector response to early and unintended pregnancy: A review of country experiences in sub -Saharan Africa. STEP UP and UNESCO Research Report. Retrieved from: http://www.popcouncil.org/uploads/pdfs/2015STEPUP_EducSectorResp.pdf.

Bleakley, A., Hennessy, M., \& Fishbein, M. (2006). Public Opinion on Sex education in US Schools. Archives of Pediatrics \& Adolescent Medicine, 160, 1151-1156.

Blum, R.W. (2007). Youth in sub-Saharan Africa. Journal of Adolescent Health, 41, 230-238. doi:10.1016/j.jadohealth.2007.04.005.

Blunch, N., (2011). Skills, Schooling and Non-Marital Teenage Pregnancy in Ghana, pp.122. Unpublished PhD dissertation, the George Washington University, Washington, DC 
Boamah, E.A., Asante, K.P., Mahama, E., Manu, G., Ayipah, E.K., Adeniji, E., \& Owusu-Agyei, S. (2014) Use of contraceptives among adolescents in Kintampo, Ghana: a crosssectional study. Contraception, 5, 7-15. doi: https://dx.doi.org/10.2147/OAJC.S56485.

Boer, H., \& Mashamba, M.T. (2007). Gender power imbalance and differential psychosocial correlates of intended condom use among male and female adolescents in Venda, South Africa. British Journal of Health Psychology, 12, 51-63.

Bonell, C., Allen, E., Strange, V., Oakley, A., Copas, A., Johnson, A., \& Stephenson, J. (2006). Influence of family type and parenting behaviours on teenage sexual behaviour and conception. Journal of Epidemiology and Community Health, 60, 502-506. doi: 10.1136/jech.2005.042838.

Bosompra, K., (2001). Determinants of condom use intentions of university students in Ghana: An application of the theory of reasoned action. Social Science \& Medicine, 52,1057-1069.

Braeken, D., \& Cardinal, M. (2008). Comprehensive sexuality education as a means of promoting sexual health. International Journal of Sexual Health, 20(1), 50-62.

Brewer, N. T., Chapman, G. B., Gibbons, F. X., Gerrard, M., McCaul, K., \& Weinstein, N. D. (2007). Meta-analysis of the relationship between risk perception and health behavior: The example of vaccination. Health Psychology, 26,136-45.

Brook, D.W., Morojele, N. K., Zhang, C., \& Brook, J. S. (2006). "South African Adolescents: Pathways to risky sexual behaviours." AIDS Education and Prevention, 18(3), 259-272.

Bryan, A., Kagee, A., \& Broaddus, M.R. (2006). Condom use among South African adolescents: Developing and testing theoretical models of intentions and behavior. AIDS and Behavior, 10, 387-397.

Catania, J.A., Kegeles, S.M., \& Coates, T.J. (1990). Towards an understanding of risk behaviour: An AIDS Risk Reduction Model (ARRM). Health Education Quarterly, 17, 5372.

Chalmers, H., Aggleton, P., Ingham, R., \& Stone, N. (2006). Dynamic contextual analysis. A context specific approach to understanding barriers to and opportunities for change. Second ed. South Hampton, UK: Safe Passages to Adulthood Programme. http://www.safepassages.soton.ac.uk/pdfs/DCA2.pdf (accessed May 16, 2016).

Chandra-Mouli, V., Lane, C., \& Wong, S. (2015). What does not work in adolescent sexual and reproductive health: A review of evidence on interventions commonly accepted as best practices. Global Health: Science and Practice. Retrieved from: http://www.ghspjournal.org/content/3/3/333.full.pdf+html.

Chandra-Mouli, V., McCarraher, D.R., Phillips, S.J., Williamson, N.E., \& Hainsworth, G. (2014). Contraception for adolescents in Low and Middle Income Countries: Needs, barriers, and access. Reproductive Health, 11(1), 1-8.

Chandra-Mouli, V., Svanemyr, J., Amin, A., Fogstad, H., Say, L., Girard, F., \& Temmerman, M. (2015). Twenty years after International Conference on Population and Development: 
Where are we with adolescent sexual and reproductive health and rights? Journal of Adolescent Health, (56) S1-S6.

Chatterji, M., Murray, N., London, D., \& Anglewicz, P. (2004). The Factors Influencing Transactional Sex Among Young Men and Women in 12 Sub-Saharan African Countries. Policy Report. USAID. Retrieved from: http://www.policyproject.com/pubs/countryreports/Trans_Sex.pdf.

Chau K., Seck, A.T., Chandra-Mouli, V., \& Svanemyr, J. (2016). Scaling up sexuality education in Senegal: Integrating family life education into the National Curriculum. Sex Education, doi: 10.1080/14681811.2015.1123148.

Cho, J.Y., \& Lee, E. (2014). "Reducing confusion about Grounded Theory and Qualitative Content Analysis: Similarities and differences." The Qualitative Report, 19 (64):1-20.

Clark, A. E., \& Lohéac, Y., (2007). "It wasn't me, it was them!" Social influence in risky behavior by adolescents. Journal of Health Economics, 26, 763-784.

Cohen, J., (1988). Statistical power analysis for the behavioural sciences (2nd ed). Hillsdale, N.J.: Lawrence Erlbaum.

Cohen, J., Cohen, P., West, S., \& Aiken L. (2003). Applied multiple regression/correlation analysis for the behavioral sciences (3rd ed). Mahwah, NJ: Lawrence Erlbaum.

Conner, M., \& Norman, P. (Eds.) (2005). Predicting Health Behaviour: Research and practice with social cognition models, 2nd Ed. Maidenhead: Open University Press.

Cook, S.M.C., \& Cameron S.T. (2015). "Social issues of teenage pregnancy." Obstetrics, Gynecology \& Reproductive Medicine, 25 (9): 243-48. doi:10.1016/j.ogrm.2015.06.001.

Corbett, A.M., Dickson-Gómez, J., Hilario, H., \& Weeks, M.R. (2009). A Little thing called love: condom use in high-risk primary heterosexual relationships. Perspectives on Sexual and Reproductive Health, 41(4):218-224, doi: 10.1363/4121809.

Corbin, J., \& Strauss, A. (1998). Basics of qualitative research: Techniques and procedures for developing Grounded Theory. (J. Corbin \& A. Strauss, Eds.) (4th ed.). London, Uk: SAGE Publications.

Couch, M., Dowsett, G. W., Dutertre, S., Keys, D., \& Pitts, M. K. (2006). Looking for more: A review of social and contextual factors affecting young people's sexual health (ARCSHS Monograph based on Report to the World Health Organization). Monograph Series Number 61. Melbourne: Australian Research Centre in Sex, Health and Society, La Trobe University. ARCSHS Monograph.

Crichton, J., Ibisomi, L., Gyimah, S. (2012). Mother-daughter communication about sexual maturation, abstinence, and unintended pregnancy: Experiences from an informal settlement in Nairobi, Kenya. Journal of Adolescence, 35(1): 21-30. doi:10.1016/j.adolescence.2011.06.008.

Crosby, R., DiClemente R. J., \& Wingood G. M. (2001). Correct condom application among African-American adolescent females: The relationship to perceived self-efficacy and the association to confirmed STDs. Journal of Adolescent Health, 29,194-199. 
Da Ros, C.T., \& Schmitt C.da.S. (2008). Global epidemiology of sexually transmitted diseases. Asian Journal of Andrology, 10(1), 110-114.

Darteh, E.K.M., \& Amo-Adjei, J. (2012). Future husbands: predictors of young males' exposure to family planning messages in Ghana. African Population Studies, 26:1.

de Vet, E., Gebhardt, W.A., Sinnige, J., Van Puffelen, A., Van Lettow, B., \& de Wit, J.B.F. (2011). Implementation intentions for buying, carrying, discussing and using condoms: The role of the quality of plans. Health Education Research, 26, 443-455. doi: $10.1093 /$ her/cyr006.

Denzin, N.K., \& Lincoln, Y.S. (2011). Handbook of Qualitative Research. Thousand Oaks: Sage Publications, Inc., 2000.

Dick, B., \& Ferguson, B.J. (2015). "Health for the world's adolescents: A second chance in the second decade." Journal of Adolescent Health, 56 (1), 3-6. doi:10.1016/j.jadohealth.2014.10.260.

DiClemente, R. J., Crittenden, C. P., Eve, R., Sales, J. M., Wingood, G. M., Crosby, R. A. \& Salazar L. F., (2008). Psychosocial predictors of HIV-associated sexual behaviors and the efficacy of prevention interventions in adolescents at-risk for HIV Infection: What Works and What Doesn't Work? Psychosomatic Medicine, 70, 598-605.

DiLorio, C., Dudley, W.N., Kelly, M., Soet, J.E., Mbwara J., \& Potter S.J. (2001). Social cognitive correlates of sexual experience and condom use among 13- through 15-yearold adolescents. Journal of Adolescent Health, 29(3), 208-216.

Djomand, G., Quaye, S., \& Sullivan, P.S. (2014). HIV epidemic among key populations in West Africa. Current Opinion in HIV and AIDS, 9(5), 506-513. doi: $10.1097 / \mathrm{COH} .0000000000000090$.

Doku, D. (2012). "Substance use and risky sexual behaviours among sexually experienced Ghanaian Youth". BMC Public Health, 12:571.

Dunkle, K. (2004). Gender-based violence, relati onship power, and risk of HIV Infection in women attending antenatal clinics in South Africa. The Lancet, 9419, 1415-1421.

Eggers, S.M., Aarø, L.E., Bos, A.E., Mathews, C., Kaaya, S.F., Onya, H., \& de Vries, H. (2016). Sociocognitive predictors of condom use and intentions among adolescents in three sub-Saharan sites. Archives of Sexual Behavior,45(2), 353-365. doi: 10.1007/s10508-015-0525-1.

Eggers, S.M., Aarø, L.E., Bos, A.E.R., Mathews, C., \& de Vries, H. (2014). Predicting condom use in South Africa: A test of two integrative models. AIDS Behavior and prevention, 18(1), 135-145. doi: 10.1007/s10461-013-0423-2.

Eisenberg, M. E., Bernat, D. H., Bearinger, L. H., Resnick, M. D. (2008). Support for comprehensive sexuality education: Perspectives from parents of school-age youth. Journal of Adolescent Health, 42, 352-359. 
Eliason, S., Baiden, F., Yankey, B.A., \& Awusabo-Asare, K. (2014). Determinants of unintended pregnancies in rural Ghana. BMC Pregnancy Childbirth, 14: 261. doi: 10.1186/1471-2393-14-261.

Estrin, D. (1999). In Ghana, young men's condom use is linked to lack of barriers, perceived susceptibility to HIV infection. International Family Planning Perspectives, 25(2), 106107.

Ferguson, R., Vanwesenbeeck, I., \& Knijn, T. (2008). A matter of facts... and more: An exploratory analysis of the content of sexuality education in The Netherlands. Sex Education, \&(1), 93-106. doi:10.1080/14681810701811878.

Fishbein, M. (1998). Changing behavior to prevent STDs/AIDS. International Journal of Gynecology \& Obstetrics, 63(Suppl 1), 175-181.

Fishbein, M. (2008). A Reasoned Action Approach to Health Promotion. Medical Decision Making, 28; 834. doi: 10.1177/0272989X08326092.

Fishbein, M., \& Ajzen, I. (2010). Predicting and changing behavior: The Reasoned Action. Approach. New York, NY: Psychology Press, Taylor \& Francis Group.

Fishbein, M., Yzer, M.C. (2003). Using theory to design effective health behavior interventions. Communication Theory, 13,164-183.

Floyd, D. L., Prentice-Dunn, S., \& Rogers, R. W. (2000). A meta-analysis of research on protection motivation theory. Journal of Applied Social Psychology, 30 (2), 407-429.

Fonner, V.A., Armstrong, K.S., Kennedy, C.E., O'Reilly, K.R., Sweat, M.D. (2014) School based sex education and HIV prevention in Low- and Middle-Income Countries: A systematic review and meta-analysis. doi:10.1371/journal.pone.0089692.

GAC (Ghana Aids Commission), (2014). 2013 Ghana Country AIDS progress report: Ghana AIDS Commission, pp.1-143. Retrieved from http://www.unaids.org/sites/default/files/country/documents//file,94605,es..pdf

GAC (Ghana AIDS Commission). (2014). HIV fact sheet 2014. Retrieved from: http://ghanaids.gov.gh/gac1/pubs/GAC\%20FACT\%20SHEET\%202014.pdf.

Gallant, M. \& Maticka-Tyndale, E. (2004). School-based HIV prevention programmes for African youth. Social Science \& Medicine, 58, 1337-1351.

Ganchimeg, T., Ota, E., Morisaki, N., Laopaiboon, M., Lumbiganon, P., Zhang, J., \& Mori, R. (2014). Pregnancy and childbirth outcomes among adolescent mothers: A World Health Organization multi-country study. BJOG: An International Journal of Obstetrics \& Gynaecology, 121 Suppl 1:40-8. doi: 10.1111/1471-0528.12630.

Ganle, J.K., Obeng, B., Segbefia, A.Y., Mwinyuri, V., Yeboah, J.Y., Baatiema, L. (2015). How intra-familial decision-making affects women's access to, and use of maternal healthcare services in Ghana: a qualitative study. BMC Pregnancy \& Childbirth, 15(1), 1. 
Gewirtzman, A., Bobrick, L., Conner, K., \& Trying, S.K. (2011). Epidemiology of sexually transmitted infections. As quoted in Gross G and S.K. Tyring (eds.), Sexually Transmitted Diseases, doi: 10.1007/978-3-642-14663-3_2.

GHS (Ghana Health Service). (2013). Annual reproductive and child health report. Annual report. Accra. http://www.ghanahealthservice.org. Accessed 15 Sept 2015.

Giles, M., Liddell, C., \& Bydawell, M. (2005). Condom use in African adolescents: the role of individual and group factors. AIDS Care, 176), 729-739.

Glanz, K., Rimer, B. K., \& Viswanath K. (Eds.). (2015). Health behavior and health education: Theory, research, and practice, 5th ed. San Francisco: Jossey-Bass.

Glasier, A., Gülmezoglu, A.M., Schmid, G.P., Moreno, C.G., \& Van Look, P.F.A. (2006). Sexual and reproductive health: A matter of life and death. Lancet, 368(9547),1595-1607.

Glick, P.J., \& Sahn, D.E. (2008). Are Africans practicing safer sex? Evidence from demographic and health surveys for eight countries. Economic Development and Cultural Change, 56, 397-439.

Godin, G., Tinka, B.A., Sow, A., Minani, I., Morin, D., \& Alary, M. (2008). Correlates of condom use among sex workers and their boyfriends in three West African countries. AIDS and Behavior, 12(3), 441-451.

Gomes, K.R.O., Speizer, I.S., Oliveira, D.D.C., Moura, L.N.B., Gomes, F.M. (2008). Contraceptive method use by adolescents in Brazilian state capital. Journal of Pediatric and Adolescent Gynecology, 21(4), 213-219. doi:10.1016/j.jpag.2007.05.002.

Gottschalk, L.B., \& Ortayli, N. (2014). "Interventions to improve adolescents' contraceptive behaviors in Low- and Middle-Income Countries: A review of the evidence base." Contraception, 90 (3), 211-225. doi:10.1016/j.contraception.2014.04.017.

Grossman, D., L., Fernández, K., Hopkins, J., Amastae, T., \& Potter, J.E. (2010). "Perceptions of the safety of oral contraceptives among a predominantly Latina population in Texas." Contraception, 81 (3), 254-260. doi:10.1016/j.contraception.2009.09.009.

GSS (Ghana Statistical Service), (2015). Demographic and health survey 2014. The DHS program. ICF International Rockville, Maryland, USA.

GSS (Ghana Statistical Service). (2009). Ghana Demographic and Health Survey 2008: Key Findings. Calverton, Maryland, USA: GSS, GHS, and ICF Macro.

GSS (Ghana Statistical Service). (2012). 2010 population \& housing census, Summary report of final results. Ghana Statistical Service, Accra. http://www.statsghana.gov.gh. Accessed 19 Oct 2015.

Harden, A., Brunton, G., Fletcher, A., \& Oakley, A. (2009). Teenage pregnancy and social disadvantage: Systematic review integrating controlled trials and qualitative studies. British Medical Journal (Clinical Research Ed.), 339(7731), 1182-1185. doi:10.1136/bmj.b4254. 
Harrison, A., Cleland, J., \& Frohlich, J. (2008). "Young people's sexual partnerships in KwaZulu-Natal, South Africa: patterns, contextual influences, and HIV risk." Studies in Family Planning, 39 (4), 295-308.

Harrison, A., Newell, M., Imrie, J., \& Hoddinott, G. (2010). HIV prevention for South African youth; which interventions work? A systematic review of current evidence. BMC Public Health, 10, 102. doi: 10.1186/1471-2458-10-102.

Heeren, G.A., Jemmott, J.B. III, Mandeya, A., \& Tyler, J.C. (2007). Theory-based predictors of condom use among university students in the United States and South Africa. AIDS Education and Prevention, 19(1), 1-12.

Hendriksen, E. S., Audrey, P., Sung-Jae, L., Coates, T.J., \& Rees, H.V. (2007). Predictors of condom use among young adults in South Africa: the Reproductive Health and HIV Research Unit National Youth Survey. American Journal of Public Health, 97, 12411248.

Hindin, M.J., McGough, L.J., \& Adanu, R.M. (2014). "Misperceptions, misinformation and myths about modern contraceptive use in Ghana." Journal of Family Planning and Reproductive Health Care, 40, 30-35.

Huaynoca, S., Chandra-Mouli, V., Yaqub N. Jr., \& Denno, D. M. (2014). "Scaling up comprehensive sexuality education in Nigeria: from national policy to nationwide application." Sex Education, 14, 2, 191-209, doi: 10.1080/14681811.2013.856292.

Hubacher, D., Mavranezouli, I., \& McGinn, E. (2008). Unintended pregnancy in sub-Saharan Africa: Magnitude of the problem and potential role of contraceptive implants to alleviate it. Contraception, 78(1), 73-78. doi:10.1016/j.contraception.2008.03.002.

Hunter, M. (2002). "The materiality of everyday sex: Thinking beyond 'prostitution'." African Studies, 61(1), 99-120.

Ingham, R. (2006). The importance of context in understanding and seeking to promote sexual health. In R. Ingham \& P. Aggleton (Eds.), Promoting Young People's Sexual Health. International Perspectives (pp. 41-60). New York, US: Routledge.

IPPF (2010). IPPF Framework for Comprehensive Sexuality Education. London: IPPF.

Izugbara, C. O. (2004). Notions of sex, sexuality and relationship among adolescent boys in rural southeastern Nigeria. Sex Education, 4(1), 63-79.

Jewkes, R., \& Abrahams, N. (2002). The epidemiology of rape and sexual coercion in South Africa: an overview. Social Science \& Medicine, 55, 1231-1244.

Jewkes, R., Morrell, R., \& Christofides, N. (2009). "Empowering teenagers to prevent pregnancy: Lessons from South Africa." Culture, Health \& Sexuality, 11(7), 675-688, doi:10.1080/1369105090284645.

Johnston, V.J., \& Mabey, D.C. (2008). Global epidemiology and control of Trichomonas vaginalis. Current Opinion in Infectious Diseases, 21, 56-64. 
Kaaya, S.F., Flisher, A.J., Mbwambo, J.K., Schaalma, H., Aarø, L.E., \& Klepp, K.I. (2002). A review of studies of sexual behaviour of school students in sub-Saharan Africa. Scandinavian Journal of Public Health, 30(Suppl 2), 148-160.

Kabiru, C.W., \& Ezeh, A. (2007). Factors associated with sexual abstinence among adolescents in four sub-Saharan African Countries. African Journal of Reproductive Health, 11(3), 111-132.

Karim, A.M., Magnani, R.J., Morgan, G.T., \& Bond, K.C. (2003). Reproductive health risk and protective factors among unmarried youth in Ghana. International Family Planning Perspectives, 29(1), 14-24.

Kastbom, A.A., Sydsjö, G., Bladh, M., Priebe, G., Svedin, C.G. (2015). Sexual debut before the age of 14 leads to poorer psychosocial health and risky behaviour in later life. Acta Paediatrica 104(1), 91-100. doi: 10.1111/apa.12803.

Kaufman, C.E., Clark, S., Manzini, N., \& May, J. (2004). Communities, opportunities, and adolescents' sexual behavior in KwaZulu-Natal, South Africa. Studies in Family Planning, 35(4), 261-274.

Kiesner, J., Cadinu, M., Poulin, F. \& Bucci M., (2002). Group identification in early adolescence: Its relation with peer adjustment and its moderator effect on peer influence. Child Development, 73, 196-208.

Kim, E.S., Strecher, V.J., Ryff, C.D. (2014). Purpose in life and use of preventive health care services. Proceedings of the National Academy of Sciences of the United States of America, 111(46), 16331-16336. doi:10.1073/pnas.1414826111.

Kirby, D. (2007). Emerging answers 2007: Research findings on programs to reduce the problems of teen pregnancy and sexually transmitted disease. National Campaign to Prevent Teen and Unplanned Pregnancy. Washington, DC.

Kirby, D. (2008). The Impact of Abstinence and Comprehensive Sex and STD/HIV Education Programs on Adolescent Sexual Behavior. Sexuality Research and Social Policy, 5(3), 617.

Kirby, D. (2011). Sex Education: Access and Impact on Sexual Behaviour of Young People. New York: United Nations.

Kirby, D., \& Laris, B.A. (2009). Effective curriculum-based sex and STD/HIV education programs for adolescents. Child Development Perspective 3(1), 21-29.

Kirby, D., Obasi, A., \& Laris, B.A. (2006). The effectiveness of sex education and HIV education interventions in schools in developing countries. In: Preventing HIV/AIDS in young people. A systematic review of the evidence from developing countries. WHO Technical Report Series, no. 938. WHO Press, World Health Organization, Geneva: Switzerland.

Koenig, M., Lutalo, T., Zhao, F., Nalugoda, F., Kiwanuka, N., Wabwire-Mangen, \& Gray, R. (2004). Coercive sex in rural Uganda: prevalence and associated risk factors. Social Science \& Medicine, 58, 787-798. 
Kohler, P., Manhart, L., \& Lafferty, W. (2008). Abstinence-Only and comprehensive sex education and the initiation of sexual activity and teen pregnancy. Journal of Adolescent Health, 42(4), 344-351. doi:10.1016/j.jadohealth.2007.08.026.

Kotchick, B. A., Shaffer, A., Forehand, R., \& Miller, K. S. (2001). Adolescent sexual risk behavior: A multi-system perspective. Clinical Psychology Review, 21, 493-519. doi: 10.1016/S0272-7358(99)00070-7.

Kristien, M., Chersich, M., Stanley, L., Van Rossen, R., \& Temmerman, M. (2010). Concurrency and the limited effectiveness of behavioural interventions on sexual risk behaviour of youth in sub-Saharan Africa. AIDS, 24 (13), 2140-2142. doi: 10.1097/QAD.0b013e32833c8745.

Krugu, J.K., Mevissen, F.E.F., Debpuur, C., \& Ruiter, R.A.C. (2016). Psychosocial correlates of condom use intentions among junior high school students in the Bolgatanga Municipality of Ghana. International Journal of Sexual Health, 28, 1, 96-110, doi: 10.1080/19317611.2015.1124162.

Krugu, J.K., Mevissen, F.E.F., Prinsen, A., \& Ruiter, R.A.C. (2016). Who's that girl? A qualitative analysis of adolescent girls' views on factors associated with teenage pregnancies in Bolgatanga, Ghana. Reproductive Health, 13, 39. Doi: 10.1186/s12978016-0161-9.

Kumi-kyereme A., Awusabo-Asare K., \& Biddlecom A. (2007). Adolescents ' sexual and reproductive health: Qualitative evidence from Ghana. Occasional Report. New York: Guttmacher Institute, No. 30.

Kumi-Kyereme, A., Awusabo-Asare, K., \& Darteh, E.K. (2014). Attitudes of gatekeepers towards adolescent sexual and reproductive health in Ghana. African Journal of Reproductive Health, 18(3), 142-153.

Kumi-Kyereme, A., Awusabo-Asare, K., Biddlecom, A., \& Tanle, A. (2007). Influence of social connectedness, communication and monitoring on adolescent sexual activity in Ghana. African Journal of Reproductive Health, 11(1), 133.

Lagarde, E., Pison, G., \& Enel, C. (1996). A study of sexual behaviour change in rural Senegal: Journal of Acquired Immune Deficiency Syndromes and Human Retrovirology, 11(3), 282-287.

Lapinski, M. K., \& Rimal, R. N. (2005). An explication of social norms. Communication Theory, 15, 127-147.

Lawton, R., Conner, M., \& McEachan, R. (2009). Desire or reason: Predicting health behaviors from affective and cognitive attitudes. Health Psychology, 28, 56-65.

Leerlooijer, J.N., Ruiter, R.A.C., Reinders, J., Darwisyah, W., Kok, G. \& Bartholomew, L.K. (2011). The World Starts With Me: using intervention mapping for the systematic adaptation and transfer of school-based sexuality education from Uganda to Indonesia. Translational Behavioral Medicine, 1, 331-340. doi: 10.1007/s13142-011-0041-3. 
Lemay, C. A., Cashman, S. B., Elfenbein, D. S., \& Felice, M. E. (2007). Adolescent mothers' attitudes toward contraceptive use before and after pregnancy. Journal of Pediatric \& Adolescent Gynecology, 20 (4), 233-240.

Mabala, R. (2006). From HIV prevention to HIV protection: Addressing the vulnerability of girls and young women in urban areas. Environment \& Urbanization, 18(2), 407-432.

Luke, N., \& Kurz, K. (2002). Cross-generational and transactional sexual relations in subSaharan Africa: Prevalence of behavior and implications for negotiating safer sexual practices. Washington, DC: International Center for Research on Women.

Macleod, C. (1999a). "Teenage pregnancy and its 'negative' consequences: Review of South African Research - Part 1." South African Journal of Psychology, 29, 1-7.

Macleod, C. (1999b). "The 'causes' of teenage pregnancy: Review of South African Research - Part 2." South African Journal of Psychology, 29, 8-16.

Macleod, C.I., \& Tracey T. (2010). "A decade later: Follow-up review of South African research on the consequences of and contributory factors in teen-aged Pregnancy." South African Journal of Psychology, 40(1), 18-31.

Macphail, C., \& Campbell, C. (2001). " I think condoms are good but, aai , I hate those things": Condom use among adolescents and young people in a Southern African township. Social Science \& Medicine, 52, 1613-1627.

Madise, N.J., Zulu, E.M., \& Ciera, J. (2007). Is Poverty a Driver for Risky Sexual Behaviour? Evidence from National Surveys of Adolescents in four African Countries. African Journal of Reproductive Health, 11(3), 83-98.

Manu, A.A., Mba, C.J., Asare, G.Q., Odoi-Agyarko, K., \& Asante, R.K.O. (2015). "Parent-child communication about sexual and reproductive health: Evidence from the Brong Ahafo region, Ghana." Reproductive Health, 12(1), 1-13. doi:10.1186/s12978-015-0003-1.

Marcotte, D.E. (2013). "High school dropout and teen childbearing." Economics of Education Review 34, 258-268. doi: 10.1016/j.econedurev.2013.01.002.

Marrone, G., Abdul-Rahman, L., De Coninck, Z., Johansson, A. (2006). Predictors of contraceptive use among female adolescents in Ghana. African Journal of Reproductive Health, 18(1), 102-109.

Matthews, C., Boon, H., Flisher, A.J., Schaalma, H.P. (2006). Factors associated with teachers' implementation of HIV/AIDS education in secondary schools in Cape Town, South Africa. AIDS Care, 18(4), 388-397.

Mavedzenge, S.M.N., Doyle, A.M., \& Ross, D.A. (2011). "HIV prevention in young people in Sub-Saharan Africa: A systematic review." Journal of Adolescent Health, 49 (6), 568586. doi:10.1016/j.jadohealth.2011.02.007.

Mawusi, P.A. (2013). Parenting and culture - Evidence from Some African Communities. University of Education, National Centre for Research into Basic Education (NCRIBE), Winneba, Ghana. Chapter in "Parenting in South American and African Contexts", book edited by Maria Lucia Seidl-de-Moura, ISBN 978-953-51-1212-9. 
McCluskey, A., \& Lovarini, M. (2005). Providing education on evidence-based practice improved knowledge but did not change behaviour: a before and after study. BMC Medical Education, 5:40. doi:10.1186/1472-6920-5-40.

McFerson, H. (2010). Poverty among women in sub-Saharan Africa : A Review of selected issues. Journal of International Women's Studies, 11(4), 50-72.

McKnight, P.E., \& Kashdan, T.B. (2009). Purpose in life as a system that creates and sustains health and well-being: An integrative, testable theory. Review of General Psychology, 13(3), 242-251. doi:10.1037/a0017152.

McQuestion, M., Ahiadeke, C., Posner, J., \& Williams, T. (2012). Psychosocial processes and sexual initiation among Ghanaian youth. Health Education \&. Behavior, 39, 268-275.

Medley, A., Kennedy, C., O'Reiily, K., \& Sweat, M. (2009). Effectiveness of peer education interventions for HIV prevention in developing countries: A systematic review and metaanalysis. AIDS Education and Prevention, 21(3), 181-206.

Meekers, D., \& Klein, M. (2002). Determinants of condom use among young people in Urban Cameroon. Studies in Family Planning, 33(4), 335-346.

Mensch, B. S., Hewett, P. C., \& Erulkar, A. S., (2003). The reporting of sensitive behavior by adolescents: A methodological experiment in Kenya. Demography, 40, 247-68.

Metzler, C. W., Noell, J., Biglan, A., Ary, D., \& Smolkowski, K. (1994). The social context for risky sexual behavior among adolescents. Journal of Behavioral Medicine, 174), 419438.

Mevissen, F. E. F., Meertens, R. M., Ruiter, R. A. C., Zimbile, H., \& Schaalma, H. (2011). Justify your love: Testing an online STI-risk communication intervention designed to promote condom use and STI-testing. Psychology and Health 26, 205-221.

Mevissen, F. E. F., Ruiter, R. A. C., Meertens, R. M., \& Schaalma, H. P. (2010). The effects of scenario-based risk information on perceptions of susceptibility to Chlamydia and HIV. Psychology and Health, 25, 1161-1174.

Michielsen, K., Chersich, M.F., Luchtersa, S., De Kokera, P., Van Rossem. R., \& Temmerman, M. (2010). Effectiveness of HIV prevention for youth in sub-Saharan Africa: systematic review and meta-analysis of randomized and nonrandomized trials. AIDS, 24, 11931202.

Miller, C.L., Miceli, P.J., Whitman, T.L., \& Borkowski, J.G. (1996). Cognitive readiness to parent and intellectual-emotional development in children of adolescent mothers. Developmental Psychology, 32, 533-541.

Mmari, K., \& Blum, R.W. (2009). Risk and protective factors that affect adolescent reproductive health in developing countries: A structured literature review. Global Public Health, 4(4), 350-366, doi: 10.1080/17441690701664418. 
Mmari, K., \& Sabherwal, S. (2013). A review of risk and protective factors for adolescent sexual and reproductive health in developing countries: An update. Journal of Adolescent Health, 53(5), 562-572. doi: 10.1016/j.jadohealth.2013.07.018.

Molla, M., Asstrøm, A.N., \& Brehane, Y. (2007). Applicability of the theory of planned behavior to intended and self-reported condom use in a rural Ethiopian population. AIDS Care: Psychological and Socio-medical Aspects of AIDS/HIV, 19(3), 425-431.

Moore, A.M., Awusabo-Asare, K., Madise, N., John-Langba, J., \& Kumi-Kyereme, A. (2007). Coerced first sex among adolescent girls in sub-Saharan Africa: prevalence and context. African Journal of Reproductive Health, 11(3), 62-82.

Moore, A.M., Biddlecom, A.E., \& Zulu, E.M. (2007). Prevalence and meanings of exchange of money or gifts for sex in unmarried adolescent sexual relationships in Sub-Saharan Africa. African Journal of Reproductive Health, 11(3), 44-61.

Morhee, R.A.S., \& Morhee, E.S.K. (2006). "Overview of the Law and availability of abortion services in Ghana." Ghana Medical Journal, (40);3.

Muhanguzi, F.K. (2011). Gender and sexual vulnerability of young women in Africa: Experiences of young girls in secondary schools in Uganda. Culture, Health \& Sexuality, $13,713-725$.

Mushwana, L., Monareng, L., Richter, S., \& Muller, H. (2015). Factors influencing the adolescent pregnancy rate in the Greater Giyani Municipality, Limpopo Province - South Africa. International Journal of Africa Nursing Sciences, 2, 10-18. doi:10.1016/j.ijans.2015.01.001.

Nadeem, E., Romo, L.F., \& Sigman, M. (2006). Knowledge about condoms among lowincome pregnant Latina adolescents in relation to the explicit maternal discussion of contraceptives. Journal of Adolescent Health, 39(1), 119.e9-119.e15. doi:10.1016/j.jadohealth.2005.09.012.

Neal, S., Matthews, Z., Frost, M., Fogstad, H., Camacho, A.V., Laski, L. (2012). Childbearing in adolescents aged 12-15 in low resource countries: a neglected issue. New estimates from demographic and household surveys in 42 countries. Acta Obstetricia et Gynecologica Scandinavica, 91, 1114-1118.

Newman, B. M., \& Newman, P. R. (2001). Group identity and alienation : Giving the we its due. Journal of Youth and Adolescence, 30, 515-538.

Njue, C., Nzioka, C., Ahlberg, B.M., Pertet, A.M., \& Voeten, H.A. (2009). "If you don't abstain, you will die of AIDS": AIDS education in Kenyan public schools. AIDS Education and Prevention, 21(2), 169-179. doi: 10.1521/aeap.2009.21.2.169.

Nyanzi, S., Pool, R., Kinsman, J. (2001). The negotiation of sexual relationships among school pupils in south-western Uganda. AIDS Care, 13(1), 83-98.

Nyembezi, A., Ruiter, R.A.C., van den Borne, B., Sifunda, S., Funani, I., \& Reddy, P. (2014). Correlates of consistent condom use among recently initiated and traditionally circumcised men in the rural areas of the Eastern Cape Province, South Africa. BMC Public Health, 14, 668. Doi: http://www.biomedcentral.com/1471-2458/14/6681. 
Nzioka, C. (2001). Perspectives of adolescent boys on the risk of unwanted pregnancy and sexually transmitted infections in Kenya. Reproductive Health Matters, 9, 108-117.

Ogunfowokan, A.A., \& Fajemilehin, R.B. (2012). Impact of a school-based sexual abuse prevention education program on the knowledge and attitude of high school girls. The Journal of School Nursing, 28(6), 459-468. doi: 10.1177/1059840512446949.

Opoku, B. (2010). "Contraceptive use among 'at-risk' women in a metropolitan area in Ghana." Acta Obstetricia et Gynecologica, 89, 1105-1107.

Osafo, J., Asampong, E., Langmagne, S., \& Ahiedeke, C. (2013). Perceptions of Parents on how Religion Influences Adolescents' Sexual Behaviours in Two Ghanaian Communities: Implications for HIV and AIDS Prevention. Journal of Religion and Health, 1-13.

Oyediran, K.A., Feyisetan, O.I., \& Akpan, T. (2011). Predictors of condom-use among young never-married males in Nigeria. Journal of Health, Population and Nutrition, 29(3), 273285.

Palinkas, L., Horwitz, S., Green, C., Wisdom, J., Duan, N., \& Hoagwood, K. (2013). Purposeful sampling for qualitative data collection and analysis in mixed method implementation research. Administration and Policy in Mental Health, 1-12. doi:10.1007/s10488-013-0528-y.

Patton, G.C., Coffey, C., Cappa, C., Currie, D., Riley, L., Gore, F., \& Ferguson J. (2012). The health of the world's adolescents: a synthesis of internationally comparable data. Lancet, 379, 1665-1675.

Paul-Ebhohimhen, V., Poobalan, A., \& van Teijlingen E. (2008). A systematic review of school-based sexual health interventions to prevent STI/HIV in sub-Saharan Africa. BMC Public Health, 8(1), 4. doi:10.1186/1471-2458-8-4.

Pearson, J. (2006). Personal control, self-efficacy in sexual negotiation, and contraceptive risk among adolescents: The role of gender. Sex Roles 54, 615-625.

Pedlow, C. T., \& Carey, M.P. (2004). Developmentally appropriate sexual risk reduction interventions for adolescents: Rationale, review of interventions, and recommendations for research and practice. Annals of Behavioral Medicine, 27(3),172-184.

Peters, G-J.Y., Ruiter, R. A. C., \& Kok, G. (2013). Threatening communication: aA critical reanalysis and a revised meta-analytic test of fear appeal theory. Health Psychology Review, 7, S8-S31.

Peters, L.W.H., Wiefferink, C.H., Hoekstra, F., Buijs, G.J., ten Dam, GT.M., \& Paulussen, T.G.W.M. (2009). A review of similarities between domain-specific determinants of four health behaviors among adolescents. Health Education Research, 24(2), 198-223.

Pettifor, A.E., O’Brien, K., MacPhail, C., Miller, W.C., \& Rees, H. (2009). Early coital debut and associated HIV risk factors among young women and men in South Africa. International Perspectives on Sexual and Reproductive Health, 35(2), 74-82. 
Petty, R.E., Brinol, P., DeMarree, K.G. (2007). The meta-cognitive model (MCM) of attitudes: Implications for attitude measurement, change and strength. Social Cognitive and Affective Neuroscience, 25 (5), 657-686.

Plummer, M.L., Ross, D.A., Wight, D., Changalucha ${ }_{\llcorner}$J., Mshana, G., Wamoyi $_{\llcorner}$J., $_{\perp}$ \& Hayes ${ }_{\perp}$ R.J. (2004). "A bit more truthful": The validity of adolescent sexual behaviour data collected in rural northern Tanzania using five methods. Sexually Transmitted Infections, 80, 49-56.

Poulin, M.J. (2007). Sex, money, and premarital relationships in Southern Malawi. Social Science Medicine, 65(11), 2383-2393. doi:10.1016/j.socscimed.2007.05.030.

Reidy, D.E., Smith-Darden, J.P., Cortina, K.S., Kernsmith, R.M., \& Kernsmith P.D. (2015). Masculine discrepancy stress, teen dating violence, and sexual violence perpetration among adolescent boys. Journal of Adolescent Health, 56(6), 619-624. doi: 10.1016/j.jadohealth.2015.02.009.

Richardson, D. (2010). Youth masculinities: compelling male heterosexuality. The British Journal of Sociology, 61(4). doi: 10.1111/j.1468-4446.2010.01339.x.

Rijsdijk, L.E., Bos, A.E.R., Lie, R., Ruiter, R.A.C., Leerlooijer, J.N., \& Kok, G. (2012). Correlates of delayed sexual intercourse and condom use among adolescents in Uganda: A cross-sectional study. BMC Public Health, 12, 817. doi:10.1186/1471-245812-817.

Rimal, R. N., \& Real, K. (2003). Understanding the influence of perceived norms on behaviors. Communication Theory, 13,184-203.

Rivis, A., \& Sheeran, P. (2003). Descriptive norms as an additional predictor in the theory of planned Behaviour: A Meta-Analysis. Current Psychology, 22(3), 218-233.

Robin, L., Dittus P., Whitaker, D., Crosby, R., Ethier, K., Mezoff, J., Kim, M., \& PappasDeluca, K. (2004). Behavioral interventions to reduce incidence of HIV, STD, and pregnancy among adolescents: A decade in review. Journal of Adolescent Health, 34, 326.

Rosenberger, J.G., Bell, D.L., McBride, K.R., Fortenberry, J.D., \& Ott, M.A. (2010). Condoms and developmental contexts in younger adolescent boys. Sexually Transmitted Infections, 86(5), 400-403. doi: 10.1136/sti.2009.040766.

Rosenstock, I.M. (1974). The Health Belief Model and preventive health behavior. Health Education \& Behavior, 2, 354-386.

Ross, D.A., Dick, B., Ferguson, J. (eds) (2006). Preventing HIV/AIDS in young people: $A$ systematic review of the evidence from developing countries. UNAIDS. Inter-Agency Task Team on Young People. WHO Technical Report Series.

Ryff, C.D. (2014) Psychological well-being revisited: Advances in the science and practice of eudaimonia. Psychotherapy and Psychosomatics, 83(1), 10-28. doi:10.1159/000353263. 
Sawyer, S.M., Afifi, R.A., Bearinger, L.H., Blakemore, S., Dick, B., Ezeh, A.C., \& Patton, G.C. (2012). Adolescence: a foundation for future health. Lancet, 379, 1630-1640. doi:10.1016/S0140-6736(12)60531-5.

Sayles, J.N., Pettifor, A., Wong, M.D., MacPhail, C., Lee, S., Hendriksen, E., \& Coates, T. (2006). "Factors associated with self-efficacy for condom use and sexual negotiation among South African youth." Journal of Acquired Immune Deficiency Syndrome, 43, 226-233.

Schaafsma, D., Stoffelen, J.M.T., Kok, G., \& Curfs, L.M. (2013). Exploring the development of existing sex education programmes for people with intellectual disabilities: An Intervention Mapping Approach. Journal of Applied Research in Intellectual Disabilities, 26, 157-166.

Schaalma, H.P., Aarø, L.E., Flisher, A.J., Mathews, C., Kaaya, S., Onya, H., Ragnarson, A., \& Klepp, K.I. (2009). Correlates of intention to use condoms among sub-Saharan African youth: The applicability of the theory of planned behaviour. Scandinavian Journal of Public Health, 37(Suppl 2), 87-91.

Schutte, L., Meertens R.M., Mevissen, F.E.F., Schaalma, H., Meijer, S., \& Kok, G. (2014). Long Live Love. The implementation of a school-based sex-education program in the Netherlands. Health Education Research, 29 (4), 583-597.

Schwarzer, R. (2014). Health behavior change. Theoretical constructs, dynamic mechanisms and clinical interventions. In: S. Cooper \& K. Ratele (Eds. ), Psychology serving humanity. New York: Psychology Press.

Sedgh, G., Finer, L.B., Bankole, A.M., Eilers, A., \& Singh, S. (2015). Adolescent pregnancy, birth and abortion rates across Countries: Levels and recent trends. Journal of Adolescent Health, 56 (2), 223-230. doi:10.1016/j.jadohealth.2014.09.007.

Selikow, T.A., Ahmed, N., Flisher, A.J, Mathews, C., \& Mukoma, W. (2009). I am not "umqwayito": A qualitative study of peer pressure and sexual risk behaviour among young adolescents in Cape Town, South Africa. Scandinavian Journal of Public Health, 37Suppl 2, 107-112. doi: 10.1177/1403494809103903.

Shai, N., Jewkes, R., Nduna, M., Dunkle, K. (2012). Masculinities and condom use patterns among young rural South Africa men: A cross-sectional baseline survey. BMC Public Health, 5, 12, 462.

Sheeran P., \& Taylor S. (1999). Predicting intentions to use condoms : A meta-analysis and comparison of the theories of reasoned action and planned behavior. Journal of Applied Social Psychology, 29 (8), 1624-1675.

Shefer, T., Kruger, L., \& Schepers, Y. (2015). Masculinity, sexuality, and vulnerability in 'working' with young men in South African contexts: 'You feel like a fool and an idiot ... a loser'. Culture, Health \& Sexuality, 17(2), S96-S111, http://dx.doi.org/10.1080/13691058.2015.1075253.

Sialubanje, C., Massar, K., Hamer, D.H., \& Ruiter, R.A.C. (2014). Personal and environmental predictors of the intention to use maternal healthcare services in Kalomo, Zambia. Health Education Research. doi: doi:10.1093/her/cyu057. 
Skirbekk, V. (2008). Fertility trends by social status. Demographic Research, 18(5), 145-180. doi: $10.4054 /$ DemRes.2008.18.5.

Slater, C., \& Robinson, J.R. (2014). Sexual health in adolescents. Clinics in Dermatology, 32, 189-195.

Smoak, N., Scott-Sheldon, L., Johnson, B., \& Carey, M. (2006). Sexual risk reduction interventions do not inadvertently increase the overall frequency of sexual behavior: A meta-analysis of 174 studies with 116,735 participants. Epidemiology and Social Science, 41(3), 374-384.

Sriranganathan, G., Jaworsky, D., Larkin, J., Flicker, S., Campbell, L., Flynn, S., Janssen, J. (2012). Peer sexual health education: Interventions for effective program evaluation. The Health Education Journal, 71 (1), 6271. http://dx.doi.org/10.1177/0017896910386266.

Steger, M.F., Frazier, P., Oishi, S., \& Kaler, M. (2006). The meaning in life questionnaire: Assessing the presence of and search for meaning in life. Journal of Counselling Psychology, 53(1), 80-93. doi:10.1037/0022-0167.53.1.80.

Steinberg, L. (2005). Cognitive and affective development in adolescence. Trends in Cognitive Sciences, $9(2), 69-74$.

Steinberg, L. (2008). A social neuroscience perspective on adolescent risk-taking. Developmental Review, 28(1), 78-106. doi: 10.1016/j.dr.2007.08.002.

Steiner, M.J., \& Cates, W., (2006). Condoms and sexually-transmitted infections. The New England Journal of Medicine, 354, 2642-2643.

Stephenson, R. (2009). Community influences on young people's sexual behavior in 3 African countries. American Journal of Public Health, 99(1), 102-109. doi: $10.2105 /$ AJPH.2007.126904.

Stöck I.H., March, L., Pallitto, C., \& Garcia-Moreno, C. (2014). Intimate partner violence among adolescents and young women: Prevalence and associated factors in nine countries: a cross-sectional study. BMC Public Health, 14, 51. doi :10.1186/1471 $245814-751$.

Stockl, H., Kalra, N., Jacobi, J., \& Watts, C. (2013). Is early sexual debut a risk factor for HIV infection among women in sub-Saharan Africa? A systematic review. American Journal of Reproductive Immunology, (Suppl 1), 27-40.

Stromquist, N.P. (2008).The gender socialization process in schools: a cross-national comparison. Background paper prepared for the education for all global monitoring report. Education for all by 2015: will we make it? http://unesdoc.unesco.org/images/0015/001555/155587e.pdf.

Suleiman, A.B., \& Deardorff, J. (2015).

Multiple dimensions of peer influence in adolescent romantic and sexual relationships: A descriptive, qualitative per spective. Archives of Sexual Behavior, 44(3), 765 775, http://dx.doi.org/10.1007/ s10508-014-0394-z. 
Sundaram, A., Juarez, F., Bankole, A., \& Singh, S. (2012). Factors associated with abortionseeking and obtaining a safe abortion in Ghana. Studies in Family Planning, 43(4), 273286. doi: 10.1111/j.1728-4465.2012.00326.

Sutherland-Addy E., (2002). Impact Assessment study of the Girls'Education Programme in Ghana. A report prepared for UNICEF-Ghana. Retrieved from http://www.unicef.org/evaldatabase/files/GHA_2002_022.pdf.

Taffa, N., Klepp, K.I., Sundby, J., \& Bjune, G. (2002). Psychosocial determinants of sexual activity and condom use intention among youth in Addis Ababa, Ethiopia. International Journal of STD \& AIDS, 13, 714-719.

Takyi, B. K. (2003). Religion and women's health in Ghana: Insights into HIV/AIDs preventive and protective behavior. Social Science \& Medicine, 56, 1221-1234.

Tenkorang, E.Y., \& Owusu, Y.A. (2012). Coerced first sexual intercourse among women in Ghana: Evidence from the Demographic and Health Survey. Culture Health \& Sexuality, 17, 167-184. Doi: 10.1007/s12119-012-9146-1.

Tolman, D. L. (2002). Dilemmas of desire: Teenage girls talk about sexuality. Cambridge, MA: Harvard University Press.

Tolman, D.L., Spencer, R., Harmon, T., Rosen-Reynoso, M., Striepe, M. (2004). Getting close, staying cool: Early adolescent boys' experiences with romantic relationships. In: Way N, Chu J, editors. Adolescent boys: Exploring diverse cultures of boyhood. New York: New York University press; pp. 235-255.

Tuwor, T., \& Sossou, M. (2008). Gender discrimination and education in West Africa: Strategies for maintaining girls in school. International Journal of Inclusive Education, $12,363-379$.

Udegbe, B.I., Fayehun, F., Isiugo-Abanihe, U.C., Nwagwu, W., Isiugo-Abanihe, I., \& Nwokocha, ${ }_{\llcorner}$E. (2015). Evaluation of the Implementation of Family Life and HIV Education Programme in Nigeria. African Journal of Reproductive Health, 19(2), 79-93.

UN (United Nations). (1995). Report of the international conference on population and development. Cairo 5-13 September 1994. New York: UN.

UNAIDS (2014). 2014 Progress report on the global plan towards the elimination of new HIV infections among children by 2015 and keeping their mothers alive. Retrieved from http://www.unaids.org/sites/default/files/documents/JC2681_2014-Global-Planprogress_en.pdf.

Underhill, K., Montgomery, P., \& Operario, D. (2007). Sexual abstinence only programmes to prevent HIV infection in high-income countries: a systematic review. British Medical Journal (Clinical Research Ed.), 335(7613), 248-252. doi:10.1136/bmj.39245.446586.BE.

UNESCO. (2009). International technical guidance on sexuality education: an evidenceinformed approach for schools, teachers and health educators. Paris: UNESCO. 
UNESCO. (2015). Comprehensive sexuality education: a global review. Retrieved from: http://unesdoc.unesco.org/images/0023/002357/235707e.pdf

UNFPA. (2014). Reproductive rights are human rights. A handbook for national human rights institutions. Retrieved from:

http://www.ohchr.org/Documents/Publications/NHRIHandbook.pdf

UNFPA (United Nations Population Fund). (2013). Adolescent pregnancy: A review of the Evidence. Prepared by: Loaiza E. and M. Liang. New York. www.unfpa.org/sites/default/files/.

UNFPA, (2010). Comprehensive Sexuality Education: Advancing Human Rights, Gender Equality and Improved Sexual and Reproductive Health. A Report on an International Consultation to Review Current Evidence and Experience. Bogotá, Columbia.

UNFPA. (2012). Status report on adolescents and young people in Sub-Saharan Africa: Opportunities and challenges. http://www.prb.org/pdf12/status-report-youthsubsaharan-Africa.pdf. Retrieved on 24-03-2016.

UNICEF (United Nations Children's Fund). (2012). Progress for children; A report card on adolescents. Division of Communication, 3 United Nations Plaza, New York, NY 10017, USA. http://www.unicef.org/media/files/_adolescents.pdf. Accessed February 9, 2016.

UNICEF. (2015). State of The World's children 2015 country statistical information. Retrieved from: http://www.unicef.org/infobycountry/ghana_statistics.html.

Van der Geugten, J., van Meijel, B., den Uyl, M.H.G., \& de Vries, N.K. (2015). Sexual and reproductive health education: Opinions of students and educators in Bolgatanga Municipality, Northern Ghana. Sex Education, 15(2), 113-128. doi:10.1080/14681811.2014.968771.

van Empelen, P., Kok, G. (2008). Action-specific cognitions of planned and preparatory behaviors of condom use among Dutch adolescents. Archives of Sexual Behavior, 374), 626-640. doi:10.1007/s10508-007-9286-9.

Varga, C.A. (2001). The forgotten fifty percent: a review of sexual and reproductive health research and programs focused on boys and young men in Sub-Saharan Africa. African Journal of Reproductive Health, 5(3), 175-195.

Wagman, J., Baumgartner, J.N., Geary, C.W., Nakyanjo, N., Ddaaki, W.G., Serwadda, D., \& Wawer, M.J. (2009). Experiences of sexual coercion among adolescent women: Qualitative findings from Rakai District, Uganda. Journal of Interpersonal Violence, 24(12), 2073-2095.

Walker, D., \& Myrick, F. (2006). Grounded Theory: An exploration of process and procedure. Qualitative Health Research, 16(4), 547-559 doi: 10.1177/1049732305285972.

Walsh, D., \& Downe, S. (2006). Appraising the quality of qualitative research. Midwifery, 22(2), 108-119. doi:10.1016/j.midw.2005.05.004.

Wamoyi, J., Wight, D. (2014). "Mum never loved me." How structural factors influence adolescent sexual and reproductive health through parent-child connectedness: A 
qualitative study in rural Tanzania. African Journal of AIDS Research, 13(2), 169-178. doi:10.2989/16085906.2014.945387.

Warenius, L., Pettersson, K., Nissen, E., Höjer, B., Chishimba, P., Faxelid, E. (2007). Vulnerability and sexual and reproductive health among Zambian secondary school students. Culture, Health \& Sexuality, 9(5), 533-544. doi:10.1080/13691050601106679.

Weaver H., Smith, G., \& Kippax, S. (2005). "School-based sex education policies and indicators of sexual health among young people: A comparison of the Netherlands, France, Australia and the United States." Sex Education, 5(2), 171-188, doi: 10.1080/14681810500038889.

Weston, C., Gandell, T., Beauchamp, J., McAlpine, L., Wiseman, C., \& Beauchamp, C. (2001). Analyzing interview data: The development and evolution of a coding system. Qualitative Sociology, 24(3).

WHO (2015). Sexual health, human rights and the law. WHO Library Cataloguing-inPublication Data. Retrieved from: http://apps.who.int/iris/bitstream/10665/175556/1/9789241564984_eng.pdf.

WHO (World Health Organisation). (2006). Preventing HIV/AIDS in young people. A systematic review of the evidence from developing countries. UNAIDS Inter-agency task team on young people, WHO Technical Report Series 928, Edited by David A. Ross, Bruce Dick \& Jane Ferguson.

WHO (World Health Organisation). (2014). Health for the world's adolescents: A second chance in the second decade. Geneva. Retrieved from www.who.int.

WHO (World Health Organisation). (2011). Unsafe abortion: Global and regional estimates of the incidence of unsafe abortion and associated mortality in 2008. WHO Library Cataloguing-in-Publication. Geneva.

Wolff, B., Blanc, A.K., \& Gage A.J. (2000). Who decides? Women's status and negotiation of sex in Uganda. Culture, Health \& Sexuality, 2(3), 303-322.

Wood, K., \& Jewkes, R. (2006). "Blood blockages and scolding nurses: Barriers to adolescent contraceptive use in South Africa." Reproductive Health Matters, 14(27), 109-118.

Yeboah, T., \& Maticka-Tyndale, E. (2008). Factors influencing the timing of first sexual intercourse among young people in Nyanza, Kenya. International Family Planning Perspectives, 34(4), 177-188.

Yidana, A., Ziblim, S., Azongo, T.B., \& Abass, Y.I. (2015). Socio-cultural determinants of contraceptives use among adolescents in Northern Ghana. Public Health Research, 5(4), 83-89. doi: 10.5923/j.phr.20150504.01. 


\section{Acknowledgments}

It has been said that PhD work requires support. Indeed, it took the support of different people across continents to get this work done. Therefore, with my deepest gratitude to God, who 'makes all things beautiful in his time', I will also like to thank the many individuals and institutions who have supported my studies and helped me in completing this dissertation.

Foremost, honour is given to who honour is due. Prof Gerjo Kok has indeed 'started a revolution across the world'. His decision to not only accept my proposal but to find the right supervisors is what has produced this work. As I said in his valedictory lecture, we will continue with the Intervention Mapping approach into the future.

As my supervisor, I have learned so much more from Prof Rob Ruiter than he could probably imagine. Rob's exciting life, shared between family, sports, academia and leadership have been part and parcel of my PhD project. From him, I learned what is possible in one life. I thanked him for his continued encouragement, the enlightening conversations we had many times, his exemplary respectful attitude and profound critique, which provided me with space for deep reflection. My appreciation extends to his incredible wife, Miranda and children (Veerie, Niek and dries) for accepting me to stay with the family on countless times to enable me to write and to play 'oware.' From Miranda, I learned that medical doctors could also be great painters, even at night. Simply incredible!

To Dr. Fraukje Mevissen, there must have been something divine about having you as my co-supervisor. With the kind of 'unstructured' life experiences from childhood, many would have failed to produce a scientist out of me. She is the perfect co-supervisor for my type. Among her PhD students, we all agree: her eye for details and passion for seeing excellence in the work of her students is unparalleled. She has been an inexhaustible source of critical reflection. Through it all, I felt your support, at a distance and still close.

Otherwise, there was always the email. I thank you for what it might have cost to make me up'.

Special thanks go to Dr. Cornelius Debpuur of the Navrongo Health Research Centre. Although due to some circumstances, he could not support me to the end of the journey, his acceptance to be the local promoter and subsequent contributions, including co-authoring one paper, provided the impetus to keep me going with the work.

Many thanks go to Prof Gerard VanBreukelen for the statistical support, amidst extremely busy schedules. I like to thank Linda Anaabah, Meret Münkel, Anne Prinsen, 
Kirsten Flore, Martha Atule, Belinda Akolgo, Tes Schmeink, Jennifer Hollenberg and Thomas Ayamga, who painstakingly assisted me to conduct the surveys or conduct and transcribed the qualitative interviews. My appreciation extends to all the young women and young men who participated in the research, either completing surveys or as respondents to the indepth qualitative interviews.

I wish to thank the members of my dissertation committee: Prof. dr. Gerjo Kok (chair), Prof. dr. Bart van den Borne, Dr. Anja Krumeich, Prof. dr. Ama de-Graft Aikins (University of Ghana) and Dr. Prisca Zwanikken (Koninklijk Instituut voor de Tropen - KIT, Amsterdam) for generously offering their time and willingness to review the dissertation.

A special note of thanks is due to Mariella Muermans, who diligently arranged for my boarding and lodging at the different locations where I took courses or attended conferences, and to all colleagues at the Department of Work and Social Psychology of Maastricht University, who provided resources and feedback as I worked on my dissertation. Additional gratitude is offered to Dilana Schaafsma, Henna Toppenberg, Sanne van Lieshout, Sylvia Roozen, Feziwe Mpondo, Lisette Schutte and Cephas Sialubanje; your friendship and support made the weight lighter for me in Maastricht. I can't forget Jornie Rinia, who, despite the short notice of my request, devoted his time and deligently designed the cover page to perfection. Jornie, thank you very much!

I must thank the organisation for internationalisation in education (NUFFIC), and it's Netherlands Fellowship Programme (NFP) for the PhD grant. Studying in top class universities in Europe would have simply been impossible without the grant. I will also like to thank the National Research Directorate of the Ghana Health Services, the Upper East Regional and Municipal Directorates of the health and education services for supporting and granting the necessary permissions for the recruitment of study participants. Many thanks to all the nurses and teachers who actively assisted with the recruitment of study participants at the health and school facilities. I hope that both the health and education services will find some value in the results of my dissertation.

I will like to thank Dr. Prisca Zwanikken, Team Leader Education at the Royal Tropical Institute (KIT). During the defense of my master thesis in 2010, Prisca affirmed to me that I should consider pursuing a PhD. A year later, she linked me up to Prof Gerjo Kok, and the result is this dissertation. Her support continued, and together with the management of KIT, accepted me back as a student intern at the KIT, a position that granted me unlimited access to the KIT study facilities.

Thank you to all my colleagues at the Youth Harvest Foundation Ghana. Especially to David Ayine, who over-stretched himself many times beyond his training to lead the 
organisation to enable me stay in school; to Abigail Adumolga, who spared me on to be a positive example for the youth; to Albert Akafari, Linda Atibilla, Urban Akagwire, Vitus Atanga, Khadijah Hamidu and Millicent Ayaba for the unfailing support in the background. Also, I should never forget the support of the Board of Trustees of the YHFG, especially, board chairperson, Dr. Francis Ansah. Thank you for your faith in me. Likewise, the Board and the entire membership of JugendPartnerschaft Ghana (JPG) deserves a special mention for their continued support to the work in Ghana that provided the platform for my research work.

Further acknowledgement and thanks to Julia Leimkugel and Gero Frisch, who prompted this work. After reading my master thesis in 2010, you said you were looking forward to meeting Dr. John Krugu one day. Voila! Your continued unflinching support and belief in me have made that dream a reality. Prof Andreas Ruppel, words cannot adequately describe what you have done to see me through this work. Any wonder why we "reproduced" you in our house? Lianne van Rijssel deserves a special mention for your friendship, support, and encouragement.

Lucien and Monique Ulrich, together with the junior Ulrichs' - Marcel, Frank, and Sjoerd - make up my "Amsterdam family". I have tasted "royalty" living and writing this dissertation in their house in Amsterdam. They helped right when I needed help most. Their support has made me a stronger person. I will forever be grateful to the family.

A special thanks to my family in Ghana. Words cannot express how grateful I am to my in-laws, especially, Rev. \& Mrs. Lazarus Akabure and the entire Abilla family for all of the sacrifices that they have made on my behalf. Their prayer for me was what sustained me thus far. My gratitude also goes to Mr. and Mrs. Adasi Ampem (Sabronum) for your continued support and encouragement all along. Very special thanks to my late father, Awinig-Krugu, and siblings, especially Timothy Krugu and the late Jacob Krugu; most of whom never stepped foot in school, yet they knew when to keep family issues away from me to allow me to concentrate on research activities. I am indebted to them all for their prayer support. I dedicate this work to my mother, Ayelikbun Krugu, who, not knowing anything about formal schooling, yet supported me all along, amidst a hard life. Mum, supporting my education remains part of the "unexplained variation" of my story.

I would also like to thank all of my friends, especially Rev.Fr. Ofori Idan, Seth Quayson, Ate Acquaye, Anthony Namoo, Armstrong Cudjoe, Rev. Samuel Apkaribo (all of Ghana) and Jonas Enberg (Sweden), who, variously, supported and incented me to strive towards my goal. Also, the prayer support of the Pastor and the entire membership of the 
Redemption Centre Assemblies of God church in Bolgatanga cannot go unnoticed. I felt your support and encouragement all along. Thank you for standing together with me.

Finally, but most importantly, I would like to express heartfelt appreciation to my beloved wife, Comfort; children: Awinong, Awingud; and nieces: Dora, Rebecca, for your patience, assistance, and support. Especially to Comfort, I appreciate that the days and nights away from the family while attending courses, conferences and particularly, writing this dissertation were truly difficult for you. I cannot thank you enough for your dedication and love. 


\section{Curriculum Vitae}

John Kingsley Krugu was born on $4^{\text {th }}$ June 1974 in Apondabogo, a farming community in the Bawku West District of Ghana. He spent his youth largely in the Ashanti region of Ghana, from where he completed his secondary education and in 1995, preceded to the Kwame Nkrumah University of Science and Technology (KNUST) in Kumasi, Ghana, for his bachelor studies. In 2001, he obtained his bachelor in BSc (Hons) Biological Sciences from KNUST.

When he completed his national service at the Navrongo Health Research Centre (NHRC) in 2002, the Centre retained him as a research assistant attached to the Navrongo Anaemia Study and later, the Bacterial Meningitis and Entomology research projects. He worked for four years at the NHRC, during which period he simultaneously, co-founded the Youth Harvest Foundation Ghana (YHFG). The YHFG was a vision that was borne in 1998 during John's bachelor training at the KNUST. Based on his challenging experiences and struggles to access formal education, he came up with a vision to start an organisation that will focus on youth development, starting with addressing the needs of the most deprived youth of his home region in the north of Ghana.

While working at the NHRC, he continued to garner support from his friends and family members around his vision. In 2002, when he received his first ever working salary, he used the income, together with support from friends, to register the YHFG as a nonGovernmental organisation (NGO) dedicated to positive youth development. He continued to work at the NHRC from 2002 - 2004, during which period he spent all his time outside working hours and weekends mobilising young people around the YHFG. His dedication to realising the vision continued to grow and many people signed up to be members of the YHFG.

As a result of the growing interest in the YHFG, by December 2004, John could no longer combine the activities of the YHFG with his work at the NHRC. One of them had to go, and he chose to pursue his vision by resigning from the NHRC in December 2004. He worked as the Executive Director (ED) of the YHFG from 2005 - 2009 when he left to the Royal Tropical Institute (KIT)/Vrije Universiteit Amsterdam in the Netherlands for his master studies.

He graduated with a Master in Public Health (MPH) from the KIT/Vrije Universiteit in Amsterdam in September 2010 and returned to Ghana where he continued to work for the YHFG. In his current position as the ED of the YHFG, he is leading different programs and 
supervising over 25 people working on various projects of the YHFG. His interest is in conducting research to increase understanding of how to address the Sexual and Reproductive Health and Rights (SRHR) of adolescents in Africa. In 2012, he started his PhD studies as an external student at the Department of Work and Social Psychology of Maastricht University in the Netherlands.

$\mathrm{He}$ is a member of the Society for AIDS in Africa (SAA) and currently an Executive Committee member of the Ghana Public Health Association. He is married to Comfort Abilla and they are parents to Andreas Awinong Krugu and Jesse Awingud Krugu.

\section{Publications}

Krugu, J.K., Mevissen, F.E.F., Münkel, M., \& Ruiter, R.A.C. (2016). Beyond Love: A qualitative analysis of factors associated with teenage pregnancy among girls with pregnancy experience in Bolgatanga, Ghana. Culture, Health and Sexuality. http://dx.doi.org/10.1080/13691058.2016.1216167

Krugu, J.K., Mevissen, F.E.F., Prinsen, A., \& Ruiter, R.A.C. (2016). Who's that girl? A qualitative analysis of adolescent girls' views on factors associated with teenage pregnancies in Bolgatanga, Ghana. Reproductive Health, 13:39. Doi: 10.1186/s12978-016-0161-9.

Krugu, J.K., Mevissen, F.E.F., Debpuur, C., \& Ruiter, R.A.C. (2016). Psychosocial correlates of condom use intentions among junior high school students in the Bolgatanga Municipality of Ghana. International Journal of Sexual Health, 28:1, 96-110, doi: 10.1080/19317611.2015.1124162.

Krugu, J.K. (2010). NGO Delivered youth peer-led interventions in West Africa - a review of the evidence. A thesis submitted in partial fulfillment of the requirement for the degree of Master of Public Health. KIT library catalog, Amsterdam.

Rondini, S., and Krugu, J.K. (2009). Knowledge, Attitude and Practices Study on Reproductive Health Among Secondary School Students in Bolgatanga, Upper East Region, Ghana. African Journal of Reproductive Health, 2009; 13[4]:51-66. 


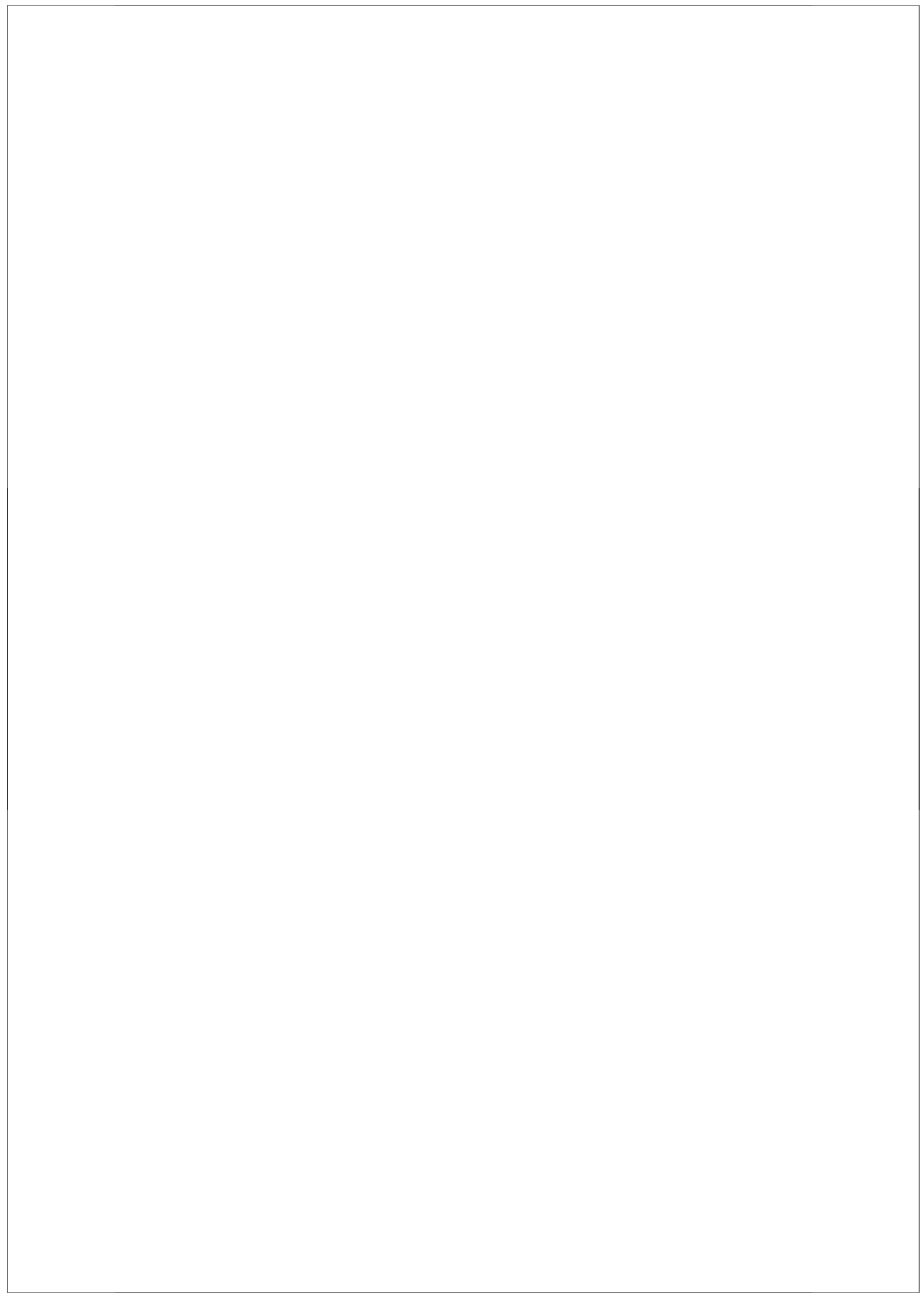

